\author{
UNIVERSIDADE DE SÃO PAULO \\ INSTITUTO DE QUÍMICA DE SÃO CARLOS
}

\title{
ESTUDO DA MATÉRIA ORGÂNICA E COMPOSIÇÃO ELEMENTAR DE SOLOS ARENOSOS DE REGIÖ̃ES PRÓXIMAS A SÃO GABRIEL DA CACHOEIRA NO AMAZONAS
}

Cleber Hilário dos Santos

Tese apresentada ao Instituto de Química de São Carlos, da Universidade de São Paulo, para a obtenção do Título de Doutor em Ciências, área de concentração Química Analítica e Inorgânica.

Orientador: Dra. Débora Marcondes Bastos Pereira Milori

Embrapa Instrumentação - São Carlos

São Carlos - SP

2014 


\section{DEDICO}

Ao meu querido amado e estimado pai Antonio Hilário dos Santos (in memoriam), que perdi no dia 27 de junho de 2010, pelo exemplo de vida, família, força, luta, coragem, superação, honestidade, caráter, bondade, principal referência em minha vida e, principalmente, por ser a pessoa que mais acreditou em mim. Meu pai, tu és o orgulho da minha vida. Muito obrigado por tudo.

À minha querida mãe Rute pelo conforto, apoio, alicerce familiar, pelas palavras de carinho, constante presença, incentivo nos momentos difíceis, superação, exemplo de vida, caráter, luta e força que me conduziram até aqui.

À minha estimada e querida irmã Valéria pelo incentivo, atenção e carinho. 


\section{AGRADECIMENTOS}

A Deus, pela vida, pela minha família e amigos, por iluminar meu caminho e me dar forças para seguir em frente, permitindo a superação dos obstáculos para a conclusão desta etapa da minha vida profissional.

À Dra. Débora Marcondes Bastos Pereira Milori (EMBRAPA INSTRUMENTAÇÃO), pelos ensinamentos, oportunidade, orientação, incentivo, amizade, confiança e atenção durante a realização deste trabalho. Meus mais sinceros agradecimentos.

A CAPES, pela bolsa de doutorado concedida.

Ao Dr. Adolpho José Melfi (ESALQ/NUPEGEL - USP), Dra. Célia Regina Montes e a Dra. Débora Ayumi Ishida (CENA/NUPEGEL - USP), pelas amostras de solos concedidas e atencioso acompanhamento durante todo o trabalho.

Ao Dr. Yves Lucas e Stephane Mounier (PROTEE - Université du Sud ToulonVar) pelo auxílio, colaborações e sugestões.

Ao Dr. Ladislau Martin Neto, Dr. Marcelo Luiz Simões e Dr. Paulino Ribeiro Villas Boas (EMBRAPA INSTRUMENTAÇÃO) pelas preciosas colaborações e sugestões.

Ao Dr. Wilson Tadeu Lopes da Silva (EMBRAPA INSTRUMENTAÇÃO), pela valiosa colaboração e inúmeras sugestões no decorrer da realização deste trabalho e, principalmente, pela amizade.

À Dra. Nádia Regina do Nascimento, a técnica de laboratório Sueli e a doutoranda Bruna Rossin (IGCE - UNESP, Rio Claro), pela acolhida, auxílio e compartilhamento de informações a respeito da Amazônia e do sistema LatossoloEspodossolo.

As analistas de laboratório Alice Raabe, Joana Dias Bresolin, Silviane Zanni Hubinger, Viviani Farias Soares e a assistente de laboratório Adriana Coatrini Thomazi (EMBRAPA INSTRUMENTAÇÃO), pela amizade, paciência, constante ajuda, criatividade e auxílio nos laboratórios de química e de espectroscopia.

Ao Dr. Gilberto Batista de Souza e ao analista de laboratório Carlos Jordão (EMBRAPA PECUÁRIA SUDESTE), pela atenção e disponibilidade para a realização das medidas de ICP OES. 
Ao Dr. Gustavo Nicolodelli e a Dra. Tania Leme de Almeida, pela amizade, ensinamentos, colaborações, sugestões e participação no desenvolvimento deste trabalho.

Ao Valentim pela prestativa ajuda nos trabalhos.

Às bibliotecárias do IQSC/USP pela atenção e pronto atendimento.

À Sílvia, Andréia e o Gustavo da sessão de pós-graduação pela simpatia, atenção e pelo excelente atendimento.

Aos estagiários, telefonistas, técnicos, pesquisadores e colegas da Embrapa Instrumentação, sempre atenciosos e prestativos.

Aos meus grandes amigos e amigas, Camila Miranda Carvalho, Lilian Martelli, Fabrício Martelli, Bruno Henrique Martins, Robson Marcel da Silva, Kelly Narimoto, Patrini Galiani, Heloisa, Geyse Casale, Wanda, Ana Paula, Aline Silverol, Francys, Márcia Palhares, Renan Arnon Romano, Jailson, Adalberto, Michelle Brugnera, Sidmar Shiguihara, Sabrina Shiguihara e Alfredo Freitas meus sinceros agradecimentos pelo incentivo, amizade, paciência, convivência e apoio nos momentos difíceis de realização deste trabalho.

Aos colegas e amigos das mais diferentes origens e épocas da Embrapa Instrumentação: Adriana Soares, Aline Segnini, Lucimar, Lívia Favoretto, Larissa, Poliana, Eduarda, Cíntia Avalhães, Letícia Leonel, Wanderson, Marcos Lorevice, Rosilene, William, Martha, Fernanda, Alexandra, Rafael Ribeiro, Bruno de Paula, Ednaldo, Fernando Hiene, Helder, Marta Saidel, Noemi Veiga, Rafael Sauce, Mathias Daroz, Marina França, Alex Watanabe, Vanessa Zulueta, Marcelo Cardinali, Fábio Plotegher, Antonio Leal, Andréa, Henrique, Luiz Neves, Caroline, Mariani, Roberta Manzano, Adriel, Gabriela Byzynski, Maria Célia, Elaine Inácio, Amanda Giroto, Juliana Scramin, Camila Florêncio, Ursula, Ana Flávia, André Venâncio, Gabriel Tabosa, Edilene Ferreira, Fabíola, Pedro Otaviani, Thiago Massaiti, Ivan, Alfredo Augusto e Anielle Ranulfi, pela excelente convivência e amizade.

As amizades feitas nos congressos e no desenvolvimento deste trabalho: Dário Primo, Luís de França, Cecília Sacramento, Daiane Carvalho, Carla Rosa, Daniela Barbosa, Otávio Leal e Graciele Santana.

À Embrapa Instrumentação pela infra-estrutura e pelo excelente ambiente de trabalho proporcionado.

Ao Instituto de Química de São Carlos da Universidade de São Paulo. 
A todos os funcionários da Embrapa Instrumentação pela ajuda prestada.

Aos meus pais pelo exemplo, honestidade, apoio, força e amor.

A minha irmã Valéria e Tios Rui, Antonio e Lourdes, pela ajuda constante, incentivo, paciência e carinho.

A todos que colaboraram direta ou indiretamente para a concretização deste trabalho.

Muito obrigado a todos! 


\section{SUMÁRIO}

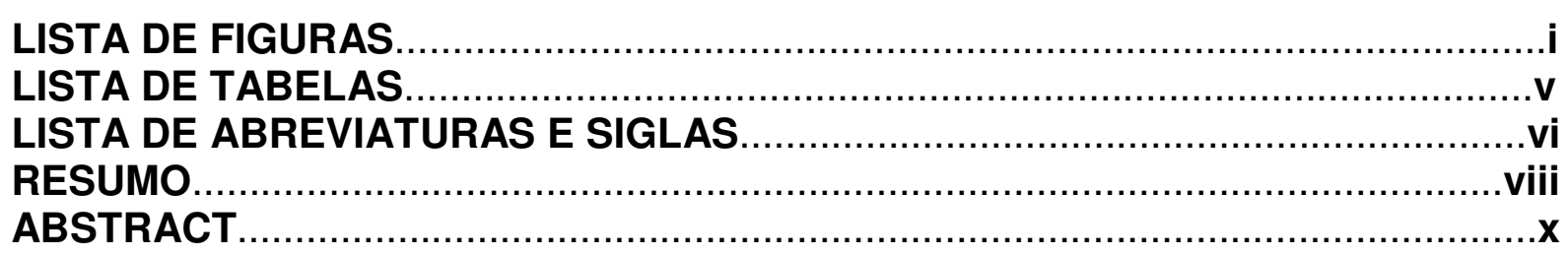

1 INTRODUÇÃO

2 OBJETIVOS

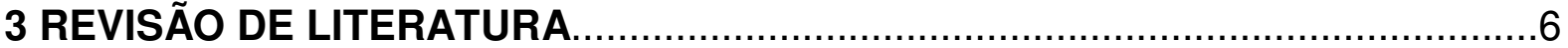

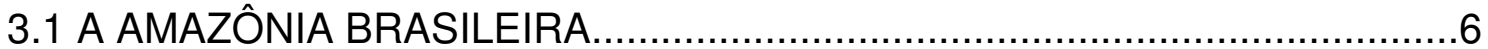

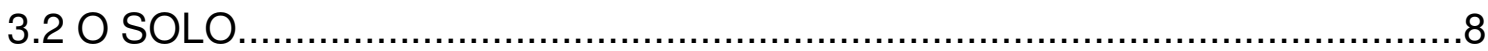

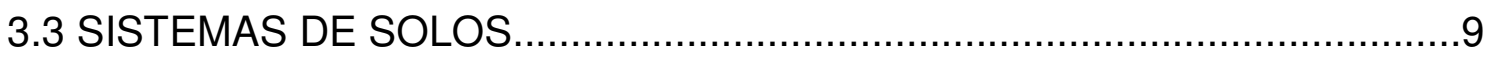

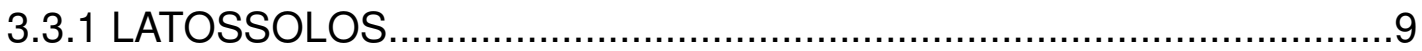

3.3.2 ESPODOSSOLOS ................................................................

3.3.3 O SISTEMA DE TRANSFORMAÇÃO LATOSSOLO -

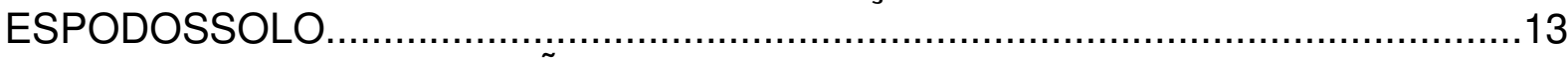

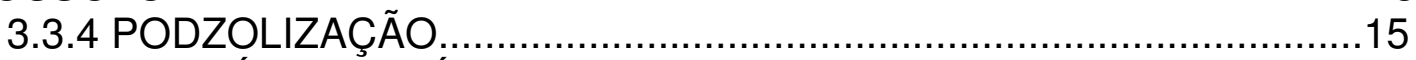

3.4 CARACTERÍSTICAS FÍSICAS DOS PERFIS DE SOLO ESTUDADO.........16

3.5 A MATÉRIA ORGÂNICA DO SOLO .....................................................18

3.5.1 SUBSTÂNCIAS HÚMICAS: CONCEITOS E MODELOS...................19

3.6 CARACTERIZAÇÃO DAS SUBSTÂNCIAS HÚMICAS..............................25

3.6.1 MÉTODOS QUÍMICOS............................................................26

3.6.1.1 ANÁLISE ELEMENTAR (CHNS) ……………..................26

3.6.2 MÉTODOS ESPECTROSCÓPICOS ..........................................28

3.6.2.1 ESPECTROSCOPIA DE ABSORÇÃO DE RADIAÇÃO NO

ULTRAVIOLETA-VISÍVEL.............................................................................28

3.6.2.2 ESPECTROSCOPIA DE FLUORESCÊNCIA DE LUZ

ULTRAVIOLETA-VISÍVEL. .31

3.6.2.3 ESPECTROSCOPIA DE FLUORESCÊNCIA INDUZIDA POR

LASER (FIL).

3.6.2.4 ESPECTROMETRIA DE EMISSÃO ÓTICA COM PLASMA

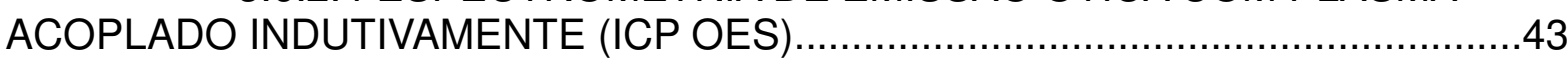

3.6.2.4.1 PREPARO DE AMOSTRAS PARA ICP OES....................46

3.6.2.5 ESPECTROSCOPIA DE EMISSÃO ÓTICA COM PLASMA

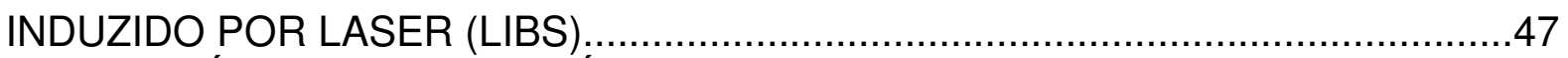

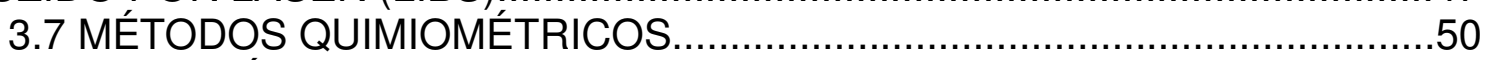

3.7.1 ANÁLISE DE FATORES PARALELOS (PARAFAC) ..........................50

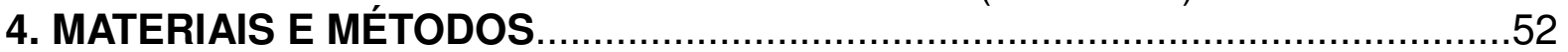

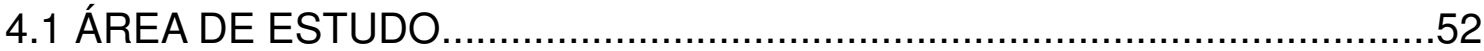

4.1.1 SEGMENTO SUPERIOR - ZONA DE PODZOLIZAÇÃO...................54

4.1.2 SEGMENTO MÉDIO - ZONA DE LATERIZAÇÃO............................55

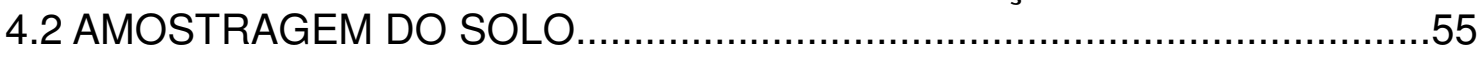

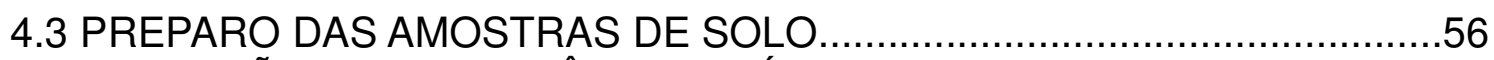

4.4 EXTRAÇÃO DAS SUBSTÂNCIAS HÚMICAS.....................................56

4.4.1 PROCEDIMENTO DE PURIFICAÇÃO DOS EXTRATOS DE ÁCIDO

FÚLVICO E ÁCIDO HÚMICO. 


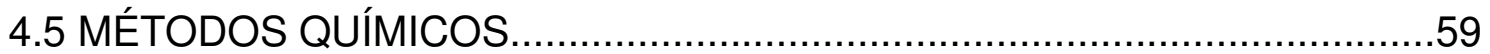

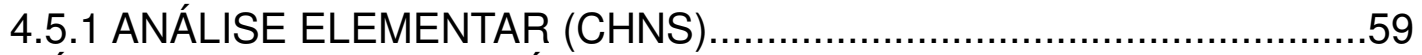

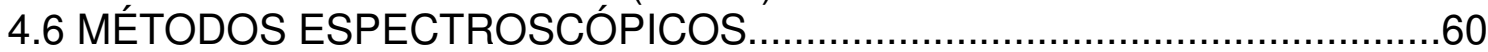

4.6.1 ESPECTROSCOPIA DE ABSORÇÃO DE RADIAÇÃO NO UV-VIS...60 4.6.1.1 DILUIÇÃO DAS AMOSTRAŞ DE ÁCIDO HÚMICO E EXTRATO DE ÁCIDO FÚLVICO 2.

4.6.2 ESPECTROSCOPIA DE FLUORESCÊNCIA DE LUZ UV-VISÍVEL....63

4.6.3 ESPECTROSCOPIA DE FLUORESCÊNNCIA INDUZIDA POR LASER

(FIL)

4.6.4 ESPECTROMETRIA DE EMISSÃO ÓTICA COM PLASMA

ACOPLADO INDUTIVAMENTE (ICP OES). 64

4.6.4.1 REAGENTES, MATERIAIS E SOLUÇÕES UTILIZADOS NO PROCEDIMENTO DE DECOMPOSIÇÃO DAS AMOSTRAS DE SOLO PARA MEDIDA DE ICP OES.

AMOSTRA

4.6.4.2 PROCEDIMENTOS DE DECOMPOSIÇÃO: DIGESTÃO DA

4.6.4.3 INSTRUMENTAÇÃO.

4.6.5 ESPECTROSCOPIA DE EMISSÃO ÓTICA COM PLASMA INDUZIDO

POR LASER (LIBS)

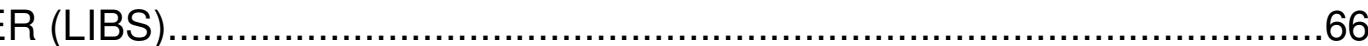

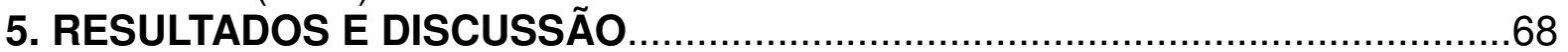

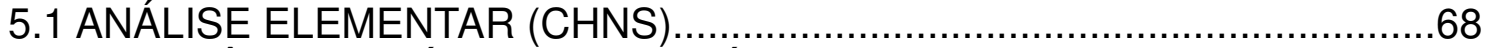

5.2 SUBSTÂNCIAS HÚMICAS EXTRAÍDAS DE SOLO ..............................70

5.3 ESPECTROSCOPIA DE ABSORÇÃO DE RADIAÇÃO NO UV-VIS.............73

5.4 ESPECTROSCOPIA DE FLUORESCÊNCIA DE LUZ UV-VISÍVEL..............76

5.4.1 EXTRATO DE ÁCIDO FÚLVICO 2 ................................................76

5.4.1.1 ESPECTROS DE VARREDURA SINCRONIZADA $(\Delta \lambda=55$

$\mathrm{nm})$

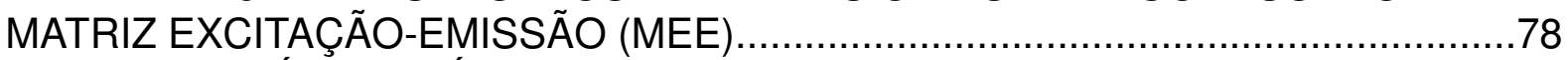

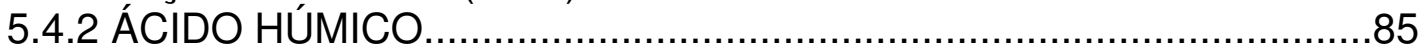

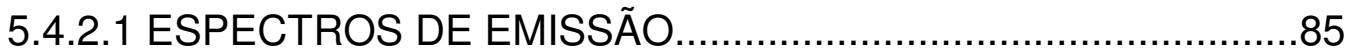

5.4.2.2 ESPECTROS DE VARREDURA SINCRONIZADA $(\Delta \lambda=55$

$\mathrm{nm})$

5.4.2.3 ESPECTROS TRIDIMENSIONAIS DE FLUORESCÊNCIA -

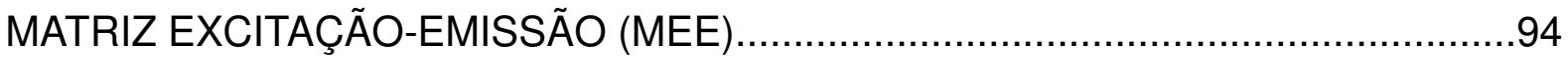

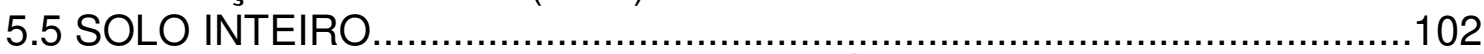

5.5.1 ESPECTROMETRIA DE EMISSÃO ÓTICA COM PLASMA ACOPLADO INDUTIVAMENTE (ICP OES) .................................................................102

5.5.2 NOVAS FERRAMENTAS DE ANÁLISE PARA SOLOS......................106

5.5.2.1 ESPECTROSCOPIA DE EMISSÃO ÓTICA COM PLASMA

INDUZIDO POR LASER (LIBS) ..............................................................106

5.5.2.2 ESPECTROSCOPIA DE FLUORESCÊNCIA INDUZIDA POR

LASER (FIL).

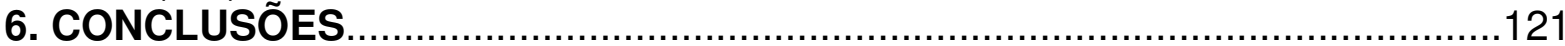

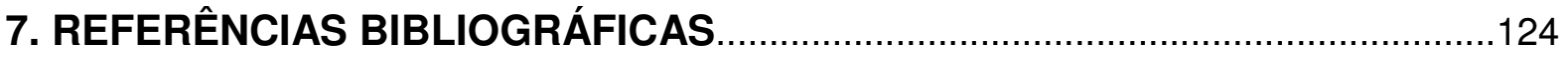




\section{LISTA DE FIGURAS}

Figura 3.1 - Mapa da Amazônia Legal - Estados do Acre, Amapá, Amazonas, Mato Grosso, Pará, Rondônia, Roraima, Tocantins e parcialmente Maranhão

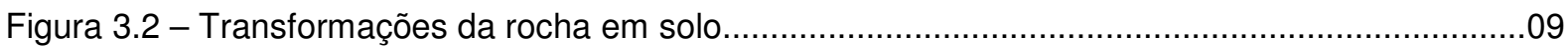

Figura 3.3 - Distribuição das principais classes de solos da Amazônia.

Figura 3.4 - Modelo de estrutura macromolecular para ácido húmico. O símbolo representa sequências de cadeias alifáticas de comprimento variável.

Figura 3.5 - Modelo tridimensional para ácido húmico, evidenciando os átomos de carbono (em azul), hidrogênio (em branco), nitrogênio (em preto) e oxigênio (em vermelho). As letras $A, B$ e $C$ indicam os espaços vazios presentes na estrutura das substâncias húmicas...

Figura 3.6 - Modelo para ácidos fúlvicos.

Figura 3.7 - Modelo de estrutura supramolecular para ácido húmico. As unidades vermelhas representam os cátions metálicos, as azuis os polipeptídeos, as pretas os polissacarídeos, as verdes as cadeias alifáticas e as marrons os fragmentos aromáticos provenientes da lignina.

Figura 3.8 - Diagrama dos níveis de energia eletrônica molecular, ilustrando os quatro tipos de transições eletrônicas possíveis.

Figura 3.9 - Grupos cromóforos presentes nas SH.......

Figura 3.10 - Diagrama de transição eletrônica de fluorescência molecular

Figura 3.11 - Espectro de emissão de fluorescência de amostra de AH extraído de solo tratado com lodo de esgoto, obtido segundo metodologia de Zsolnay et al. (1999), com comprimento de onda de excitação $\lambda_{\text {exc }}=240 \mathrm{~nm}$.

Figura 3.12 - Espectro de varredura sincronizada de fluorescência de amostra de AH extraído de solo tratado com lodo de esgoto, obtido segundo metodologia de Kalbitz et al. (1999), com $\Delta \lambda=\lambda_{\mathrm{em}}-\lambda_{\mathrm{exc}}$ $=55 \mathrm{~nm}$.

Figura 3.13 - Espectro de emissão de fluorescência de amostra de AH extraído de solo tratado com lodo de esgoto, obtido segundo metodologia de Milori et al. (2002), com comprimento de onda de excitação $\lambda_{\mathrm{exc}}=465 \mathrm{~nm}$......

Figura 3.14 - Espectro de fluorescência no modo matriz excitação-emissão (MEE) (ou curvas de nível) obtidos para os AH na camada de 0-10 cm: (a) W100 - irrigação com água de consumo e $100 \%$ da FNM; e (b) E100-irrigação com efluente e 100\% da FNM..

Figura 3.15 - Esquema experimental do equipamento de FIL portátil.

Figura 3.16 - Espectrômetro FIL portátil com excitação em 405 nm: 1 - chave de energia do laser; 2 caixa de controle do laser; 3 - saída para o cabo ótico; 4 - ponta emissora/coletora do cabo ótico; 5 saída para USB e porta paralela; 6 - chave geral da caixa e fusível de proteção; 7 - cabo de força geral.

Figura 3.17 - Esquema dos processos que ocorrem no plasma.

Figura 3.18 - Esquema de um espectrômetro LIBS.

Figura 4.1 - Localização da área de estudo na cidade de São Gabriel da Cachoeira, AM. A topossequência está representada pela linha amarela na figura inferior à direita..... 
Figura 4.2 - Esquema da topossequência. Os números de 1 até 10 representam os horizontes e camadas de solo. As letras a até $\mathrm{k}$ representam os segmentos formados a partir da delimitação visual das rupturas de declive.

Figura 4.3 - Esquema simplificado da extração e purificação das substâncias húmicas do solo .58

Figura 4.4 - Sistema LIBS de bancada da Ocean Optics, modelo LIBS 2500 plus: (1) fonte de energia; (2) laser; (3) câmara de ablação; (4) conjunto de espectrômetros.....

Figura 5.1 - Dados dos teores de carbono obtidos para todas as amostras de solo inteiro do Espodossolo Humilúvico (a) e Latossolo Amarelo (b), nos perfis de amostragem.

Figura 5.2 - Foto ilustrativa do fracionamento químico das SH para o Espodossolo Humilúvico. (a) e (b) Fração ácido húmico como precipitado $(F A H)$ + Fração ácido fúlvico (FAF) como sobrenadante obtidos para os horizontes A1, A2, Bh, Bhs, Tr e K1, respectivamente; (c) Amostras obtidas após centrifugação (AH precipitado nos tubos).

Figura 5.3 - Foto ilustrativa do fracionamento químico das $\mathrm{SH}$ para o Latossolo Amarelo. (a) FAH como precipitado + FAF como sobrenadante, obtidos para os horizontes A2 e BA; (b) Amostras obtidas após centrifugação (AH precipitado nos tubos).

Figura 5.4 - Espectros de absorção de radiação no UV-Vis obtidos para os AH (concentração $10 \mathrm{mg}$ $\mathrm{L}^{-1}, \mathrm{pH} 8,0$ ) do Espodossolo Humilúvico (a) e Latossolo Amarelo (b), nos perfis de amostragem.

Figura 5.5 - Espectros de absorção de radiação no UV-Vis obtidos para os extratos de ácido fúlvico 2 (amostras diluídas, pH 8,0) do Espodossolo Humilúvico (a) e Latossolo Amarelo (b), nos perfis de amostragem.

Figura 5.6 - Espectros de varredura sincronizada de fluorescência obtidos para os EAF2 (amostras diluídas, $\mathrm{pH}$ 8,0) do Espodossolo Humilúvico (a) e Latossolo Amarelo (b), com comprimento de onda de emissão e excitação $\left(\Delta \lambda=\lambda_{\mathrm{em}}-\lambda_{\mathrm{ex}}=55 \mathrm{~nm}\right)$, nos perfis de amostragem.....

Figura 5.7 - Valores do índice de humificação $\left(\mathrm{I}_{450} / \mathrm{I}_{370}\right)$ obtidos para os EAF2 do Espodossolo Humilúvico (a) e Latossolo Amarelo (b) pela metodologia de Kalbitz et al. (1999), nos perfis de amostragem.

Figura 5.8 - Espectros de fluorescência total no modo MEE (ou curvas de nível) obtidos para os EAF2 extraídos dos horizontes (a) A1, (b) A2, (c) E1, (d) E2, (e) Bh, (f) Bhs, (g) Tr, (h) K1 e (i) K2 do Espodossolo Humilúvico.

Figura 5.9 - Espectros de fluorescência total no modo MEE (ou curvas de nível) obtidos para os EAF2 extraídos dos horizontes (a) A2, (b) BA, (c) Bw1, (d) Bw2, (e) Bw3, (f) Tr, (g) Kn1, (h) Kn3 e (i) Kn4 do Latossolo Amarelo.

Figura 5.10 - Fluoróforos 1, 2 e 3 obtidos pelo método PARAFAC e descritivos da fluorescência tridimensional (MEE) dos EAF2 para o Espodossolo Humilúvico e Latossolo Amarelo.......

Figura 5.11 - Espectros de emissão de fluorescência obtidos para as amostras de $\mathrm{AH}$ (concentração $10 \mathrm{mg} \mathrm{L}^{-1}, \mathrm{pH} 8,0$ ) do Espodossolo Humilúvico (a) e Latossolo Amarelo (b), com comprimento de onda de excitação $\left(\lambda_{\mathrm{ex}}=240 \mathrm{~nm}\right)$, nos perfis de amostragem.

Figura 5.12 - Valores do índice de humificação $A_{4} / A_{1}$ obtidos para os $A H$ extraídos do Espodossolo Humilúvico (a) e Latossolo Amarelo (b) pela metodologia de Zsolnay et al. (1999), nos perfis de amostragem.

Figura 5.13 - Espectros de emissão de fluorescência obtidos para as amostras de $\mathrm{AH}$ (concentração $10 \mathrm{mg} \mathrm{L}^{-1}, \mathrm{pH} 8,0$ ) do Espodossolo Humilúvico (a) e Latossolo Amarelo (b), com comprimento de onda de excitação $\left(\lambda_{\mathrm{ex}}=465 \mathrm{~nm}\right)$, nos perfis de amostragem. 
Figura 5.14 - Valores do índice de humificação $A_{465}$ obtidos para os AH extraídos do Espodossolo Humilúvico (a) e Latossolo Amarelo (b) pela metodologia de Milori et al. (2002), nos perfis de amostragem.

Figura 5.15 - Espectros de varredura sincronizada de fluorescência obtidos para as amostras de $\mathrm{AH}$ (concentração $10 \mathrm{mg} \mathrm{L}^{-1}, \mathrm{pH} 8,0$ ) do Espodossolo Humilúvico (a) e Latossolo Amarelo (b), com comprimento de onda de emissão e excitação $\left(\Delta \lambda=\lambda_{\mathrm{em}}-\lambda_{\mathrm{ex}}=55 \mathrm{~nm}\right)$, nos perfis de amostragem...91

Figura 5.16 - Valores do índice de humificação $\left(\mathrm{I}_{460} / \mathrm{l}_{378}\right)$ obtidos para os AH extraídos do Espodossolo Humilúvico (a) e Latossolo Amarelo (b) pela metodologia de Kalbitz et al. (1999), nos perfis de amostragem

Figura 5.17 - Correlação entre os resultados obtidos pelas metodologias de Milori et al. (2002) $\left(A_{465}\right)$ e Zsolnay et al. (1999) $\left(A_{4} / A_{1}\right)$ para os $A H$ extraídos do Espodossolo Humilúvico.

Figura 5.18 - Correlação entre os resultados obtidos pelas metodologias de Milori et al. (2002) $\left(\mathrm{A}_{465}\right)$ e Kalbitz et al. (1999) $\left(\mathrm{l}_{460} / \mathrm{I}_{378}\right)$ para os AH extraídos do Espodossolo Humilúvico.

Figura 5.19 - Correlação entre os resultados obtidos pelas metodologias de Zsolnay et al. (1999) $\left(A_{4} / A_{1}\right)$ e Kalbitz et al. (1999) $\left(I_{460} / I_{378}\right)$ para os $\mathrm{AH}$ extraídos do Espodossolo Humilúvico...

Figura 5.20 - Espectros de fluorescência total no modo MEE (ou curvas de nível) obtidos para as amostras de $\mathrm{AH}$ (concentração $10 \mathrm{mg} \mathrm{L}^{-1}, \mathrm{pH}$ 8,0) dos horizontes (a) A1, (b) A2, (c) Bh, (d) Bhs, (e) $\mathrm{Tr}$, (f) K1 e (g) K2 do Espodossolo Humilúvico.

Figura 5.21 - Espectros de fluorescência total no modo MEE (ou curvas de nível) obtidos para as amostras de $\mathrm{AH}$ (concentração $10 \mathrm{mg} \mathrm{L}^{-1}, \mathrm{pH}$ 8,0) dos horizontes (a) A2 e (b) BA do Latossolo Amarelo.

Figura 5.22 - Fluoróforos 1 e 2 obtidos pelo método PARAFAC e descritivos da fluorescência tridimensional (MEE) dos AH extraídos do Espodossolo Humilúvico e Latossolo Amarelo.

Figura 5.23 - Contribuições à fluorescência dos fluoróforos 1 e 2 dos AH extraídos do Espodossolo Humilúvico (a) e Latossolo Amarelo (b), nos perfis de amostragem.

Figura 5.24 - Correlação entre os resultados obtidos pela metodologia de Milori et al. (2002) $\left(A_{465}\right)$ e a contribuição a fluorescência do fluoróforo 1 (a) e fluoróforo 2 (b) para os AH extraídos do Espodossolo Humilúvico.

Figura 5.25 - Dados dos teores de alumínio (a) e ferro (b) obtidos para as amostras de solo do Espodossolo Humilúvico por ICP OES no perfil de amostragem.

Figura 5.26 - Dados dos teores de alumínio (a) e ferro (b) obtidos para as amostras de solo do Latossolo Amarelo por ICP OES no perfil de amostragem.

Figura 5.27 - Espectro típico de LIBS obtido para o horizonte superficial organo-mineral A1 do Espodossolo Humilúvico sem correção do offset.

Figura 5.28 - Espectro LIBS da amostra do Espodossolo Humilúvico no horizonte de transição $(\operatorname{Tr})$.

Figura 5.29 - Linhas de emissão de $C$ em diferentes amostras do Espodossolo Humilúvico: (a) da linha de C em 193,03 nm interferida por Al no horizonte espódico Bhs e (b) da linha de C em 247,9 $\mathrm{nm}$ no horizonte de transição Tr.

Figura 5.30 - Espectro de uma amostra do horizonte espódico Bhs do Espodossolo Humilúvico (linha cheia) em comparação com a amostra de referência de Al (linha pontilhada) e de grafite (linha tracejada). 
Figura 5.31 - Correlação entre o teor de carbono determinado por CHNS (método padrão) e as intensidades LIBS da linha de C em 193,03 nm.

Figura 5.32 - Área LIBS da linha de C em 193,03 nm das amostras do Espodossolo Humilúvico no perfil de amostragem

Figura 5.33 - Correlação entre o teor de alumínio determinado por ICP OES (método padrão) e as intensidades LIBS da linha de Al em 199,01 nm do Espodossolo Humilúvico (a) e Latossolo Amarelo (b), nos perfis de amostragem

Figura 5.34 - Espectros de FIL obtidos para todas as amostras de solo inteiro do Espodossolo Humilúvico (a) e Latossolo Amarelo (b), nos perfis de amostragem.

Figura 5.35 - Valores de $\mathrm{H}_{\mathrm{FIL}}$ obtidos para todas as amostras de solo inteiro do Espodossolo Humilúvico (a) e Latossolo Amarelo (b), nos perfis de amostragem.

Figura 5.36 - (a) Foto do perfil do Espodossolo Humilúvico mostrando a localização aproximada das fotomicrografias (b, c, d, e) de lâminas delgadas obtidas ao microscópio petrográfico. As setas brancas em (a) indicam os canais constituídos por restos de raízes decompostas; (b) horizonte Bh (espódico) com iluviação de matéria orgânica amorfa (monomórfica) depositada na porosidade entre os cristais de quartzo; (c) o topo do horizonte Bhs apresenta matéria orgânica polimórfica depositada na porosidade, porém em menor quantidade do que em Bh; (d) na base do horizonte Bhs foi observado plasma ferruginoso; (e) imagem obtida na transição entre os horizontes Bhs e de transição mostra no lado esquerdo plasma ferruginoso e do lado direito um pedotúbulo preenchido por raiz em avançado estágio de decomposição cortado por uma raiz fresca e fina

Figura 5.37 - Foto do perfil do Espodossolo Humilúvico mostrando canais de precipitação de Fe e de decomposição da $\mathrm{MO}$ indicados pelas setas branca e verde, respectivamente...... 118

Figura 5.38 - Correlação entre o grau de humificação determinado por FIL $\left(\mathrm{H}_{\mathrm{FIL}}\right)$ e a contribuição a fluorescência dos fluoróforos 1 (a) e 2 (b) para os $\mathrm{AH}$ extraídos do Espodossolo Humilúvico. 119 


\section{LISTA DE TABELAS}

Tabela 3.1: Teores de areia, argila e silte obtidos pela Análise Granulométrica para o Espodossolo Humilúvico. Adaptada de Ishida (2010)

Tabela 3.2: Teores de areia, argila e silte obtidos pela Análise Granulométrica para o Latossolo Amarelo. Adaptada de Ishida (2010).

Tabela 4.1 - Diluição das amostras de AH do Perfil P1 (Espodossolo Humilúvico) para análise de

fluorescência no modo excitação-emissão (MEE).

Tabela 4.2 - Diluição das amostras de AH do Perfil P2 (Latossolo Amarelo) para análise de fluorescência no modo excitação-emissão (MEE).

Tabela 4.3 - Diluição dos EAF2 das amostras do Perfil P1 (Espodossolo Humilúvico) para análise de fluorescência no modo excitação-emissão (MEE).

Tabela 4.4 - Diluição dos EAF2 das amostras do Perfil P2 (Latossolo Amarelo) para análise de fluorescência no modo excitação-emissão (MEE).

Tabela 4.5 - Parâmetros operacionais utilizados na análise por ICP OES

Tabela 5.1 - Teores de carbono das amostras de solo inteiro dos Perfis P1 (Espodossolo Humilúvico) e P2 (Latossolo Amarelo) obtidos pelo método de Análise Elementar.

Tabela 5.2 - Valores dos rendimentos do fracionamento químico obtidos para as amostras de AH extraídos do Espodossolo Humilúvico e Latossolo Amarelo, nos perfis de amostragem.

Tabela 5.3 - Principais picos encontrados nos espectros de MEE obtidos nos estudos das SHs........79

Tabela 5.4 - Teores totais de alumínio e ferro das amostras de solo inteiro dos Perfis P1 (Espodossolo Humilúvico) e P2 (Latossolo Amarelo) obtidos por ICP OES. 


\section{LISTA DE ABREVIATURAS E SIGLAS}

\begin{tabular}{|c|c|}
\hline ACF & Área do Espectro de Emissão de FIL \\
\hline AF & Ácido Fúlvico \\
\hline $\mathrm{AH}$ & Ácido Húmico \\
\hline ALS & Alternating Least Squares \\
\hline ANN & Rede Neural Artificial \\
\hline CHNS & Análise Elementar \\
\hline CORCONDIA & Diagnóstico de Consistência do Tensor Núcleo \\
\hline COT & Carbono Orgânico Total \\
\hline CTC & Capacidade de Troca de Cátions \\
\hline EAF2 & Extrato de Ácido Fúlvico 2 \\
\hline EEFM & Excitation-Emission Fluorescence Matrix \\
\hline EEM & Excitation-Emission Matrix \\
\hline EPR & Ressonância Paramagnética Eletrônica \\
\hline ES & Espodossolos \\
\hline FAAS & Espectroscopia de Absorção Atômica em Chama \\
\hline FAF & Fração Ácido Fúlvico \\
\hline $\mathrm{FAH}$ & Fração Ácido Húmico \\
\hline FIL & Fluorescência Induzida por Laser \\
\hline FTIR & Infravermelho com Tansformada de Fourier \\
\hline IBGE & Instituto Brasileiro de Geografia e Estatística \\
\hline ICP OES & Espectrometria de Emissão Ótica com Plasma Acoplado Indutivamente \\
\hline ICP-MS & Espectrometria de Massa com Plasma Indutivamente Acoplado \\
\hline IHSS & Sociedade Internacional de Substâncias Húmicas \\
\hline INPE & Instituto Nacional de Pesquisas Espaciais \\
\hline IPCC & Painel Intergovernamental sobre Mudanças Climáticas \\
\hline LIBS & Espectroscopia de Emissão Ótica com Plasma Induzido por Laser \\
\hline LOD & Limite de Detecção \\
\hline LOQ & Limite de Quantificação \\
\hline
\end{tabular}




$\begin{array}{ll}\text { MEE } & \text { Matrizes de Fluorescência de Excitação-Emissão } \\ \text { MO } & \text { Matéria Orgânica } \\ \text { MOD } & \text { Matéria Orgânica Dissolvida } \\ \text { MON } & \text { Matéria Orgânica Natural } \\ \text { MOS } & \text { Matéria Orgânica do Solo } \\ \text { NIST } & \text { National Institute of Standard and Technology } \\ \text { PARAFAC } & \text { Análise de Fatores Paralelos } \\ \text { PCA } & \text { Análise de Componentes Principais } \\ \text { RMN } & \text { Ressonância Magnética Nuclear } \\ \text { SH } & \text { Substância Húmica } \\ \text { SiBCS } & \text { Sistema Brasileiro de Classificação de Solos } \\ \text { TFSA } & \text { Fração de Terra Fina Seca ao Ar } \\ \text { TPA } & \text { Terra Preta Antropogênica } \\ \text { TPI } & \text { Terra Preta de Índio } \\ \text { USEPA } & \text { United States Environmental Protection Agency } \\ \text { UV-Vis } & \text { Ultravioleta-Visível } \\ \text { WRB } & \text { World Reference Base for Soil Resources }\end{array}$




\section{RESUMO}

A Amazônia representa a maior biodiversidade do mundo e representa um reservatório enorme e dinâmico de carbono, não só na biomassa, mas também no solo. O ciclo do carbono neste bioma é muito importante, principalmente para questões abordadas às mudanças climáticas. Avaliar e compreender a dinâmica do carbono e outros elementos no solo da Amazônia pode ajudar os cientistas a melhorar os modelos e antecipar cenários. Novos métodos, que permitem medições de carbono do solo in situ, são uma abordagem fundamental para este tipo de região, devido aos custos financeiros para a coleta e envio de amostras de solo da floresta para o laboratório, e demanda muito tempo nesta atividade. No presente estudo, uma topossequência de um sistema Latossolo-Espodossolo com caulim associado, desenvolvido a partir de rochas granito gnáissicas do embasamento cristalino, foi estudada. As amostras foram coletadas em São Gabriel da Cachoeira, estado do Amazonas. Dois perfis de solo: Espodossolo Humilúvico (P1) no topo e Latossolo Amarelo (P2) na meia encosta da topossequência foram descritos e amostrados em um total de dezoito amostras. Os objetivos principais foram avaliar e caracterizar através de métodos químicos e espectroscópicos a matéria orgânica e a composição elementar nestes solos arenosos utilizando a análise elementar (CHNS), espectroscopia de emissão ótica com plasma induzido por laser (LIBS), espectrometria de emissão ótica com plasma acoplado indutivamente (ICP OES), espectroscopia de fluorescência induzida por laser (FIL), fluorescência de luz UVVisível e absorção de radiação na região no UV-Visível. Através dos resultados obtidos pela análise elementar foi possível notar que para o Espodossolo Humilúvico houve variações diferenciadas nos teores de carbono, mas para o Latossolo Amarelo, não se pode inferir uma tendência de incremento ou decréscimo do teor de carbono ao longo do perfil, pois o teor de carbono para a maioria das amostras de solo foi inferior a $0,3 \%$, o limite de detecção do CHNS. A espectroscopia de matrizes de fluorescência de excitação-emissão (MEE) foi uma técnica mais seletiva e sensível do que a fluorescência bidimensional para os ácidos húmicos $(\mathrm{AH})$, mostrando informações interessantes, variações estruturais e grande diferença entre os cromóforos que emitem fluorescência nos extratos de ácido fúlvico 2 (EAF2) e AH. A combinação dos espectros de MEE com a análise de fatores paralelos (PARAFAC) permitiu caracterizar qualitativamente os EAF2, podendo identificar e associar com mais clareza os três fluoróforos obtidos, com seus respectivos componentes, ácidos fúlvicos (grupos de fluoróforos simples e complexos) e proteína, com diagnóstico de consistência do tensor núcleo (CORCONDIA) de 85,8\%. Esta combinação permitiu caracterizar quantitativamente os $\mathrm{AH}$, identificando a contribuição das intensidades de dois fluoróforos, associados aos $\mathrm{AH}$, grupos de fluoróforos mais complexos e simples, com CORCONDIA de $84,2 \%$. A partir dos resultados de LIBS, uma forte correlação foi encontrada e os coeficientes de correlação de Pearson's obtidos para o ajuste logarítmico foi de $R=$ 0,98 e $\mathrm{R}=0,99$ para o carbono e o alumínio, respectivamente, entre os valores obtidos por LIBS e as técnicas de referências (CHNS e ICP OES) para o Espodossolo Humilúvico. Nenhuma relação foi observada para o ferro, provavelmente devido aos teores estarem abaixo do limite de detecção. A técnica FIL mostrou para o Espodossolo Humilúvico que o horizonte de transição (Tr) estaria funcionando como uma "peneira molecular", acumulando a matéria orgânica pouco humificada, permitindo a passagem para os horizontes de caulim (K1 e K2) de compostos com estruturas mais humificadas, mais complexas, de difícil 
degradação (mais recalcitrantes), mas de menor tamanho molecular, como anéis aromáticos condensados e/ou conjugação de anéis aromáticos simples, corroborando com a eficiência da extração do AH. Para o Latossolo Amarelo, observou-se um aumento no grau de humificação do horizonte superficial BA em relação ao A2. Logo, estes resultados contribuem para um melhor entendimento sobre a quantificação de carbono, grau de humificação e alterações estruturais da matéria orgânica dos solos arenosos da região de São Gabriel da Cachoeira na Amazônia.

Palavras-chave: matéria orgânica, solo inteiro, substâncias húmicas, grau de humificação, sistema Latossolo-Espodossolo, podzolização, fluoróforos, PARAFAC. 


\begin{abstract}
The Amazon represents the world's biggest biodiversity, comprehending a large and dynamic carbon pool, considering its biomass and soil, as well. The carbon cycle in this biome is very important, especially in questions regarding climatic changes. To evaluate and to understand the carbon and other elements cycles in Amazonian soil can help scientists to improve models and foresee scenarios. New methods, allowing carbon measurements on site, are a crucial approach for this kind of region, due to the financial costs to collect and ship soil samples from forest to laboratory, and the time spent in this activity. In the present study, it was analyzed a topsequence of an Oxisol-Spodosol system with kaolin associated, generated from granitic-gneiss rocks of crystalline basement. The soil samples were collected in São Gabriel da Cachoeira, Amazonas state, Brazil, considering two different soil profiles: Spodosols (P1), at the top layer, and yellow Oxisols (P2) at the topsequence hillside, representing a total of eighteen samples. The main purpose of this study was to evaluate and characterize the organic matter content and elemental composition by chemical and spectroscopic methods using elemental analysis (CHNS), laserinduced breakdown spectroscopy (LIBS), inductively coupled plasma optical emission spectrometry (ICP OES), laser-induced fluorescence spectroscopy (LIFS), fluorescence spectroscopy and UV-Visible spectroscopy. The CHNS results showed differences in the carbon content for the Spodosol (P1) samples; however, it was not observed any differences for the Oxisol (P2) samples, once the carbon content data obtained for these samples were lower than the equipment detection limit $(0.3 \%)$. The excitation-emission matrix (EEM) fluorescence spectroscopy was more sensitive for detecting humic acids (HA) than the two-dimensional fluorescence spectroscopy, showing interesting information, structural variations and large difference among chromophores that emit fluorescence in fulvic acid extracts 2 (EAF2) and HA. The EAF2 were qualitatively characterized by combining the EEM spectra with parallel factor analysis (PARAFAC), which allowed to identify clearly the three fluorophores obtained and their respective components, fulvic acids (simple and complex groups of fluorophores) and protein, with core consistency diagnostic (CORCONDIA) of $85.8 \%$. These data also allowed to quantify the HA, identifying contributions of intensities from two fluorophores associated with $\mathrm{HA}$, complex groups and simple fluorophores, presenting CORCONDIA of $84.2 \%$. Regarding the carbon and aluminum content results for the Spodosol samples, a strong correlation was found between the LIBS values and the standard techniques (CHNS and ICP OES). The Pearson's coefficients obtained by logarithmic fit were $R=0.98$ and $R=0.99$ for carbon and aluminum, respectively. It was not observed any differences for the iron contents from the analyzed samples, probably due to the low content observed regarding the detection limit this element presents. The LIFS technique indicated that the transition horizon ( $\mathrm{Tr}$ ) would be acting as a "molecular sieve" in the Spodosol soil (P1), accumulating less humified organic matter, and allowing passage to kaolin horizons ( $\mathrm{K} 1$ and $\mathrm{K} 2$ ) of compounds with more humified, more complex, difficult to degrade (recalcitrant) structures, but with lower molecular size, such as condensed aromatic rings and/or combination of simple aromatic rings. These results were in accordance to the HA extraction efficiency. For the yellow Oxisol (P2) samples, it was observed a humification degree increase in the surface horizon BA compared to the A2 horizon. This way, the data obtained contribute to a better understanding regarding carbon quantification, humification degree and organic matter structural alterations on sandy soils in São Gabriel da Cachoeira, at the Amazonian region.
\end{abstract}


Keywords: organic matter, whole soil, humic substances, humification degree, Oxisol-Spodosol system, podzolization, fluorophores, PARAFAC. 


\section{INTRODUÇÃO}

A quantificação do carbono estocado nos meios naturais e a avaliação da sua vulnerabilidade às mudanças climáticas ou de uso do solo representa um domínio de pesquisa em plena expansão e, que se faz necessário. As florestas tropicais têm um papel particularmente importante neste contexto, em razão de suas elevadas fitomassas e de suas vulnerabilidades às pressões antrópicas. O estoque de carbono em áreas sob floresta é constituído essencialmente pela biomassa viva e pela matéria orgânica dos solos.

Desta forma, as florestas tropicais são consideradas importantes, pois contribuem com o ecossistema, pela biodiversidade, sequestro de carbono, regulação dos recursos hídricos e ciclos de nutrientes. A maioria destes contribuem para sustentar a vida humana a nível local, regional e mesmo em escala global (Metzeger et al., 2006). Mesmo quando perturbadas, através da remoção total da cobertura florestal, estes ecossistemas continuam a fornecer, pelo menos por algum tempo, os serviços que são essenciais para a agricultura (Blanche et al., 2006).

As florestas tropicais são reconhecidamente os ecossistemas mais produtivos e de maior diversidade de nosso planeta. Dentre elas, a Amazônia que é a maior floresta tropical do mundo, com uma área total de aproximadamente $6,5 \times 10^{6} \mathrm{~km}^{2}$. Representa cerca de $60 \%$ do território brasileiro. Sua importância ambiental, social e econômica é incontestável. Em termos quantitativos de água, a região abriga cerca de $20 \%$ da disponibilidade mundial de água doce (Bispo, 2007; Manzi, 2008). Quanto à sua dimensão, a Amazônia representa 56\% das florestas tropicais do planeta, sendo que somente a parcela brasileira contém cerca de $40 \%$ das florestas tropicais restantes no mundo e dotadas de um papel vital na manutenção da biodiversidade, clima e hidrologia regional, bem como na manutenção do estoque terrestre de carbono (Houghton et al., 2000; Laurance et al., 2001, Manzi, 2008).

É consenso que a biomassa florestal desempenha um papel importante no ciclo global do carbono, principalmente nos dias atuais, cuja relevância é maior, devido aos debates acerca do papel que as florestas desempenham sobre as mudanças climáticas globais (Oliveira, 2012).

A floresta amazônica é um reservatório enorme e dinâmico de carbono que pode ser gradualmente liberado para a atmosfera através da combinação da ação do desmatamento e da perda de carbono do solo devido à mudança no uso do solo e 
do impacto das alterações climáticas (Malhi et al., 2006; IPCC, 2007). A relação entre os estoques de carbono e a fixação de carbono na vegetação natural permanece como uma das questões menos estudadas na compreensão do ciclo do carbono da Amazônia. Basicamente, a quantidade e a qualidade dos recursos naturais de carbono orgânico são altamente influenciadas pelos tipos de vegetação e usos do solo. A maioria dos estudos sobre os estoques de carbono na vegetação não considera as limitações intrínsecas do solo, as quais podem gerar diferentes taxas de produção da biomassa.

Mais de $18 \%$ da região amazônica é coberta por sistemas LatossoloEspodossolo (Radam Brasil, 1978), que são caracterizados pela justaposição de Espodossolos (ES) e Latossolos nas mesmas unidades de paisagem (Lucas et al., 1984; Lucas et al., 2012).

Pesquisas constataram que, na Amazônia, principalmente na bacia do alto rio Negro, encontram-se extensas áreas de solos lateríticos (Latossolos) que estão passando por empobrecimento que precede a instalação de um novo processo de formação dos solos conhecido como podzolização (Lucas et al., 1987; Bravard; Righi, 1990; Fritsch, 2002; Nascimento et al., 2004, 2008; Bueno, 2009).

Os ES têm a peculiaridade de apresentar um horizonte com acúmulo de matéria orgânica (MO) em subsuperfície. Para esta classe de solos, os processos envolvidos na sua formação, genericamente conhecidos como podzolização, têm sido intensivamente estudados desde o século XIX (Lopes, 2010).

A Amazônia apresenta uma vasta área de Espodossolos, caracterizados pela presença de horizontes arenosos espessos, recobrindo horizontes mais argilosos. A matéria orgânica produzida nos horizontes superficiais é transferida em profundidade, por meio das águas de percolação, através dos horizontes arenosos. Como consequência, o material orgânico é acumulado na transição entre horizontes arenosos e argilosos, numa profundidade que varia de 1 a 3 metros, formando horizontes profundos ricos em matéria orgânica (horizontes espódicos Bh).

Apesar dos Espodossolos tropicais cobrirem grandes áreas distribuídas mundialmente - mais de $140.000 \mathrm{~km}^{2}$ somente na Amazônia - o seu conhecimento é relativamente incompleto. A maior parte deste conhecimento restringe-se a estudos sobre a dinâmica desses solos e foram conduzidos na Guiana Francesa (Boulet et al., 1982; Veilon, 1991), no Brasil (Lucas et al., 1984, 1988; Dubroeucq; Volkoff, 1998; Horbe et al., 2004, Nascimento et al., 2004; Montes et al., 2007; Patel- 
Sorrentino et al., 2007; Fritsch et al., 2009) e no Peru (Veillon; Soria-Solano, 1988). Sistemas similares foram descritos superficialmente na África (Braummer, 1973; Schwartz, 1988) e em Bornéu (Brabant, 1987).

No Brasil, há carência de estudos sobre Espodossolos, porém tem grande destaque os realizados em solos localizados na Amazônia que ocorrem em transições Latossolo-Espodossolo (Lucas et al., 1987; Bravard; Righi, 1989; Dubroeucq; Volkoff, 1998; Mafra et al., 2002). A escassez de estudos sobre Espodossolos no Brasil levou esta ordem a ser uma das menos estruturadas no Sistema Brasileiro de Classificação de Solos (SiBCS) (Gomes et al., 2007). Utilizamse critérios derivados da World Reference Base for Soil Resources (FAO, 1971) e da Soil Taxonomy (USDA, 1999). Desta forma este estudo pode contribuir para o incremento das informações já conhecidas.

Os Espodossolos da Amazônia armazenam grandes quantidades de carbono nos horizontes superficiais. Baseado no estudo de uma pequena coleção de perfis, menos de 30 para toda a Amazônia, Batjes e Dijkshoorn (1999) e Bernoux et al. (2002) estimaram que nos primeiros $30 \mathrm{~cm}$ destes solos a média de carbono

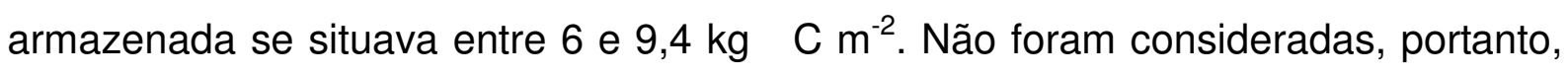
as acumulações de $\mathrm{C}$ existentes nos horizontes $\mathrm{Bh}$ profundos em razão da dificuldade de se atingir estes horizontes devido ao colapso dos materiais arenosos que ocorre durante as sondagens ou abertura de poços.

Trabalhos realizados por parte da equipe envolvida neste estudo, identificaram, em profundidade, horizontes Bh espessos em Espodossolos hidromórficos típicos, localizados na bacia do alto rio Negro (Montes et al., 2011 ). A quantificação do carbono, baseada em mais de 500 amostras indica que os perfis de Espodossolos armazenam em média $86,8 \pm 7,1 \mathrm{~kg} \mathrm{C} \mathrm{m}^{-2}[(10-40 \mathrm{~cm}-17,0 \pm 4,0 \mathrm{~kg} \mathrm{C}$ $\mathrm{m}^{-2}$ (horizonte superficial); $115-200 \mathrm{~cm}-3,1 \pm 0,9 \mathrm{~kg} \mathrm{C} \mathrm{m}^{-2}$ (horizontes arenosos); 220 -

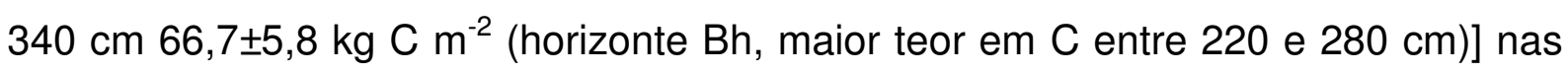
áreas com drenagem deficiente. Se considerarmos que, em todos os lugares na Amazônia onde os Espodossolos foram estudados com mais detalhes, constatou-se a presença do Bh profundo, é licito supor que o armazenamento de carbono profundo ocorre na maior parte da área de Espodossolo. A partir da extrapolação desses dados, realizada com base em mapas de solos digitalizados (IBGE, 2009) chegou-se a um valor de 13,6 Pg de carbono C armazenado nos Espodossolos hidromórficos, 12,3 Pg C acima das estimativas anteriores (Bernoux et al., 2002). 
Este valor pode estar ainda subestimado, pois grandes áreas cobertas por sistemas de solos, onde os Espodossolos ocorrem em pequenas manchas que não aparecem nos mapas digitalizados.

A descoberta desses reservatórios de carbono traz à tona o problema de sua estabilidade face às mudanças de uso do solo ou climática. Ressalta-se que no alto rio Negro, em trabalho recente (Bueno, 2009), foi evidenciado que os Espodossolos das bordas dissecadas dos platôs, em que estes solos sofrem incisão da rede de drenagem e rebaixamento do nível freático, os mesmos apresentam um teor de matéria orgânica nos horizontes A e Bh significativamente menor (Podzóis bem drenados, como, por exemplo, em Schwartz (1988)). Assim, esse efeito, que no alto rio Negro tem causas hidrológicas e geomorfológicas naturais, pode ser também esperado se houver redução da umidade do solo provocada por uso do solo ou redução da precipitação por mudança climática.

Além disso, qualquer mudança significativa na cobertura vegetal seja devida modificações locais, por exemplo, desmatamento, seja devida a mudanças globais, como flutuação climática, poderia alterar significativamente, a dinâmica da água no solo. Essas mudanças tendem a afetar a remobilização (turnover) do carbono no solo, mas a direção da mudança (aumento ou decréscimo da mineralização do carbono orgânico) não fica clara e dependeria, mais provavelmente, das condições específicas e das propriedades dos solos em questão (Solomon et al., 2007).

A matéria orgânica é um importante constituinte do solo, sendo um componente fundamental na qualidade dos sistemas agrícolas em razão do seu conteúdo e sua qualidade serem os mais importantes fatores que mantêm a fertilidade e a sustentabilidade agrícola (Reeves, 1997).

O entendimento sobre a dinâmica da matéria orgânica no processo de podzolização contribui para análise das condições pedoambientais, uma vez que ela influencia fortemente nos processos pedogenéticos atuantes no solo e na dispersão dos complexos metálicos aos ambientes aquáticos (Rossin, 2013).

Avaliar e compreender a dinâmica do carbono e de outros elementos no solo da Amazônia pode ajudar os cientistas a melhorar os modelos e antecipar cenários. Novos métodos, que permitem medições de carbono do solo in situ, são uma abordagem fundamental para este tipo de região, devido aos custos financeiros para a coleta e envio de amostras de solo da floresta para o laboratório, e demanda muito tempo nesta atividade. A possibilidade de aplicação da espectroscopia de emissão 
ótica com plasma induzido por laser (LIBS) e a fluorescência induzida por laser (FIL) para a análise semi-quantitativa de carbono, alumínio e o grau de humificação da $\mathrm{MO}$, podem, portanto, serem utilizadas como ferramentas de triagem no campo para selecionar amostras relevantes para futuras investigações em laboratório e futuramente serem levados para análises em campo.

Outro ponto relevante é que este estudo auxiliou no desenvolvimento de técnicas de caracterização da matéria orgânica, em relação à sua rápida caracterização no solo, por meio de técnicas espectroscópicas, sobretudo técnicas de fluorescência.

\section{OBJETIVOS}

Avaliar e caracterizar através de métodos químicos e espectroscópicos a matéria orgânica e a composição elementar dos solos arenosos da região de São Gabriel da Cachoeira na Amazônia em um perfil de até $4 \mathrm{~m}$.

Quantificar carbono, ferro e alumínio nos solos arenosos amazônicos através da análise elementar (CHNS) e espectrometria de emissão ótica com plasma acoplado indutivamente (ICP OES) e, avaliar o potencial da quantificação pela espectroscopia de emissão ótica com plasma induzido por laser (LIBS) para estes elementos.

Avaliar alterações estruturais, grau de humificação e identificar os fluoróforos suscetíveis de discriminar os diferentes tipos de matéria orgânica do solo (MOS) através da espectroscopia de fluorescência induzida por laser (FIL), fluorescência de luz UV-Visível e absorção de radiação na região no UV-Visível. A análise de fatores paralelos (PARAFAC) foi usada para extrair informações a partir dos dados clássicos obtidos pela espectroscopia de fluorescência tridimensional, EEFM (Excitationemission fluorescence matrix - matriz de excitação e emissão de fluorescência). 


\section{REVISÃO DE LITERATURA}

\subsection{A AMAZÔNIA BRASILEIRA}

A bacia amazônica é uma das maiores bacias hidrográficas da superfície emersa do planeta, com uma área total de 6,5 milhões de $\mathrm{km}^{2}$ (Fritsch et al., 2011), sendo aproximadamente 5 milhões em território brasileiro e o restante dividido entre os países da Bolívia, Colômbia, Equador, Venezuela, Peru, Suriname e Guiana (Soares-Filho et al., 2006). Segundo O Instituto Brasileiro de Geografia e Estatística (IBGE), a área de abrangência da Amazônia Legal corresponde em sua totalidade aos estados do Acre, Amapá, Amazonas, Mato Grosso, Pará, Rondônia, Roraima e Tocantins, e parcialmente, ao estado do Maranhão, alcançando uma área correspondente a cerca de $60 \%$ do território brasileiro (Figura 3.1).

Figura 3.1 - Mapa da Amazônia Legal - Estados do Acre, Amapá, Amazonas, Mato Grosso, Pará, Rondônia, Roraima, Tocantins e parcialmente Maranhão.

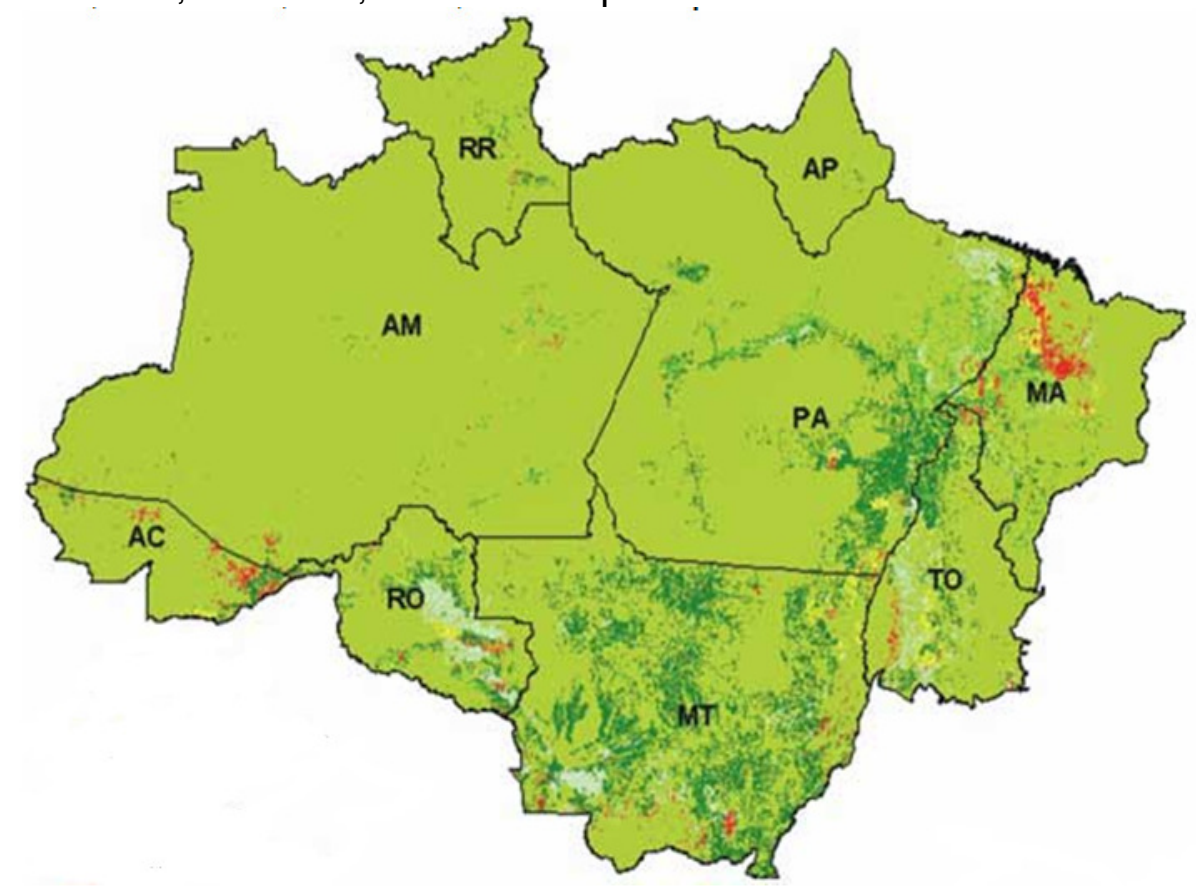

Fonte: www.ibge.gov.br

Situada na zona das florestas tropicais e em grande parte protegida das atividades antrópicas, a bacia amazônica controla os principais ciclos biogeoquímicos do planeta (dentre eles o ciclo do carbono). Ela constitui, por isso, um dos ecossistemas mais importantes para abordar o estudo destes ciclos e 
revelar, por um lado, os processos maiores que controlam a dinâmica dos metais e da $\mathrm{MO}$ e, por outro, o impacto da pressão antrópica (efeito estufa, desmatamento, e mudança climática) sobre a dinâmica destes processos (Bueno, 2009).

Apesar de se constituir em aproximadamente $1,5 \%$ da superfície terrestre, a Amazônia possui cerca de 20 a 25\% da biodiversidade do planeta e armazena mais de $100 \mathrm{GTg}$ de carbono na vegetação e solo, equivalente a aproximadamente 14 vezes as emissões anuais globais pela utilização de combustíveis fósseis (carvão mineral, petróleo e gás natural) e 60 vezes as emissões anuais por desflorestamento em todo planeta. Além disso, é importante observar que a capacidade que a vegetação apresenta em absorver carbono está muito intimamente associada aos padrões espaço-temporais dos regimes de precipitação (Sombrock, 2001; Malhi et al., 2006; Aragão et al., 2008).

A Amazônia é limitada a oeste pela Cordilheira dos Andes (com elevações de até $6000 \mathrm{~m}$ ), ao norte pelo Planalto das Guianas (com picos montanhosos de até $3000 \mathrm{~m}$ ), ao sul pelo Planalto Central (altitudes típicas de $1200 \mathrm{~m}$ ) e a leste pelo Oceano Atlântico, por onde toda a água captada na bacia escoa para o mar, o qual corresponde a $20 \%$ da descarga de água doce global nos oceanos $\left(209.000 \mathrm{~m}^{3} \mathrm{~s}^{-1}\right)$. O rio Amazonas exporta quantidades consideráveis de sólidos suspensos para o oceano (13,5 t s${ }^{-1}$ ) (Fritsch et al., 2011).

Devido a sua grande extensão e baixa densidade populacional, a Amazônia ainda é o bioma brasileiro mais bem conservado, com $85 \%$ de suas florestas primárias intactas (INSTITUTO NACIONAL DE PESQUISAS ESPACIAIS, 2006). Contudo, esta riqueza natural vem sofrendo pressão antrópica traduzida pela exploração desordenada de madeira e expansão dos sistemas agrícolas e outras formas de uso do solo (Furtado, 1997). Estas atividades antropogênicas causam mudanças de cobertura e uso do solo e representam a liberação dos estoques de carbono contidos na vegetação para a atmosfera (Fearnside, 1996).

Apesar da expansão da área desmatada, a Amazônia Brasileira ainda representa cerca de $40 \%$ das florestas tropicais remanescentes do mundo e desempenha um papel vital na manutenção da biodiversidade, clima e hidrologia regional, bem como na manutenção do estoque terrestre de carbono (Laurance et al., 2001; Manzi, 2008; Zanetti, 2012).

O conhecimento da paisagem e as condições do solo da região amazônica mantiveram-se limitados até 1960 (FAO-Unesco, 1971; Sombroek, 1996). Jacomine 
e Camargo (1996) relataram que as duas principais divisões do solo da classificação brasileira de solo, Latossolos e Podzólicos, cobrem quase 75\% da Bacia Amazônica. A área restante é composta de 13 divisões de solo.

$\mathrm{Na}$ Amazônia os principais solos agriculturáveis encontrados são os Latossolos Amarelos e os Argissolos, representando $74,7 \%$ da região, considerados solos pobres em nutrientes, com alto teor de acidez e com baixa capacidade de troca de cátions (CTC) (Vieira; Santos, 1987; Cannavan, 2007), tornando-se um fator limitante para a produtividade e sustentabilidade dos sistemas de produção agrícola desta região. Porém, na mesma região é encontrado um dos solos mais férteis do mundo identificado como Terra Preta Antropogênica (TPA) ou Terra Preta de Índio (TPI), representando uma pequena parcela dos solos amazônicos, provavelmente cobrindo pelo menos entre 0,1 a 0,3\% (15.500 - $\left.20.700 \mathrm{~km}^{2}\right)$ da área florestada da Amazônia (Sombroek et al., 2003; Cunha et al., 2009).

\subsection{O SOLO}

O solo tem um papel de fundamental importância nos ciclos da natureza, participando, direta ou indiretamente, da maioria das atividades que ocorrem no planeta (Figura 3.2). Além de ser o principal substrato para a agricultura, devido à sua capacidade de "filtro biológico", como receptor de resíduos urbanos e industriais indiscriminadamente. Entretanto, o que não se tem levado em consideração é sua capacidade limitada de depuração de resíduos, dependendo de suas qualidades químicas, físicas e mineralógicas, além do conhecimento de tais características dos resíduos que serão agregados ao solo, sob o risco de torna-lo improdutivo e infértil (Ibrahim, 2002; Landgraf; Messias; Rezende, 2005). 
Figura 3.2 - Transformações da rocha em solo.

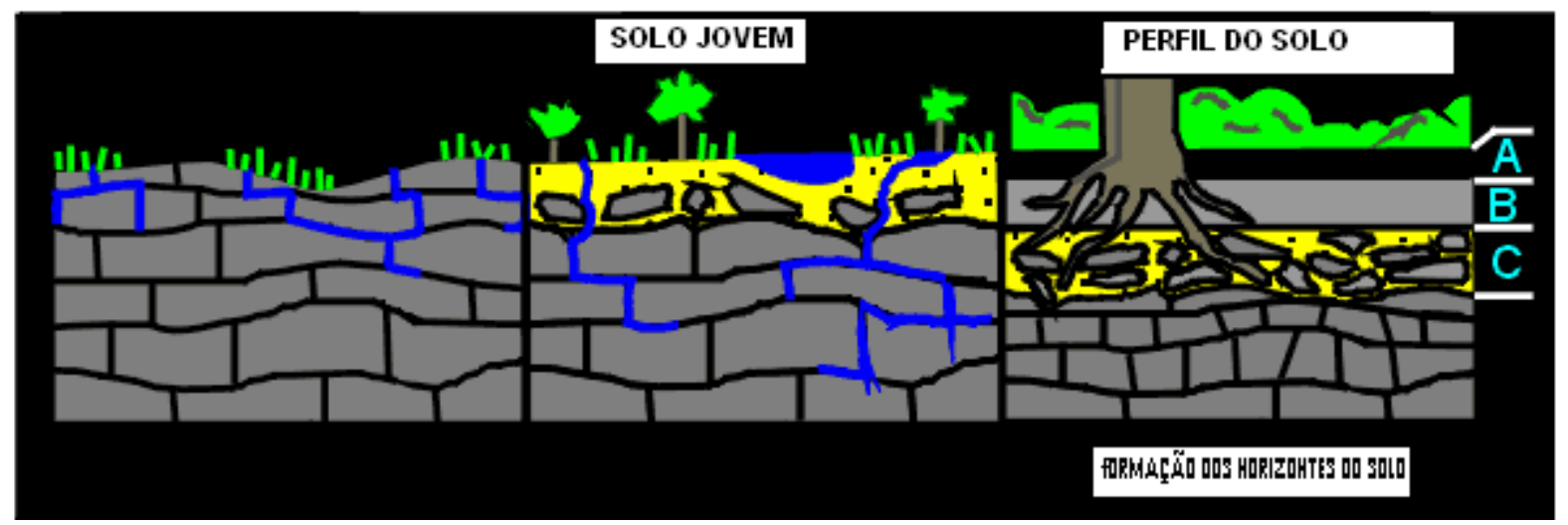

Fonte: Nascimento (1995).

De acordo com Manahan (2001), o solo é uma mistura variável de minerais, matéria orgânica, e água, capaz de suportar o crescimento das plantas na superfície da terra. O produto final é resultado da ação do intemperismo através de processos físicos, químicos e biológicos nas rochas, que produz grande quantidade de argila mineral. A porção orgânica do solo consiste em biomassa das plantas que se encontra em vários estágios de decomposição (Almeida, 2007).

O solo tem um papel de fundamental importância nos ciclos da natureza, participando, direta ou indiretamente, da maioria das atividades que ocorrem no planeta. Além de ser o principal substrato para a agricultura, o solo também é suporte para estradas e para construções civis, sendo muitas vezes utilizado indevidamente como depósito de resíduos. É nos solos que se realiza a maior parte dos processos de reciclagem de nutrientes dos quais o planeta depende para manter-se vivo. Dentre esses processos, incluem-se: a formação e estruturação dos próprios solos, a decomposição da matéria orgânica, a reciclagem de nutrientes e a formação dos gases componentes da atmosfera terrestre (Ibrahim, 2002; Landgraf; Messias; Rezende, 2005; Martins, 2009).

\subsection{SISTEMAS DE SOLOS}

\subsubsection{LATOSSOLOS}

Os Latossolos, distribuindo-se em praticamente todo o território nacional, são as unidades de solos mais representativos do Brasil, ocupando $38,7 \%$ da área total 
do país (Coelho, 2002; Almeida 2007). São típicos de regiões equatoriais e tropicais, de clima quente e úmido, distribuídos, sobretudo, em amplas e antigas superfícies de erosão, sedimentos, e terraços fluviais antigos, normalmente em relevo suavemente ondulado e plano (Reatto et al., 1997).

Grande parte dos solos da Amazônia Central, classificados como Latossolos Amarelos são argilosos com predominância de argila tipo caulinita e abundância de óxidos de Fe e Al (Alfaia, 1997). São solos que apresentam, em geral, boas propriedades físicas, como elevada profundidade efetiva e boa drenagem, porém, apresentam limitações pela saturação por alumínio e baixa fertilidade natural (Sanches et al., 1982; Reatto et al., 1997; Almeida, 2007).

De modo geral, os Latossolos da região amazônica representam um mistério em termos de sustentabilidade ambiental, principalmente os processos de formação, neoformação e transformação pedogenética de seus minerais, como, por exemplo, a caulinita que é o argilomineral mais encontrado na fração argila (Ibanga et al., 1983; Couceiro; Santana, 1999).

A Figura 3.3 mostra a distribuição espacial dos Latossolos (Fritsch et al., 2002; Nascimento et al., 2004; Bueno, 2009; Rossin, 2013).

Figura 3.3 - Distribuição das principais classes de solos da Amazônia.

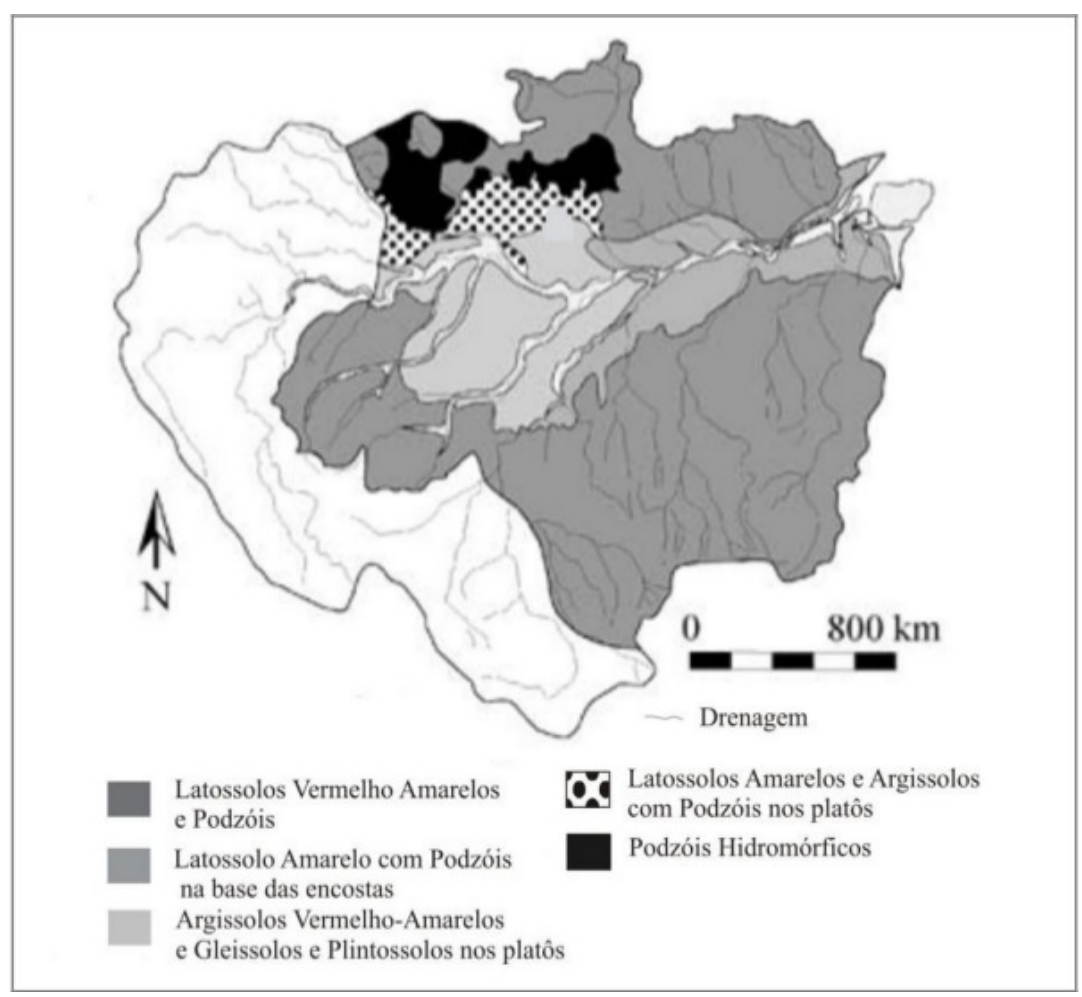

Fonte: Fritsch et al. (2009). 
A destruição dos solos lateríticos, em especial os Latossolos, que se caracterizam pela predominância de óxidos de ferro e minerais de argila, além de grande estabilidade dos agregados, com alto grau de floculação, boa permeabilidade, baixos teores de silte, menor capacidade de troca catiônica (Ker, 1997), é, então, considerado um estágio precedente ao de podzolização.

Segundo Bueno (2009), essa transformação das coberturas lateríticas ocorre devido a processos de transformações na textura e na cor das coberturas, isto é, a partir do empobrecimento das frações finas, e amarelecimento dos solos. Esse amarelecimento é resultado da dissolução dos óxidos de ferro e está ligado ao processo de substituição do Fe pelo Al nas estruturas das goethitas e hematitas com consequente formação dos hidróxidos de alumínio - gibbsita (Fritsch et al., 2002, 2005).

Assim, o amarelecimento dos Latossolos é apontado por Fritsch et al. (1989, 2005) como o principal responsável pela degradação e depleção das argilas, quebrando a estrutura dos solos lateríticos, sendo que essa destruição nos horizontes superiores do solo está relacionada à nova formação da goethita rica em Al e que está ligada à dissolução preferencial da caulinita nestes horizontes (Fritsch et al., 2002).

O empobrecimento dos solos lateríticos em argila e seu amarelecimento está associado à dissolução dos óxidos de ferro e das caulinitas (Fritsch et al., 1989; Balan et al., 2005) o que facilita a perda de colóides e materiais finos através das águas de percolação devido a ruptura das ligações ferro-argila e, portanto, da quebra dos agregados do solo (Bueno, 2009).

Aos processos de transformação mineralógica e geoquímicos agregam-se mais dois de natureza físico-química: a lixiviação e a lessivagem, que são os processos principais utilizados para explicar a perda dos materiais mais finos. Lixiviação associada à dissolução dos minerais e transporte de íons em suspensão e a lessivagem atribuída ao transporte de partículas ou colóides suspensos (Bueno, 2009).

A partir dos processos descritos anteriormente, em especial os de lixiviação e lessivagem, os horizontes dos Latossolos começam a se diferenciar em lluviais (Bs, $B$ B) e Eluvias (E), que são, respectivamente, horizontes de acumulações absolutas e perdas relativas e marcam o início do processo de podzolização (Fritschet al., 1990; Bueno, 2009). 


\subsubsection{ESPODOSSOLOS}

Segundo Bueno (2009) os Espodossolos, anteriormente classificados como Podzóis, são solos com uma morfologia espetacular, apresentando horizontes arenosos sobre níveis pouco permeáveis, enriquecidos em matéria orgânica e em metais, ocupando grandes superfícies da alta bacia amazônica.

Estes solos são constituídos por material mineral, apresentando horizonte diagnóstico B espódico, simbolizado por Bh, Bs ou Bhs, conforme prevalência do acúmulo de matéria orgânica e compostos organometálicos, óxidos de alumínio e, ou ferro ou ambos, que se localiza imediatamente abaixo de horizonte E, A (mais raramente), ou horizonte hístico (Lundström et al., 2000a; Oliveira, 2007). Sobre os horizontes espódicos encontram-se horizontes oriundos de eluviação (A ou E), denominados de álbicos, arenosos e horizontes de iluviação, chamados de espódicos (Bh, Bs ou Bhs) (Lucas et al., 1996; Dubroecq; Volkoff, 1999; Rossin, 2013).

Os Espodossolos apresentam textura arenosa ao longo do perfil, sendo poucos os casos reconhecidos com textura média. Quimicamente são solos ácidos e de baixa fertilidade natural (Oliveira, 2007).

Os Espodossolos são solos comuns em climas mais frios, sendo encontrado com frequência sob vegetação de coníferas e ericáceas no norte do hemisfério norte (Lundström et al., 2000a; Gomes, 2005). Neste caso, a vegetação e o clima frio e úmido dão condições para a ocorrência do processo de podzolização e consequentemente a formação de Espodossolos. No Brasil, os estudos que avaliam a gênese, a evolução das paisagens regionais e a formação dos Espodossolos, relacionam-se predominantemente a condições equatoriais da floresta amazônica, localizadas na bacia do rio Negro. Tais trabalhos enfatizam os mecanismos envolvidos na transição Latossolo/Espodossolo, comuns naquele local (Lopes, 2010).

São essencialmente arenosos e caracterizados pela acumulação de quartzo em detrimento dos argilominerais, especialmente da caulinita. Esse acúmulo de quartzo é atribuído à podzolização, que pressupõe a hidrólise dos argilominerais e a migração da $\mathrm{MO}$ e de complexos organometálicos para subsuperfície (Bravard; Righi, 1989). A migração da $\mathrm{MO}$ e de complexos organometálicos pode gerar um horizonte endurecido no contato com o lençol freático, denominado ortstein húmico, 
ou ainda, bandas de coloração preta (Horbe; Horbe; Suguio, 2004).

No Brasil, há carência de estudos sobre Espodossolos, porém tem grande destaque os realizados em solos localizados na Amazônia que ocorrem em transições Latossolo-Espodossolo (Lucas et al., 1987; Bravard; Righi, 1989; Dubroeucq; Volkoff, 1998; Mafra et al., 2002). A escassez de estudos sobre Espodossolos no Brasil levou esta ordem a ser uma das menos estruturadas no Sistema Brasileiro de Classificação de Solos (SiBCS) (Embrapa, 2006). Utiliza-se de critérios derivados da World reference base for soil resources (WRB) (FAO, 2006) e da Soil Taxonomy (USDA, 1999). Os Espodossolos são conhecidos como Podzols segundo a World reference base for soil resources e Spodosols segundo o Soil Taxonomy.

No SiBCS, a ordem dos Espodossolos é dividida em Espodossolos Humilúvicos, quando há o acúmulo predominante de carbono orgânico no horizonte espódico sendo este denominado horizonte Bh; Espodossolos Ferrihumilúvicos, com acúmulo de carbono orgânico, ferro e alumínio, com presença de horizonte Bhs e, Espodossolos Ferrilúvicos, os quais caracterizam-se pelo acúmulo de ferro, apresentando horizonte Bs. A presente denominação das subordens parece não deixar dúvidas quanto ao domínio de complexos orgânicos-Fe no horizonte $B$ espódico de Espodossolos brasileiros, não obstante constatação de maior participação do Al em relação ao Fe no Brasil e no mundo (Andriesse, 1969; Anderson et al., 1982; Farmer et al., 1983; Oliveira, 2007).

\subsubsection{O SISTEMA DE TRANSFORMAÇÃO LATOSSOLO-ESPODOSSOLO}

A complexidade natural da Amazônia criou diversas possibilidades de pesquisa nessa região, cujos resultados têm permitido melhor entendimento dos processos de formação desse importante bioma brasileiro. Entre esses processos, destacam-se aqueles relacionados à formação das coberturas pedológicas arenosas (podzolização), associadas à destruição dos solos lateríticos e a gênese dos Podzóis, que recobrem, especialmente, extensas áreas da bacia do rio Negro (Diniz, 2010).

A transformação de Latossolos em solos arenosos como Espodossolos foi verificada na Amazônia em materiais formados sobre rochas sedimentares (Lucas, 1989) ou mesmo sobre o embasamento cristalino (Andrade, 1990; Dubroeucq; 
Volkoff, 1998). Dubroeucq, Volkoff e Faure (1999), Mafra (2000), Nascimento et al. (2004), Arenare (2007) e Bueno (2009) constataram que indicadores do processo de tranformação do solo podem ser observados nas zonas limitrófes entre os Espodossolos e os Latossolos sobrejacentes. Foram observadas, primeiramente, alterações na coloração com aumento nos processos de dissolução dos óxidos de Fe e Al. Com a evolução do processo observa-se a desestabilização e dissolução de caulinitas e posterior evolução final para Espodossolos.

Latossolos e Espodossolos são típicos de regiões climáticas completamente distintas, pois enquanto os primeiros são característicos de regiões tropicais úmidas, os segundos têm sua distribuição zonal nas regiões frias do globo, onde o baixo pH da solução de percolação desempenha um papel fundamental na sua gênese (Ishida, 2010). Entretanto, estes dois tipos de solos formam nas zonas intertropicais um importante sistema pedológico que tem sido alvo de estudo em várias regiões: Indonésia (Brabant, 1987; Thomas; Thorp; Mcalister, 1999), Guiana Francesa (Boulet et al., 1982; Lucas et al., 1986; Veillon, 1990), Congo (Schwartz, 1988), Polinésia Francesa (Jamet et al., 1996) e Peru (Veillon; Soria-Solano, 1988).

A partir da década de 1950, o desenvolvimento do processo de podzolização começa a ser mais estudado nas regiões tropicais. No entanto, os primeiros estudos sobre a origem dos Espodossolos neste tipo de clima associavam esses solos aos materiais de origem psamíticos tais como o quartzito, arenito ou formações eólicas, coluvionais e aluvionais arenosas (Dubroeucq et al., 1999). A formação desses solos arenosos pode ser atribuída a duas causas principais: das quais, uma seria relacionada com a deposição de sedimentos nas bordas dos vales (Klinge, 1965; Sombroek, 1984), e outra consideraram que os Espodossolos fazem parte de um estágio final de degradação das coberturas pedológicas tropicais e poderiam ser originados a partir de solos ferralíticos independentemente do material de origem (Lucas et al., 1984; Lucas, 1989).

No caso da bacia do alto rio Negro, há pouco conhecimento sobre a formação desses solos arenosos, devido à dificuldade de acesso e à impossibilidade de abertura de trincheiras num ambiente pantanoso, com uma camada arenosa e, algumas vezes, presença de horizonte espódico Bh endurecido (Dubroeucq; Blancaneaux, 1987; Mafra et al., 2002).

Dubroeucq e Volkoff (1998), Bravard e Righi (1990) e Nascimento et al. (2004) afirmaram que a podzolização ocorre somente a partir de material laterítico sob 
condições redutoras e previamente intemperizado. Evidências sugerem que para a ocorrência da podzolização, mudanças texturais e a instalação de condições de hidromorfia são necessárias para promover o amarelecimento prévio das lateritas e o empobrecimento das argilas (Fritsch et al., 1986; Nascimento et al., 2004; Bueno, 2009).

De acordo com estudos realizados por Montes et al. $(2007,2011)$, a formação dos Espodossolos está intimamente relacionada com a origem dos grandes depósitos de argilas cauliníticas brancas do alto rio Negro. Nesse sentido, as condições para desencadear a podzolização estão ligadas ao intemperismo inicial do saprolito ferralítico durante tempo suficientemente longo para permitir, com alta perda de cátions nos horizontes superficiais e formação de soluções hiperácidas, a dissolução das caulinitas e da gibbsita. Concomitantemente, os complexos organometálicos promovem a migração, vertical e lateral, do ferro e do alumínio (Pereira, 2011).

\subsubsection{PODZOLIZAÇÃO}

O processo pedogenético predominante nos Espodossolos é a podzolização, a qual é estudada há mais de um século (Lundström et al., 2000b). Assim pode-se assumir que sua gênese, suas propriedades e sua distribuição são bem conhecidas. Sendo assim, são pouco os estudos de podzolização em solos de regiões tropicais e subtropicais, comparando-se com aqueles de clima mais frio, do hemisfério norte, principalmente em zonas sob florestas boreais e clima úmido, onde é o processo de formação de solo predominante (Gomes, 2005).

Várias teorias têm sido propostas para explicar a formação dos Espodossolos (DeConinck, 1980; Anderson et al., 1982; Lundström et al., 2000a; Buurman; Jongmans, 2005). No entanto, aspectos como a mobilização, migração e o acúmulo de $\mathrm{MO}$ com ou sem metais como Al e Fe no horizonte B desses solos, em ambientes tropicais, ainda não estão totalmente elucidados (Hees; Lundström; Giesler, 2000).

A podzolização é o processo de formação que origina os Espodossolos. Este processo é caracterizado pelo transporte de $\mathrm{MO}$, Fe e Al dos horizontes superficiais (O, A) para os horizontes espódicos (iluviação), onde precipitam (DeConinck, 1980). Esse processo envolve o intemperismo dos minerais primários pela ação dos ácidos orgânicos e a translocação do alumínio e ferro na forma de complexos orgânicos dos 
horizontes superficiais para os horizontes espódicos (Anderson et al., 1982; Bravard; Righi, 1990; Lundström, 1993; Lucas et al., 1996; Patel-Sorrentino et al., 2007).

Das teorias existentes para explicar como ocorre a mobilização e imobilização da $\mathrm{MO}, \mathrm{Fe}$ e Al no perfil do solo, as mais difundidas no meio científico são as teorias do fulvato e da proto-imogolita (Farmer; Russel; Berrow, 1980; Anderson et al., 1982; Farmer; Fraser, 1982; Lundström, 1993; Patel-Sorrentino et al., 2007; Ishida, 2010).

Buurman e Jongmans (2005) consideram que as principais explicações dos processos envolvidos na gênese desses solos são: (i) mobilização de complexos organometálicos não saturados dos horizontes $\mathrm{A}$ ou $\mathrm{E}$, seguido de precipitação no horizonte B após saturação do complexo por metais (teoria do fulvato); (ii) transporte de géis de alofana e proto-imogolita, com subsequente precipitação no horizonte $\mathrm{B} e$ adsorção no húmus móvel (teoria da proto-imogolita); e (iii) formação in situ de imogolita/alofana no horizonte B por processos de intemperismo decorrente da ação do ácido carbônico e subsequente ou concomitante precipitação de ácidos fúlvicos (AF) nos precipitados ricos do horizonte B (teoria do fulvato-bicarbonato).

Estudos que ressaltaram a importância da $\mathrm{MO}$ no processo de podzolização foram realizados na região Amazônica. Bravard e Righi (1990) assinalaram a produção de complexos organo-ácidos e sua habilidade de migração no perfil, além de diferenciar a matéria orgânica encontrada nos Latossolos da encontrada nos Espodossolos (Rossin, 2013). A MO possui participação ativa na gênese dos Espodossolos, tendo uma influência importante no processo de podzolização (Burman; Jongmans, 2005), pois está diretamente envolvida nos estágios de mobilização, transporte e precipitação (Buurman; Jongmans, 2005).

\subsection{CARACTERÍSTICAS FÍSICAS DOS PERFIS DE SOLO ESTUDADO}

As análises granulométricas dos solos estudados foram realizadas por Ishida (2010). Para a determinação das frações granulométricas dos solos (Espodossolo Humilúvico e Latossolo Amarelo) o método utilizado foi o da pipeta, de acordo com Camargo et al. (1986).

Segundo Ishida (2010), de acordo com a Tabela 3.1 relativa ao Espodossolo Humilúvico, observa-se teores elevados da fração areia nos horizontes superficiais (A1 e A2) e álbicos E1 e E2, atingindo valores superiores a 87\%. Para os horizontes espódicos (Bh e Bhs) seus teores continuam elevados, mas baixam bruscamente no 
horizonte de transição e nos horizontes de caulim.

Tabela 3.1 - Teores de areia, argila e silte obtidos pela Análise Granulométrica para o Espodossolo Humilúvico. Adaptada de Ishida (2010).

\begin{tabular}{|c|c|c|c|c|c|c|}
\hline $\begin{array}{l}\text { Horizonte/ } \\
\text { Camada }\end{array}$ & $\begin{array}{l}\text { Profundidade } \\
(\mathrm{cm})\end{array}$ & $\begin{array}{l}\text { Profundidade } \\
\text { de coleta }(\mathrm{cm})\end{array}$ & Areia $^{(1)}$ & $\frac{\text { Silte }^{(2)}}{---\%}$ & Argila $^{(3)}$ & $\begin{array}{c}\text { Relação } \\
\text { silte / argila }\end{array}$ \\
\hline $\mathrm{A} 1$ & $0-5$ & 5 & 87,99 & 5,11 & 5,14 & 0,99 \\
\hline $\mathrm{A} 2$ & $5-30$ & 15 & 90,51 & 6,98 & 2,51 & 2,78 \\
\hline E1 & $30-180$ & 130 & 87,03 & 11,87 & 1,10 & 10,79 \\
\hline E2 & $180-202,5$ & 182 & 88,93 & 9,12 & 1,95 & 4,68 \\
\hline $\mathrm{Bh}$ & $202,5-204$ & 204 & 78,70 & 15,19 & 6,11 & 2,49 \\
\hline Bhs & $204-214$ & 214 & 70,30 & 15,51 & 14,19 & 1,09 \\
\hline Transição & 214-245 & 227 & 11,16 & 37,89 & 50,95 & 0,74 \\
\hline K1 & $245-290$ & 252 & 8,26 & 64,79 & 26,95 & 2,40 \\
\hline $\mathrm{K} 2$ & $290+$ & 313 & 2,90 & 67,78 & 29,32 & 2,31 \\
\hline
\end{tabular}

(1) Fração areia $=$ de 0,05 a $2 \mathrm{~mm}$, (2) Fração silte $=$ de 0,002 a $0,05 \mathrm{~mm}$, (3) Fração argila $=$ inferior a $0,002 \mathrm{~mm}$.

Para o Latossolo Amarelo, Ishida (2010) observou teores elevados da fração areia nos horizontes superficial (A2), de transição (BA) e latossólicos (Bw1, Bw2 e Bw3), indicando que nestes horizontes estaria ocorrendo perda das frações finas (silte e argila). Nos horizontes de caulim (Kn1, Kn3 e Kn4) e na transição, os teores da fração argila comparado aos demais horizontes pouco variaram, entretanto, os teores da fração silte foram superiores a 59,17\% (Tabela 3.2).

Tabela 3.2 - Teores de areia, argila e silte obtidos pela Análise Granulométrica para o Latossolo Amarelo. Adaptada de Ishida (2010).

\begin{tabular}{ccccccc}
$\begin{array}{c}\text { Horizonte/ } \\
\text { Camada }\end{array}$ & $\begin{array}{c}\text { Profundidade } \\
(\mathrm{cm})\end{array}$ & $\begin{array}{c}\text { Profundidade } \\
\text { de coleta }(\mathrm{cm})\end{array}$ & $\begin{array}{c}\text { Areia }^{(1)} \\
\text { - -----------\%----- }\end{array}$ & $\begin{array}{c}\text { Silte }^{(2)} \\
\text { Argila }^{(3)}\end{array}$ & $\begin{array}{c}\text { Relação } \\
\text { silte/argila }\end{array}$ \\
\hline A2 & $10-20$ & 15 & 58,96 & 20,55 & 20,49 & 1,00 \\
BA & $20-30$ & 25 & 70,11 & 8,65 & 21,24 & 0,41 \\
Bw1 & $30-60$ & 45 & 68,44 & 7,97 & 23,58 & 0,34 \\
Bw2 & $60-90$ & 70 & 61,39 & 12,92 & 25,69 & 0,50 \\
Bw3 & $90-120$ & 105 & 35,78 & 33,13 & 31,09 & 1,07 \\
Transição & $120-210$ & 160 & 4,75 & 64,79 & 30,46 & 2,13 \\
Kn1 & $210-250$ & 230 & 9,65 & 67,72 & 22,63 & 2,99 \\
Kn2 & $250-320$ & 290 & 12,79 & 59,17 & 28,04 & 2,11 \\
Kn3 & $320-380$ & 340 & 9,55 & 63,11 & 27,34 & 2,31 \\
Kn4 & $380+$ & 395 & 9,10 & 77,03 & 13,88 & 5,55 \\
\hline
\end{tabular}

(1) Fração areia $=$ de 0,05 a $2 \mathrm{~mm}$, (2) Fração silte $=$ de 0,002 a $0,05 \mathrm{~mm}$, (3) Fração argila $=$ inferior a $0,002 \mathrm{~mm}$. 


\subsection{A MATÉRIA ORGÂNICA DO SOLO}

Os conceitos modernos de qualidade do solo e sustentabilidade agrícola têm sido abordados de maneira ampla, visto que incluem a necessidade de aumentar a produtividade agrícola, a preservação dos recursos naturais e qualidade ambiental. Essa visão atribui à matéria orgânica um importante papel como componente dos agroecossistemas para promover sustentabilidade agrícola (Martin-Neto et al., 2004; Abbruzzini, 2011).

A matéria orgânica do solo (MOS) é considerada um dos indicadores mais úteis de qualidade do solo, pois além de desempenhar importantes efeitos no solo, os quais refletem em sua capacidade de funcionar dentro dos limites do ecossistema para sustentar a produtividade biológica, manter a qualidade ambiental e promover a saúde de plantas e animais (Araújo et al., 2008), a MOS juntamente com o solo desempenham importante papel no ambiente global, uma vez que participa do ciclo do carbono na terra e por este motivo, tem atraído grande interesse devido ao fenômeno do aquecimento global e a perspectiva de se utilizar o solo como reservatório do dióxido de carbono $\left(\mathrm{CO}_{2}\right)$ liberado à atmosfera pela atividade humana, através da conversão de área sob vegetação natural em sistemas agrícolas (Cerri; Cerri, 2007).

Segundo Stevenson (1994), a MOS consiste de uma mistura de compostos em vários estágios de decomposição, que resultam da degradação biológica de resíduos de plantas e animais, e da atividade sintética de micro-organismos. A MO inclui todos os constituintes orgânicos do solo, inclusive tecidos de plantas e animais não decompostos, seus produtos de decomposição parcial e a biomassa do solo (Stevenson, 1994; Schnitzer, 1982).

A matéria orgânica interfere em várias propriedades do solo, tais como: retenção de água no solo, formação de agregados, densidade do solo, $\mathrm{pH}$, capacidade tampão, capacidade de troca catiônica, mineralização, sorção de pesticidas e outros agroquímicos, infiltração, aeração e atividade microbiana. Sua quantidade presente no solo varia de acordo com o clima, o tipo de vegetação ou cobertura, textura e regime de saturação hídrica e ainda, o manejo (Santos, 2007).

A MOS é constituída basicamente de substâncias húmicas ( $\mathrm{SH}$ ) e substâncias não húmicas. As substâncias não húmicas (carboidratos, aminoácidos, proteínas, ácidos orgânicos de baixa massa molecular, entre outras) pertencem a grupos bem 
conhecidos e possuem características físicas e químicas bem definidas. Geralmente correspondem aos compostos mais facilmente degradados por micro-organismos, tendo normalmente tempo mais curto de vida no ambiente. As $\mathrm{SH}$, por sua vez, são macromoléculas ou estruturas supramoleculares, com massa molecular e estruturas variáveis. Possuem características físicas e químicas não bem definidas e que podem ser divididos em ácidos húmicos $(\mathrm{AH})$, ácidos fúlvicos (AF) e huminas, com base nas suas características de solubilidade (Stevenson, 1994).

\subsubsection{SUBSTÂNCIAS HÚMICAS: CONCEITOS E MODELOS}

As SH estão presentes em todos os solos e águas naturais que contém MO. Nos solos a MO pode apresentar-se em quantidades muito variadas, desde $0,5 \%$ (solos desérticos) e 95\% (solos turfosos) (Luchese; Fávero; Lenzi, 2002). No Brasil, a maior parte dos solos apresentam teores de $\mathrm{MO}$ entre 1 e $3 \%$ contudo, podemos encontrar solos com teores superiores a esses. As $\mathrm{SH}$ podem compor mais de $80 \%$ da matéria orgânica de um solo e, por essa razão essas substâncias podem ter um profundo papel nos aspectos físicos e químicos do solo.

As SH são os componentes mais recalcitrantes da MOS e são constituídas de uma mistura heterogênea de compostos orgânicos naturais com elevada massa molar, em que cada fração (ácidos húmicos, ácidos fúlvicos e huminas) deve ser considerada como sendo constituída de uma série de moléculas de tamanhos diferentes. A maioria delas não possui a mesma configuração estrutural ou grupos reativos na mesma posição (Stevenson, 1994).

As SH são substâncias amorfas, escuras e contêm uma grande variedade de grupos funcionais, tais como, carboxílicos, fenólicos, enólicos, hidroxílicos, quinonas e nitrogênio presente como nitrilas e estruturas heterocíclicas (Stevenson, 1994; Saab, 1999; Martin-Neto et al., 2004). Possuem massa molar aparente que varia de centenas a milhares de unidade de massa atômica e são substâncias bastante resistentes à degradação química e biológica (Schnitzer; Khan, 1978; Stevenson, 1994; Schulten; Schnitzer, 1997). Segundo Stevenson (1994), os caminhos pelos quais as substâncias húmicas são formadas são inúmeros, devido à grande quantidade de possíveis estruturas precursoras e ao enorme número de possibilidades de interação entre elas.

Estas substâncias são formadas a partir do processo denominado 
"humificação", o qual se destaca por possibilitar a alteração de estruturas químicas da MOS por meio da degradação de resíduos orgânicos via lixiviação, trituração e catabolismo. Variáveis como temperatura, regime de água do solo, pH e nutrientes livres controlam esse processo, que proporciona um aumento nos grupos Ccarboxílicos, C-aromáticos e C-alquil, principalmente fenólicos e a diminuição de grupos O-alquil (Zech et al.,1997).

Entende-se por humificação o processo de transformação de material macromorfologicamente identificável em compostos amorfos, englobando as mudanças em resíduos vegetais e MOS (Rosa et al., 2005). Assim, as principais transformações que ocorrem durante o processo de humificação é a modificação das estruturas da lignina, perda de compostos fenólicos e polissacarídeos e enriquecimento em estruturas aromáticas não lignínicas recalcitrantes (Zech et al., 1997).

Segundo a Sociedade Internacional de Substâncias Húmicas (IHSS) e a literatura internacional (Stevenson, 1994; Huang et al., 2012) as SH podem ser classificadas com base na sua solubilidade em meio aquoso e se dividem em:

- ácidos húmicos: fração solúvel em extrato alcalino, que precipita após acidificação;

- ácidos fúlvicos: fração que permanece em solução quando o extrato alcalino é acidificado;

- humina: fração insolúvel em qualquer intervalo de $\mathrm{pH}$.

Destas três frações, os ácidos húmicos são mais suscetíveis às mudanças estruturais decorrentes de práticas de manejo do solo e dos processos de degradação da MOS (Tatzber et al., 2008).

A divisão das $\mathrm{SH}$ em $\mathrm{AH}, \mathrm{AF}$ e humina é uma classificação operacional levando-se em conta apenas às características de solubilidade em meio aquoso e não as propriedades inerentes a essas substâncias.

Devido à complexidade e heterogeneidade das substâncias húmicas ainda não há um consenso na explicação da composição química, estrutura, forma e tamanho molecular dessas substâncias, fato que dificulta o melhor entendimento da sua dinâmica no meio ambiente (Fialho, 2007).

Apesar de se conhecer os grupos funcionais e a composição elementar que compõem as $\mathrm{SH}$, ainda hoje não existe um modelo estrutural definitivo. Muitas estruturas foram propostas, cada uma delas foi caracterizada por grupos funcionais similares e a presença de componentes aromáticos e alifáticos. 
$\mathrm{Na}$ literatura há duas propostas de modelos que tentam explicar a estrutura das substâncias húmicas: o modelo macromolecular e o supramolecular (Schulten; Schnitzer, 1997; Piccolo; Conte, 2000; Piccolo, 2001; Sutton; Sposito, 2005).

Baseados em uma variedade de técnicas analíticas, tais como: espectroscopia, degradação oxidativa, pirólise e microscopia eletrônica, Schulten e Schnitzer (1993) sugeriram uma estrutura para os AH na Figura 3.4.

Figura 3.4 - Modelo de estrutura macromolecular para ácido húmico. O símbolo representa sequências de cadeias alifáticas de comprimento variável.

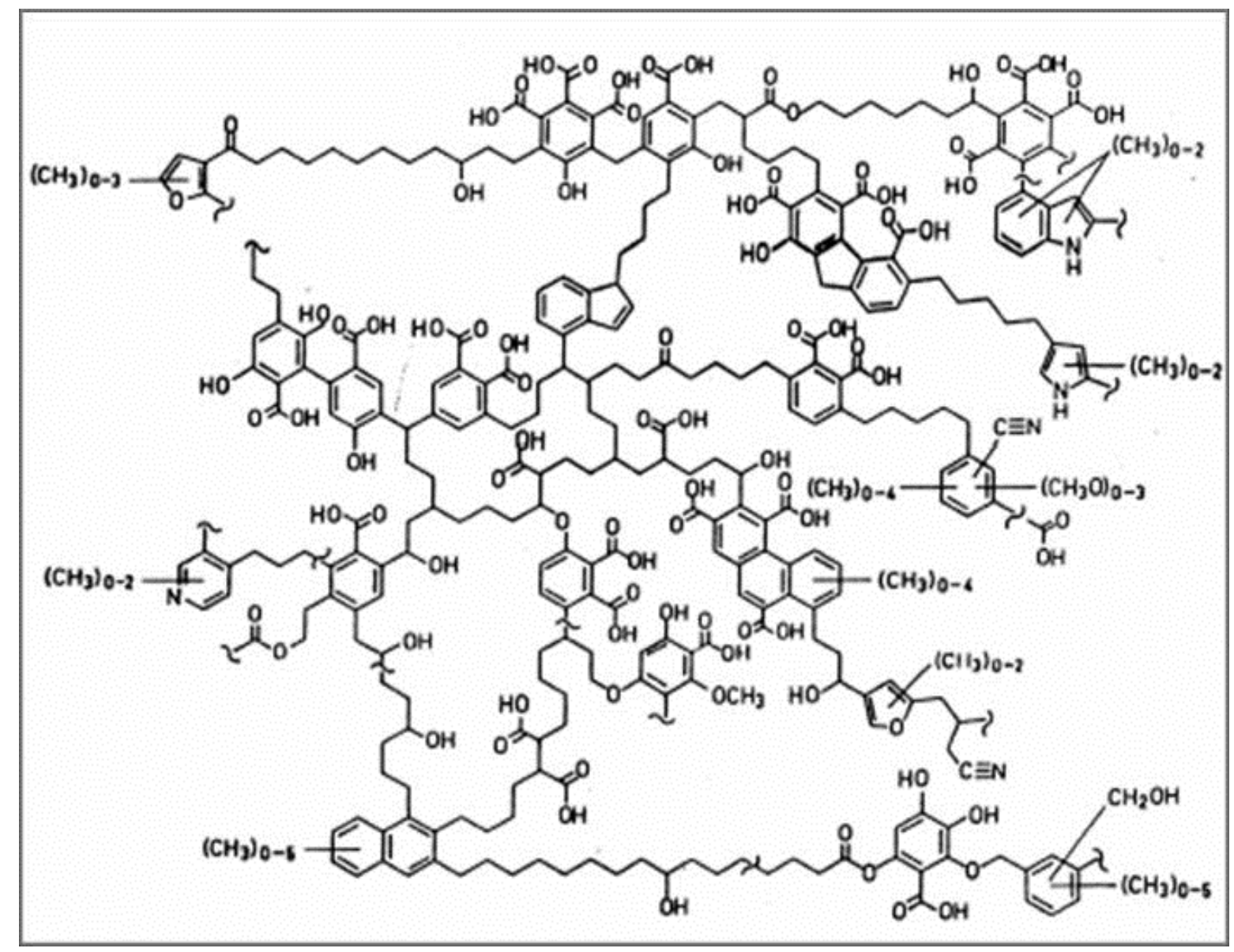

Fonte: Schulten e Schnitzer (1993).

No modelo estrutural da Figura 3.4 os $\mathrm{AH}$ apresentam grandes porções alifáticas, as funções oxigenadas estão presentes como grupos carboxílicos, hidroxílicos, fenólicos, éter e éster e as funções nitrogenadas presentes como nitrilas e estruturas heterocíclicas. A composição elementar da estrutura do ácido húmico é $\mathrm{C}_{308} \mathrm{H}_{328} \mathrm{O}_{90} \mathrm{~N}_{5}$ e tem tamanho molecular de $5540 \mathrm{Da}$.

Baseado em experimentos de pirólise acopladas a um espectrômetro de 
massas, Schulten e Shnitzer (1997) propuseram um modelo tridimensional pelo qual o AH é representado como uma macromolécula na Figura 3.5.

Figura 3.5 - Modelo tridimensional para ácido húmico, evidenciando os átomos de carbono (em azul), hidrogênio (em branco), nitrogênio (em preto) e oxigênio (em vermelho). As letras $A, B$ e $C$ indicam os espaços vazios presentes na estrutura das substâncias húmicas.

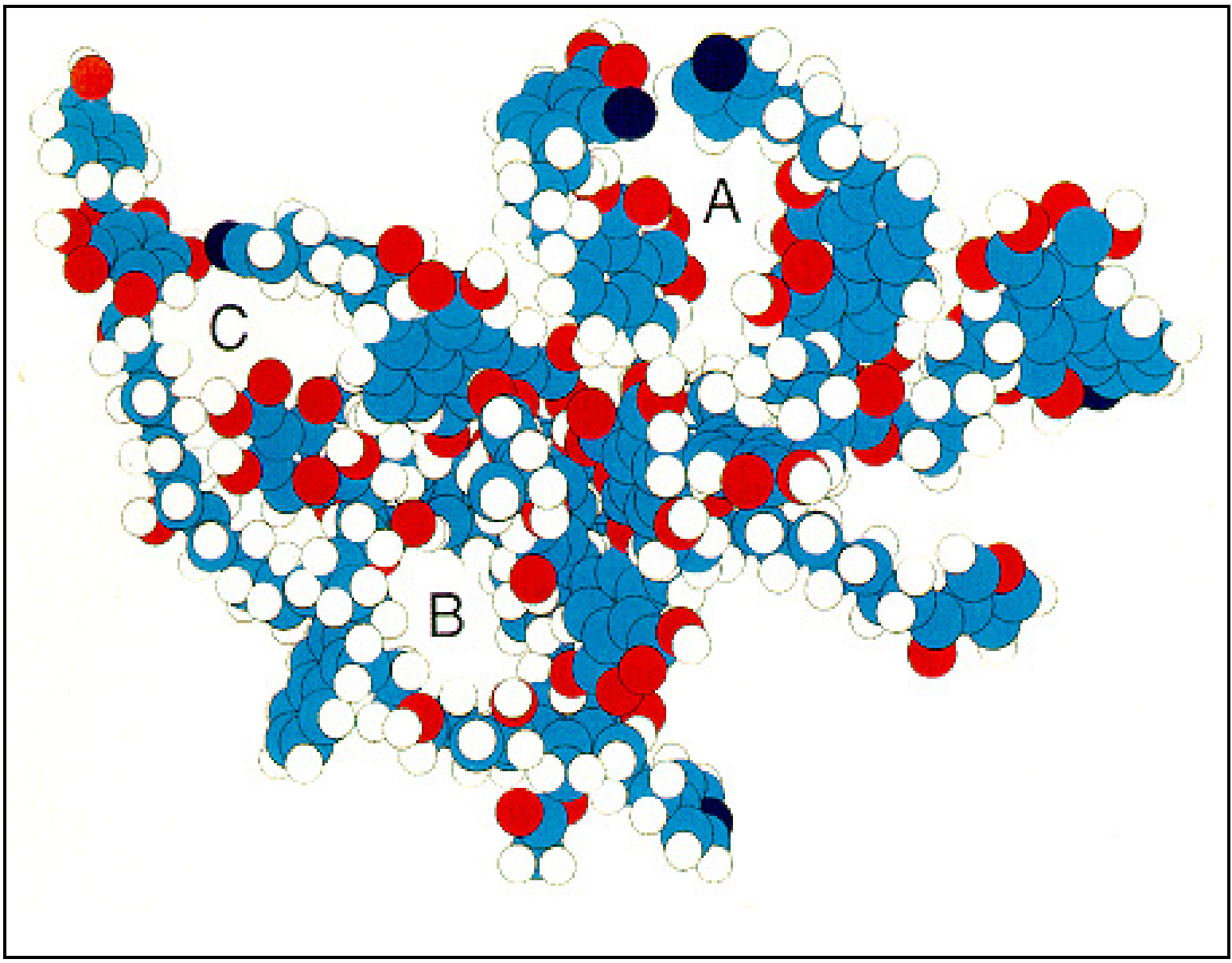

Fonte: Schulten e Schnitzer (1997).

Schulten e Shnitzer (1997) constataram que o modelo estrutural da Figura 3.5, apresentava uma série de espaços vazios de diferentes tamanhos no interior da macromolécula. Estes espaços vazios poderiam alojar outros compostos orgânicos, hidrofóbicos ou hidrofílicos, tais como materiais proteináceos e carboidratos, pesticidas, lipídios, agrotóxicos e outros poluentes. Poderiam também estar presentes compostos inorgânicos como argilas e oxi-hidróxidos.

A Figura 3.6 mostra o modelo de ácidos fúlvicos proposto por Alvarez-Puebla et al. (2006). 
Figura 3.6 - Modelo para ácidos fúlvicos.

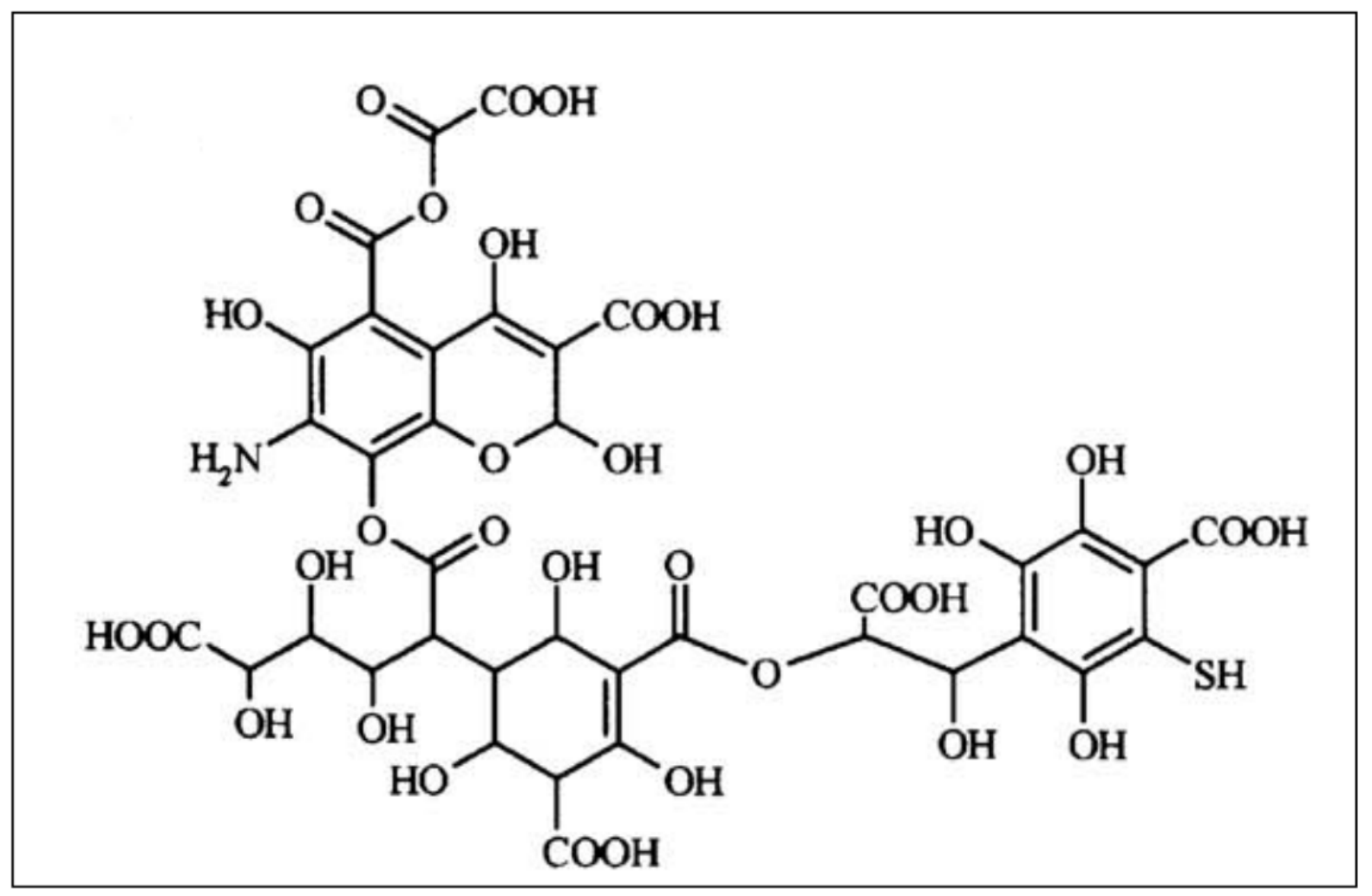

Fonte: Alvarez-Puebla et al. (2006).

De acordo com Duchaufour (1982), citado por Benites et al. (2003), os ácidos fúlvicos são os compostos húmicos de maior solubilidade por apresentarem maior polaridade e menor tamanho molecular. Estes compostos são os principais responsáveis por mecanismos de transporte de cátions dentro do solo (CTC), por meio de complexos organo-metálicos, o que caracteriza o processo de queluviação. Os ácidos húmicos constituem a fração mais estudada e apresentam pouca solubilidade em meio ácido, condição normalmente encontrada nos solos brasileiros. Estes compostos são responsáveis pela maior parte da CTC em camadas superficiais de solos, mais afetada pelo aporte de resíduos orgânicos. A humina consiste em um aglomerado de materiais húmicos e não húmicos (Rice; Maccarthy, 1990). Apesar de apresentar baixa reatividade e cerca de $80 \%$ desta fração estar complexada com a fração mineral (Silva; Mendonça, 2007), a humina é responsável por mecanismos de agregação de partículas e, na maioria dos solos tropicais, representa a maior parte do carbono humificado do solo.

O conceito de "supramolecularidade" foi recentemente proposto para os $\mathrm{AH}$. Esse modelo foi embasado por Conte e Piccolo (1999), dando origem à teoria 
supramolecular, na qual as SH são formadas por moléculas pequenas e heterogêneas de várias origens, auto-organizadas em conformações supramoleculares, o que explicaria o grande tamanho molecular aparente das $\mathrm{SH}$.

De acordo com esse modelo, os ácidos fúlvicos são associações de pequenas moléculas hidrofílicas dispersas em solução devido à repulsão eletrostática das cargas negativas provenientes da dissociação dos grupos ácidos, como por exemplo, os carboxílicos, a qualquer valor de $\mathrm{pH}$. Os ácidos húmicos são constituídos por associações de estruturas predominantemente hidrofóbicas (cadeias polimetilênicas, ácidos graxos e esteróides), que são estabilizadas em pH neutro por forças dispersivas hidrofóbicas (van der Waals, ח-ா, e ligações $\mathrm{CH}-\pi)$. Os ácidos húmicos crescem gradualmente em tamanho com o decréscimo do pH até a sua precipitação.

O modelo supramolecular foi reforçado por Simpson et al. (2002), que demonstraram que as SH extraídas dos solos são formadas por uma mistura de substâncias agregadas de baixa massa molar (próximo de 2000 Da), e propuseram um modelo estrutural na Figura 3.7 para ilustrar como as principais estruturas identificadas nas $\mathrm{SH}$ poderiam formar um agregado na presença de cátions metálicos de ocorrência natural nos ecossistemas terrestres.

Figura 3.7 - Modelo de estrutura supramolecular para ácido húmico. As unidades vermelhas representam os cátions metálicos, as azuis os polipeptídeos, as pretas os polissacarídeos, as verdes as cadeias alifáticas e as marrons os fragmentos aromáticos provenientes da lignina.

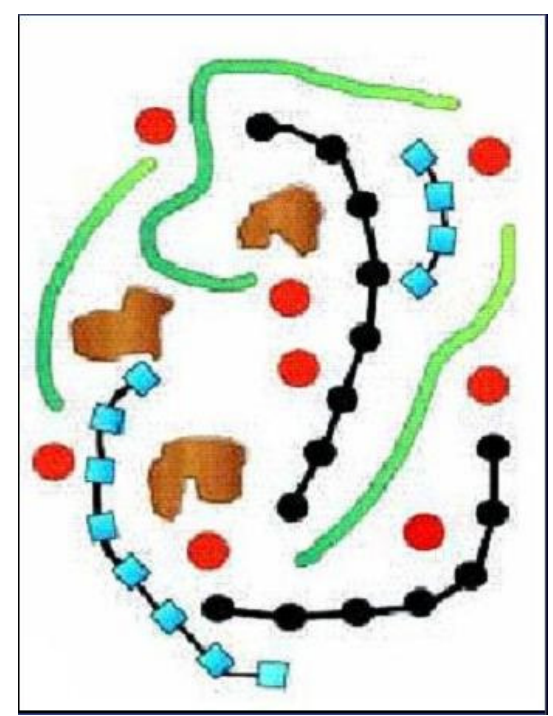

Fonte: Simpson et al. (2002). 
Utilizando ferramentas computacionais e dados experimentais, (Diallo et al., 2003) excluíram os modelos que estabelecem que as SH sejam macromoléculas com elevada massa molar ou uma mistura de compostos orgânicos complexos e heterogêneos e observaram que as estruturas existentes possuem as características necessárias para sustentar o modelo supramolecular.

O maior obstáculo encontrado na definição de um modelo estrutural para as SHs englobando estrutura, composição, tamanho e reatividade química é a heterogeneidade, sendo que há uma variação destas nos ecossistemas naturais aquáticos e terrestres. Porém, o que podemos afirmar é que o conhecimento das características estruturais dessas substâncias é muito importante para melhor compreensão da atividade e dinâmica dessas moléculas no meio ambiente.

\subsection{CARACTERIZAÇÃO DAS SUBSTÂNCIAS HÚMICAS}

A MO exerce papel fundamental no processo de formação dos Espodossolos, sendo composta por SH que são produtos da degradação oxidativa e subsequente humificação do material orgânico (Aiken et al., 1979; Stevenson, 1994; Sutton; Sposito, 2005). AH são obtidos através de extração, métodos de fracionamento e de purificação, e tem sido estudados e caracterizados por métodos químicos e espectroscópicos. A caracterização das SH é importante para entender as mudanças químicas da MOS em diferentes situações, tais como manejo do solo ou eventos naturais, a fim de compreender o ciclo do carbono e desenvolver modelagem de mudanças climáticas globais.

A utilização de técnicas espectroscópicas fornece informações úteis sobre a composição química das $\mathrm{SH}$, como é o caso da ressonância paramagnética eletrônica (EPR) (Senesi, 1990; Martin-Neto et al., 1991, 1998, 2001; Novotny; Martin-Neto, 2002), infravermelho com transformada de fourier (FTIR) (Stevenson, 1994; Olk et al., 2000; González-Pérez et al., 2004; Jouraiphy et al., 2005), ressonância magnética nuclear de ${ }^{13} \mathrm{C}\left({ }^{13} \mathrm{C}\right.$ RMN) (Carvalho et al., 2004; GonzálezPérez et al., 2004; Ikeya et al., 2004; Adani et al., 2006), espectroscopia de absorção de radiação no ultravioleta-visível (UV-Vis) e fluorescência convencional (Senesi, et al., 1991; Kalbitz et al., 1999; Zsolnay et al., 1999; Olk et al., 2000; Bayer et al., 2002; Milori et al., 2002).

Essas técnicas são capazes de fornecer informações a respeito que têm uma 
relação direta com o grau de humificação dos $\mathrm{AH}$, como a concentração de radicias livres do tipo semiquinona determinados por EPR (Schnitzer; Levesque, 1979; Gonzáles-Pérez et al., 2007), e o grau de aromaticidade avaliado por ${ }^{13} \mathrm{C}$ RMN (Stevenson, 1994). No entanto, estas técnicas geralmente requerem extração e fracionamento químico das $\mathrm{SH}$, e os produtos desse tratamento ( $\mathrm{AF}, \mathrm{AH}$ e Humina) podem ser modificados em relação a sua forma in situ (Feller; Beare, 1997; Favoretto et al., 2008). Além disso, demanda um longo tempo gasto para preparar as amostras para a análise espectroscópica, o que aumenta o custo.

No que diz respeito às questões agrícolas e ambientais, é extremamente importante o desenvolvimento de métodos analíticos rápidos e capazes de atender às demandas de quantificação de carbono e fornecer informações a respeito sobre a estrutura química da MOS. Técnicas fotônicas são uma alternativa promissora, por serem rápidas e não necessitarem de tratamentos com reagentes químicos (Milori et al., 2011). Dentre essas técnicas, destacam-se a espectroscopia de emissão ótica com plasma induzido por laser (LIBS) e a fluorescência induzida por laser (FIL). A primeira delas é comumente utilizada para determinar a composição elementar de amostras, mas, se devidamente calibrada, pode ser usada para determinar a concentração dos elementos constituintes da amostra. No caso de solos, LIBS tem sido utilizada para determinar o teor de carbono (Cremers et al., 2001; Ebinger et al., 2003; Da Silva et al., 2008). A técnica FIL permite a análise de materiais que emitem fluorescência tais como, por exemplo, substâncias húmicas, e tem sido empregada para determinação do grau de humificação de amostras de solo (Milori et al., 2006).

\subsubsection{MÉTODOS QUÍMICOS}

\subsubsection{ANÁLISE ELEMENTAR (CHNS)}

$\mathrm{Na}$ constituição da MO, o carbono apresenta predominância (cerca de 58\%), e portanto, a determinação do carbono orgânico total tem sido utilizada para estimar quantitativamente a fração orgânica do solo (Nelson; Sommers, 1996). Diferentes procedimentos analíticos foram desenvolvidos e têm sido empregados para determinar o teor de carbono no solo, desde aqueles baseados na dicromatometria (Walkey-Black) e suas variações, até as automatizadas que empregam a combustão a seco. 
Atualmente, a técnica mais utilizada para a determinação de carbono no solo é a análise elementar (CHNS). A determinação de carbono por CHNS é o método recomendado pelo Painel Intergovernamental sobre Mudanças Climáticas (IPCC) para avaliação de estoques de carbono no solo. Esta técnica trouxe avanços consideráveis, permitindo análises rápidas e confiáveis.

Este método é baseado na oxidação da amostra em altas temperaturas (aproximadamente $1000{ }^{\circ} \mathrm{C}$ ). Após combustão total, os gases resultantes são separados por uma coluna cromatográfica e detectados, geralmente, por condutividade térmica (Skoog; Holler; Nieman, 2002). Por esta técnica, analisam-se simultaneamente os elementos $\mathrm{C}, \mathrm{H}, \mathrm{N}$ e S presentes tanto em amostras orgânicas quanto inorgânicas, estando nas formas líquidas, sólidas ou gasosas. O princípio operacional consiste em três etapas: a amostra, a qual é mantida em cápsula de estanho, é oxidada produzindo uma mistura de gases $\left(\mathrm{N}_{2}, \mathrm{CO}_{2}, \mathrm{H}_{2} \mathrm{O}\right.$ e $\left.\mathrm{SO}_{2}\right)$ que são separados em uma coluna cromatográfica e quantificados por meio de um detector de termocondutividade, gerando um sinal elétrico proporcional à quantidade do gás, que posteriormente são convertidos em teores percentuais dos elementos $(\% \mathrm{C}, \% \mathrm{H}$, $\% \mathrm{~N}, \% \mathrm{~S}$ e cinzas).

Através dessa metodologia, é possível que sejam calculados estoques de carbono de amostras de solos, a razão $\mathrm{C} / \mathrm{N}$, pela qual se estabelece a disponibilidade do nitrogênio para as plantas e micro-organismos, além de estimativas do grau de humificação da MOS. Trata-se de uma técnica que facilita a caracterização de uma substância, não apenas pela rapidez, como pelas informações que podem ser obtidas (Martelli, 2011). Entretanto, existem outros fatores limitantes nesta metodologia que devem ser considerados como a necessidade de moagem muito fina das amostras (partículas menores do que 0,15 $\mathrm{mm}$ ) que torna o processo mais dispendioso, bem como a utilização de pequena quantidade de amostra (aproximadamente $10 \mathrm{mg}$ ), que podem levar a problemas de representatividade do solo (Chatterjee et al., 2009). Considerando essas limitações e a necessidade de desenvolvimento de uma metodologia cada vez mais precisa, rápida determinação e de fácil execução, os métodos espectroscópicos estão sendo cada vez mais estudados e utilizados (Chatterjee et al., 2009; Sato, 2013). 


\subsubsection{MÉTODOS ESPECTROSCÓPICOS}

Segundo Mangrich (2001) o conhecimento das estruturas húmicas das SH é essencial para entender a sustentabilidade dos diferentes sistemas agrícolas, a lixiviação de espécies químicas e o ciclo global de carbono, causando danos ao meio ambiente como o empobrecimento do solo e a poluição das águas.

As técnicas espectroscópicas têm sido bastante utilizadas para a caracterização da MOS. Técnicas como espectroscopia de infravermelho com transformada de Fourier (FTIR), ressonância magnética nuclear de hidrogênio $1 \mathrm{e}$ carbono 13 (RMN ${ }^{1} \mathrm{H}$ e $\mathrm{RMN}{ }^{13} \mathrm{C}$ ), ressonância paramagnética eletrônica (EPR), absorção e fluorescência de luz uv-visível e fluorescência induzida por laser (FIL) fornecem informações sobre os grupos funcionais que constituem a $\mathrm{MO}$ e possibilitam a avaliação do grau de humificação, embora, em sistemas tropicais, esses estudos ainda são reduzidos (Martin-Neto et al., 1991; Bayer et al., 1997; Milori et al., 2002; Gonzáles-Perez et al., 2004).

Essas técnicas possuem vantagens como à utilização de pequenas quantidades de amostras e a sua fácil execução (Stevenson, 1994), sendo que cada uma delas oferece determinadas informações, e seus resultados complementam-se entre si, evidenciando tendências e peculiaridades das amostras estudadas.

\subsubsection{ESPECTROSCOPIA DE ABSORÇÃO DE RADIAÇÃO NO ULTRAVIOLETA- VISÍVEL}

A espectroscopia de absorção de luz na região do Ultravioleta (200 - $400 \mathrm{~nm}$ ) e Visível $(400-800 \mathrm{~nm})$ permite a identificação de transições de elétrons dos orbitais moleculares $\sigma-, \pi-$, e $n$ - de seu estado energético fundamental para orbitais de maior energia em um estado excitado (Skoog; Holler; Nieman, 2002).

A Figura 3.8 representa a posição relativa dos níveis de energia referentes aos orbitais ligante, anti-ligantes e os prováveis tipos de transições que podem ocorrer em moléculas orgânicas. As transições possíveis de serem observadas nos espectros eletrônicos são: $\sigma \rightarrow \sigma^{*}, n \rightarrow \sigma^{*}, n \rightarrow \pi^{*}$ e $\pi \rightarrow \pi^{*}$ (Skoog; Holler; Nieman, 2002). 
Figura 3.8 - Diagrama dos níveis de energia eletrônica molecular, ilustrando os quatro tipos de transições eletrônicas possíveis.

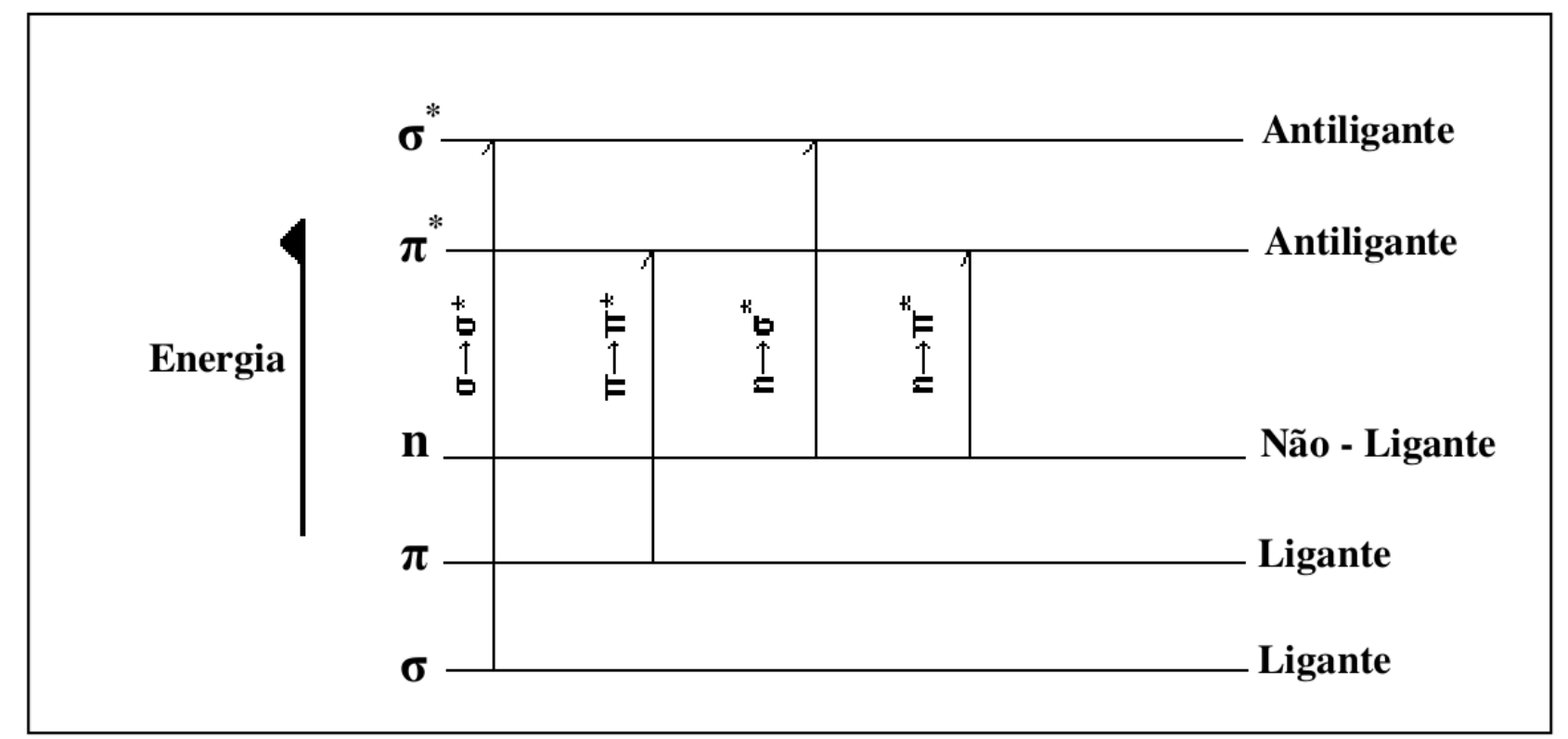

Fonte: Skoog; Holler; Nieman, (2002).

As transições do tipo $\sigma \rightarrow \sigma^{*}$ é o único tipo que pode ocorrer com elétrons envolvidos em ligações simples, por exemplo, o metano, $\mathrm{CH}_{4}$, que apresenta em sua estrutura somente ligações simples $\mathrm{C}$-H. Dos quatro tipos de transições possíveis, esta é a que requer uma maior quantia de energia. As transições $n \rightarrow \sigma^{*}$ são características de compostos saturados contendo átomos com pares de elétrons não compartilhados, tais como, oxigênio, nitrogênio e enxofre. Em geral, a energia requerida nessas transições é menor que o tipo $\sigma \rightarrow \sigma^{*}$ e podem ser produzidas por radiação na região entre 150 e $250 \mathrm{~nm}$, com a maior parte dos picos aparecendo abaixo de $200 \mathrm{~nm}$. De todas estas, as de maior probabilidade são aquelas que requerem menor energia para sua ocorrência $n \rightarrow \pi^{*}$ e $\pi \rightarrow \pi^{*}$ (Rohatgi-Mukherjee, 1992), porque as energias necessárias para esses processos situam-se em uma região espectral experimentalmente conveniente (200 a $700 \mathrm{~nm}$ ). Para ambos os casos as transições requerem a presença de grupos funcionais insaturados para fornecer os orbitais $\pi$ (Skoog; Holler; Nieman, 2002).

A absorção das substâncias húmicas no UV-Vis é influenciada pelo pH (que deve estar entre 7 e 8), tipo de solvente e concentração salina do meio (Chen et al., 1977; Fialho, 2007).

A absorção de radiação visível e de ultravioleta de maior comprimento de onda é restrita a um número limitado de grupos funcionais (chamados cromóforos), 
que contêm elétrons na camada mais externa com energias de excitação relativamente baixas (Skoog; Holler; Nieman, 2002).

Segundo Fuentes et al. (2006), em geral, os cromóforos são grupos funcionais que contêm elétrons que podem ser promovidos com uma absorção de luz específica, presente nas $\mathrm{SH}$, responsáveis pela absorção na região do ultravioleta, são anéis aromáticos diferentemente substituídos com vários tipos de grupos funcionais, tais como fenóis, ácidos carboxílicos e cadeias alifáticas.

A parte da molécula orgânica responsável pela produção de cor nos compostos é denominada de cromóforos. Os grupos responsáveis pela cor escura das substâncias húmicas ainda não estão completamente estabelecidos, mas se suspeita de uma combinação de vários tipos de estruturas (Figura 3.9), onde pode ser observado anéis aromáticos com diversos graus de substituição por diferentes tipos de grupos funcionais como carbonilas, ácidos carboxílicos e cadeias alifáticas (Baes; Bloom, 1990; Korshin et al., 1997).

Figura 3.9 - Grupos cromóforos presentes nas SH.

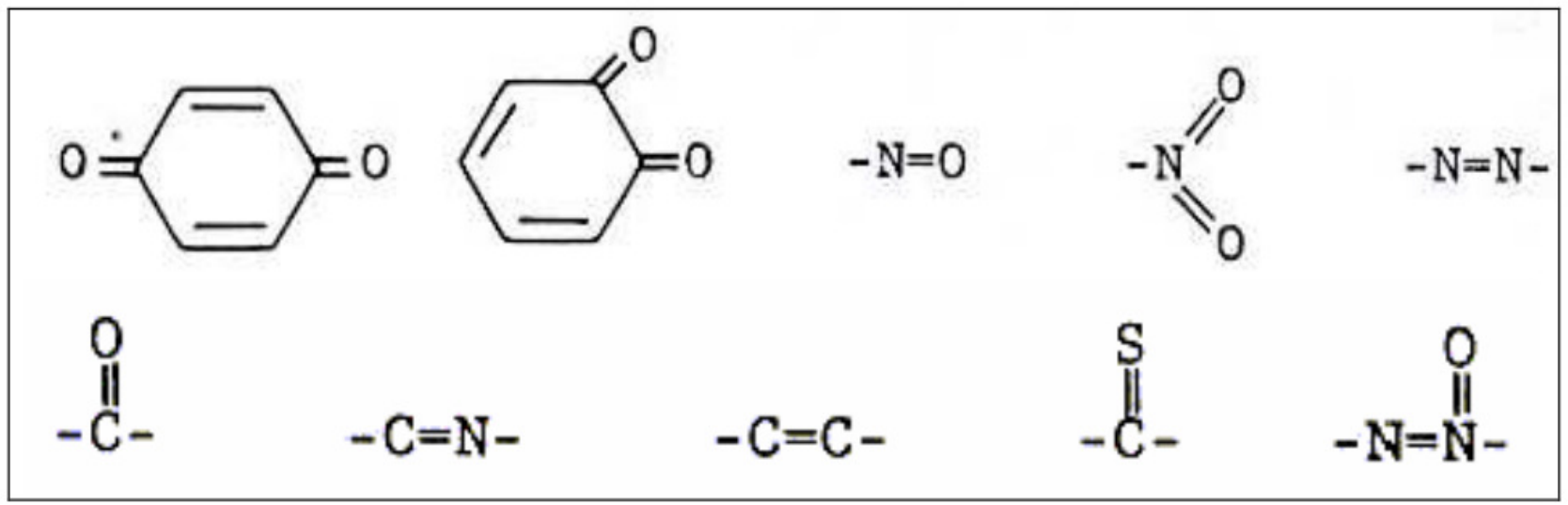

Alguns autores consideram o espectro de absorção das SH de pouca utilidade prática, mas, uma importante quantidade de pesquisas (Chen et al., 1977; Kulovaara et al., 1996; Peuravuori; Pihlaja, 1997) têm demonstrado que uma adequada análise pode fornecer informações importantes acerca de sua estrutura química. $\mathrm{Na}$ literatura são utilizadas as absorbâncias em diversos comprimentos de onda específicos e/ou as razões entre elas para determinar o grau de humificação e/ou conteúdo de material húmico (McDonald et al., 2004).

Nos estudos das SH de solo, entre as razões registradas, a chamada razão 
$E_{4} / E_{6}$ (razão entre as absorbâncias nos comprimentos de onda em 465 e 665 nm) é a mais utilizada e controversa na literatura, no entanto a sua equivalente em limnologia é a razão $E_{2} / E_{3}$ (razão entre as absorbâncias nos comprimentos de onda em 250 e 365 nm). Ambas as razões apresentam uma relação inversa com o grau de condensação de anéis aromáticos e com o grau de humificação das SH (Stevenson, 1994; McDonald et al., 2004). Assim, se a razão $E_{4} / E_{6}$ é baixa, indica alto grau de condensação dos grupos aromáticos e se for alta infere-se a presença de um número relativamente maior de estruturas alifáticas (Ouatmane et al., 2002).

A espectroscopia de absorção no UV-Vis, no entanto, não fornece informações sobre componentes estruturais da matéria orgânica dissolvida (MOD), por isso a espectroscopia de fluorescência vem sendo muito aplicada nos estudos de caracterização das fontes, degradação e transformação da MOD em águas naturais. Esta técnica apresenta uma maior sensibilidade em relação à espectroscopia de absorção no UV-Vis, permitindo discriminar os diferentes tipos de cromóforos da MOD (Hudson et al., 2007).

\subsubsection{ESPECTROSCOPIA DE FLUORESCÊNCIA DE LUZ ULTRAVIOLETA- VISÍVEL}

Fotoluminescência ou Luminescência é a propriedades que numerosas substâncias têm de emitir luz sob o efeito de uma excitação causada por radiação ultravioleta ou na região do visível (Skoog; Holler; Nieman, 2002).

De acordo com Lakowicz (1999), o fenômeno de luminescência é formalmente dividido em fluorescência e fosforescência, dependendo da natureza do estado excitado envolvido no processo. O processo de luminescência de uma molécula está diretamente relacionado com os processos de absorção e dissipação de energia da mesma. A energia absorvida é dependente da diferença de energia entre o estado fundamental e o estado excitado.

Quando a energia absorvida por uma molécula não for suficiente para sua ionização ou dissociação, ela permanecerá no estado excitado por um determinado tempo, chamado tempo de vida do estado excitado. Para retornar ao estado fundamental a energia absorvida deve ser dissipada, o que normalmente ocorre por decaimentos não radioativos em que o excesso de energia é transferida na forma de vibrações, rotações e translações. Esta degradação térmica converte a energia de 
excitação em movimento térmico do ambiente aquecendo-o (Atkins, 1998). Porém quando o descarte de energia pela molécula é feito pela emissão de um fóton temos um decaimento radioativo que é chamado de fotoluminescência (Novotny, 2002; Narimoto, 2006).

No estado fundamental os elétrons da molécula ocupam o nível de menor energia vibracional, mas ao serem excitados podem ser promovidos para qualquer nível vibracional de um estado excitado, como mostra a Figura 3.10. Dependendo do tempo de vida do estado excitado o processo é denominado fluorescência ou fosforescência. Na fluorescência, a emissão da radiação cessa quase que imediatamente $\left(10^{-8} \mathrm{~s}\right)$, já na fosforescência pode durar vários segundos. O tempo $10^{-8} \mathrm{~s}$, é o tempo de vida de um átomo no estado excitado para o qual o retorno ao estado fundamental é frequentemente utilizado para diferenciar fluorescência de fosforescência.

Figura 3.10 - Diagrama de transição eletrônica de fluorescência molecular.

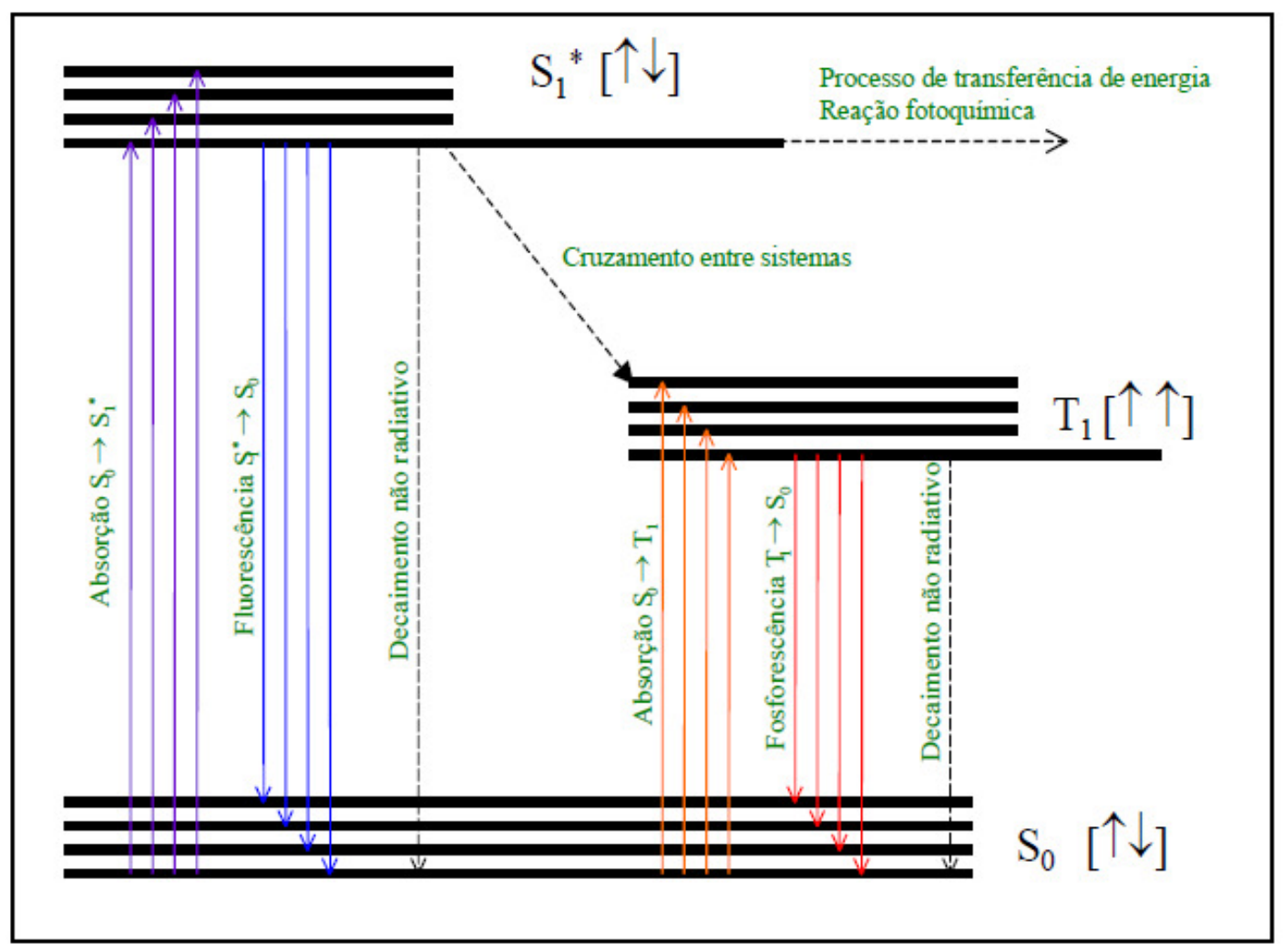

Fonte: Santos (2006). 
$\mathrm{Na}$ espectroscopia de fluorescência os elétrons na molécula de interesse são excitados e transferidos de orbitais moleculares do estado fundamental para orbitais moleculares ligantes e antiligantes do estado excitado. Transições desse tipo envolvem a promoção de elétrons não ligantes (n) ou ligantes $(\pi)$ para orbitais antiligantes $\left(\pi^{*}\right)$. Normalmente uma molécula excitada eletronicamente volta ao seu estado excitado mais baixo por uma série de relaxações vibracionais rápidas e conversões internas que não produzem emissão de radiação. Esses processos são altamente prováveis em sistemas moleculares contendo átomos com pares de elétrons desemparelhados como nitrogênio e oxigênio ou sistemas aromáticos e ou alifáticos insaturados com elevado grau de ressonância, isto é, deslocalização de elétrons, como é o caso das SH (Senesi et al., 1991).

A fluorescência dos compostos orgânicos envolve transições singleto-singleto onde não há mudanças de spin, entretanto, na fosforescência é necessário um estado intermediário tripleto, devido à reversão do spin entre o estado fundamental e o excitado, que retarda a emissão, devido às regras de seleção de spin (Figura 3.8) (Skoog; Holler; Nieman, 2002).

A espectroscopia de fluorescência é uma técnica muito sensível e aplicada para o estudo seletivo de "fluoróforos" (grupos cromóforos que apresentam fluorescência em comprimento de onda específico). É também uma técnica bastante seletiva, uma vez que ambos os comprimentos de onda, de excitação e de emissão, dependem do mesmo composto de interesse, fazendo com que o sinal de fluorescência coletado seja característico para cada molécula em estudo (Santos, 2006; Fialho, 2007).

Esta técnica fornece informações que podem ser usadas para diferenciar e classificar a MO natural de acordo com a sua origem, gênese e natureza, também para identificar estruturas moleculares e funcionalidades, sendo sensível à presença de metais pesados e contaminantes orgânicos (Milori et al., 2002; Narimoto, 2006). Nos estudos de SH o uso da técnica de fluorescência é baseado na presença estável de várias estruturas fluorescentes intrínsecas à molécula húmica e aos seus precursores, particularmente anéis aromáticos, grupos quinonas e fenóis (Senesi et al., 1991).

Geralmente os espectros de fluorescência permitem diferenciar os AH pela sua natureza e origem (Senesi et al., 1991). Uma intensidade de fluorescência baixa e comprimentos de onda longos, característica típica de $\mathrm{AH}$ naturais com 
independência da origem, podem ser associados a compostos de alta massa molecular que possuem sistemas com ligações insaturadas e anéis aromáticos condensados e/ou substituídos por grupos que atraem os elétrons tais como carbonila e carboxila (Senesi et al., 1991). Já as altas intensidades de fluorescência e comprimentos de onda curtos podem ser associados a compostos de baixa massa molecular com baixo grau de condensação aromática e baixos níveis de cromóforos conjugados, altamente substituídos por grupos doadores de elétrons como hidroxila, metoxila e grupos amino (Senesi et al., 1991; Olk et al., 2000; Peuravuori et al., 2002).

Com a utilização das análises de fluorescência pode-se, por exemplo, diferenciar compostos orgânicos que contêm grupos funcionais aromáticos, visto que fornecem valores superiores de intensidade de fluorescência em comparação aos outros tipos de estruturas químicas (Costa, 2011). Além disso, a intensidade de fluorescência mostra-se maior em sistemas aromáticos que apresentam um maior grau de condensação, ou seja, quanto maior o número de anéis aromáticos, maior será a eficiência do processo de fluorescência (Liying et al., 2009; Wheihong et al., 2009).

Algumas metodologias têm sido sugeridas na literatura no sentido de aplicar esta técnica para avaliação do grau de humificação das SH (Zsolnay et al., 1999; Kalbitz et al., 1999; Milori et al., 2002). Todas as técnicas baseiam-se no fato de as estruturas mais complexas (anéis condensados e/ ou, substituídos) terem seus espectros de absorção e emissão deslocados para o vermelho (Abreu Junior et al., 2009).

Usualmente os espectros bidimensionais de fluorescência podem ser adquiridos de três modos: emissão, excitação e varredura sincronizada (Senesi, 1992).

1) Modo de emissão: os espectros são obtidos medindo-se a intensidade relativa da radiação emitida como uma função do comprimento de onda, mantendo-se constante o comprimento de onda de excitação.

2) Modo de excitação: os espectros são obtidos medindo-se a intensidade relativa de emissão em um comprimento de onda fixo, enquanto o comprimento de onda de excitação é variado.

3) Modo de varredura sincronizada: os espectros são obtidos medindo a intensidade de fluorescência enquanto simultaneamente são varridos os comprimentos de onda 
de excitação e emissão, mantendo-se constante a diferença de comprimentos de onda entre eles: $\Delta \lambda=\lambda_{\mathrm{em}}-\lambda_{\mathrm{exc}}$. Quando essa diferença é usada, esta técnica pode aumentar a intensidade de alguns picos, aumentando a sensibilidade do método.

Os espectros de fluorescência das $\mathrm{SH}$ são constituídos pela soma dos espectros dos diferentes tipos de fluoróforos presentes nelas, como consequência da complexidade molecular e heterogeneidade das mesmas (Narimoto, 2006).

Na metodologia proposta por Zsolnay et al. (1999), o índice de humificação é baseado na localização do espectro de fluorescência adquirido no modo de emissão com excitação da amostra no ultravioleta $(240 \mathrm{~nm})$. O espectro de emissão total foi dividido em quatro partes e o índice de humificação foi calculado através da razão entre as áreas do último quarto $(570-641 \mathrm{~nm})$ e primeiro quarto (356-432 nm), denominado $A_{4} / A_{1}$. A ideia básica deste método é que se as moléculas fluorescentes tornam-se mais condensadas, seus espectros de emissão (com excitação em 240nm) tenderão a exibir um deslocamento em direção a maiores comprimentos de onda. Então esta relação $A_{4} / A_{1}$ pode ser usada como índice de humificação. Um espectro de fluorescência adquirido no modo de emissão para uma solução de $A H$, segundo a metodologia de Zsolnay et al. (1999), é apresentado na Figura 3.11.

Figura 3.11 - Espectro de emissão de fluorescência de amostra de AH extraído de solo tratado com lodo de esgoto, obtido segundo metodologia de Zsolnay et al. (1999), com comprimento de onda de excitação $\lambda_{\text {exc }}=240 \mathrm{~nm}$.

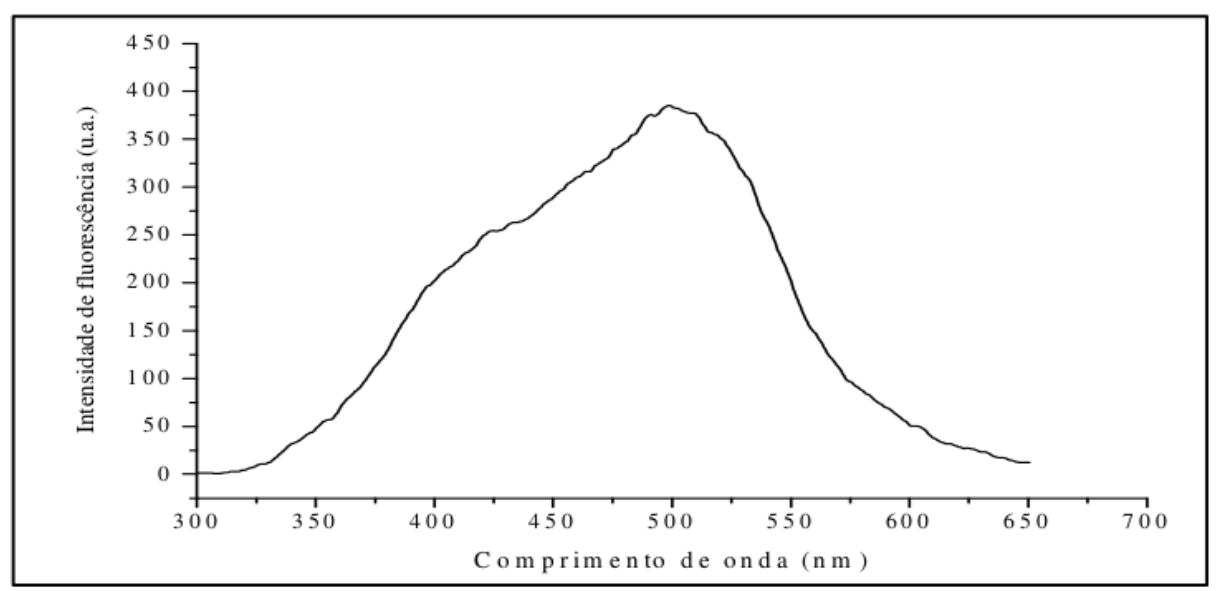

Fonte: Narimoto (2006).

$\mathrm{Na}$ metodologia proposta por Kalbitz et al. (1999), mediu-se o espectro de varredura sincronizada. De acordo com esta metodologia, o espectro de varredura sincronizada das $\mathrm{SH}$ apresentam dois picos ao redor de 360 e $400 \mathrm{~nm}$ e um ombro 
em torno de $470 \mathrm{~nm}$. Esses perfis mudam dependendo do grau de humificação, e isto pode ser medido através da razão entre os picos de fluorescência. A região do espectro com comprimentos de onda mais para o vermelho (maior comprimento de onda) é associada a núcleos aromáticos substituídos e/ou conjugados. A região mais para o azul (menor comprimento de onda) é associada a compostos mais simples. Assim, a razão entre a intensidade de fluorescência em 400 e $360 \mathrm{~nm}\left(\mathrm{I}_{400} / \mathrm{I}_{360}\right)$, ou 470 e 360 nm, pode ser utilizada para medir o grau de humificação das SH dissolvidas em $\mathrm{NaHCO}_{3} 0,05 \mathrm{~mol} \mathrm{~L}^{-1}(\mathrm{AH})$. A Figura 3.12 mostra um espectro de fluorescência adquirido no modo de varredura sincronizada obtido para uma solução de $\mathrm{AH}$.

Figura 3.12 - Espectro de varredura sincronizada de fluorescência de amostra de $\mathrm{AH}$ extraído de solo tratado com lodo de esgoto, obtido segundo metodologia de Kalbitz et al. (1999), com $\Delta \lambda=\lambda_{\text {em }}-\lambda_{\text {exc }}=55 \mathrm{~nm}$.

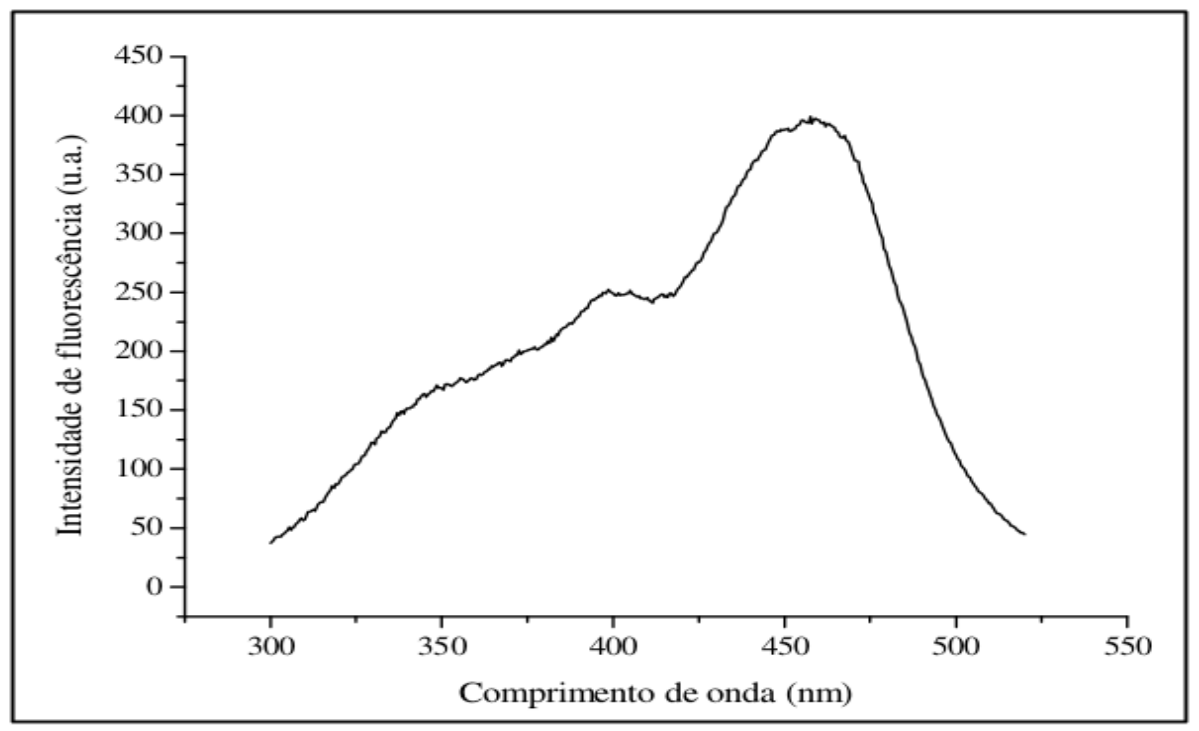

Fonte: Narimoto (2006).

Milori et al. (2002) trabalhando com AH dissolvidos, ajustados para uma concentração de $20 \mathrm{mg} \mathrm{L}^{-1}$ e $\mathrm{pH}=8,0$, observaram que o comprimento de onda na região do azul (465 nm) foi mais eficiente para excitar estruturas cuja condensação aumenta durante o processo de humificação. Portanto, nesta proposta a área total sob o espectro de emissão de fluorescência com excitação em 465 nm ( $\left.A_{465}\right)$ é proporcional ao grau de humificação (Figura 3.13). Seus estudos foram realizados com amostras de ácidos húmicos extraídos de diferentes solos brasileiros, sobre 
condições climáticas distintas e com diferenças texturais e mineralógicas.

Figura 3.13 - Espectro de emissão de fluorescência de amostra de AH extraído de solo tratado com lodo de esgoto, obtido segundo metodologia de Milori et al. (2002), com comprimento de onda de excitação $\lambda_{\text {exc }}=465 \mathrm{~nm}$.

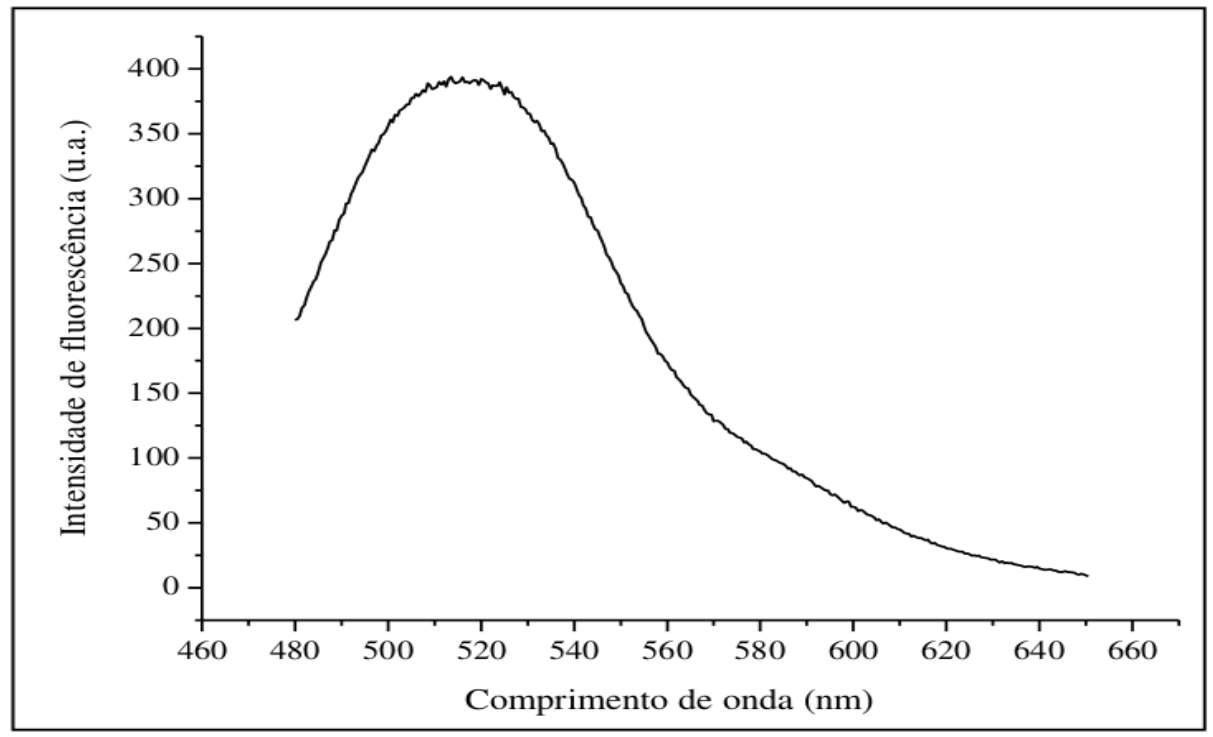

Fonte: Narimoto (2006).

A espectroscopia tridimensional de matrizes de fluorescência de excitaçãoemissão (MEE) ou do inglês Excitation-Emission Matrix (EEM) tem sido, desde 1990, amplamente utilizada de forma satisfatória para caracterizar a MOD, mas os relatórios sobre a sua utilização para caracterizar as propriedades da matéria orgânica natural (MON) (McKnight et al., 2001; Wu; Tanoue, 2001; Chen et al., 2002, 2003), identificando as fontes de MON, monitorando as contaminações nas águas naturais e, em estudos de fracionamento de $\mathrm{SH}$ só apareceram recentemente na literatura (Sierra, 2006; Liu et al., 2009).

A espectroscopia de fluorescência MEE é uma técnica rápida, seletiva e sensível. A vantagem excepcional desta técnica é que a informação sobre as características da fluorescência podem ser inteiramente adquiridas pela mudança de comprimento de onda de excitação e de emissão simultaneamente. A espectroscopia de fluorescência MEE tem sido usada com sucesso para avaliar as características da matéria orgânica natural e substâncias húmicas de diversas origens (Coble, 1996; Baker, 2001; Lu; Jaffe, 2001; Reynolds, 2002; Chen et al., 2003). Tem provado ser uma técnica útil para diferenciar as mudanças e transformação da matéria 
orgânica em ambientes naturais (Sheng; Yu, 2006).

Espectroscopia tridimensional de MEE são geradas pela obtenção de espectros de excitação e, de emissão de uma amostra. Os espectros de excitação são produzidos pela medida da intensidade de luminescência mantendo-se constante o comprimento de onda de emissão e varrendo-se o de excitação. Espectros de emissão são obtidos de forma contrária, mas através do mesmo princípio, mantendo-se a excitação constante e varrendo-se o modo de emissão (Trevisan, 2003).

A modalidade de MEE baseia-se na obtenção de um espectro tridimensional a partir de vários espectros individuais de emissão. Os laboratórios, que estudam SH por fluorescência, utilizam diferentes valores de comprimentos de onda de excitação e de emissão, dificultando uma comparação entre os estudos. Por esta razão, ainda não foi bem estabelecida uma "impressão digital" consistente das SH obtidas por fluorescência (Sierra et al., 2005). A MEE apresenta a vantagem de capturar vários espectros em um extenso intervalo de comprimentos de onda de excitação-emissão, requerendo, portanto, uma série de varreduras até a medida se completar.

Em geral, há quatro tipos de modo de aquisição de espectros de fluorescência: emissão, excitação, varredura sincronizada e matrizes de fluorescência de excitação-emissão (MEE). Os índices de humificação anteriormente mencionados são calculados com base no espectro de emissão e varredura sincronizada, que gera um perfil de espectro e não pode fornecer toda a informação de fluorescência sobre a composição da MO (He et al., 2013). Por outro lado o espectro de MEE apresenta todas as informações de fluorescência sobre a composição e configuração da MOD. Além disso, o espectro de MEE pode ser utilizado para a caracterização qualitativa e quantitativa da $\mathrm{MO}$ quando combinadas com técnicas quantitativas, como, por exemplo, a análise de fatores paralelos (PARAFAC). A combinação dos espectros de MEE com PARAFAC tem sido utilizada para caracterizar a transformação da MO durante a compostagem (Marhuenda-Egea et al., 2007), reatividade redox da MO durante o processo de transferência de elétrons (Cory; Mcknight, 2005) e a eficiência de remoção da MO durante o processo de tratamento de água (Bieroza et al., 2009, 2011), respectivamente.

A Figura 3.14 mostra um espectro MEE obtido de uma amostra de $\mathrm{AH}$ extraído de solo irrigado com água de consumo e submetido à aplicação de efluente de esgoto tratado e $100 \%$ de fertilização nitrogenada mineral (FNM). 
Figura 3.14 - Espectro de fluorescência no modo matriz excitação-emissão (MEE) (ou curvas de nível) obtidos para os AH na camada de 0-10 cm: (a) W100 - irrigação com água de consumo e 100\% da FNM; e (b) E100-irrigação com efluente e 100\% da FNM.

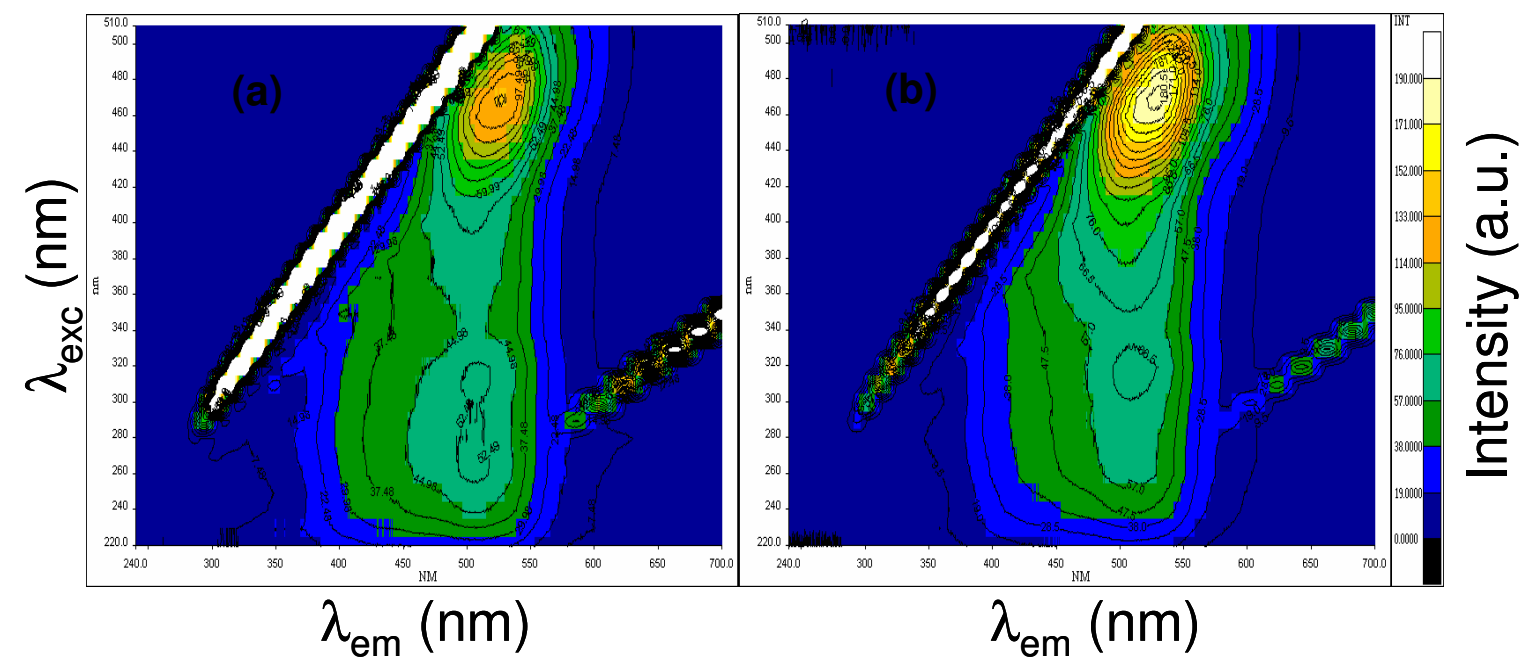

Fonte: Santos (2008).

O gráfico tridimensional é formado por uma matriz de dados espectrais de excitação-emissão adquiridos a partir de uma solução de $\mathrm{AH}$, conforme observado na Figura 3.14. Os valores de intensidade de emissão de fluorescência seguem as escalas de cores e aparecem sob a forma de curvas de nível (Santos, 2008). Podese observar ainda, no canto superior esquerdo do gráfico, uma extensa faixa de emissão proveniente das ressonâncias das radiações incidentes (Olendzki, 2006).

Esta técnica tem sido utilizada, com sucesso, na diferenciação estrutural de $\mathrm{SH}$ extraídas de solos, com e sem adubação com rejeitos orgânicos (Bertoncini et al., 2005; Plaza et al., 2006), no estudo das reações de metais, como o $\mathrm{Cu}^{2+}, \mathrm{Zn}^{2+} \mathrm{e}$ $\mathrm{Ni}^{2+}$ por SH extraídas de turfas, compostos e solos (Plaza et al., 2005; Provenzano et al., 2004).

Yu et al. (2010) em seu trabalho utilizaram a espectroscopia de fluorescência MEE combinada com o PARAFAC em diferentes compostos para explorar a viabilidade na modelagem das componentes para a avaliação da maturidade do composto. Todos os 60 espectros de fluorescência MEE dos compostos foram decompostos com sucesso usando o PARAFAC em um modelo de três componentes. Componentes 1 [excitação/emissão $\left(\lambda_{\text {exd }}\left(\lambda_{\text {em }}\right)=230 / 330-410 \mathrm{~nm}\right.$ ] e 3 (220/280 - $340 \mathrm{~nm})$ atribuídas aos ácidos húmicos e proteínas, respectivamente, foram as mais adequadas na avaliação da maturação do que a componente 2 
(250/350 - 450), atribuída aos ácidos fúlvicos.

Mounier et al. (2011) citam a utilização da combinação da espectroscopia de fluorescência de MEE com o PARAFAC em estudos sobre propriedades de complexos de cobre da MOD em amostras de água provenientes do rio Negro, norte do Brasil (São Gabriel da Cachoeira), com uma grande variedade de concentração de cobre $\left(1,7 \times 10^{-9}\right.$ a $\left.10^{-3} \mathrm{~mol} \mathrm{~L}^{-1}\right)$. Os resultados mostraram que o PARAFAC permite a avaliação quantitativa dos parâmetros de complexação do cobre, e confirmam que para esta amostra natural, apenas dois ligantes fluorescentes apresentaram dois tipos de sítios de complexação para cada componente.

Os vários índices de humificação já existentes na literatura não fornecem toda a informação de fluorescência na composição da $\mathrm{MO}$ e os resultados da avaliação dos mesmos são as vezes inconsistentes. Em estudos desenvolvidos por $\mathrm{He}$ et al. (2013) os espectros de MEE combinados ao PARAFAC foram utilizados para investigar a humificação da MO. O resultado mostrou que a razão entre o volume na região de fluorescência de ácidos húmicos e ácidos fúlvicos e o volume na região de fluorescência das proteínas não só revelou a heterogeneidade da MO, mas também fornecem uma informação mais precisa sobre a humificação da MO.

\subsubsection{ESPECTROSCOPIA DE FLUORESCÊNCIA INDUZIDA POR LASER (FIL)}

A espectroscopia de fluorescência induzida por laser (FIL) é uma das ferramentas mais sensíveis para propostas analíticas. Os mesmos conceitos básicos utilizados para a espectroscopia de fluorescência em solução são válidos para FIL. A diferença consiste apenas no fato de a excitação do material fluorescente ser feita através de um laser. O uso do laser apresenta vantagens, tais como: a intensidade de luz mais alta em um comprimento de onda de excitação específico, o que produz boa relação sinal-ruído quando comparada a fluorescência induzida por lâmpada; e maior seletividade na excitação, tendo, portanto, menos fatores de interferência no sinal de fluorescência (Milori et al., 2003).

O uso de técnicas espectroscópicas, tais como o EPR, FTIR, ${ }^{13} \mathrm{C} R M N$, espectroscopia de absorção de radiação no ultravioleta-visível e fluorescência convencional, exigem a extração e fracionamento químico das $\mathrm{SH}$ do solo, tornando a análise de solos um processo trabalhoso. Além disso, os produtos deste tratamento (ácido húmico, ácido fúlvico e humina) podem ser modificados em 
relação a sua forma in situ (Feller; Beare, 1997). Em contrapartida, a FIL aplicada a solos é uma técnica recente, que tem se mostrado eficiente na análise da MO de solos inteiros (solos não submetidos a tratamentos químicos ou físicos), fornecendo resultados de uma maneira ágil, limpa, e em condições próximas das naturais (Milori et al., 2003, 2006; González-Pérez et al., 2007; Favoretto et al., 2008; Martins et al., 2011).

A espectroscopia de FIL tem como princípio básico excitar a amostra de solo com um laser com emissão na região do azul ou violeta o que resulta na fluorescência de grupos funcionais mais complexos da MOS, tais como estruturas aromáticas e heterocíclicas (Milori et al., 2002; Martin-Neto et al., 2009).

O espectrômetro FIL portátil, ilustrado nas Figuras 3.15 e 3.16, para análise do grau de humificação é constituído por um laser de diodo emitindo em 405 nm, com potência máxima de $50 \mathrm{~mW}$, acoplado a um cabo ótico composto por seis fibras óticas que excitam a amostra e uma fibra ótica central que coleta o sinal de fluorescência do solo. A fluorescência e a reflectância da amostra são conduzidas até um miniespectrômetro de alta sensibilidade. Antes de atingir 0 miniespectrômetro, o sinal é filtrado para atenuar o sinal de reflectância. A emissão da amostra é então decomposta através de uma grade de difração fixa e detectada por um conjunto de fotodiodos previamente calibrados. Desta forma, obtêm-se o espectro de emissão que é enviado para um computador, o qual é responsável por fazer o controle, a aquisição e o tratamento de dados (Milori et al., 2011).

Figura 3.15 - Esquema experimental do equipamento de FIL portátil.

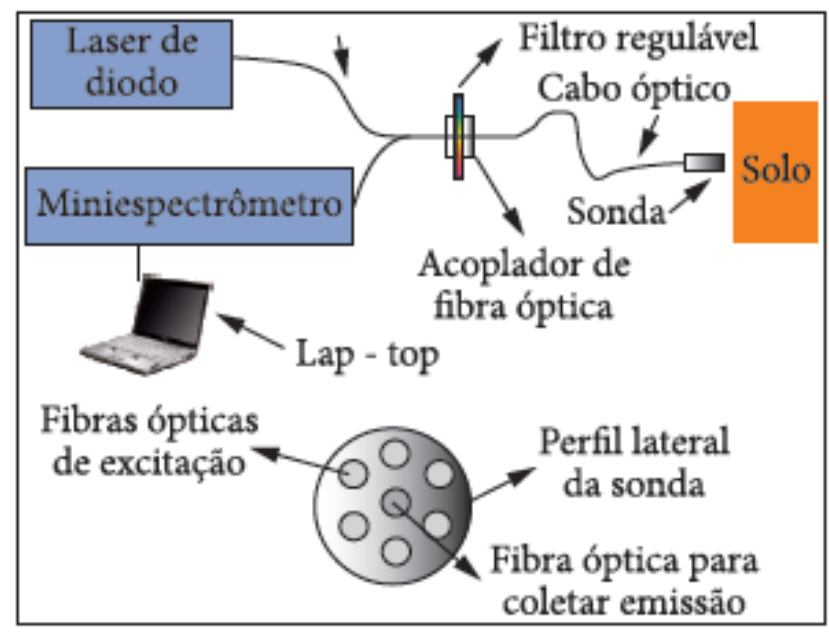

Fonte: Milori et al. (2011). 
Figura 3.16 - Espectrômetro FIL portátil com excitação em 405 nm: 1 - chave de energia do laser; 2 - caixa de controle do laser; 3 - saída para o cabo ótico; 4 ponta emissora/coletora do cabo ótico; 5 - saída para USB e porta paralela; 6 chave geral da caixa e fusível de proteção; 7 - cabo de força geral.
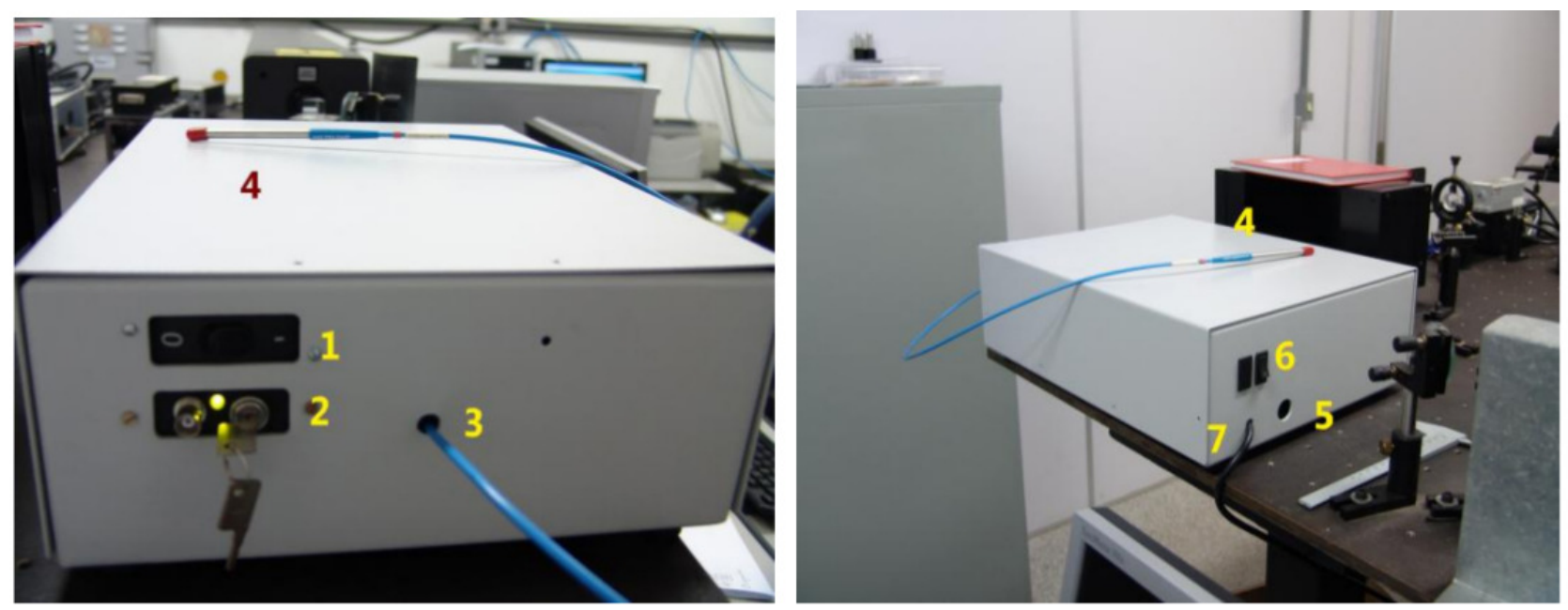

Fonte: Martelli (2011).

A proposta de cálculo para obtenção do índice de humificação pela metodologia de FIL é a razão entre o valor da área (ACF) sobre espectro de emissão de fluorescência (com excitação em 405 nm) e o valor de carbono orgânico total (COT) presente na amostra de solo inteiro (Milori et al., 2004, 2006), ou seja:

$$
H_{\text {FIL }}=\frac{A C F}{C O T}
$$

A adoção da área sobre a curva de fluorescência (ACF) como parâmetro para estimativa da humificação se baseia na metodologia para análise de fluorescência de AH em solução proposta por Milori et al. (2002), ou seja, o índice de humificação $\mathrm{A}_{465}$.

É possível propor a FIL como parâmetro para estudar os processos de humificação em solos submetidos à adição de diferentes compostos orgânicos de origem agroindustrial e urbana. Segundo Santos (2006), sua utilização é de maior relevância para os Latossolos, solos em que os conteúdos de ferro inviabilizam os estudos dos parâmetros de humificação através das técnicas espectroscópicas de ${ }^{13} \mathrm{C}$ RMN e EPR. Santos (2009), mostrou em seu estudo que a FIL foi eficiente na determinação do grau de humificação da MO irrigados com esgoto sanitário tratado, observando variações no teor de carbono e no $\mathrm{H}_{\mathrm{FIL}}$ para os solos irrigados com esgoto sanitário, decorrentes do aumento da atividade de decomposição da $\mathrm{MO}$, estimulada pelo aumento de água no solo. 
Segundo Pigatin (2011), a técnica de FIL se mostrou coerente com os resultados obtidos por fluorescência em solução para os ácidos húmicos extraídos de solos submetidos ou não à adição dos compostos orgânicos.

Rossin (2013), utilizou FIL para estudar a distribuição e as mudanças na natureza da $\mathrm{MO}$ presente nos solos no decorrer da evolução da microbacia de águas escuras e da evolução pedo-geomorfológica. Os resultados obtidos destacaram que o Podzol Espesso é mais humificado em relação aos demais, portanto, mais antigo. O Gleissolo, mais humificado do que o Podzol Hidromórfico e o Criptopodzol, pode ser considerado como mais antigo que os dois últimos.

\subsubsection{ESPECTROMETRIA DE EMISSÃO ÓTICA COM PLASMA ACOPLADO INDUTIVAMENTE (ICP OES)}

A espectrometria de emissão ótica com plasma acoplado indutivamente (ICP OES) do inglês inductively coupled plasma optical emission spectrometry, é uma técnica instrumental que apresenta numerosas aplicações na caracterização de materiais (Matias, 2007).

A ICP OES surgiu como técnica analítica na metade dos anos 60 (Greenfield et al., 1964; Wendt; Fassel, 1965), e desde então essa técnica tem tido grande aceitação entre os químicos analíticos, principalmente devido ao fácil manuseio dos equipamentos, capacidade de realizar análises multielementares e ao relativamente baixo efeito de matriz (Dubuisson et al., 1997).

Esta técnica analítica possibilita a determinação rápida de vários elementos em diferentes faixas de concentração, baseada no espectro de emissão dos mesmos (Vandecasteele; Block, 1997). Como vantagens, apresenta característica multielementar e simultânea, alta precisão e exatidão, alta seletividade e sensibilidade, rapidez, baixos limites de detecção, bem como ampla faixa dinâmica linear de trabalho (Giné-Rosias, 1998).

Na técnica de ICP OES são gerados espectros eletromagnéticos nas regiões do ultravioleta e visível, a partir de transições eletrônicas em átomos e íons excitados. O plasma fornece energia suficientemente alta para promover excitação da maioria dos elementos, sendo medida a intensidade da radiação emitida em comprimentos de onda específicos, correspondendo à concentração do analito de interesse (Giné-Rosias, 1998). 
A espectroscopia ótica de emissão utiliza esse fenômeno para a determinação quantitativa de elementos em uma ampla variedade de amostras (amostras ambientais, água, sangue, urina, óleos, combustíveis, solventes orgânicos, solos, cerâmicas, refratários, plantas, tecidos animais, metais e ligas, plásticos, óxidos, alimentos, bebidas entre outros) (Ide; Nakamura, 2002; Trevizan et al., 2003). A amostra pode ser introduzida no plasma na forma gasosa, líquida ou suspensão.

O plasma é um gás parcialmente ionizado, produzido a partir de uma descarga em uma corrente de gás inerte (argônio), mediante aquecimento por indução em uma tocha de quartzo localizada dentro de uma bobina de indução ligada a um gerador de radiofrequência, que opera a frequência e potência apropriada (Vandecasteele; Block, 1997).

Plasmas de argônio apresenta densidade eletrônica entre 2 a $6.10^{15} \mathrm{e}^{-} \mathrm{cm}^{-3}$. Os elétrons absorvem energia suficiente para manter a temperatura entre $6000 \mathrm{e}$ 10000 K no plasma (Montaser; Golightly, 1992; Harris, 2003). Devido à elevada temperatura uma quantidade significativa de átomos e íons excitados é formada, fazendo do plasma uma ótima fonte de emissão atômica.

A solução introduzida em um ICP OES é transformada em um aerosol no nebulizador, sendo que somente cerca de 2 a $3 \%$ do aerosol formado atinge 0 plasma. Ao atingir a tocha ocorrem processos de dessolvatação, vaporização, atomização, excitação e ionização. Os processos de atomização e excitação dos átomos geram espectros atômicos, ao passo que a ionização e excitação da espécie iônica, geram espectros iônicos (Giné-Rosias, 1998). Um esquema dos processos que ocorrem no plasma é apresentado na Figura 3.17. 
Figura 3.17 - Esquema dos processos que ocorrem no plasma.

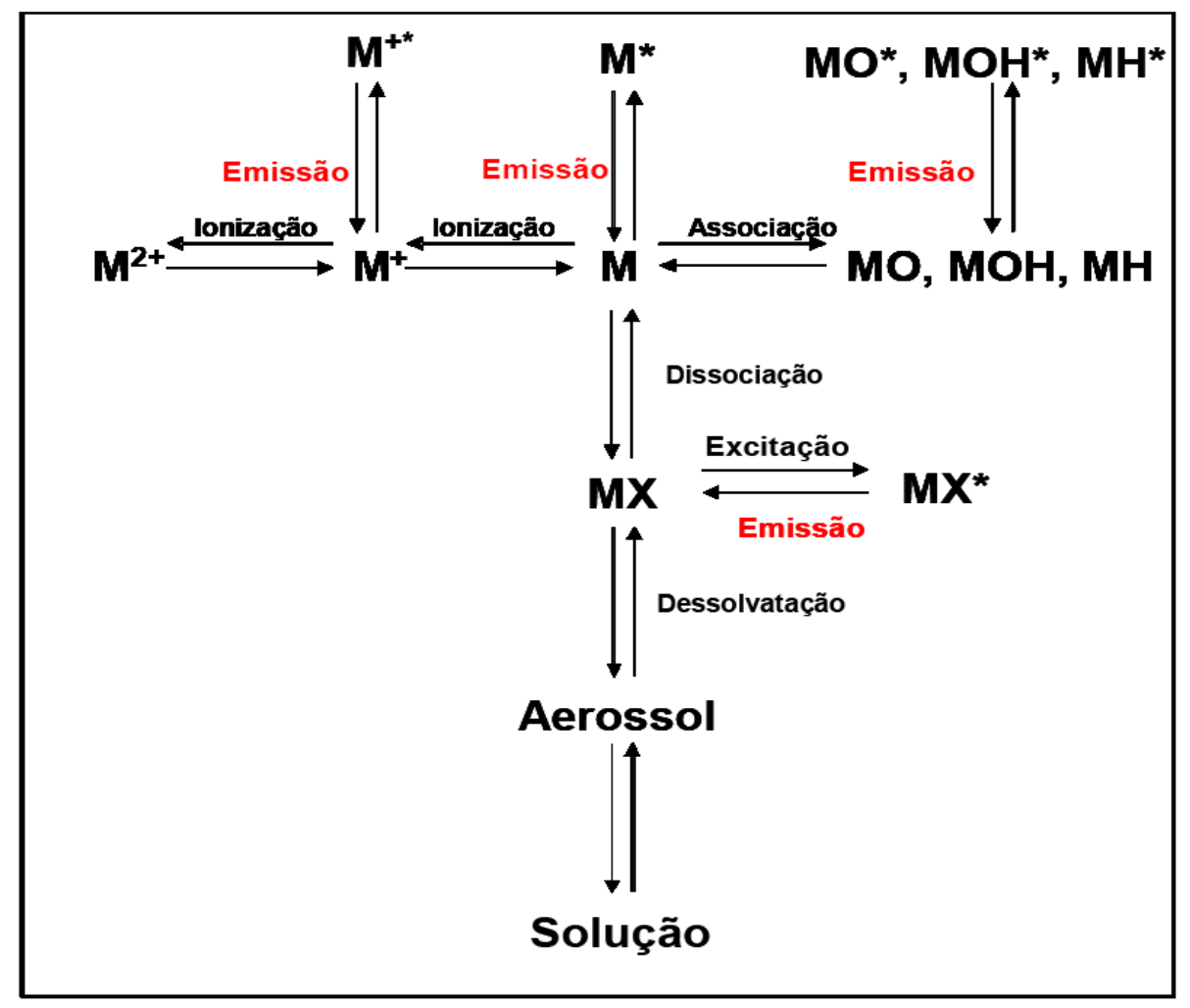

Fonte: Giné-Rosias (1998).

Esse método tem sido bastante atrativo ao possibilitar análises multielementares em uma ampla faixa de concentração em uma mesma amostra (Santos, 1999). O espectro de um elemento apresenta uma série de linhas que podem ser usadas para quantificação. A seleção da linha mais adequada deve considerar a sensibilidade da linha, a possibilidade de interferências espectrais, além da faixa linear de calibração (Montaser; Golightly, 1992).

As informações espectroscópicas obtidas por esta técnica podem ser: qualitativas, informando o comprimento de onda no qual a radiação é emitida ou absorvida; quantitativas, informando a quantidade de radiação emitida ou absorvida em um comprimento de onda específico, dependente da concentração (Boss et al., 1997; Almeida, 2007).

Almeida (2007) analisou e identificou em seu estudo, os metais $\mathrm{Fe}, \mathrm{Mn}, \mathrm{Cu}$, $\mathrm{Zn}, \mathrm{Cr}$, Ni, através de ICP OES, em frações húmicas obtidas por diferentes procedimentos de extração, relacionando-os de acordo com sua distribuição nas mesmas e comparou com os resultados obtidos na extração sequencial de metais. $O$ autor concluiu que não se pode fazer o fracionamento dos metais através dos 
métodos de extração da $\mathrm{MO}$, isto é, devido a geração de artefatos químicos causados pelos condicionantes químicos, tais como, uso de solução alcalina forte que pode causar hidrólise dos metais (precipitação) e até mesmo quebra de cristais (aumento da disponibilidade de metais em solução), levando a resultados discrepantes da realidade no solo.

Santos (2010), avaliou o procedimento de decomposição de amostras de solos (Latossolo Vermelho eutroférrico e Latossolo Vermelho distrófico) submetidas à adição de lodo de esgoto visando à determinação dos teores totais de $\mathrm{Ba}, \mathrm{Cd}, \mathrm{Cr}$, $\mathrm{Cu}, \mathrm{Ni}, \mathrm{Pb}$ e Zn utilizando ICP OES. Os resultados obtidos mostraram concentrações significativas de $\mathrm{Cr}$, $\mathrm{Cu}, \mathrm{Ni}$ e $\mathrm{Zn}$ ligados às frações óxidos de $\mathrm{Mn}$ e $\mathrm{Fe}$ e à fração residual, indicando assim a baixa mobilidade e disponibilidade destes elementos nos solos.

Silva et al. (2013) em seu estudo, realizou diferentes procedimentos de extração de Fe, Al, Si e C orgânico com o intuito de compreender o processo de podzolização em solos associados às depressões de topo dos Tabuleiros Costeiros do Nordeste brasileiro. Determinou-se nas amostras o teor de Fe, Al e Si pelos extratores ditionito-citrato- bicarbonato de sódio, oxalato de amônio e pirofosfato de sódio e fez o fracionamento químico da matéria orgânica do solo. O Fe e Al foram determinados por espectrometria de absorção atômica e o Si por ICP OES. Os autores concluíram que o aumento dos teores de $\mathrm{C}$ orgânico, $\mathrm{Fe}$ e $\mathrm{Al}$ pelos diferentes extratores nos horizontes iluviais de cada solo, relativamente aos horizontes eluviais, refletem a morfologia de campo e reforçam a importância do processo de podzolização nos solos estudados, que é apenas incipiente no perfil de Neossolo Quartzarênico espódico.

\subsection{PREPARO DE AMOSTRAS PARA ICP OES}

Uma etapa importante e crítica na caracterização de materiais por ICP OES é a escolha de um procedimento adequado para a digestão das amostras, que podem ser divididas entre aquelas que já estão na forma de uma solução aquosa (sangue, urina, amostras de água), na forma sólida (solos, cerâmica, refratários, metais, tecidos animais, plantas, plásticos), ou em outras formas de líquidos (solventes orgânicos, óleos, combustíveis) (Matias, 2007).

As amostras sólidas analisadas por ICP OES geralmente são convertidas em 
uma solução representativa empregando um método de digestão apropriado (Ingle; Crouch, 1988). Para quase todos os métodos de digestão existentes são utilizados reagentes químicos que podem ser ácidos diluídos e concentrados, mistura de ácidos, mistura de ácidos com outros reagentes ou sais, entre outros.

A decomposição por via úmida pode ser promovida em sistemas abertos e sistemas fechados, com aquecimento convencional ou assistido por microondas. Diferentes procedimentos têm sido propostos para a decomposição de amostras de solo, mas, a maioria é voltada à determinação para fins de fertilidade.

Atualmente, encontram-se na literatura diferentes metodologias empregadas para a decomposição de amostras de solo (Bettinelli et al., 2000; Sandroni et al., 2003; Vieira et al., 2005). A United States Environmental Protection Agency (USEPA) recomenda três métodos: o 3050, que emprega decomposição em frascos abertos em meio de $\mathrm{HCl}, \mathrm{HNO}_{3}$ e $\mathrm{H}_{2} \mathrm{O}_{2}$, o 3051, que emprega decomposição por radiação microondas em meio $\mathrm{HNO}_{3}$ e o 3052, que além do $\mathrm{HNO}_{3}$, emprega o $\mathrm{HF}$, podendo ainda utilizar outras combinações de reagentes, como $\mathrm{HCl}$ e $\mathrm{H}_{2} \mathrm{O}_{2}$ (USEPA, 1995; Santos, 2010).

Segundo Hoening e Kersabiec (1996), para fins ambientais um ataque ácido forte usando água régia $\left(\mathrm{HNO}_{3}+\mathrm{HCl}\right)$ é geralmente satisfatório na determinação de elementos traços em amostras de solos, sedimentos e rochas. De uma forma geral, os procedimentos de decomposição total empregados para amostras de solo diferem entre si quanto ao sistema de aquecimento e à mistura de ácidos empregados.

\subsubsection{ESPECTROSCOPIA DE EMISSÃO ÓTICA COM PLASMA INDUZIDO POR LASER (LIBS)}

Espectrometria de emissão ótica com plasma induzido por laser, conhecida pelo acrônimo LIBS (Laser Induced Breakdown Spectroscopy) é uma técnica espectroanalítica baseada na observação da radiação emitida por átomos, íons e moléculas em um microplasma que é formado pela interação entre a amostra e pulsos de laser de alta energia. O termo "breakdown" refere-se a um fenômeno coletivo relacionado à ruptura dielétrica das ligações moleculares do material, que ocorre anteriormente à formação do plasma e envolve propriedades da amostra, tais como elasticidade e compressibilidade. Essa técnica tem possibilitado medidas qualitativas e quantitativas de metais de forma não intrusiva em qualquer tipo de 
material, independente de seu estado físico, sólido, líquido ou gasoso (Santos Junior et al., 2006).

A Figura 3.18 apresenta um esquema típico de um espectrômetro LIBS constituído por um laser, um conjunto ótico, uma unidade de detecção e um computador para controle e processamento de dados. Neste sistema, quando a lente convergente focaliza um pulso de laser na amostra, as moléculas componentes do material são dissociadas tanto em átomos devido à ruptura das ligações moleculares, quanto em íons e elétrons devido à ruptura das ligações eletrônicas no ponto focal da lente (Sacchi, 1991). Essa ruptura (breakdown) é promovida pelo gradiente de campo elétrico intenso do laser criado na superfície da amostra.

Figura 3.18 - Esquema de um espectrômetro LIBS.

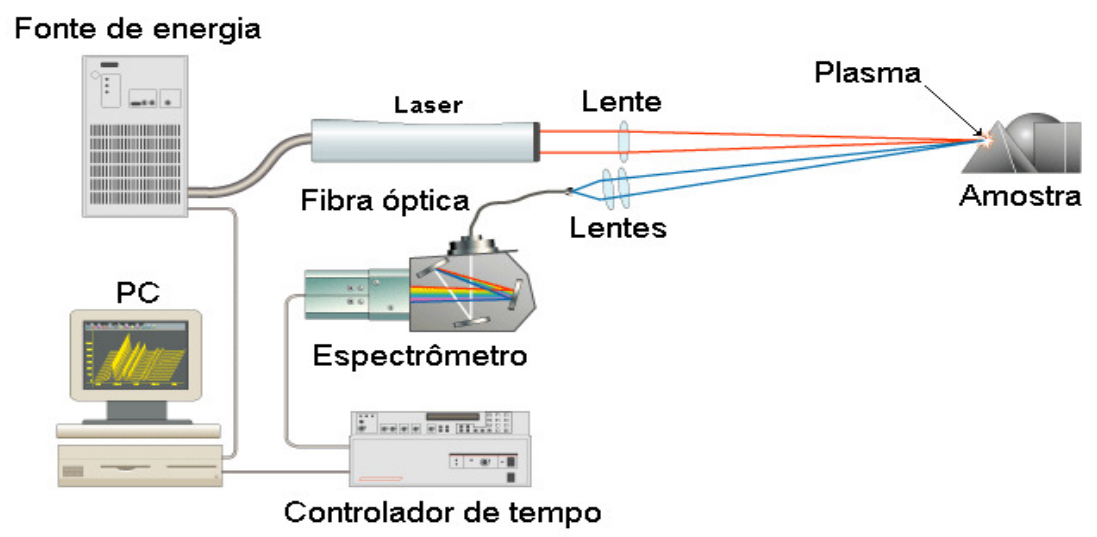

Fonte: (Figura adaptada de www.appliedphotonics.co.uk).

Com a focalização do laser numa pequena área da superfície da amostra ocorre a ablação de pequena quantidade do material, da ordem de nanogramas a picogramas. O material ablado é superaquecido instantâneamente e as colisões entre elétrons livres e elétrons ligados aos átomos resultam em uma avalanche eletrônica provocando a geração de um plasma com temperaturas na faixa de 10000 a $20000 \mathrm{~K}$ (Markolf, 1999). A temperatura do plasma, que permanece aproximadamente constante por um curto espaço de tempo (< $10 \mu \mathrm{s})$, é suficientemente energética para excitar os elétrons das espécies atômicas e iônicas presentes no plasma. Com o resfriamento do plasma, os elétrons excitados retornam aos seus estados fundamentais liberando a energia absorvida na forma de radiação eletromagnética, cujas frequências são características de cada espécie excitada. $A$ 
identificação dos átomos presentes na amostra se dá pela identificação das linhas de emissão, que já são bem conhecidas, e a quantificação da concentração das espécies ocorre pela determinação da intensidade das linhas de emissão (Ferioli; Buckley, 2006).

Em geral, a técnica LIBS emprega um laser pulsado com alta irradiância, da ordem de $\mathrm{GW} \mathrm{cm}^{-2}$, para possibilitar uma ruptura (breakdown), no meio a ser investigado, promovendo a formação de um plasma de alta temperatura (10000 a $20000 \mathrm{~K})$. Durante a relaxação, os átomos, íons e fragmentos de moléculas excitados no plasma emitem um espectro de emissão característico do material volatilizado da amostra. Geralmente, esse espectro é analisado nas regiões UV-VIS, mas vale ressaltar que emissões de raios- $X$ também são possíveis, dependendo da energia do laser incidente na amostra e podem ser alvo de futuras investigações (Samuels et al., 2003; Kumar et al., 2004).

A técnica LIBS tem sido empregada com certa facilidade em análises qualitativas, mas ainda requer esforço considerável em análises quantitativas, devido às dificuldades de calibração e a inexistência de materiais de referência com propriedades certificadas para massas menores que 0,1 mg. Quando comparada as técnicas analíticas já consagradas, tais como a espectroscopia de absorção atômica em chama (FAAS), ICP OES e espectrometria de massa com plasma indutivamente acoplado (ICP-MS), LIBS é muito versátil e apresenta características atrativas como: (1) análises rápidas (0,5 min) e diretas tanto in situ como in vivo; (2) massas amostradas entre 0,1 e $100 \mu \mathrm{g}$ (tipicamente $1 \mu \mathrm{g}$ ); (3) pode dispensar totalmente ou simplificar o preparo da amostra; (4) aplicável para análise de sólidos, líquidos e gases; (5) possibilidade de análise direta de materiais de difícil dissolução; (6) possibilidade de realizar medidas a distância (Santos Junior et al., 2006).

O limite de detecção da técnica LIBS ainda é relativamente alto se comparado com os que são obtidos com as técnicas espectroanalíticas já consagradas como ICP OES e ICP-MS (Fichet et al., 2006). Entretanto, essa figura de mérito deve ser reavaliada, quando se consideram limites de detecção absolutos $(<1 \mathrm{fg})$ nas massas amostradas.

LIBS é comumente utilizada para determinar a composição elementar de amostras, mas, se devidamente calibrada, pode ser usada para determinar a concentração dos elementos constituintes da amostra. No caso de solos, LIBS tem sido utilizada para determinar o teor de carbono (Cremers et al., 2001; Ebinger et al., 
2003; Da Silva et al., 2008; Milori et al., 2011).

O uso da técnica LIBS combinada com rede neural artificial (ANN), utilizando ICP OES como técnica de referência, pode resultar em um método rápido, direto e limpo para determinações multielementares com grande aplicação potencial em estudos de sustentabilidade ambiental. Ferreira et al. (2011) utilizou dois tipos de solos para estudos de sustentabilidade, em que o lodo de esgoto foi aplicado ao solo como fertilizante agrícola. Os autores relatam que os valores determinados para os elementos $\mathrm{Ba}, \mathrm{Co}, \mathrm{Cu}$ e $\mathrm{Mn}\left(\mathrm{mg} \mathrm{kg}^{-1}\right)$ por LIBS-ANN mostrou correlação acima de 98\% com os valores determinados por ICP OES, alta exatidão e precisão, limites inferiores de detecção e grande potencial de aplicação na análise de diferentes tipos de solos.

\subsection{MÉTODOS QUIMIOMÉTRICOS}

\subsubsection{ANÁLISE DE FATORES PARALELOS (PARAFAC)}

Utilizando-se a espectroscopia de MEE, a medida de uma única amostra gera uma superfície ou uma matriz de intensidades de fluorescência. Extrapolando-se para um conjunto de amostras, tem-se a formação de um tensor tridimensional, definido por três dimensões (amostras - comprimento de onda de excitação comprimento de onda de emissão) (Lima, 2001; Trevisan, 2003).

O método de análise de fatores paralelos ou PARAFAC do termo em inglês Parallel Factor Analysis é a mais estável e robusta forma de análise e decomposição espectral aplicada a dados multidimensionais trilineares. As primeiras aplicações realizadas pelos químicos ocorreram a partir dos anos noventa (Trevisan, 2003).

O modelo PARAFAC pode ser considerado "not nested", ou seja, seus componentes não são obrigatoriamente ortogonais, de modo que a variância somada para cada componente não é igual à variância total do modelo (Trevisan, 2003).

O algoritmo de análise de fatores paralelos (PARAFAC) foi utilizado com sucesso para tratar uma grande quantidade de amostras de matéria orgânica dissolvida fluorescente analisadas pela espectroscopia tridimensional MEE, levando à decomposição de um conjunto de compostos fluorescentes (Stedmon et al., 2003; Stedmon; Markager, 2003, 2005; Holbrook et al., 2006). Devido às suas 
propriedades únicas, a modelagem por PARAFAC proporciona uma decomposição espectral singular, que é mais facilmente interpretável do que as decomposições bilineares (Luciani et al., 2008).

O PARAFAC vem sendo amplamente utilizado em vários trabalhos científicos como um algoritmo de decomposição poderoso. O PARAFAC é um método de análise multi-modos baseado em uma decomposição multilinear do conjunto de dados. Considerando $x_{i, j, k}$ como a intensidade de fluorescência de uma dada amostra i de um dado par (j,k) de comprimentos de onda de excitação e emissão, $a_{\text {if }}$ como a concentração do componente f na amostra $i, b_{\text {if }}$ como a quantidade da intensidade de fluorescência emitida por f no comprimento de onda de emissão $\lambda_{j}$ e $c_{k f}$ como a quantidade da intensidade de excitação absorvida por f no comprimento de onda de excitação $\lambda_{k}$, dados pela lei de Lambert-Beer em uma aproximação de primeira ordem (Guo et al., 2007, 2012; Luciani et al., 2008; He et al., 2013):

$$
\forall(i, j, k) \in([1 ; I],[1 ; J],[1 ; K]), \quad x_{i, j, k}=\sum_{f=1}^{F} \mathbf{a}_{i f} \mathbf{b}_{j f} \mathbf{c}_{k f}+\varepsilon_{i, j, k},
$$

onde $\varepsilon$ é o termo do erro residual. Esta relação trilinear entre uma variável medida $\mathrm{x}_{\mathrm{i}, \mathrm{j}, \mathrm{k}}$ e três outras variáveis desconhecidas é um dos 3 fatores do modelo PARAFAC de grau $F$.

Para cada componente, $f$, os vetores $a_{f}, b_{f}$ e $c_{f}$ representam, respectivamente o seu perfil de concentração através das amostras fixadas, seu espectro de emissão normalizado e seu espectro de excitação normalizado. Estes vetores são chamados vetores de loadings de decomposição. Como muitos outros métodos de decomposição linear como análise de componentes principais (PCA), no PARAFAC a otimização do modelo é obtido pela minimização da soma dos erros quadráticos do modelo (Luciani et al., 2008; He et al., 2013).

O algoritmo usado para esta otimização do modelo PARAFAC é o Alternating Least Squares (ALS) 'da caixa de ferramentas N-way para MATLAB', que inicializa assumindo os loadings em dois modos e usa-os para estimar os loadings do próximo modo, até a minimização dos resíduos. Isto é feito para cada modo, até a convergência total gerados, ou seja, sem ocorrer mudanças significativas. Em algumas situações, certas restrições como não-negatividade, unimodalidade e 
ortogonalidade podem ser usadas para melhorar a convergência do algoritmo e/ou obter uma melhor interpretação física dos loadings, como semelhanças espectrais, perfis de pH e tempo de retenção (Trevisan, 2003; Luciani et al., 2008).

O PARAFAC também pode ser usado para a quantificação e, neste caso, os loadings do modo de concentração ou scores obtidos após decomposição são relacionados com as concentrações conhecidas do grupo de calibração. Novas amostras de concentração desconhecida podem ser analisadas com a inserção destas amostras em um tensor contendo as amostras de calibração, de modo que tanto as amostras desconhecidas como as de calibração são usadas na decomposição. Reduzindo-se desta maneira a presença de erros sistemáticos (Trevisan, 2003).

O principal problema encontrado ao utilizar o PARAFAC é a escolha do número ideal de fatores para a decomposição. Uma escolha errônea pode gerar interpretações falsas do sistema em estudo, inviabilizando totalmente a análise. Análises de variância residual, diagnóstico de consistência do tensor núcleo, ou termo em inglês Core Consistency Diagnostic (CORCONDIA) e técnicas de validação cruzada como split-half, são parâmetros importantes que tem sido usado com eficiência para a escolha do número de fatores a serem utilizados para a decomposição (Luciani et al., 2008).

\section{MATERIAIS E MÉTODOS}

\section{1 ÁREA DE ESTUDO}

A área onde foi desenvolvido este estudo encontra-se localizada em propriedade do Ministério da Aeronáutica, à margem esquerda do rio Negro, à $26 \mathrm{~km}$ da cidade de São Gabriel da Cachoeira, no estado do Amazonas, com latitude 0 ‘6'24,5”' S e longitude 66 54'19,3” W (Figura 4.1). 
Figura 4.1 - Localização da área de estudo na cidade de São Gabriel da Cachoeira, AM. A topossequência está representada pela linha amarela na figura inferior à direita.

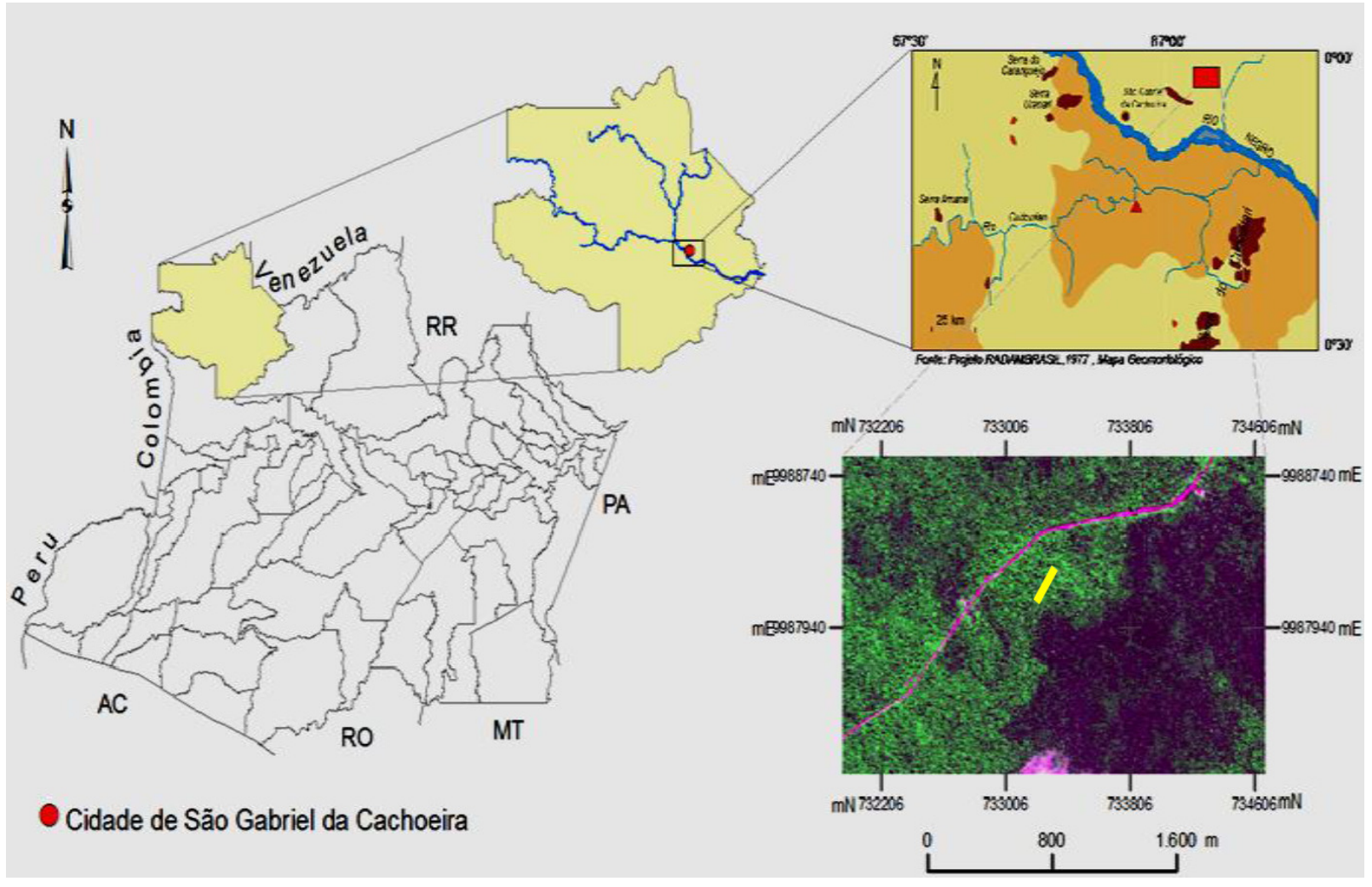

Fonte: Ishida (2010).

O clima da região do rio Negro é uniformemente equatorial úmido, de acordo com a classificação de Köeppen, caracterizado por uma temperatura média de $25^{\circ} \mathrm{C}$ em São Gabriel da Cachoeira, sendo as médias mensais máxima de $30^{\circ} \mathrm{C}$ e mínima de $22^{\circ} \mathrm{C}$. A precipitação anual varia entre 3000 a $4000 \mathrm{~mm}$, com menor precipitação nos meses de agosto a outubro e maior em dezembro a maio (Silva; Jesus; Ribeiro, 1977; Ishida, 2010).

Foi estudado por meio de uma topossequência, um sistema LatossoloEspodossolo com caulim associado, desenvolvido a partir de rochas granito gnáissicas do embasamento cristalino. Foram descritos e amostrados nesta topossequência, da montante para a jusante quatro perfis de solo: Espodossolo Humilúvico (P1) no topo, dois Latossolos amarelos (P2 e P3) na meia encosta e Gleissolo Háplico (P4) na base (Ishida, 2010).

A Figura 4.2 descreve de forma simplificada a topossequência estudada, caracterizada por quatro perfis de solo, onde da montante para a jusante foram identificados três domínios: o domínio podzolizado-hidromórfico (zona de 
podzolização), o laterítico hidromórfico (zona de laterização) e o hidromórfico (zona de gleização), que ocupam respectivamente os segmentos superior, médio e inferior da paisagem local (Ishida, 2010). Neste estudo foram estudadas as amostras dos perfis $\mathrm{P} 1$ (correspondente à zona de podzolização) e P2.

Figura 4.2 - Esquema da topossequência. Os números de 1 até 10 representam os horizontes e camadas de solo. As letras a até $\mathrm{k}$ representam os segmentos formados a partir da delimitação visual das rupturas de declive.

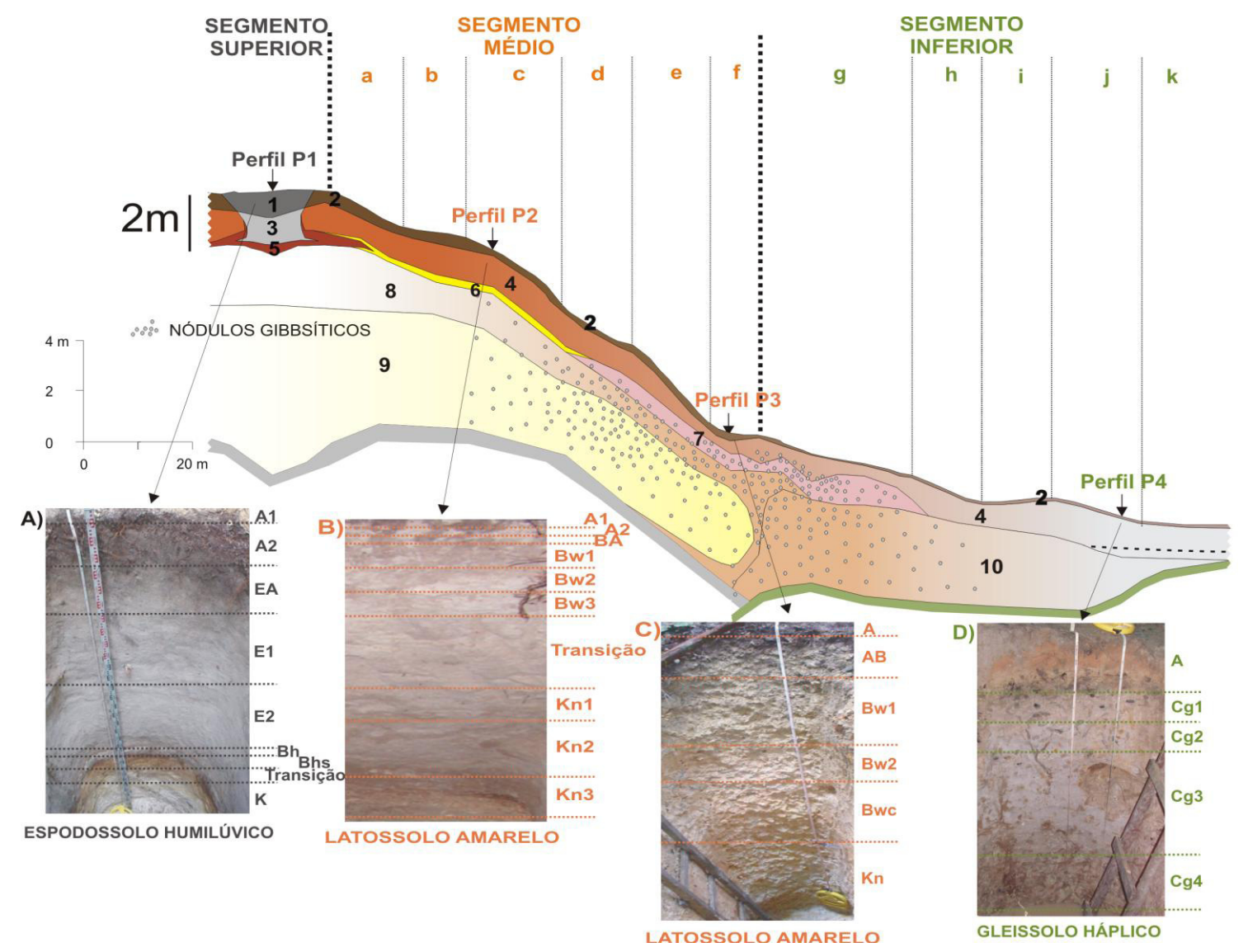

Fonte: Adaptado de Ishida (2010).

\subsubsection{SEGMENTO SUPERIOR - ZONA DE PODZOLIZAÇÃO}

Desenvolve-se em terreno levemente côncavo, na porção central do interfluvio, em uma zona de transição entre floresta e campinarana caracterizadas por árvores altas e com troncos grossos e árvores altas com troncos finos. Nesta zona desenvolve-se um Espodossolo Humilúvico (perfil P1) com uma camada com acúmulo expressivo de caulinita imediatamente abaixo dos horizontes espódicos.

O perfil 1 apresenta a seguinte sequência de horizontes: $O$ (superficial 
orgânico); A (superficial organo-mineral); E (álbicos); Bh e Bhs (espódicos); K1 e K2 (camadas de caulim embranquecido) na base (Ishida, 2010) (Figura 4.2).

\subsubsection{SEGMENTO MÉDIO - ZONA DE LATERIZAÇÃO}

Nesta zona está sendo estudado um Latossolo Amarelo (perfil P2), localizado na parte superior do segmento médio. Camadas espessas de caulim também se desenvolvem na base desse Latossolo Amarelo.

O perfil 2 apresenta a seguinte sequência de horizontes: $O$ (superficial orgânico); A1 e A2 (superficiais organo-minerais); BA (transição); Bw1, Bw2 e Bw3 (conjunto intermediário de horizontes latossólicos) franco-argilo-arenosos a francoargilo-siltosos; Kn1, Kn3 e Kn4 (conjunto inferior de camadas de caulim com nódulos de gibbsita) (Figura 4.2).

\subsection{AMOSTRAGEM DO SOLO}

O estudo dos solos foi feito em uma topossequência a partir de pontos de trincheiras e de sondagens, de acordo com o procedimento proposto por Boulet et al. (1982). Conforme descrito em Ishida (2010), os trabalhos foram divididos em etapas: (i) realização de vinte e seis pontos de sondagens com a finalidade de estabelecer a locação das trincheiras; (ii) a partir da análise dos pontos de sondagens foram estabelecidos os pontos para abertura das trincheiras; (iii) abertura de quatro trincheiras nos pontos que apresentaram as sequências mais representativas; (iv) descrição morfológica dos perfis de solo nas trincheiras seguindo os critérios de cor, textura e estrutura propostos por Santos et al. (2005) e a denominação dos solos obedecendo à classificação brasileira (Embrapa, 2006).

Ao longo da topossequência nos perfis P1 e P2 são encontradas camadas com acúmulo expressivo de caulinita que não se enquadram nos critérios de classificação dos horizontes pedológicos (Embrapa, 2006). Devido a esta dificuldade será utilizado o termo caulim e a letra $K$ para designar estas camadas. A letra $n$ associada à letra $\mathrm{K}$ será utilizada para designar a presença de nódulos gibbsíticos nesses caulins (Ishida, 2010). As amostras foram coletadas por meio de tradagem manual. As profundidades de coleta foram adaptadas às características do solo estudado. 


\subsection{PREPARO DAS AMOSTRAS DE SOLO}

Depois de coletadas, as amostras de solos foram levadas para o laboratório onde foi realizada uma limpeza manual cuidadosa para retirar as raízes e restos de folhas. A seguir as amostras foram secas à temperatura ambiente, moídas com auxílio de almofariz e pistilo e passadas em peneira de malha de 2,0 $\mathrm{mm}$ para a obtenção da fração de terra fina seca ao ar (TFSA). Em seguida, parte dessas amostras de solo foram moídas e passadas em peneira de 35 mesh para realização do fracionamento químico por solubilidade das SHs e, 100 mesh para análises espectroscópicas e análise elementar.

\subsection{EXTRAÇÃO DAS SUBSTÂNCIAS HÚMICAS}

Todas as amostras de solo foram submetidas a um processo de extração e fracionamento químico das substâncias húmicas por diferença de solubilidade, seguindo a metodologia recomendada pela Sociedade Internacional de Substâncias Húmicas (IHSS), ilustrado pela Figura 4.3, que utiliza solução de $\mathrm{NaOH} 0,1 \mathrm{~mol} \mathrm{~L}^{-1}$ diluída para extrair o ácido húmico e $\mathrm{HCl} 0,1 \mathrm{~mol} \mathrm{~L}^{-1}$ para sua precipitação (Swift, 1996).

Inicialmente fez-se uma extração com $\mathrm{HCl} 0,1 \mathrm{~mol} \mathrm{~L}^{-1}$ em proporção de $1 \mathrm{~g}$ solo: $10 \mathrm{~mL}$ de solução. Dessa forma, foi pesada uma quantia em torno de 300 a 400 $\mathrm{g}$ das amostras dos solos arenosos (Espodossolo Humilúvico e Latossolo Amarelo). A solução foi agitada manualmente durante 1 hora e, após deixar a solução em repouso, separou-se o sobrenadante do resíduo por sifonação. O sobrenadante separado é o extrato 1 de ácido fúlvico (AF Extrato 1).

Em seguida foi feita uma extração com $\mathrm{NaOH} 0,1 \mathrm{~mol} \mathrm{~L}^{-1}$, resultando no final uma relação solo-solução 1:10. A solução foi submetida à agitação intermitente durante 4 horas. A seguir, a suspensão ficou em repouso por 16 horas e 0 sobrenadante foi isolado através de uma centrifugação (10.000 rpm - 15 minutos) e reservado para posterior acidificação. O material insolúvel resultante da centrifugação, denominado (fração mineral + humina), foi separado para purificação. Esta purificação foi feita através da lavagem do material insolúvel com água ultra pura (Millipore - Milli-Q), até que o material fosse neutralizado $(\mathrm{pH}=7,0)$. Em seguida, o material foi seco em estufa $\left(35^{\circ} \mathrm{C}\right)$ durante 3 dias. 
$\mathrm{O}$ sobrenadante isolado foi acidificado com $\mathrm{HCl} 6 \mathrm{~mol} \mathrm{~L}^{-1}$, com agitação simultânea até atingir pH 1-2 e mantido novamente em repouso por 16 horas, para decantação. Na sequência, a solução foi centrifugada (10.000 rpm - 15 minutos) para separar o AH (precipitado) e as frações de AF (sobrenadante - AF Extrato 2), que foi separado por sifonação e dialisado.

Terminada a fase de extração, iniciou-se a purificação dos $\mathrm{AH}$, redissolvendo o precipitado através da adição de um pequeno volume conhecido de $\mathrm{KOH} \mathrm{0,1} \mathrm{mol}$ $\mathrm{L}^{-1}$. A seguir, adicionou-se cloreto de potássio $(\mathrm{KCl})$ na forma sólida, para atingir uma concentração de $0,3 \mathrm{~mol} \mathrm{~L}^{-1}$ de íons $\left[\mathrm{K}^{+}\right]$. Após, centrifugou-se a solução sob alta velocidade (12.000 rpm - 15 minutos) para que os sólidos suspensos fossem removidos.

$\mathrm{O} A \mathrm{H}$ foi então reprecipitado, adicionando-se $\mathrm{HCl} 6 \mathrm{~mol} \mathrm{~L}^{-1}$ com agitação simultânea até que fosse atingido pH 1,0-1,5, e após, a suspensão foi mantida em repouso por 16 horas. Centrifugou-se a solução (10.000 rpm - 15 minutos) e o sobrenadante foi então descartado.

O precipitado $(\mathrm{AH})$ foi dissolvido e suspenso em solução $\mathrm{HCl} 0,1 \mathrm{~mol} \mathrm{~L}^{-1}+\mathrm{HF}$ $0,3 \mathrm{~mol} \mathrm{~L}^{-1}$ num recipiente plástico e agitado durante 16 horas a temperatura ambiente.

A seguir, a solução foi centrifugada (10.000 rpm - 15 minutos) e após descartar o sobrenadante, o precipitado foi transferido, com o auxilio de água desionizadadesionizada (Milli-Q) para uma membrana de diálise (Spectra/Por 6000 $8000 \mathrm{D})$ de $25 \mathrm{~cm}$ de comprimento e $5 \mathrm{~cm}$ de largura, preparada segundo a metodologia de Mc Phie (1971). Procedeu-se a diálise contra água desionizada até que a água da diálise apresentasse teste negativo de cloreto $\left(\mathrm{Cl}^{\prime}\right)$ com nitrato de prata $\left(\mathrm{AgNO}_{3}\right)$. Para isso, tal procedimento foi repetido durante aproximadamente seis dias, fazendo-se a troca da água desionizada duas vezes por dia. Finalmente, as amostras de $\mathrm{AH}$ foram congeladas, liofilizadas e armazenadas em recipientes plásticos e mantidas em dessecador para posteriores análises químicas e espectroscópicas.

Os extratos de ácido fúlvico 2 (EAF2) foram transferidos, com o auxílio de água desionizada (Milli-Q) para uma membrana de diálise, preparada segundo metodologia anteriormente descrita. Os EAF2 foram submetidos à diálise por um período de seis dias, trocando-se a água desionizada duas vezes por dia. 
Figura 4.3 - Esquema simplificado da extração e purificação das substâncias húmicas do solo.

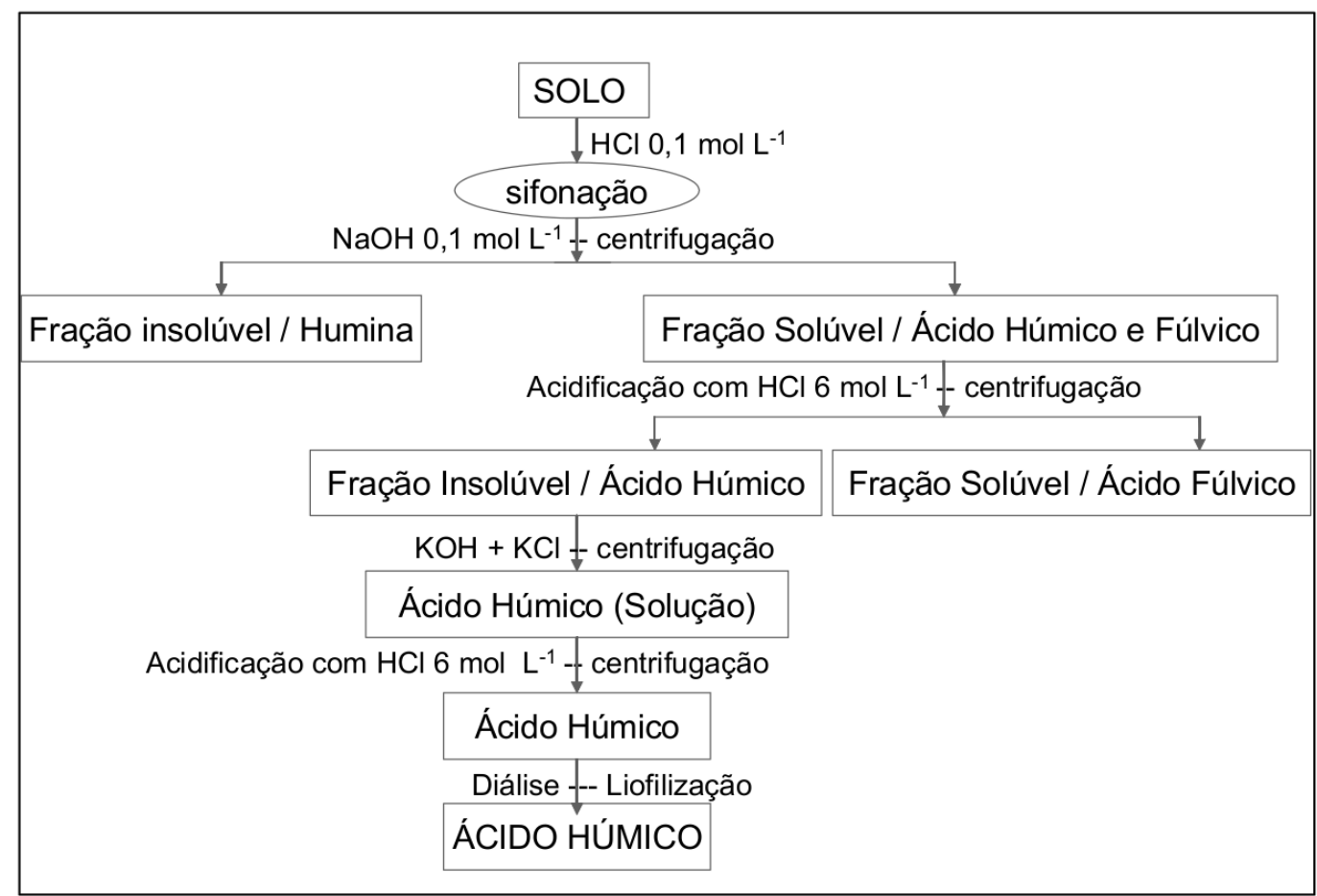

\subsubsection{PROCEDIMENTO DE PURIFICAÇÃO DOS EXTRATOS DE ÁCIDO FÚLVICO E ÁCIDO HÚMICO}

A purificação dos ácidos tem como finalidade a diminuição do teor de cinzas e a remoção de compostos inorgânicos de baixo massa molecular, o qual não é componente estrutural destas substâncias húmicas (Guerra; Santos, 1999).

$\mathrm{O} \mathrm{AH}$ extraído dos solos de acordo com o procedimento utilizado contém frequentemente íons metálicos que podem interferir em sua caracterização. Alguns $\mathrm{AH}$, dependendo de suas origens, podem apresentar um teor de cinzas de até $30 \%$. Um método satisfatório de redução nesta quantidade pode ser obtido por repetidas etapas de dissolução - precipitação - centrifugação e utilização da diálise, utilizando-se membranas específicas (Narimoto, 2006; Santos, 2008).

A purificação dos $\mathrm{AH}$ é feita geralmente com solução mista de $\mathrm{HCl}$ e $\mathrm{HF}$, que promove a quebra das ligações Si-O entre a argila e a matéria orgânica, solubilizando dessa forma os argilo-minerais. Sanches-Monedero et al. (2002) verificaram que o tratamento com $\mathrm{HCl}-\mathrm{HF}$ reduz de forma significativa o teor de cinzas dos $\mathrm{AH}$ sem grandes alterações na sua estrutura e na sua composição 
química.

As amostras de $\mathrm{AH}$ foram purificadas através de diálise utilizando membranas Spectra/Por 6000 - 8000 D, durante seis dias, em água desionizada.

Antes de serem utilizadas na purificação dos AH e EAF2, as membranas de diálise foram devidamente tratadas para remoção de glicerina e traços de compostos sulfurosos, seguindo o procedimento estabelecido por McPhie (1971) para remoção dessas impurezas:

1. Removeu-se a quantidade de tubos de diálise (aproximadamente $25 \mathrm{~cm}$ cada) necessária para o experimento e deixou-se ferver por 1 hora em 1 litro de etanol $50 \%$, sempre manuseando os tubos com luvas cirúrgicas limpas.

2. As membranas foram então agitadas por 1 hora a temperatura ambiente em solução de bicarbonato de sódio $\left(\mathrm{NaHCO}_{3}\right)$ 0,01 mol L ${ }^{-1}$ e EDTA dissódico 0,001 mol $\mathrm{L}^{-1}$.

3. Repetiu-se o procedimento com água destilada, depois com nova solução de $\mathrm{NaHCO}_{3} 0,01 \mathrm{~mol} \mathrm{~L}^{-1}$ e EDTA $0,001 \mathrm{~mol} \mathrm{~L}^{-1}$, e, por fim, com água destilada.

\subsection{MÉTODOS QUÍMICOS}

\subsubsection{ANÁLISE ELEMENTAR (CHNS)}

A determinação de carbono do solo foi feita em triplicata, utilizando-se $10 \mathrm{mg}$ das amostras de solo inteiro, por combustão a $1000 \stackrel{\circ}{\circ}$. O equipamento de análise elementar é um CHNS/O da marca Perkin Elmer modelo 2400, pertencente à Embrapa Instrumentação. As amostras de solos foram moídas em partículas menores do que 0,15 mm (100 mesh) e, pesadas diretamente em cápsulas de estanho, utilizando uma microbalança (Perkin Elmer AD-6 Auto Balance Controller), que é conectada ao CHNS/O para aquisição direta das massas. Em seguida, as cápsulas de estanho foram fechadas e inseridas no interior do forno. Todos os resultados para a análise elementar com base em um valor de um padrão conhecido, a acetanilida, um padrão orgânico de composição elementar conhecida. 


\subsection{MÉTODOS ESPECTROSCÓPICOS}

\subsubsection{ESPECTROSCOPIA DE ABSORÇÃO DE RADIAÇÃO NO UV-VIS}

Os espectros de absorção de radiação no UV-Vis das amostras de ácidos húmicos, foram obtidos em soluções de $200 \mathrm{mg} \mathrm{L}^{-1}$, preparadas com 2,0 mg de amostra em $10 \mathrm{~mL}$ de $\mathrm{NaHCO}_{3}$ 0,05 mol L-1 (Stevenson, 1994), ajustadas para $\mathrm{pH}$ em torno de 8, e por diluição foram preparadas as soluções de $10 \mathrm{mg} \mathrm{L}^{-1}$.

As medidas foram feitas na região de 800 a $200 \mathrm{~nm}$. Utilizou-se um Espectrômetro de Absorção UV - Vis SHIMADZU modelo UV-1601PC, pertencente à Embrapa Instrumentação.

Os espectros de absorbância de radiação no UV-Vis para os extratos de ácidos fúlvicos apenas dialisado, foram obtidos em meio com concentração de $\mathrm{NaHCO}_{3}$ 0,05 mol L-1. Para isso, diluiu-se $42 \mathrm{mg}$ de $\mathrm{NaHCO}_{3}$ em $10 \mathrm{~mL}$ de EAF2 dialisado ajustando-se $\circ \mathrm{pH}$ para valor 8,0 que confere um $\mathrm{pH}$ ótimo para as medidas de absorbância. A necessidade da utilização de uma solução tampão deve-se à influência que o pH e a concentração de sais podem ter na razão $E_{4} / E_{6}$ (Chen et al., 1977; Hayes et al., 1989).

Estas análises foram utilizadas para minimizar o efeito de reabsorção (reduzindo o efeito de filtro interno) nos EAF2, pois estes mesmos extratos foram analisados por fluorescência de luz UV-Visível, reduzindo assim, a reabsorção de fluoróforos que poderia interferir nas análises dos espectros de fluorescência obtidos no modo MEE. As condições de análise e instrumentação são idênticas àquelas para $\mathrm{AH}$.

\subsubsection{DILUIÇÃO DAS AMOSTRAS DE ÁCIDO HÚMICO E EXTRATO DE ÁCIDO FÚLVICO 2}

Antes das análises utilizando as técnicas espectroscópicas de absorção de radiação no UV-Vis e fluorescência, as concentrações de todas as amostras ( $\mathrm{AH}$ e EAF2) foram ajustadas para torná-las comparáveis entre si e para evitar (minimizar) os efeitos de filtro interno (Guo et al., 2012).

Para minimizar o "efeito de filtro interno" relacionados com a absorção de luz 
pela própria solução (Lakowicz, 1999), as soluções são diluídas quando necessário por água desionizada, ou como neste estudo, por bicarbonato de sódio. Um fator de diluição foi escolhido para obter soluções de AH e EAF2 com absorção inferior a 0,1 e 0,3 a 254 nm (Ohno; Bro, 2006; Borisover et al., 2009; Ma et al., 2010; Richard et al., 2011). Em qualquer comprimento de onda superior a $254 \mathrm{~nm}$, a absorbância de uma solução foi ainda menor. Este procedimento deve ser aplicado com muito cuidado para evitar contaminação ou mudanças físico-químicas (Luciani et al., 2009).

Luciani et al. (2009) mostrou em seu trabalho que é possível corrigir o efeito de filtro interno, usando simplesmente uma diluição controlada, demonstrando boa capacidade da diluição controlada com o PARAFAC no caso de misturas padrão de dois fluoróforos e, no caso de amostras de matéria orgânica dissolvida.

As diluições das amostras de $\mathrm{AH}$ e dos EAF2, foram feitas com $\mathrm{NaHCO}_{3} 0,05$ mol L $\mathrm{L}^{-1}$, com o auxílio do Espectrômetro de Absorção UV-Visível, até que a absorção em $254 \mathrm{~nm}$ ficasse menor que 0,1 e 0,3, respectivamente, para as amostras de $\mathrm{AH}$ e EAF2, para evitar o efeito de reabsorção (reduzindo o efeito de filtro interno) (Luciani et al., 2008, 2009).

As amostras que apresentaram absorbância menor que 0,1 para $\mathrm{AH}$ e 0,3 para os EAF2 e, que não necessitavam ser diluídas, fez-se a correção por 2 (diluição por 2), que na literatura é chamada de diluição controlada (Noirtin, 2010).

Após as diluições, as amostras de $\mathrm{AH}$ e os EAF2 foram analisados por espectroscopia de fluorescência de luz UV-Visível. Todas as diluições feitas para os AH e EAF2, estão apresentados nas Tabelas de 4.1-4.4.

Tabela 4.1 - Diluição das amostras de AH do Perfil P1 (Espodossolo Humilúvico) para análise de fluorescência no modo excitação-emissão (MEE).

\begin{tabular}{ccc}
\hline $\begin{array}{c}\text { Horizonte/ } \\
\text { Camada }\end{array}$ & $\begin{array}{c}\text { Profundidade } \\
\text { (cm) }\end{array}$ & $\begin{array}{c}\text { Número de Diluições } \\
\text { (vezes) }\end{array}$ \\
\hline A1 & $0-5$ & 4 \\
A2 & $5-30$ & 4 \\
Bh & $202,5-204$ & 5 \\
Bhs & $204-214$ & 7 \\
Transição & $214-245$ & 8 \\
K1 & $245-290$ & 10 \\
K2 & $290+$ & 8 \\
\hline
\end{tabular}


Tabela 4.2 - Diluição das amostras de AH do Perfil P2 (Latossolo Amarelo) para análise de fluorescência no modo excitação-emissão (MEE).

\begin{tabular}{ccc}
\hline $\begin{array}{c}\text { Horizonte/ } \\
\text { Camada }\end{array}$ & $\begin{array}{c}\text { Profundidade } \\
\text { (cm) }\end{array}$ & $\begin{array}{c}\text { Número de Diluições } \\
\text { (vezes) }\end{array}$ \\
\hline A2 & $10-20$ & 5 \\
BA & $20-30$ & 4 \\
\hline
\end{tabular}

Tabela 4.3 - Diluição dos EAF2 das amostras do Perfil P1 (Espodossolo Humilúvico) para análise de fluorescência no modo excitação-emissão (MEE).

\begin{tabular}{ccc}
\hline $\begin{array}{c}\text { Horizonte/ } \\
\text { Camada }\end{array}$ & $\begin{array}{c}\text { Profundidade } \\
\text { (cm) }\end{array}$ & $\begin{array}{c}\text { Número de Diluições } \\
\text { (vezes) }\end{array}$ \\
\hline A1 & $0-5$ & 20 \\
A2 & $5-30$ & 6 \\
E1 & $30-180$ & 2 \\
E2 & $180-202,5$ & 2 \\
Bh & $202,5-204$ & 40 \\
Bhs & $204-214$ & 40 \\
Transição & $214-245$ & 60 \\
K1 & $245-290$ & 8 \\
K2 & $290+$ & 2 \\
\hline
\end{tabular}

Tabela 4.4 - Diluição dos EAF2 das amostras do Perfil P2 (Latossolo Amarelo) para análise de fluorescência no modo excitação-emissão (MEE).

\begin{tabular}{ccc}
\hline $\begin{array}{c}\text { Horizonte/ } \\
\text { Camada }\end{array}$ & $\begin{array}{c}\text { Profundidade } \\
\text { (cm) }\end{array}$ & $\begin{array}{c}\text { Número de Diluições } \\
\text { (vezes) }\end{array}$ \\
\hline A2 & $10-20$ & 10 \\
BA & $20-30$ & 10 \\
Bw1 & $30-60$ & 2 \\
Bw2 & $60-90$ & 2 \\
Bw3 & $90-120$ & 2 \\
Transição & $120-210$ & 2 \\
Kn1 & $210-250$ & 2 \\
Kn3 & $320-380$ & 2 \\
Kn4 & $380+$ & 2 \\
\hline
\end{tabular}

Não foram obtidos pelo fracionamento químico, amostras de $\mathrm{AH}$ dos horizontes álbicos (E1 e E2) do Espodossolo Humilúvico e dos horizontes Bw1, Bw2 e Bw3 (conjunto intermediário de horizontes latossólicos) franco-argilo-arenosos a franco-argilo-siltosos; Kn1, Kn3 e Kn4 (conjunto inferior de camadas de caulim com nódulos de gibbsita) do Latossolo Amarelo, pois os mesmos possuem teores de carbono abaixo do limite de detecção do CHNS e, por isso, não foram efetuadas as 
diluições destas amostras de $\mathrm{AH}$, conforme pode ser observado nas Tabelas $4.1 \mathrm{e}$ 4.2 .

\subsubsection{ESPECTROSCOPIA DE FLUORESCÊNCIA DE LUZ UV-VISÍVEL}

Os $\mathrm{AH}$ foram dissolvidos em uma solução de bicarbonato de sódio $\left(\mathrm{NaHCO}_{3}\right)$ $0,05 \mathrm{~mol} \mathrm{~L}^{-1}$ com concentração de $10 \mathrm{mg} \mathrm{L}^{-1}$ e o pH igual a 8 (Milori et al., 2002). Essa concentração foi utilizada para minimizar o efeito de reabsorção de fluorescência e reduzir interação entre moléculas. Os EAF2 foram preparados diluindo-se $42 \mathrm{mg}$ de $\mathrm{NaHCO}_{3}$ em $10 \mathrm{~mL}$ de EAF2 dialisado, ajustando-se o pH para valor 8 .

Após o preparo das soluções de AH e das diluições dos EAF2 e das amostras de $\mathrm{AH}$, os espectros de fluorescência foram obtidos nos modos de emissão, excitação-emissão (MEE) e varredura sincronizada, segundo as metodologias proposta por Zsolnay et al. (1999), Milori et al. (2002), kalbitz et al. (1999) e Luciani et al. $(2008,2009)$. As medidas foram feitas em um espectrômetro de luminescência Perkin Elmer modelo LS-50B pertencente à Embrapa Instrumentação. A abertura das fendas de entrada e de saída foi de $10 \mathrm{~nm}$ e a velocidade de varredura foi de 500 $\mathrm{nm} \min ^{-1}$.

Na metodologia proposta por Zsolnay et al. (1999), mediu-se o espectro de emissão com excitação em 240 nm, intervalo de varredura entre 300 e 700 nm e filtro de $290 \mathrm{~nm}$. A área sobre o maior quarto de emissão entre 570 e $641 \mathrm{~nm}\left(\mathrm{~A}_{4}\right)$, dividida pela área sobre o menor quarto entre 356 e $432 \mathrm{~nm}\left(A_{1}\right)$, denominado $A_{4} / A_{1}$, foi utilizada como índice de humificação.

$\mathrm{Na}$ metodologia proposta por Milori et al. (2002), mediu-se o espectro de emissão com excitação em 465 nm, intervalo de varredura entre 480 e 700 nm com filtro aberto. A determinação do índice de humificação foi baseada na área sob a curva de emissão com excitação em 465 nm ( $\left.A_{465}\right)$.

Na metodologia proposta por Kalbitz et al. (1999), foram obtidos espectros de varredura sincronizada entre 300 e 520 nm simultaneamente com excitação e emissão com filtro aberto, tomando como diferença constante de comprimento de onda $55 \mathrm{~nm}\left(\Delta \lambda=\lambda_{\text {em }}-\lambda_{\text {ex. }}\right)$. $\mathrm{O}$ índice de humificação $\left(\mathrm{I}_{468} / \mathrm{I}_{374}\right)$ foi determinado a partir da razão entre as intensidades de fluorescência em 400 e 360 nm ou 470 e 
$360 \mathrm{~nm}$, respectivamente.

Os espectros de fluorescência no modo excitação-emissão (MEE) foram adquiridos no intervalo de varredura entre 240 a 700 nm para emissão e 220 a 510 $\mathrm{nm}$ para excitação. Foram obtidos com filtro de $290 \mathrm{~nm}$, com um incremento de excitação de $10 \mathrm{~nm}$ totalizando 30 varreduras.

\subsubsection{ESPECTROSCOPIA DE FLUORESCÊNCIA INDUZIDA POR LASER (FIL)}

A avaliação do grau de humificação da MOS foi realizada através da espectroscopia de FIL. Os espectros de emissão de FIL foram obtidos a partir de amostras de solo secas à temperatura ambiente, moídas e peneiradas em peneira com abertura de malha de 100 mesh (TFSA). Após isto, cerca de 0,5 g de cada amostra foram submetidas a 10 ton de pressão durante 2 minutos para formar pastilhas, resultantes da prensagem em moldes de aço $(1 \mathrm{~cm}$ de diâmetro e $2 \mathrm{~mm}$ de espessura). Para cada amostra de solo foram preparadas duas pastilhas. A utilização de pastilhas de solo é devido à sua fácil manipulação em laboratório e a superfície plana das suas faces, ideal para a análise de FIL.

As medidas foram feitas em triplicata para as amostras pastilhadas de solo inteiro (solo não submetido a tratamento químico ou físico), utilizando-se o espectrômetro FIL portátil (descrito no item 3.6.2.3). Os parâmetros adotados nas análises foram:

- Intervalo de varredura entre 475 e $800 \mathrm{~nm}$;

- Tempo de integração: $30 \mathrm{~ms}$;

- Boxcar: 4;

- Average: 5.

\subsubsection{ESPECTROMETRIA DE EMISSÃO ÓTICA COM PLASMA ACOPLADO INDUTIVAMENTE (ICP OES)}

\subsubsection{REAGENTES, MATERIAIS E SOLUÇÕES UTILIZADOS NO PROCEDIMENTO DE DECOMPOSIÇÃO DAS AMOSTRAS DE SOLO PARA MEDIDA DE ICP OES}

Todas as soluções utilizadas foram empregadas utilizando reagentes de grau 
analítico e água desionizada purificada em sistema MILLI-Q (resistividade 18,2 $\mathrm{M} \Omega \mathrm{cm})$.

Para a decomposição das amostras de solos foram utilizados os seguintes reagentes: $\mathrm{HNO}_{3} 65 \% \mathrm{v} \mathrm{v}^{-1}$ e $\mathrm{HCl} 36 \% \mathrm{v} \mathrm{v}^{-1}$. As soluções de referência para obtenção das curvas analíticas foram preparadas após diluição adequada de soluções estoque contendo $1000 \mathrm{mg} \mathrm{L}^{-1}$ de $\mathrm{Cu}$, Fe, Ca, Mg, Al, S, Na, K e P (Padrões rastreados pelo NIST). As soluções dos analitos na concentração de:

$\rightarrow \mathrm{Fe}$ e $\mathrm{Al}=0 ; 2 ; 4 ; 6 ; 8 ; 10$ e $20 \mathrm{mg} \mathrm{L}^{-1}$;

A solução de água régia utilizada na decomposição das amostras de solo foi preparada a partir de $1 \mathrm{HNO}_{3}: 3 \mathrm{HCl}\left(\mathrm{v} \mathrm{v}^{-1}\right)$.

\subsubsection{PROCEDIMENTOS DE DECOMPOSIÇÃO: DIGESTÃO DA AMOSTRA}

Foram transferidos para um ernlenmeyer $20 \mathrm{~mL}$ de água régia $\left(1 \mathrm{HNO}_{3}: 3 \mathrm{HCl}\right)$ e $1 \mathrm{~g}$ de amostra de solo, cobriu-se com um becker e aqueceu-se suavemente (temperatura em torno de $110^{\circ} \mathrm{C}-120{ }^{\circ} \mathrm{C}$ ) até cessar o desprendimento de vapores castanhos (nitroso) e a solução clarear. A seguir, adicionou-se $30 \mathrm{~mL}$ de água desionizada (Milli-Q) e ferveu-se por 5 minutos (ajudou no desprendimento dos vapores finais).

Após resfriamento, adicionou-se um pouco de água Milli-Q ao erlenmeyer, transferindo a solução resultante para um balão volumétrico de $50 \mathrm{~mL}$, completando o volume com água Milli-Q e homogeneizou-se. A seguir, efetuou-se uma filtração por gravidade, transferindo o filtrado límpido para frascos graduados (tubos tipo Falcon), suficiente para a determinação.

\subsubsection{INSTRUMENTAÇÃO}

A quantificação dos teores totais de Fe e Al foram feitas com o auxílio do espectrômetro de emissão ótica com plasma acoplado indutivamente (ICP OES) com configuração radial (VISTA PRO-CCD, Varian, Mulgrave, Austrália). Os parâmetros instrumentais e os comprimentos de onda selecionados para os elementos Fe e Al estão descritos na Tabela 4.5. 
Tabela 4.5 - Parâmetros operacionais utilizados na análise por ICP OES.

\begin{tabular}{cc}
\hline Parâmetros instrumentais & ICP OES (Visão Radial) \\
\hline Potência da rádio freqüência $(\mathrm{KW})$ & 1,3 \\
Vazão do gás do plasma $\left(\mathrm{L} \mathrm{min}^{-1}\right)$ & 15 \\
Vazão do gás de nebulização $\left(\mathrm{L} \mathrm{min}^{-1}\right)$ & 0,6 \\
Vazão do gás auxiliar $\left(\mathrm{L} \mathrm{m \textrm {m } ^ { - 1 }}\right)$ & 1,5 \\
Nebulizador & V-Groove \\
Câmara de nebulização & Sturman-Masters \\
Detector & Dispositivo de carga acoplada $(\mathrm{CCD})$ \\
Sistema de difração & Policromador Littrow com grade Echelle \\
Altura de observação $(\mathrm{mm})$ & Variável (de 4 a 20) \\
Comprimento de onda $(\mathrm{nm})$ & Fe $(\lambda=259,940 \mathrm{~nm})$ \\
& $\mathrm{Al}(\lambda=237,12 \mathrm{~nm})$ \\
\hline
\end{tabular}

\subsubsection{ESPECTROSCOPIA DE EMISSÃO ÓTICA COM PLASMA INDUZIDO POR} LASER (LIBS)

Para a análise por espectroscopia de LIBS, foram utilizadas as mesmas amostras pastilhadas de solo inteiro (descrito no item 4.6.3). Os espectros de emissão das amostras foram obtidos utilizando um sistema LIBS de bancada da "Ocean Optics", modelo LIBS 2500 plus (Figura 4.6), pertencente à Embrapa Instrumentação.

Figura 4.4 - Sistema LIBS de bancada da Ocean Optics, modelo LIBS 2500 plus: (1) fonte de energia; (2) laser; (3) câmara de ablação; (4) conjunto de espectrômetros.

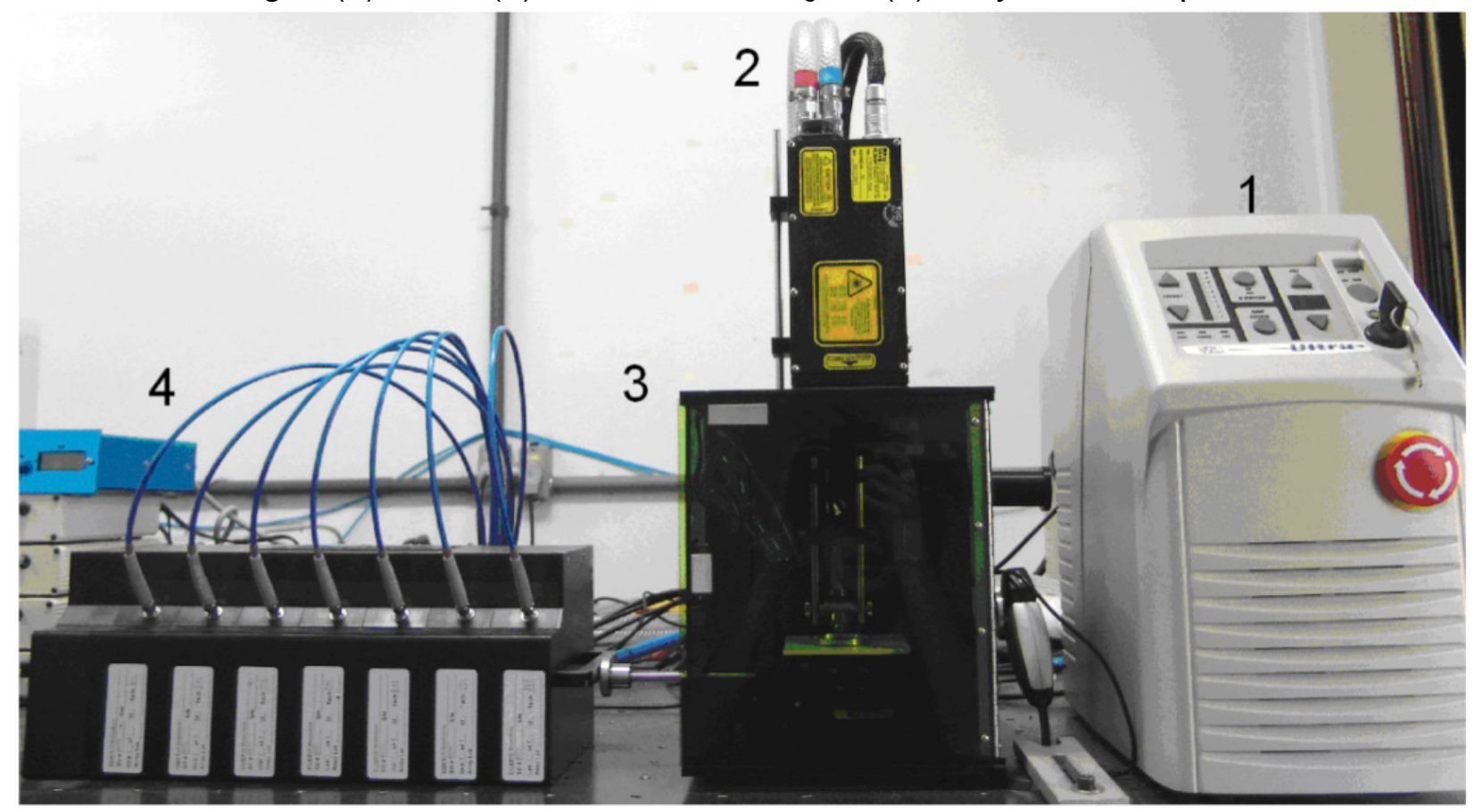

Fonte: Silva (2008). 
O sistema é equipado com um laser de Nd:YAG pulsado (Q-switched) emitindo em $1064 \mathrm{~nm}$ com energia máxima do pulso de $75 \mathrm{~mJ}$, duração de pulso de $8 \mathrm{~ns}$, tempo de integração de 2,1 ms, diâmetro do feixe do laser (laser spot) em torno de 0,5 mm, taxa de repetição de até $500 \mathrm{~Hz}$; detector CCD (charge-coupled device) de 14336 pixels; sete espectrômetros cobrindo a faixa espectral de 190-980 $\mathrm{nm}$ e com resolução ótica em torno de $0,1 \mathrm{~nm}$. Para cada amostra foram feitas 60 medidas, cada uma dessas em área diferente da pastilha, sendo que cada uma corresponde ao acúmulo de 1 tiro de limpeza e 2 tiros para aquisição (Da Silva et al., 2008).

Para a quantificação elementar a partir de um espectro de LIBS é necessário escolher as linhas de emissão adequada. As linhas de emissão foram escolhidas de modo a evitar problemas com o limite de detecção do LIBS e a reabsorção da emissão. A fim de quantificar com precisão elementos em um espectro de LIBS, foi corrigido o offset subtraindo o efeito de radiação de fundo próximo à linha de emissão do elemento. Após a correção do offset, a relação sinal/ruído foi melhorada pela média dos 60 espectros. Devido à resolução do espectrômetro, a linha do $\mathrm{C}$ em 193,03 nm sofre interferência pelas linhas de Al pertencentes a um dubleto em 193,23 nm e 193,47 nm. A fim de se obter apenas a contribuição do C, uma deconvolução foi realizada no espectro médio de cada amostra para permitir a separação dos picos, obtendo-se assim a área de emissão de cada pico. O mesmo tratamento foi feito com as linhas de Al em 199,01 nm, mas para o $\mathrm{Fe}$ não foi possível observar linhas no espectro LIBS das pastilhas, provavelmente devido a sua concentração estar abaixo do limite de detecção ótica. 


\section{RESULTADOS E DISCUSSÃO}

\subsection{ANÁLISE ELEMENTAR (CHNS)}

O método analítico de combustão a seco (análise elementar) tem sido bastante usado em estudos de determinação de carbono do solo, visto que sua combustão à temperatura de aproximadamente $925{ }^{\circ} \mathrm{C}$ oxida todo o carbono das amostras, tanto as formas orgânicas quanto as inorgânicas, sendo, portanto, considerado como método padrão de referência (Mc Carthy et al., 2010).

Os valores obtidos dos teores de carbono pela análise elementar são apresentados na Tabela 5.1 e Figura 5.1. O resultado final foi calculado a partir da média aritmética de experimentos feitos em triplicata.

Tabela 5.1 - Teores de carbono das amostras de solo inteiro dos Perfis P1 (Espodossolo Humilúvico) e P2 (Latossolo Amarelo) obtidos pelo método de Análise Elementar.

\begin{tabular}{cccc}
\hline Amostras $^{(1)}$ & $\begin{array}{c}\text { Horizonte/ } \\
\text { Camada }\end{array}$ & $\begin{array}{c}\text { Profundidade } \\
\text { (cm) }\end{array}$ & Teor de Carbono \% \\
\hline EH & $\mathrm{A} 1$ & $0-5$ & $3,00 \pm 0,10$ \\
EH & $\mathrm{A} 2$ & $5-30$ & $0,77 \pm 0,10$ \\
EH & $\mathrm{E} 1$ & $30-180$ & $<$ LOD \\
EH & $\mathrm{E} 2$ & $180-202,5$ & $<\mathrm{LOD}$ \\
EH & $\mathrm{Bh}$ & $202,5-204$ & $0,38 \pm 0,07$ \\
EH & Bhs & $204-214$ & $0,33 \pm 0,06$ \\
EH & Transição & $214-245$ & $3,21 \pm 0,01$ \\
EH & $\mathrm{K} 1$ & $245-290$ & $0,73 \pm 0,07$ \\
EH & $\mathrm{K} 2$ & $290+$ & $<$ LOD \\
\hline & & & \\
LA & $\mathrm{A} 2$ & $10-20$ & $0,95 \pm 0,02$ \\
LA & $\mathrm{BA}$ & $20-30$ & $0,62 \pm 0,07$ \\
LA & Bw1 & $30-60$ & $<$ LOD \\
LA & Bw2 & $60-90$ & $<$ LOD \\
LA & Bw3 & $90-120$ & $<$ LOD \\
LA & Transição & $120-210$ & $<$ LOD \\
LA & Kn1 & $210-250$ & $<$ LOD \\
LA & Kn3 & $320-380$ & $<$ LOD \\
LA & Kn4 & $380+$ & $<$ LOD \\
\hline
\end{tabular}

${ }^{(1)} \mathrm{EH}$ : Espodossolo Humilúvico; LA: Latossolo Amarelo.

< LOD (limite de detecção): abaixo do limite de deteç̧ão do analisador elementar (CHNS). 
Como pode ser observado na Tabela 5.1 o teor de carbono das amostras dos horizontes álbicos E1 e E2 do Espodossolo Humilúvico é inferior a 0,3\%, o limite de detecção do CHNS. O horizonte superficial A1 do Espodossolo Humilúvico apresentou alto teor de carbono. Conforme Tabela 5.1 e Figura 5.1 (a), nota-se uma diminuição nos teores de carbono dos horizontes superficiais orgânicos (A1 e A2) até os horizontes espódicos (Bh e Bhs). Neste perfil, observa-se que a MO produzida na superfície está sendo transferida, dos horizontes superiores, acumulando-se na transição ( $\mathrm{Tr}$ ) entre os horizontes arenosos (Bh e Bhs) e o caulim (K1 e K2), numa profundidade que varia de 1 a 3 metros. Desta forma, justifica-se o alto teor de carbono e $\mathrm{MO}$ encontrado no horizonte transição.

A textura do solo influencia bastante na retenção da matéria orgânica pela formação de complexos organominerais favorecidos por compostos humificados (Sato, 2013).

A partir dos resultados obtidos para os teores de carbono do Espodossolo Humilúvico, observa-se que o maior conteúdo de argila no horizonte de transição (50,95\%) (Tabela 3.1) pode favorecer a estabilidade da MO pela formação de complexos organominerais (Canellas et al., 2001), pois a MOS é degradada predominantemente na superfície e se desloca em profundidade, acumulando-se no horizonte Tr, com isso o teor maior de carbono orgânico foi observado através da análise elementar para esse horizonte, se comparado aos demais horizontes que apresenta textura arenosa (Tabela 3.1 e Figura 5.1 (a)).

Esses resultados corroboram com os estudos desenvolvidos por Bardy et al. (2008), que trouxe grande contribuição em relação à caracterização da matéria orgânica dos horizontes dos Espodossolos. Segundo os autores os poros, que aumentam com a perda dos minerais de argila, permitem a mobilização e o fracionamento da matéria orgânica durante sua acumulação nos Espodossolos, conforme observado nos resultados citados anteriormente, onde o carbono se desloca ao longo do perfil dos horizontes superficiais arenosos, acumulando-se na transição (Tr), entre os horizontes arenosos espódicos (Bh e Bhs) e o caulim (K1 e $\mathrm{K} 2)$.

Como pode ser observado na Tabela 5.1, para a maioria das amostras de solo inteiro do Latossolo Amarelo o teor de carbono é inferior a 0,3\%, o limite de detecção do CHNS. Não se pode inferir uma tendência de incremento ou decréscimo do teor de carbono em profundidade para este solo, pois o teor de carbono para as 
amostras dos horizontes intermediários e profundos é inferior a 0,3\% (< o limite de detecção).

Figura 5.1 - Dados dos teores de carbono obtidos para todas as amostras de solo inteiro do Espodossolo Humilúvico (a) e Latossolo Amarelo (b), nos perfis de amostragem.
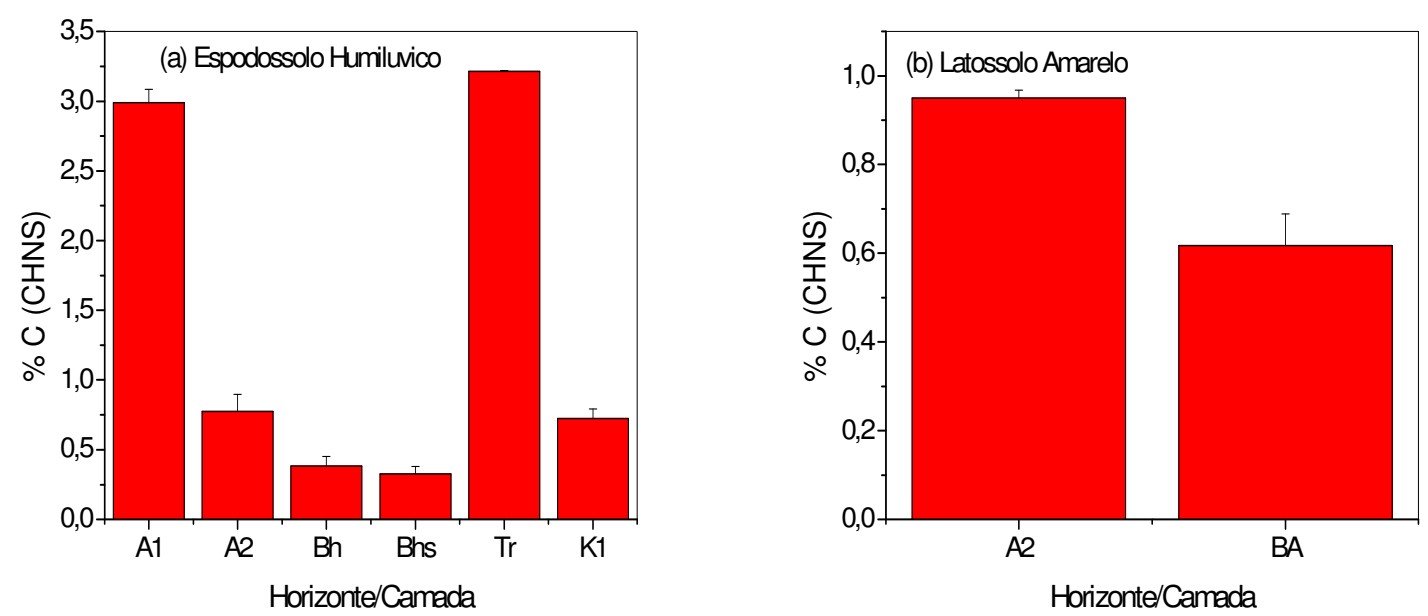

*Espodossolo Humiluvico: horizontes E1, E2 e K2 (teor de carbono < LOD).

*Latossolo Amarelo: horizonte Bw1, Bw2, Bw3, Tr, Kn1, Kn3 e Kn4 (teor de carbono < LOD).

Através dos resultados obtidos para os teores de carbono do Latossolo Amarelo (Tabela 5.1 e Figura 5.1 (b)), observou-se uma diminuição no teor de carbono do horizonte superficial A2 em relação ao BA, pois conforme observação de campo de Ishida (2010), estes horizontes são constantemente influenciados pela $\mathrm{MO}$, devido à presença na superfície do solo de uma serrapilheira constituída por manto de raízes e folhas, em decomposição, ocasionando esta diminuição, devido a degradação da MOS, corroborando com os resultados obtidos por (Santos, 2006; Carvalho et al., 2007).

\subsection{SUBSTÂNCIAS HÚMICAS EXTRAÍDAS DE SOLO}

A extração das SH é de grande importância para a obtenção de resultados relevantes de caracterização, pois nesta etapa podem ocorrer alterações estruturais nas $\mathrm{SH}$.

Foram submetidos ao fracionamento químico das SH cerca de 300 a $400 \mathrm{~g}$ de solo das amostras de solos arenosos (Espodossolo Humilúvico e Latossolo 
Amarelo), obtendo-se assim uma quantidade de amostra de $\mathrm{AH}$ significativa para os horizontes A1, A2, Bh e Bhs (Espodossolo Humilúvico) e quantidades inferiores à 6 mg para os horizontes $\mathrm{Tr}$, K1 e K2. Na Figura 5.2 ( $\mathrm{a}$, b e c) observa-se quantidades mais representativas de $\mathrm{AH}$ precipitado para os horizontes $\mathrm{A} 1, \mathrm{~A} 2$ e Bhs e quantidades muito pequenas de $\mathrm{AH}$ principalmente para os horizontes $\mathrm{Tr}$ e K1. Para os horizontes álbicos E1 e E2 do Espodossolo Humilúvico, não foram possíveis à obtenção de $\mathrm{AH}$.

Para o Latossolo Amarelo obteve-se $\mathrm{AH}$ apenas para os horizontes superficiais A2 e BA, não sendo possível extrair os AH para os demais horizontes. Observa-se na Figura 5.3 (a) pouca quantidade de fração de AH precipitada após acidificação com HCl $6 \mathrm{~mol} \mathrm{~L}^{-1}$, notando-se o mesmo na Figura 5.3 (b), pouca quantidade de $\mathrm{AH}$ precipitado nos tubos após centrifugação.

Figura 5.2 - Foto ilustrativa do fracionamento químico das SH para o Espodossolo Humilúvico. (a) e (b) Fração ácido húmico como precipitado (FAH) + Fração ácido fúlvico (FAF) como sobrenadante obtidos para os horizontes A1, A2, Bh, Bhs, Tr e K1, respectivamente; (c) Amostras obtidas após centrifugação (AH precipitado nos tubos).
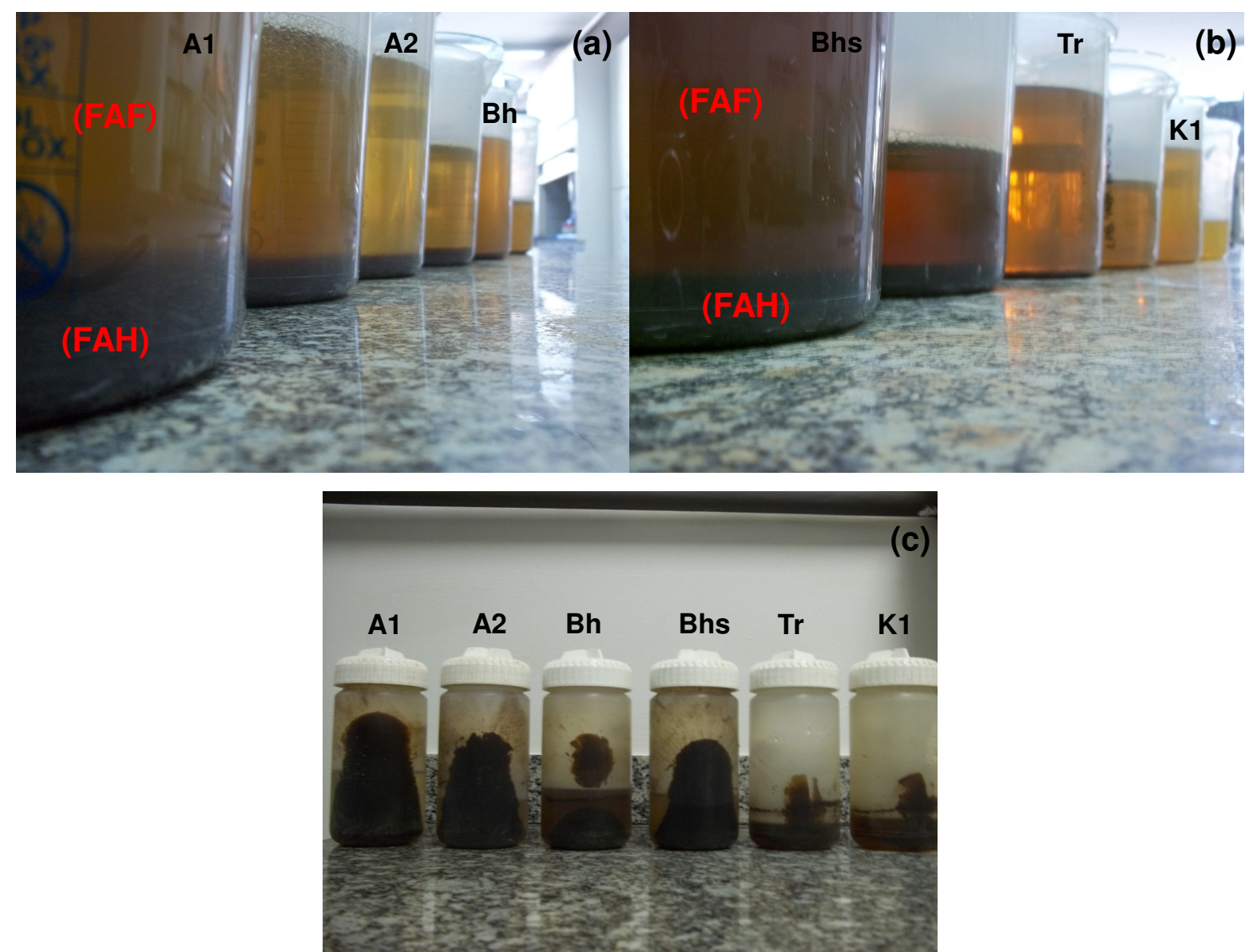
Figura 5.3 - Foto ilustrativa do fracionamento químico das SH para o Latossolo Amarelo. (a) FAH como precipitado + FAF como sobrenadante, obtidos para os horizontes A2 e BA; (b) Amostras obtidas após centrifugação (AH precipitado nos tubos).

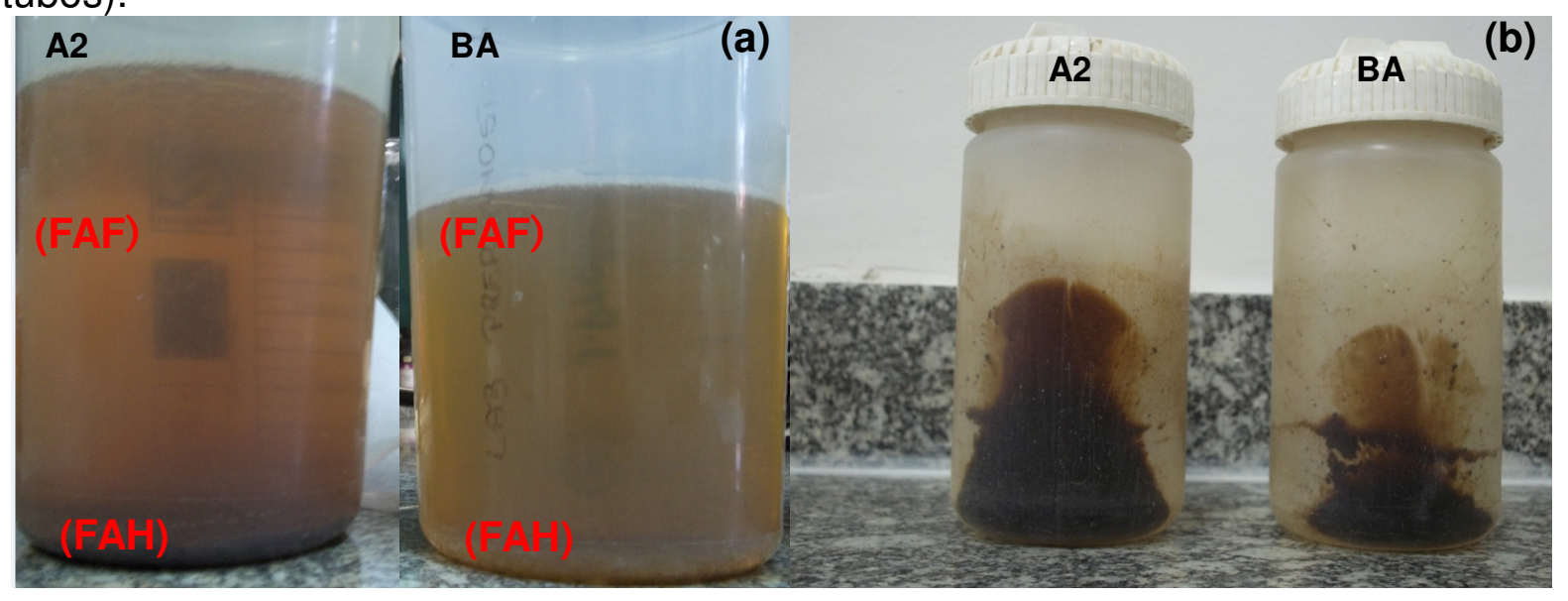

Os valores dos rendimentos obtidos no fracionamento químico dos $\mathrm{AH}$ dos solos arenosos são apresentados na Tabela 5.2.

Tabela 5.2 - Valores dos rendimentos do fracionamento químico obtidos para as amostras de AH extraídos do Espodossolo Humilúvico e Latossolo Amarelo, nos perfis de amostragem.

\begin{tabular}{ccccc}
\hline Amostras $^{(1)}$ & Horizonte/Camada & $\begin{array}{c}\text { Massa inicial } \\
\text { de solo }(\mathbf{g})\end{array}$ & $\begin{array}{c}\text { Massa final de } \\
\mathbf{A H}(\mathbf{g})\end{array}$ & $\begin{array}{c}\text { Rendimentos } \\
(\%)\end{array}$ \\
\hline $\mathrm{EH}$ & $\mathrm{F}$ & $350,02 \pm 0,01$ & $1,5608 \pm 0,0001$ & $0,450 \pm 0,010$ \\
$\mathrm{EH}$ & $\mathrm{A} 2$ & $350,04 \pm 0,01$ & $0,8768 \pm 0,0001$ & $0,250 \pm 0,010$ \\
$\mathrm{EH}$ & $\mathrm{Bh}$ & $300,03 \pm 0,01$ & $0,2863 \pm 0,0001$ & $0,100 \pm 0,010$ \\
$\mathrm{EH}$ & $\mathrm{Bhs}$ & $312,75 \pm 0,01$ & $0,9161 \pm 0,0001$ & $0,290 \pm 0,010$ \\
$\mathrm{EH}$ & $\mathrm{Tr}$ & $300,08 \pm 0,01$ & $0,0060 \pm 0,0001$ & $0,002 \pm 0,001$ \\
$\mathrm{EH}$ & $\mathrm{K} 1$ & $316,31 \pm 0,01$ & $0,0050 \pm 0,0001$ & $0,002 \pm 0,001$ \\
$\mathrm{EH}$ & $\mathrm{K} 2$ & $367,62 \pm 0,01$ & $0,0050 \pm 0,0001$ & $0,001 \pm 0,001$ \\
\hline & & & & \\
LA & $\mathrm{A} 2$ & $300,05 \pm 0,01$ & $0,5254 \pm 0,0001$ & $0,180 \pm 0,001$ \\
LA & $\mathrm{BA}$ & $361,32 \pm 0,01$ & $0,0935 \pm 0,0001$ & $0,026 \pm 0,001$ \\
\hline
\end{tabular}

${ }^{(1)}$ EH: Espodossolo Humilúvico; LA: Latossolo Amarelo.

Através da Tabela 5.2, observou-se um baixo rendimento no fracionamento químico para os $\mathrm{AH}$ extraídos do Espodossolo Humilúvico e Latossolo Amarelo. Deve-se ressaltar que estes resultados corroboram com os resultados das substâncias húmicas extraídas descritos anteriormente, obtendo-se quantidades significativas de $\mathrm{AH}$ para os horizontes A1, A2, Bh e Bhs (Espodossolo Humilúvico) e horizontes A2 e BA (Latossolo Amarelo). 
Estes resultados também corroboram com os resultados obtidos para o teor de carbono através do CHNS, não sendo possível a obtenção de $\mathrm{AH}$ para os horizontes intermediários e profundos do Latossolo Amarelo, pois para estes horizontes os teores de carbono foram inferiores a 0,3\%, o limite de detecção do CHNS. Para o Espodossolo Humilúvico, não foi possível a obtenção de AH para os horizontes álbicos (E1 e E2) e para o horizonte $\mathrm{K} 2$ à quantidade de $\mathrm{AH}$ obtida foi muito pequena, concordando com os resultados dos teores de carbono obtidos para estes horizontes, que ficaram abaixo do limite de detecção do CHNS.

\subsection{ESPECTROSCOPIA DE ABSORÇÃO DE RADIAÇÃO NO UV-VIS}

Experimentos de absorção de radiação no UV-Vis foram realizados, a fim de se efetuar as diluições necessárias dos $\mathrm{AH}$ e dos EAF2, conforme descrito no item 4.6.1, na seção de materiais e métodos.

Os espectros de absorção de radiação no UV-Vis na região de 200 a 800 nm dos $\mathrm{AH}$ extraídos dos solos (Espodossolo Humilúvico e Latossolo Amarelo) são apresentados na Figura 5.4.

Figura 5.4 - Espectros de absorção de radiação no UV-Vis obtidos para os $A H$ (concentração $10 \mathrm{mg} \mathrm{L}^{-1}, \mathrm{pH} 8,0$ ) do Espodossolo Humilúvico (a) e Latossolo Amarelo (b), nos perfis de amostragem.
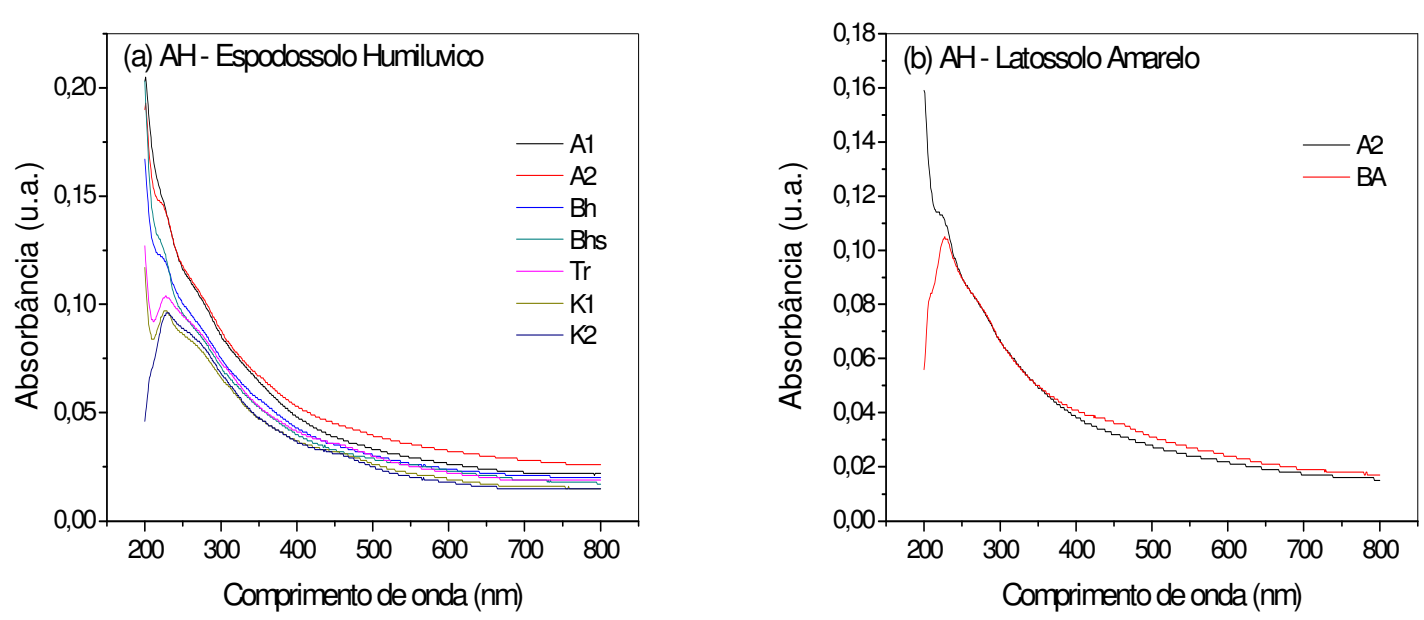

*Espodossolo Humiluvico: não foi possível a extração de AH dos horizontes álbicos (E1 e E2). *Latossolo Amarelo: não foi possível a extração de AH das camadas mais profundas.

Nos espectros de absorção de radiação no UV-Vis de $\mathrm{AH}$, a absorção diminui com comprimento de onda crescente e dá pouca informação estrutural (Figura 5.4). 
Com isso, nos espectros de UV-Vis dos $\mathrm{AH}$ estudados não se distingue nenhuma banda que possa ser atribuída a determinado cromóforo ou grupo principal, conforme também encontrado por Santos (2006).

Os espectros de absorção de radiação no UV-Vis na região de 200 a 800 nm dos EAF2 do Espodossolo Humilúvico e Latossolo Amarelo são apresentados na Figura 5.5. Os espectros de UV-Vis dos EAF2 apresentaram decréscimo linear na absorção com o aumento do comprimento de onda, mesma tendência observada nos espectros de UV-Vis dos AH. Além da absorção máxima, observou-se um ombro na região próxima de $280 \mathrm{~nm}$.

Figura 5.5 - Espectros de absorção de radiação no UV-Vis obtidos para os extratos de ácido fúlvico 2 (amostras diluídas, pH 8,0) do Espodossolo Humilúvico (a) e Latossolo Amarelo (b), nos perfis de amostragem.
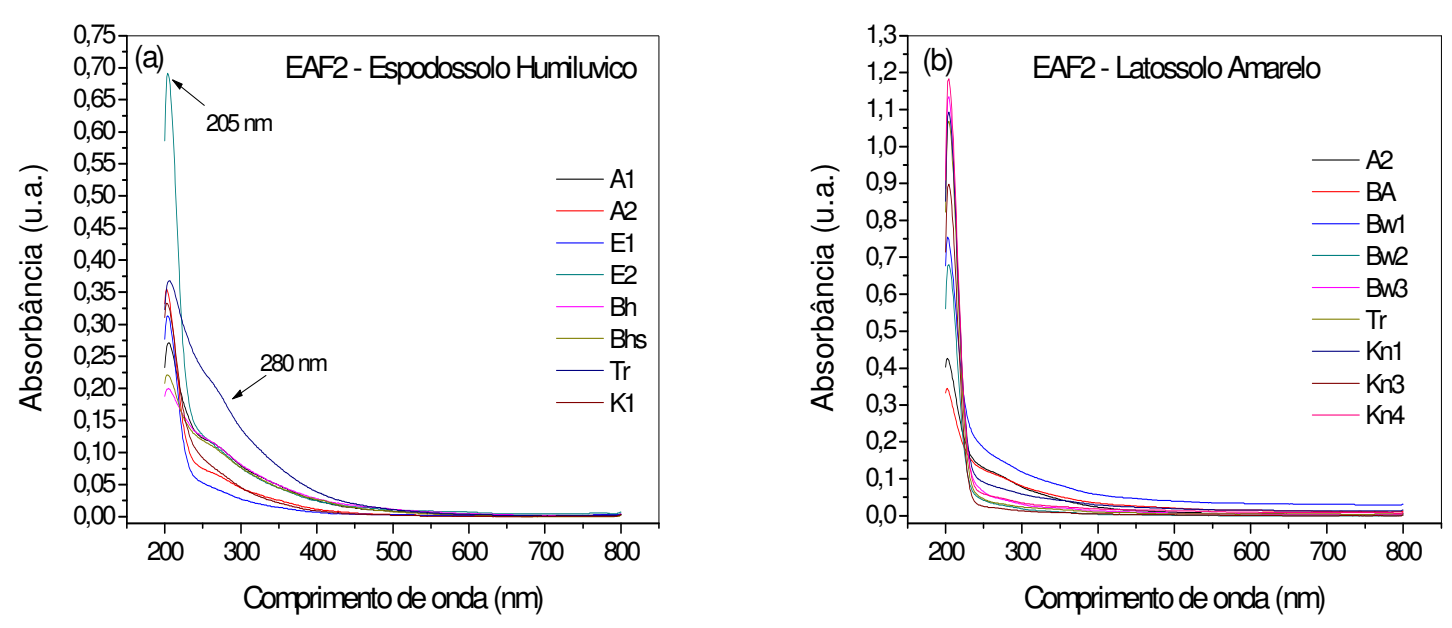

As mudanças mais evidentes da MOS, na região do UV-Vis, ocorreram na fração AF (Figura 5.5). A banda em 205 nm é característica de carbonilas (aldeídos, cetonas, ácidos carboxílicos e ésteres). O ombro em $280 \mathrm{~nm}$ é característico de grupos cromóforos, como estruturas insaturadas e/ou aromáticas (fenóis), muito típico de $\mathrm{SH}$.

Os espectros de absorção de radiação no UV-Vis dos AH e EAF2 (Figuras 5.4 e 5.5) também foram utilizados para efetuar todas as diluições necessárias, observando-se nos espectros que a absorção em $254 \mathrm{~nm}$ foi menor que 0,1 e 0,3, respectivamente, correção necessária para minimizar o efeito de reabsorção (mitigação do efeito de filtro interno).

Os espectros de fluorescência podem ser alterados devido à absorção de 
radiação pela amostra. Essa absorção, que depende da concentração da amostra, provoca a atenuação da intensidade, tanto da radiação que incide nos fluoróforos como da radiação emitida pelos mesmos, e pode provocar distorções espectrais. Por exemplo, a radiação (fluorescência) emitida a baixos comprimentos de onda poderá estar sujeita a uma maior atenuação do que a que é emitida a maiores comprimentos de onda, uma vez que a amostra absorve mais a comprimento de onda menores, e daí resulta uma distorção do espectro. Este efeito é chamado de "efeito de filtro interno" (Inner Filter Effect) (Lakowicz, 1983; Rocha, 2007).

$O$ efeito de filtro interno depende da capacidade das amostras para absorver radiação e dado que estas nem sempre têm a mesma absortividade, uma mesma concentração em diferentes amostras irá provocar uma atenuação da radiação diferente. Assim sendo, para uma comparação das intensidades de fluorescência de bandas em espectros de diversas amostras é necessário que estes efeitos sejam minimizados ou corrigidos de modo a que as interpretações sejam efetuadas de um modo correto (Ohno; Bro, 2006; Rocha, 2007; Luciani et al., 2008; Borisover et al., 2009; Ma et al., 2010; Richard et al., 2011).

A intensidade de fluorescência é proporcional à concentração do fluoróforo em soluções muito diluídas (absorbância muito baixa). O efeito de filtro interno é consequência da (Rocha, 2007):

(a) Absorção de parte da radiação incidente por outros cromóforos que competem com o fluoróforo que está sendo analisado (efeito de filtro interno primário - Primary Inner Filter Effect);

(b) Reabsorção de parte da fluorescência emitida antes que esta deixe a cubeta (efeito de filtro interno secundário - Secondary Inner Filter Effect).

Existem dois métodos para minimizar ou corrigir os efeitos de filtro interno:

- Diluição da amostra (Yappert et al., 1989; Tucker et al., 1992; Kowalczuk et al., 2003; Baker et al., 2004; Hua et al., 2007);

- Correção matemática dos espectros (Holland et al., 1977; Tucker et al., 1992; Kubista et al., 1994; MacDonald et al., 1997; McKnight et al., 2001; Mendonça et al., 2004; Riesz et al., 2005).

O método empregado neste estudo foi o da "diluição da amostra", até apresentar uma absorção suficientemente baixa para não haver efeito de filtro interno. 
Observou-se nos espectros de absorção de radiação no UV-Vis dos $\mathrm{AH}$ e EAF2 (Figuras 5.4 e 5.5), depois de efetuadas todas as diluições necessárias, que a absorção em $254 \mathrm{~nm}$ foi menor que 0,1 e 0,3, reduzindo assim, a reabsorção de fluorescência que poderia interferir nas análises dos espectros obtidos no modo matriz excitação-emissão (MEE).

\subsection{ESPECTROSCOPIA DE FLUORESCÊNCIA DE LUZ UV-VISÍVEL}

Os espectros de fluorescência das $\mathrm{SH}$ são constituídos pela soma dos espectros dos diferentes tipos de fluoróforos, consequência da complexidade molecular e da heterogeneidade dessas substâncias (Narimoto, 2006; Fialho 2007). Desta forma, os espectros apresentam bandas que são avaliadas de acordo com suas intensidades e posição no espectro, ou seja, deslocamento para maiores ou menos comprimentos de onda (Miikki et al., 1997).

Nas substâncias húmicas, os grupos doadores de elétrons (hidroxil e metoxil) ligados a anel aromático aumentam a intensidade de fluorescência, provavelmente por aumentar a probabilidade de transição entre o estado excitado (singleto) e o estado fundamental (Senesi, 1990). Miano et al. (1990) verificaram, estudando polímeros sintéticos, que possuem estruturas semelhantes às $\mathrm{SH}$, a influência que determinados grupos provocam na fluorescência: $\mathrm{OH}, \mathrm{OCH}_{3}, \mathrm{OC}_{2} \mathrm{H}_{5}, \mathrm{NH}_{2}$, NHR e $\mathrm{NR}_{2}$ aumentam a intensidade de fluorescência deslocando o pico para $\lambda$ mais longos; $\mathrm{COOH}, \mathrm{COH}, \mathrm{COR}$ e COOR deslocam o pico para $\lambda$ mais longos diminuindo a intensidade de fluorescência; $\mathrm{NO}_{2}$ e $\mathrm{NO}$ deslocam muito $\circ \lambda$ para o vermelho com diminuição da intensidade de fluorescência.

\subsubsection{EXTRATO DE ÁCIDO FÚLVICO 2}

\subsubsection{ESPECTROS DE VARREDURA SINCRONIZADA $(\Delta \lambda=55 \mathrm{~nm})$}

Os espectros de varredura sincronizada provêm melhor resolução dos picos e seletividade dos sinais do que os espectros de excitação e emissão (Chen et al., 2003; Peuravuori et al., 1997; Senesi, 1990). Na metodologia proposta por Kalbitz et al. (1999), mediu-se o espectro de varredura sincronizada com diferença constante entre excitação e emissão $(\Delta \lambda=55 \mathrm{~nm})$, permitindo a avaliação do grau de 
humificação dos EAF2. Espectros típicos de $\mathrm{SH}$ em geral apresentam duas bandas com a intensidade máxima em torno de $360 \mathrm{~nm}$ e $465 \mathrm{~nm}$, além de um ombro em $470 \mathrm{~nm}$. Os pequenos deslocamentos destes máximos dependem principalmente da origem e concentração de núcleos aromáticos altamente substituídos e/ou sistemas conjugados insaturados capazes de exibir alto grau de ressonância. No presente estudo para os EAF2 foi possível à identificação de dois picos, um em torno de 450 $\mathrm{nm}$ e outro em $370 \mathrm{~nm}$, e com isso usar a razão $\mathrm{I}_{450} / \mathrm{I}_{370}$ como índice de humificação.

A Figura 5.6 apresenta os espectros de varredura sincronizada dos EAF2, com $\Delta \lambda=55 \mathrm{~nm}$. Apesar dos espectros apresentarem bandas largas, a banda de 440 a $480 \mathrm{~nm}$ é característica de compostos aromáticos policondensados ou aromáticos ligados a grupos funcionais do tipo hidroxil e metoxil (Senesi,1990; Miano et al., 1990; Chen et al., 2003). O pico em torno de $370 \mathrm{~nm}$ é mais característico de fluoróforos mais simples, com baixo nível de policondensação aromática e poucos cromóforos conjugados (Senesi et al., 1991; Valeur, 2001; Bertoncini et al., 2005).

Figura 5.6 - Espectros de varredura sincronizada de fluorescência obtidos para os EAF2 (amostras diluídas, pH 8,0) do Espodossolo Humilúvico (a) e Latossolo Amarelo (b), com comprimento de onda de emissão e excitação ( $\Delta \lambda=\lambda_{\mathrm{em}}-\lambda_{\mathrm{ex}}=55$ $\mathrm{nm})$, nos perfis de amostragem.
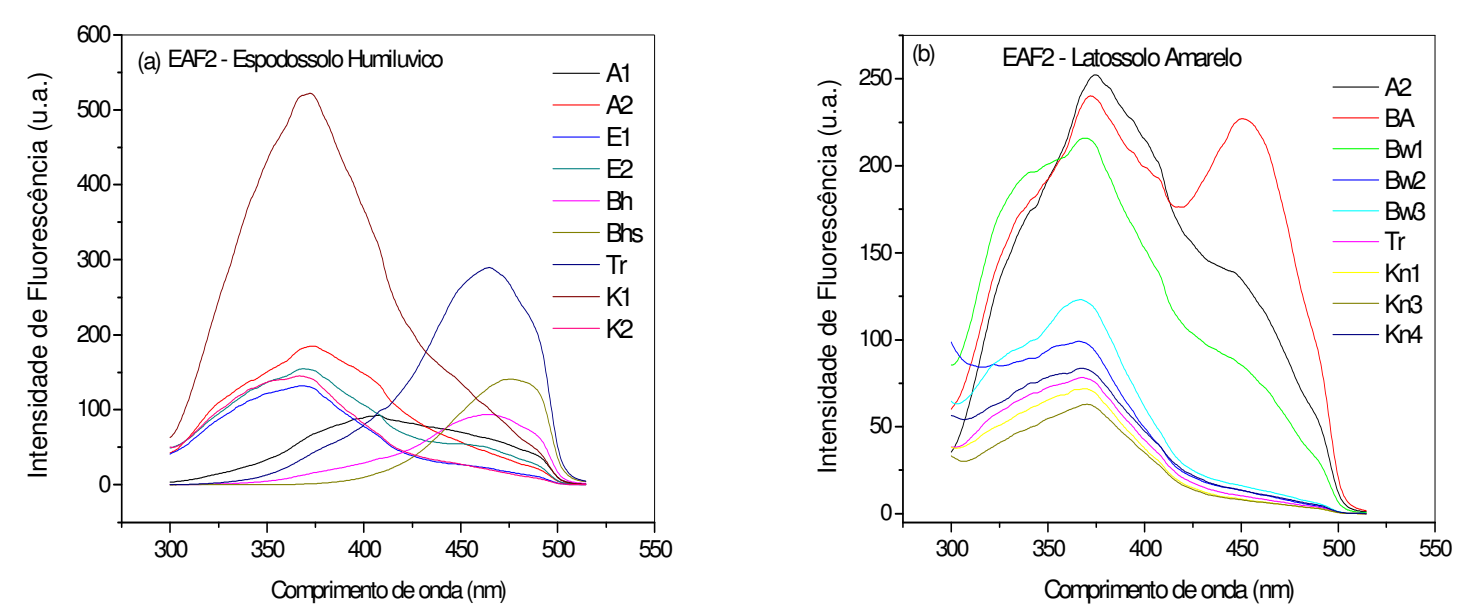

A partir dos resultados obtidos para o índice de humificação $I_{450} / I_{370}$ através da metodologia proposta por Kalbitz et al. (1999) para os EAF2 do Espodossolo Humilúvico (Figura 5.7 (a)), observamos ligeira diminuição no grau de humificação entre os horizontes superficiais orgânicos $A 1$ e A2, ocorrendo um aumento a partir dos horizontes espódicos (Bh e Bhs), mas aumentando de forma mais acentuada no 
horizonte $\operatorname{Tr}$, que é uma característica do processo de podzolização, processo pedogenético predominante neste tipo de solo, a MO é eluviada ao longo do perfil se acumulando no horizonte de transição (entre os horizontes espódicos e os de caulim). A presença de EAF2 com elevada humificação no horizonte de transição, indica que esta fração tem alta mobilidade no perfil do solo, sendo contrário com o modelo que moléculas humificadas possuem grande tamanho molecular.

Para o Latossolo Amarelo (Figura 5.7 (b)) observou-se um aumento no grau de humificação do horizonte superficial $\mathrm{A} 2$ para o BA, devido à degradação da $\mathrm{MO}$ relacionada aos ácidos fúlvicos derivados de resíduos de árvores das florestas (serrapilheira). A partir do horizonte Bw2 nota-se um comportamento praticamente uniforme, ressaltando que praticamente não se tem carbono nos perfis Bw2 para baixo (Tabela 5.1).

Figura 5.7 - Valores do índice de humificação $\left(\mathrm{I}_{450} / \mathrm{l}_{370}\right)$ obtidos para os EAF2 do Espodossolo Humilúvico (a) e Latossolo Amarelo (b) pela metodologia de Kalbitz et al. (1999), nos perfis de amostragem.
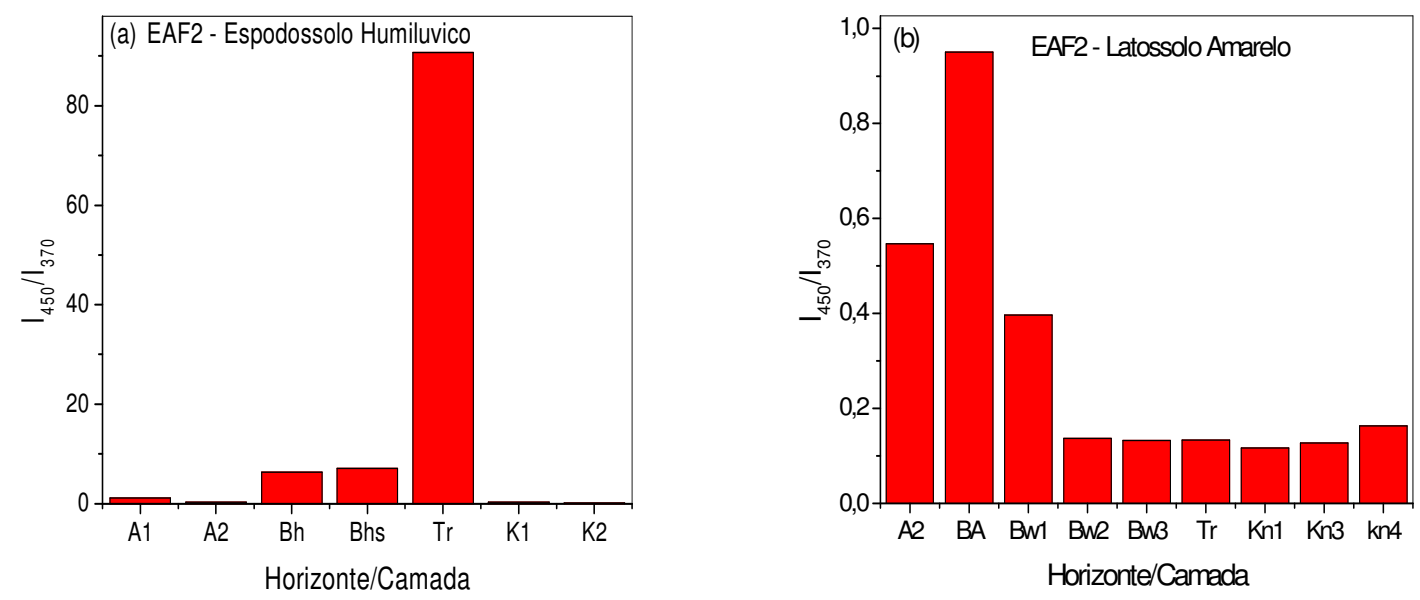

\subsubsection{ESPECTROS TRIDIMENSIONAIS DE FLUORESCÊNCIA - MATRIZ EXCITAÇÃO-EMISSÃO (MEE)}

Estudos associado aos dados espectrais obtidos de MEE podem ser analisados através: da localização de picos (Coble et al., 1998), de integração regional de parte da matriz (Chen et al., 2003), de ferramentas quimiométricas como análise de componentes principais (Boehme et al., 2004), por fatores paralelos / PARAFAC (Stedmon et al., 2003;. Yamashita; Jaffé, 2008; Kowalczuk et al., 2009) e 
de fatores paralelos associada a outras técnicas quimiométricas (Hall e Kenny, 2007). Dentre as formas citadas para a análise de dados obtidos pelas MEE a localização de picos pode ser considera a mais simples, por não necessitar de quase nenhum tratamento matemático posterior, o que é exigido através das outras análises.

Chen et al. (2003) consideram o espectro de MEE melhor para caracterizar as substâncias húmicas em relação aos espectros obtidos por fluorescência bidimensional, principalmente por ocorrer mudança da intensidade máxima de emissão com a variação do comprimento de onda de excitação. Os principais picos observados nos MEEs constam na Tabela 5.3 (Coble, 1996; Chen et al., 2003).

Tabela 5.3 - Principais picos encontrados nos espectros de MEE obtidos nos estudos das SHs.

\begin{tabular}{cccc}
\hline Pico & Características & $\boldsymbol{\lambda}_{\text {exc }}$ máximo & $\boldsymbol{\lambda}_{\text {em }}$ máximo \\
\hline A & Tipo ácido fúlvico & $250-260$ & $380-460$ \\
C & SHs provenientes de ambientes terrestres & $330-350$ & $420-480$ \\
& Tipo ácido húmico & $260-380$ & $>500$ \\
T & Semelhante à proteína (triptofano) & $270-280$ & $320-350$ \\
B & Semelhante à proteína (tirosina) & $270-280$ & $300-320$ \\
\hline
\end{tabular}
Fonte: Adaptado de Coble (1996) e Azevedo (2005).

Os espectros de fluorescência tridimensionais no modo MEE (ou curvas de nível) dos EAF2 estão representados nas Figuras 5.8 e 5.9. Todos foram obtidos a partir da dissolução de $42 \mathrm{mg}$ de $\mathrm{NaHCO}_{3}$ em $10 \mathrm{~mL}$ de EAF2 dialisado ajustando-se $\circ \mathrm{pH}$ para 8,0, o que confere um $\mathrm{pH}$ ótimo para as medidas de absorbância, conforme descrito no item 4.6.1 (materiais e métodos). Após o preparo das solubilizações e das diluições dos EAF2 (Tabelas 4.3 e 4.4), descritas no item 4.6.1.1 (materiais e métodos), os espectros de fluorescência adquiridos no modo MEE foram tratados pelo método do PARAFAC. 
Figura 5.8 - Espectros de fluorescência total no modo MEE (ou curvas de nível) obtidos para os EAF2 extraídos dos horizontes (a) A1, (b) A2, (c) E1, (d) E2, (e) Bh, (f) Bhs, (g) Tr, (h) K1 e (i) K2 do Espodossolo Humilúvico.

\section{Intensidade (u.a.)}

(a) A1

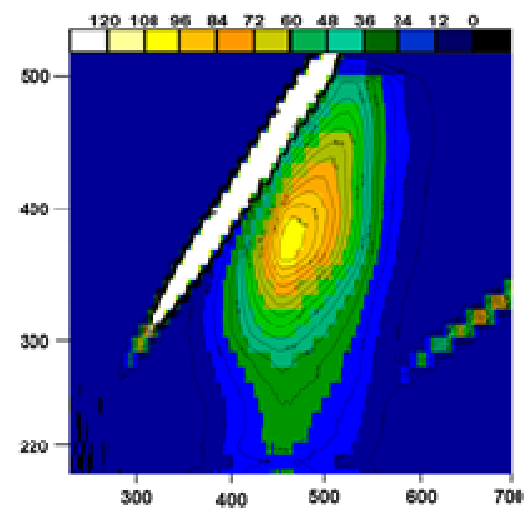

(d) E2

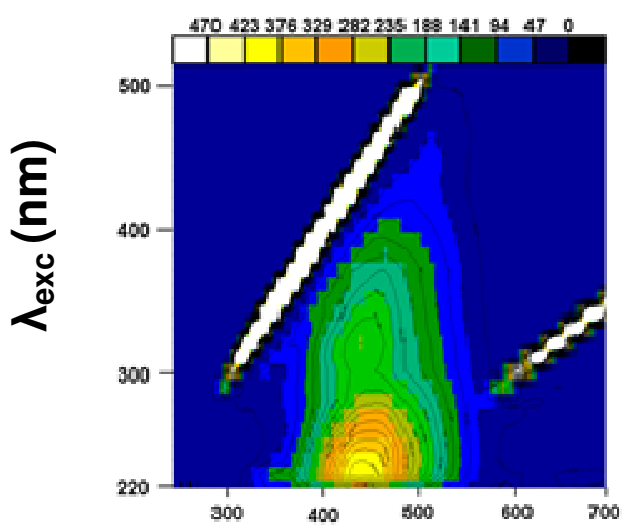

(g) $\operatorname{Tr}$

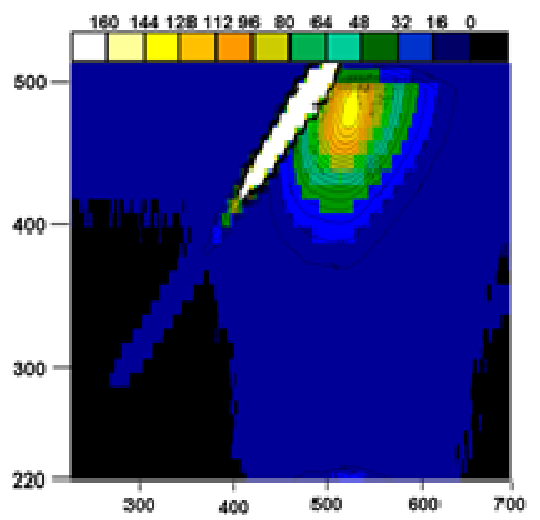

(b) A2

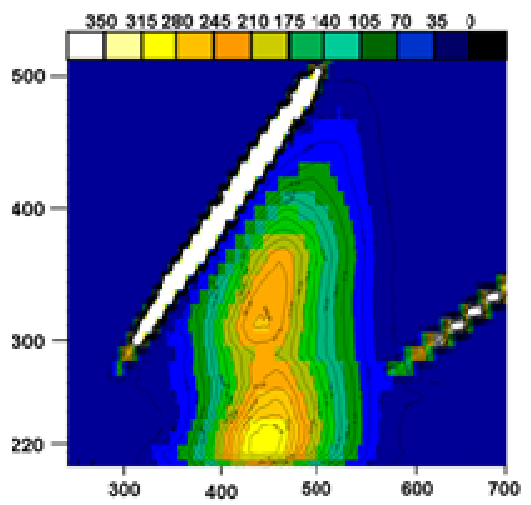

(e) $\mathrm{Bh}$

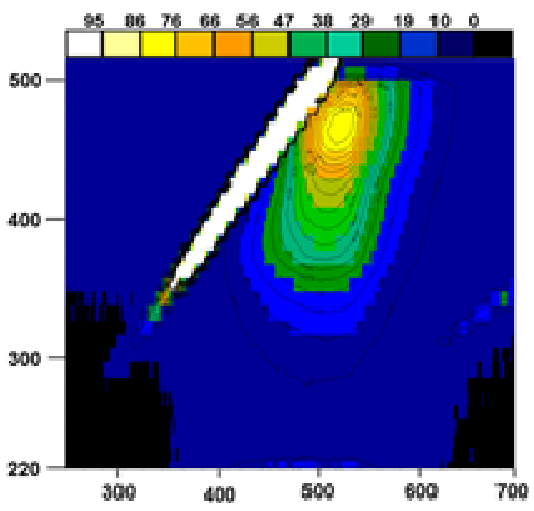

(h) K1

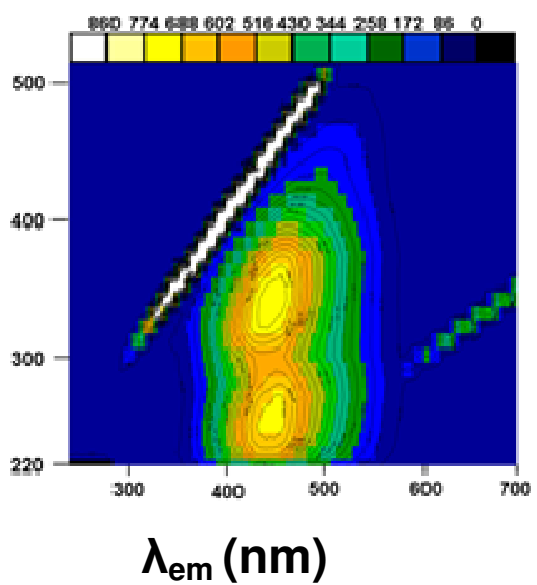

(c) E1

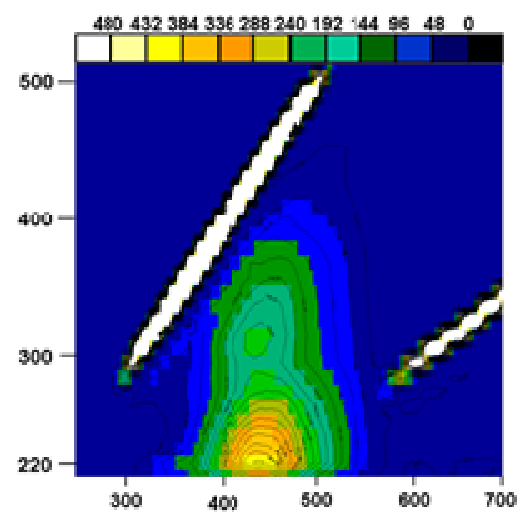

(f) Bhs

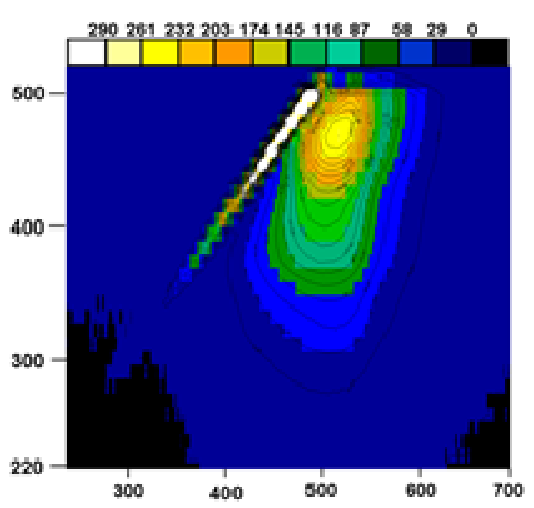

(i) $\mathrm{K} 2$

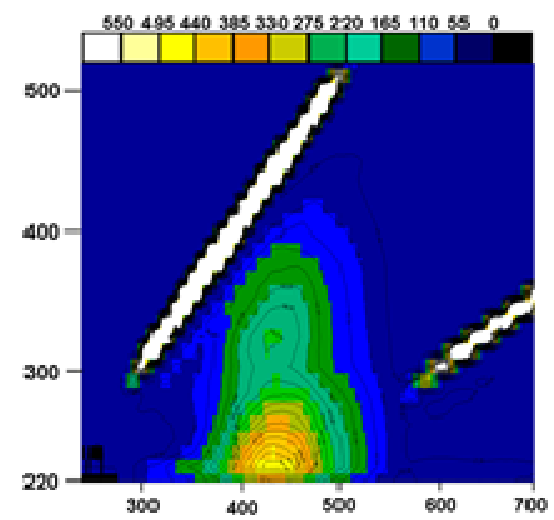


Figura 5.9 - Espectros de fluorescência total no modo MEE (ou curvas de nível) obtidos para os EAF2 extraídos dos horizontes (a) A2, (b) BA, (c) Bw1, (d) Bw2, (e) Bw3, (f) $\mathrm{Tr}$, (g) Kn1, (h) Kn3 e (i) Kn4 do Latossolo Amarelo.

\section{Intensidade (u.a.)}
(a) A2
(b) BA
(c) Bw1

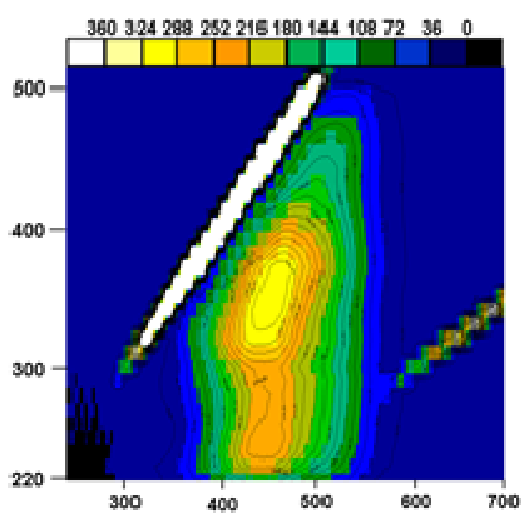

(d) Bw2

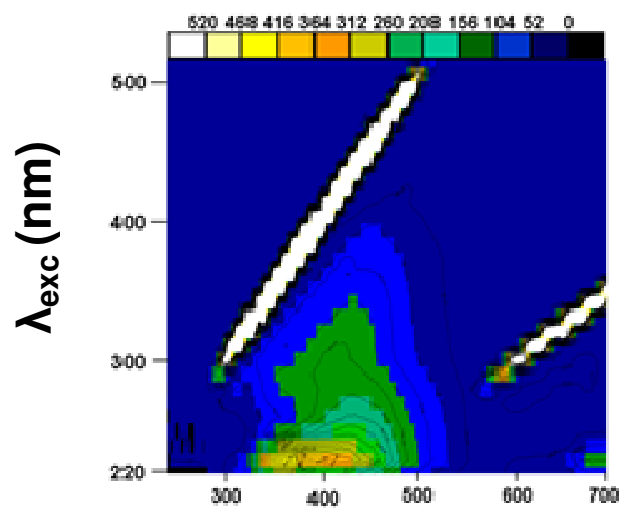

(g) Kn1

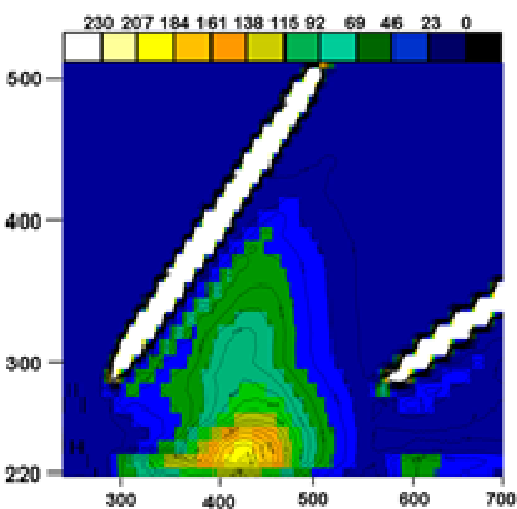

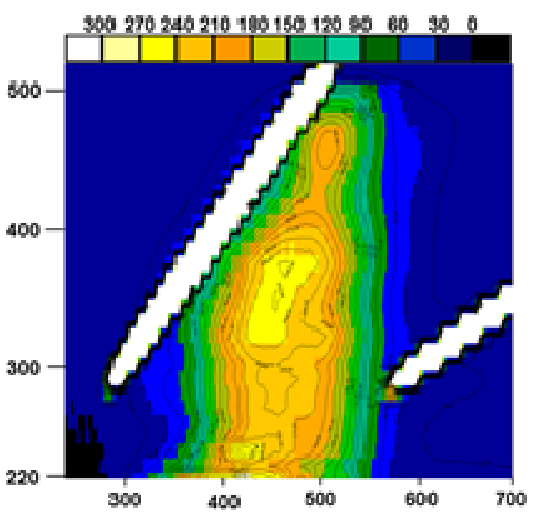

(e) Bw3

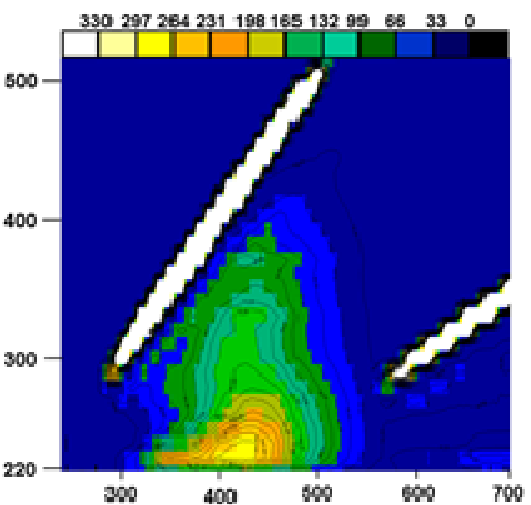

(h) Kn3
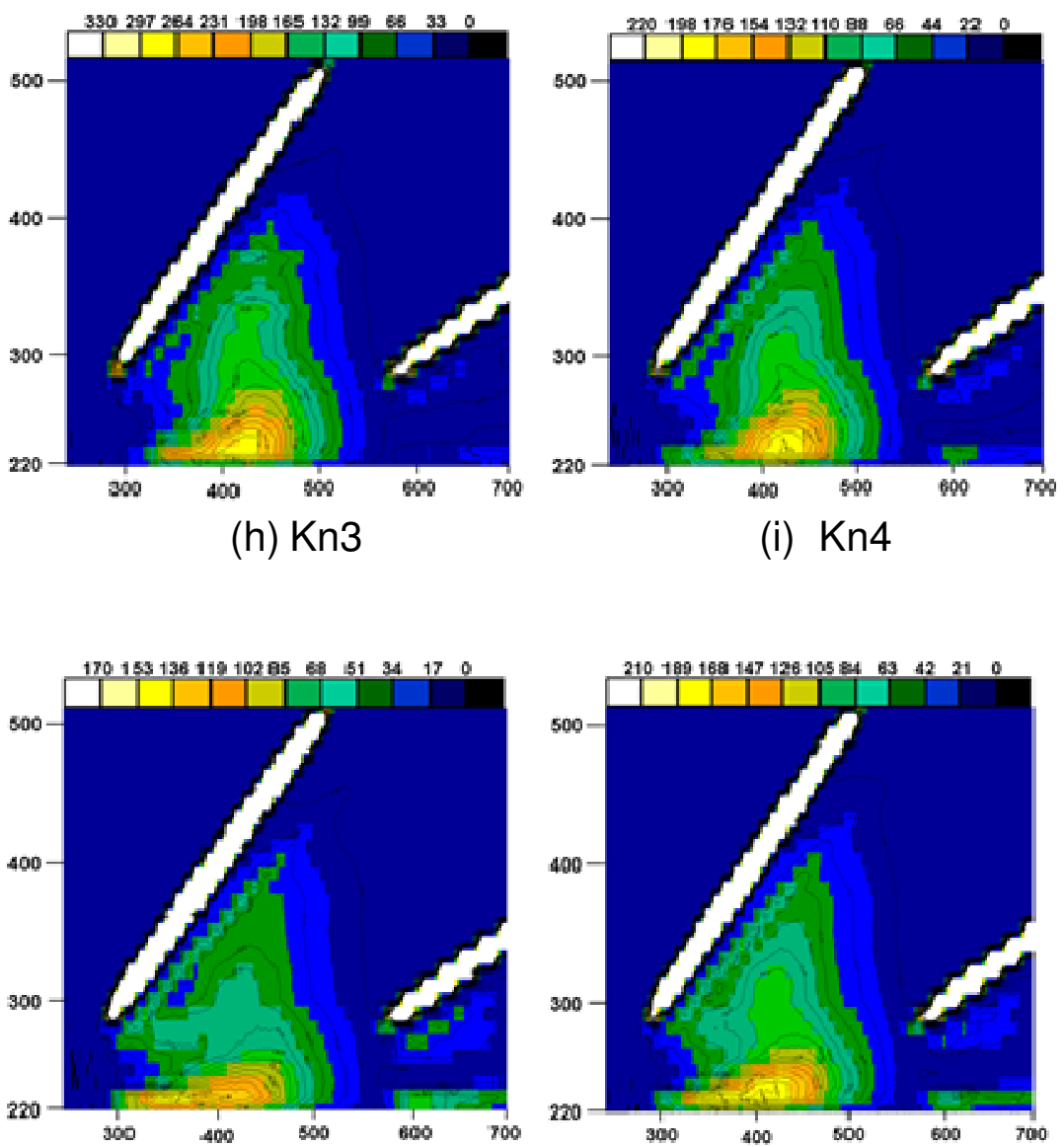

(i) $\mathrm{Kn} 4$

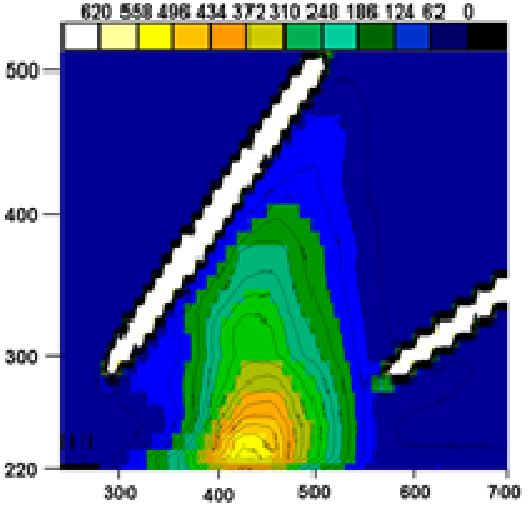

(f) $\mathrm{Tr}$

\section{$\lambda_{\mathrm{em}}(\mathrm{nm})$}


Os valores de intensidade de emissão de fluorescência seguem as escalas de cores colocadas acima das figuras e aparecem sob a forma de curvas de nível.

Ao analisar as Figuras 5.8 (Espodossolo Humilúvico) e 5.9 (Latossolo Amarelo), representando os espectros de curvas de nível dos EAF2 utilizando a localização de picos, foi possível observar a presença de três regiões características de fluorescência: o Pico C ( $\left.\lambda_{\text {exc }} / \lambda_{\text {em }} 350 / 450 \mathrm{~nm}\right)$ e Pico $A\left(\lambda_{\text {exc }} / \lambda_{\text {em }} 250 / 450 \mathrm{~nm}\right)$ (Coble, 1996), ambos podendo caracterizar a presença de SH provenientes de ambientes terrestres e uma região de menor intensidade associada aos picos semelhantes a proteínas $\left(\lambda_{\text {exc }} / \lambda_{\text {em }} 250 / 375 \mathrm{~nm}\right)$. Este pico está associado com substâncias como o triptofano (Coble, 1996).

Na Figura 5.8 (Espodossolo Humilúvico), foi possível observar ao analisar os espectros tridimensionais de fluorescência, que mudanças estruturais alteram tanto a intensidade quanto a posição de máximos dos espectros. Nos horizontes superficiais orgânicos (A1 e A2), álbicos (E1 e E2) e caulim (K1 e K2), nota-se que o deslocamento do pico para a região azul do espectro, ou seja, deslocado para menores comprimentos de onda, associada a compostos com estruturas mais simples, sugere que esse deslocamento pode ser originário da presença de moléculas com menor conteúdo aromático (Matthews et al., 1996), ou seja, com um menor grau de humificação. Pode-se associar a estes horizontes também os picos semelhantes à proteína do tipo triptofano que apresentam emissão próxima a 375 $\mathrm{nm}$ e, podem estar relacionados a dois fatores: 1) compostos de estrutura muito mais simples e mais lábeis ou 2) originários de compostos lábeis existentes nos aquíferos suspensos oriundos dos períodos chuvosos.

Para os horizontes espódicos (Bh e Bhs) e transição (Tr) (Figura 5.8), observa-se um deslocamento do pico para a região vermelha do espectro, ou seja, deslocado para maiores comprimentos de onda, associada a compostos com estruturas mais complexas, de conteúdo aromático, predominando estruturas mais humificadas, como núcleos aromáticos condensados e/ou substituídos.

Na Figura 5.9 (Latossolo Amarelo), ao analisar os espectros tridimensionais de fluorescência, foi possível observar as três regiões de fluorescência, o Pico A e C e uma região semelhante aos picos de proteínas do tipo triptofano (Coble, 1996). Para o horizonte A2 o deslocamento do pico para a região azul do espectro (menor comprimento de onda), pode ser associada a compostos com estruturas mais simples, menos humificados e menor conteúdo aromático. No horizonte BA, o 
deslocamento para o vermelho (maior comprimento de onda), são indicadores de fragmentos aromáticos mais conjugados, estruturas mais humificadas e complexas. Nestes horizontes também é possível observar picos semelhantes à proteína do tipo triptofano, que pode ser atribuído aos mesmos fatores das amostras do Espodossolo Humilúvico.

Para os horizontes intermediários (Bw1, Bw2, Bw3 e Tr) e profundos (Kn1, kn3 e Kn4), não se observou mudanças estruturais significativas, poucas variações espectrais ao longo do perfil, destacando-se o pico semelhante à proteína do tipo triptofano e o Pico A (Coble, 1996). Uma hipótese seria que estes horizontes, por se situarem abaixo do Espodossolo Humilúvico, podem ter sofrido influência dos períodos chuvosos devido à oscilação no nível dos aquíferos suspensos, e terem sido lavados, ou seja, a MO humificada oriunda das camadas superficiais estaria sendo lixiviada ao longo do perfil.

A análise quantitativa dos dados espectrais de fluorescência MEE pode ser melhorada através da aplicação de PARAFAC (Andersen; Bro, 2003; Stedmon et al., 2003). PARAFAC é uma técnica de análise multivariada utilizada para a decomposição de MEE complexos em componentes fluorescentes independentes que representam grupos de fluoróforos semelhantes (Ishii; Boyer, 2012).

Os espectros de fluorescência no modo matriz excitação-emissão (MEE) obtidos para os extratos de ácido fúlvico 2 do Espodossolo Humilúvico e Latossolo Amarelo, foram tratados pelo método matemático PARAFAC. Com o emprego deste método, foi possível identificar de modo qualitativo a presença de três fluoróforos (Figura 5.10), com diagnóstico de consistência do tensor núcleo (CORCONDIA) de $85,8 \%$. 
Figura 5.10 - Fluoróforos 1, 2 e 3 obtidos pelo método PARAFAC e descritivos da fluorescência tridimensional (MEE) dos EAF2 para o Espodossolo Humilúvico e Latossolo Amarelo.

Fluoróforo 1

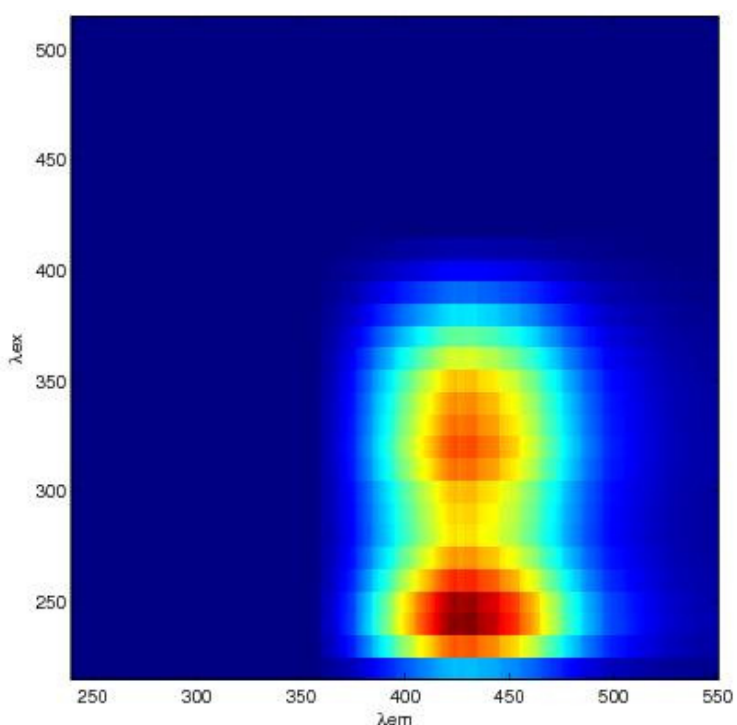

Fluoróforo 2

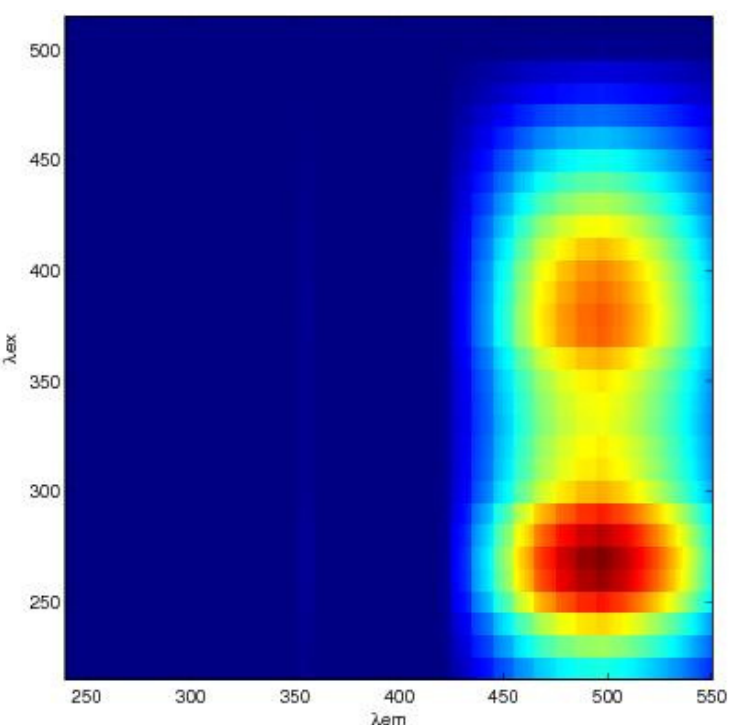

Fluoróforo 3

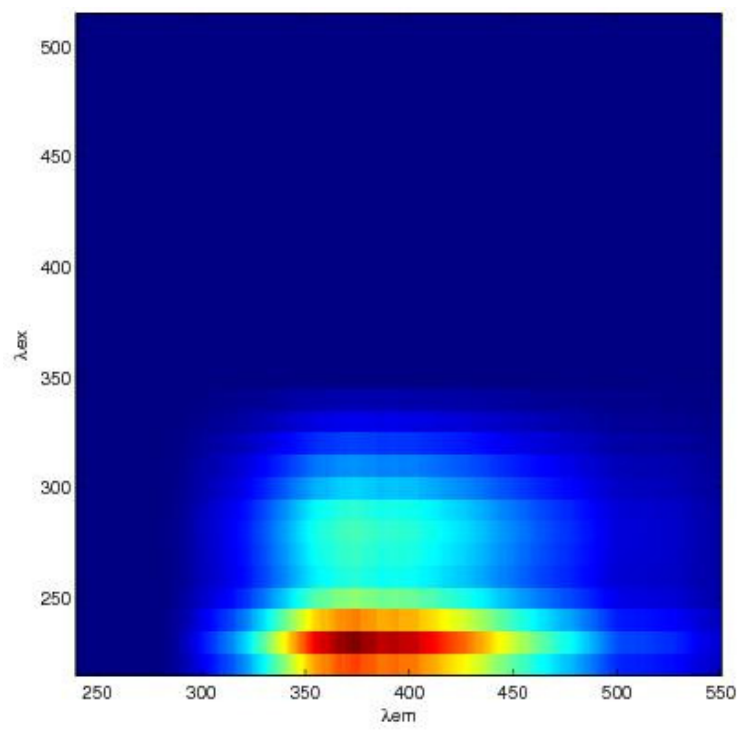

O fluoróforo 1 (255/380-460 nm) é típico das componentes do tipo A (Coble, 1996) e associadas aos ácidos fúlvicos (grupos de fluorórofos mais simples). O fluoróforo 2 é composto por dois picos não-separados de excitação diferente. Um pico com comprimento de onda dominante próximo a (350/400-450 nm) e o outro variando (275/400-500 nm), que corresponde às componentes do tipo C (Coble, 1996) e é usualmente associado aos ácidos fúlvicos (grupos de fluoróforos mais complexos). O fluoróforo 3, com comprimentos de onda de excitação de $250 \mathrm{~nm}$ e de 
emissão de $375 \mathrm{~nm}$, corresponde as componentes proteína do tipo triptofano (Coble, 1996) (Figura 5.10).

A combinação dos espectros de MEE com PARAFAC permitiu caracterizar qualitativamente os EAF2, podendo identificar e associar com mais clareza os três fluoróforos obtidos, com seus respectivos componentes, ácidos fúlvicos (grupos de fluoróforos simples e complexos) e proteína do tipo triptofano, conforme descrito anteriormente. Os fluoróforos obtidos (Figura 5.10) através da combinação de MEE e PARAFAC neste estudo corroboram com os fluoróforos obtidos nos trabalhos de Luciani et al. (2008), Mounier et al. (2011) e He et al. (2013).

\subsection{2 ÁCIDO HÚMICO}

Os experimentos de fluorescência foram realizados no intuito de avaliar o comportamento da fração ácido húmico em perfis de solo da Amazônia.

\subsubsection{ESPECTROS DE EMISSÃO}

Os espectros de emissão para os AH foram medidos com excitação em 240 e $465 \mathrm{~nm}$. Através desses espectros, foi calculado o grau de humificação das amostras usando as metodologias propostas por Zsolnay et al. (1999) e Milori et al. (2002), respectivamente.

Os espectros de emissão dos $\mathrm{AH}$ obtidos com excitação em $240 \mathrm{~nm}$ são mostrados na Figura 5.11. 
Figura 5.11 - Espectros de emissão de fluorescência obtidos para as amostras de $\mathrm{AH}$ (concentração $10 \mathrm{mg} \mathrm{L}^{-1}, \mathrm{pH} \mathrm{8,0)}$ do Espodossolo Humilúvico (a) e Latossolo Amarelo (b), com comprimento de onda de excitação $\left(\lambda_{\mathrm{ex}}=240 \mathrm{~nm}\right)$, nos perfis de amostragem.
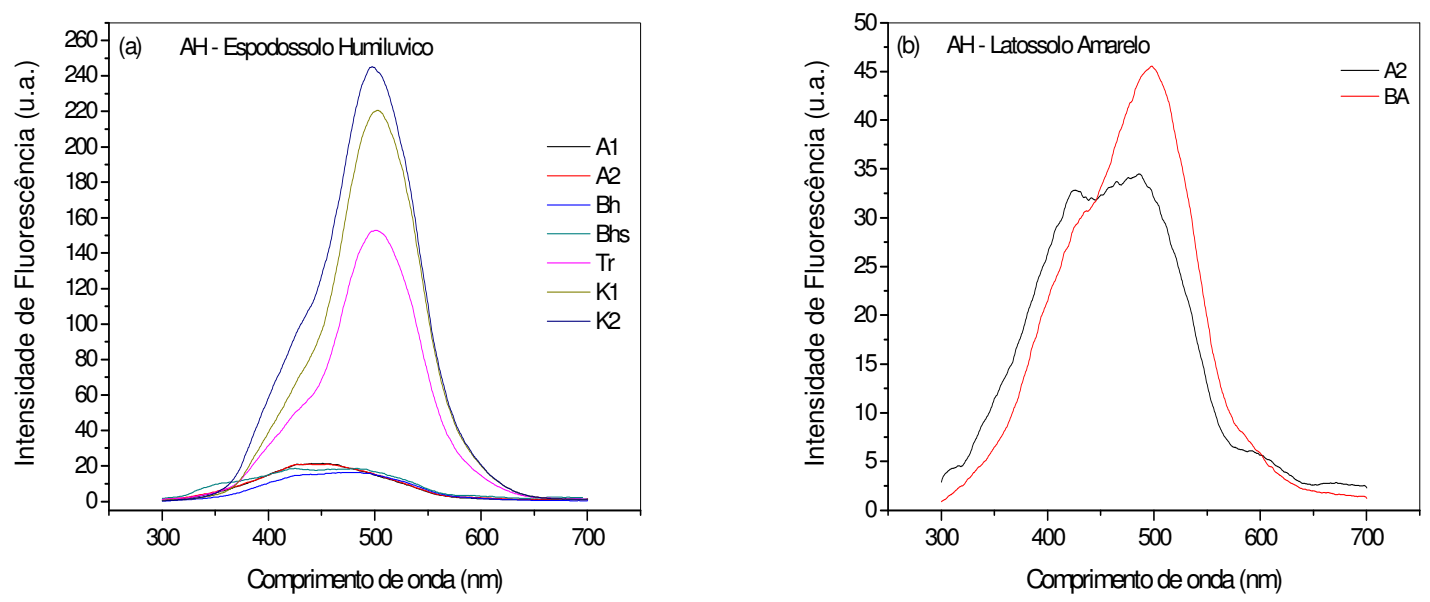

*Espodossolo Humiluvico: não foi possível a extração de AH dos horizontes álbicos (E1 e E2). *Latossolo Amarelo: não foi possível a extração de $\mathrm{AH}$ das camadas mais profundas

Os espectros de emissão com excitação em $240 \mathrm{~nm}$ das amostras de AH extraídos dos solos mostrados na Figura 5.11 (a) e (b), apresentam uma banda larga cujo máximo de intensidade ocorre próximo a $500 \mathrm{~nm}$. Observando os espectros da Figura 5.11 (a), nota-se uma intensidade de fluorescência maior para as amostras de AH extraídos do Espodossolo Humilúvico dos horizontes de transição (Tr) e, principalmente para as dos horizontes inferiores de caulim (K1 e K2). Para o Latossolo Amarelo (Figura 5.11 (b)), como foi extraído AH apenas para as camadas superficiais, observou-se que o horizonte superficial BA apresentou uma intensidade de fluorescência maior do que o A2.

Zsolnay et al. (1999), trabalhando com excitação com radiação ultravioleta em $240 \mathrm{~nm}$ de amostras de MO em solução, observaram que o sinal de fluorescência dos espectros de emissão de matéria orgânica dissolvida apresentaram um deslocamento para comprimentos de ondas maiores, denotando desta maneira uma continuidade no processo de humificação. 
Figura 5.12 - Valores do índice de humificação $A_{4} / A_{1}$ obtidos para os $A H$ extraídos do Espodossolo Humilúvico (a) e Latossolo Amarelo (b) pela metodologia de Zsolnay et al. (1999), nos perfis de amostragem.
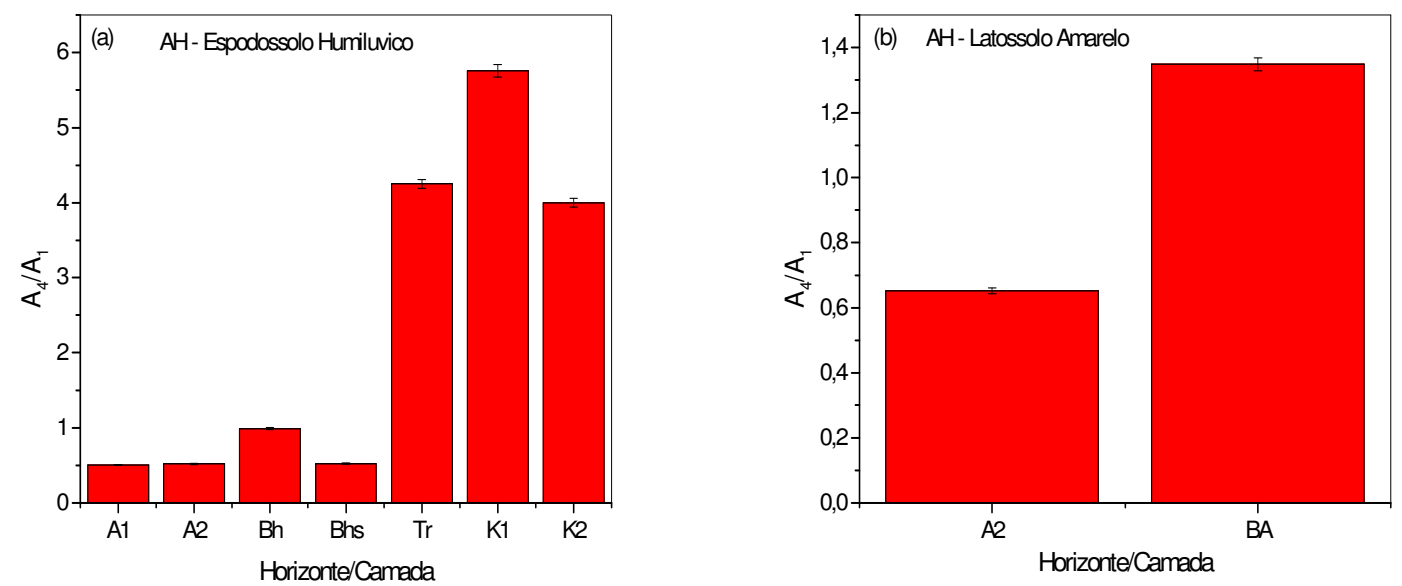

*Espodossolo Humiluvico: não foi possível a extração de AH dos horizontes álbicos (E1 e E2). *Latossolo Amarelo: não foi possível a extração de AH das camadas mais profundas.

A partir dos resultados obtidos para 0 índice de humificação $A_{4} / A_{1}$ proposto por Zsolnay et al. (1999) para o Espodossolo Humilúvico (Figura 5.12 (a)), observouse que o menor grau de humificação foi determinado nos $\mathrm{AH}$ dos horizontes superficiais orgânicos (A1 e A2), não apresentando variações significativas entre si, provavelmente em decorrência do aporte de resíduos vegetais de árvores das florestas, serrapilheira (compostas por raízes muito finas). Os AH dos horizontes $\mathrm{Tr}$ e de caulim (K1 e K2) apresentaram os maiores grau de humificação. Pela técnica de análise elementar não foi possível medir carbono para o horizonte K2, ou seja, a pouca quantidade de carbono que tem está em um tipo de estrutura com eficiência quântica de fluorescência muito alta. Devem ser compostos aromáticos condensados de pequeno tamanho molecular que passaram pelo horizonte $\mathrm{K} 1 \mathrm{e}$ estão se acumulando em K2 (acúmulo de carbono mais humificado).

Esse fato também pode estar relacionado com as diferenças texturais apresentadas neste perfil, visto que o maior conteúdo de argila no horizonte $\mathrm{Tr}$ $(50,95 \%)$ determinado por Ishida (2010), pode favorecer a estabilidade da MO humificada por meio da formação de complexos organominerais, tornando a $\mathrm{MO}$ relativamente mais protegida da degradação microbiana (Canellas et al., 2001).

Observou-se para o Latossolo Amarelo um aumento no grau de humificação para o AH do horizonte superficial BA em relação ao A2 (Figura 5.12 (b)), pois conforme observação de campo de Ishida (2010), estes horizontes são 
constantemente influenciados pela $\mathrm{MO}$, ocasionando este aumento, devido a degradação da MOS. Não se pode inferir uma tendência de aumento do grau de humificação em profundidade para este solo, pois não foi possível a extração de AH para as camadas intermediárias e profundas.

Os espectros de emissão dos $\mathrm{AH}$ obtidos com excitação em 465 nm são mostrados na Figura 5.13.

Figura 5.13 - Espectros de emissão de fluorescência obtidos para as amostras de $\mathrm{AH}$ (concentração $10 \mathrm{mg} \mathrm{L}^{-1}, \mathrm{pH} 8,0$ ) do Espodossolo Humilúvico (a) e Latossolo Amarelo (b), com comprimento de onda de excitação $\left(\lambda_{\mathrm{ex}}=465 \mathrm{~nm}\right)$, nos perfis de amostragem.
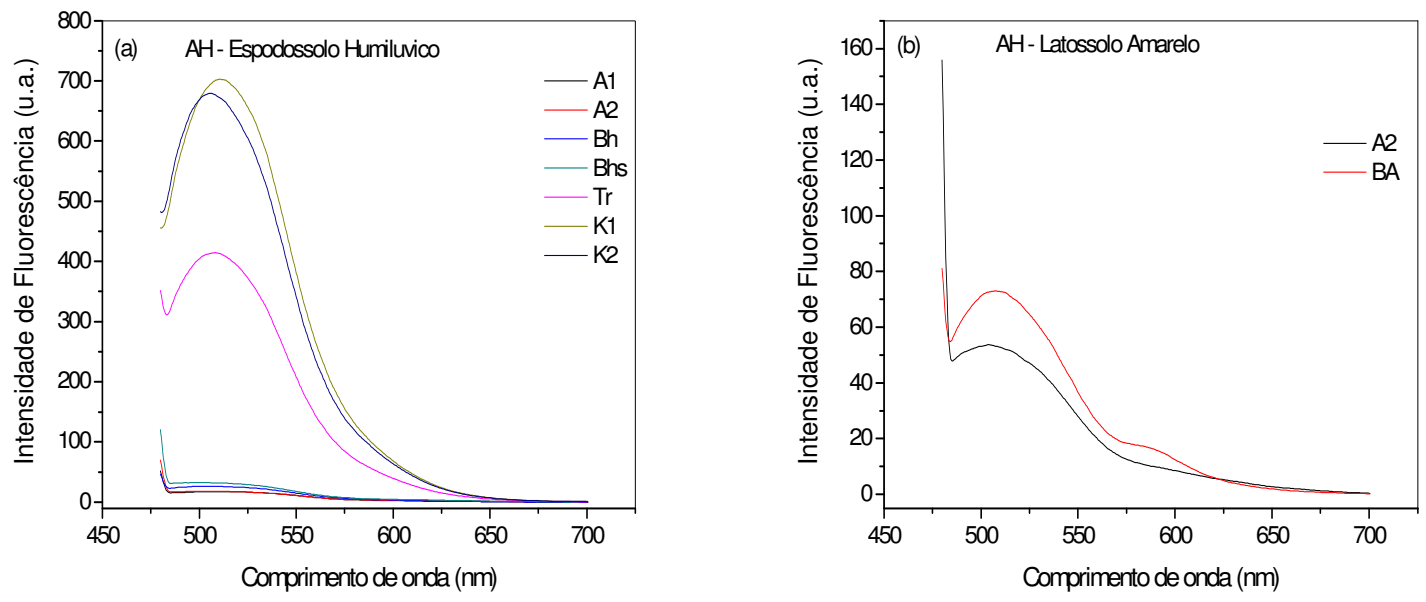

*Espodossolo Humiluvico: não foi possível a extração de AH dos horizontes álbicos (E1 e E2). *Latossolo Amarelo: não foi possível a extração de AH das camadas mais profundas.

Os espectros de emissão com excitação em 465 nm mostrados na Figura 5.13 apresentam uma única banda larga centrada em $510 \mathrm{~nm}$. Observou-se uma intensidade de fluorescência maior para as amostras de $\mathrm{AH}$ extraídos do Espodossolo Humilúvico dos horizontes $\operatorname{Tr}$ e, principalmente para os horizontes de caulim (K1 e K2) (Figura 5.13 (a)). Para o Latossolo Amarelo (Figura 5.13 (b)), notase que o horizonte superficial BA apresentou uma intensidade de fluorescência maior que o A2. Estes mesmos comportamentos foram observados nos espectros de emissão com excitação em $240 \mathrm{~nm}$ adquiridos segundo a metodologia de Zsolnay et al. (1999).

A Figura 5.14 mostra os índices de humificação $A_{465}$ (Milori et al., 2002) das amostras de $\mathrm{AH}$ dos solos estudados. 
Figura 5.14 - Valores do índice de humificação $\mathrm{A}_{465}$ obtidos para os $\mathrm{AH}$ extraídos do Espodossolo Humilúvico (a) e Latossolo Amarelo (b) pela metodologia de Milori et al. (2002), nos perfis de amostragem.
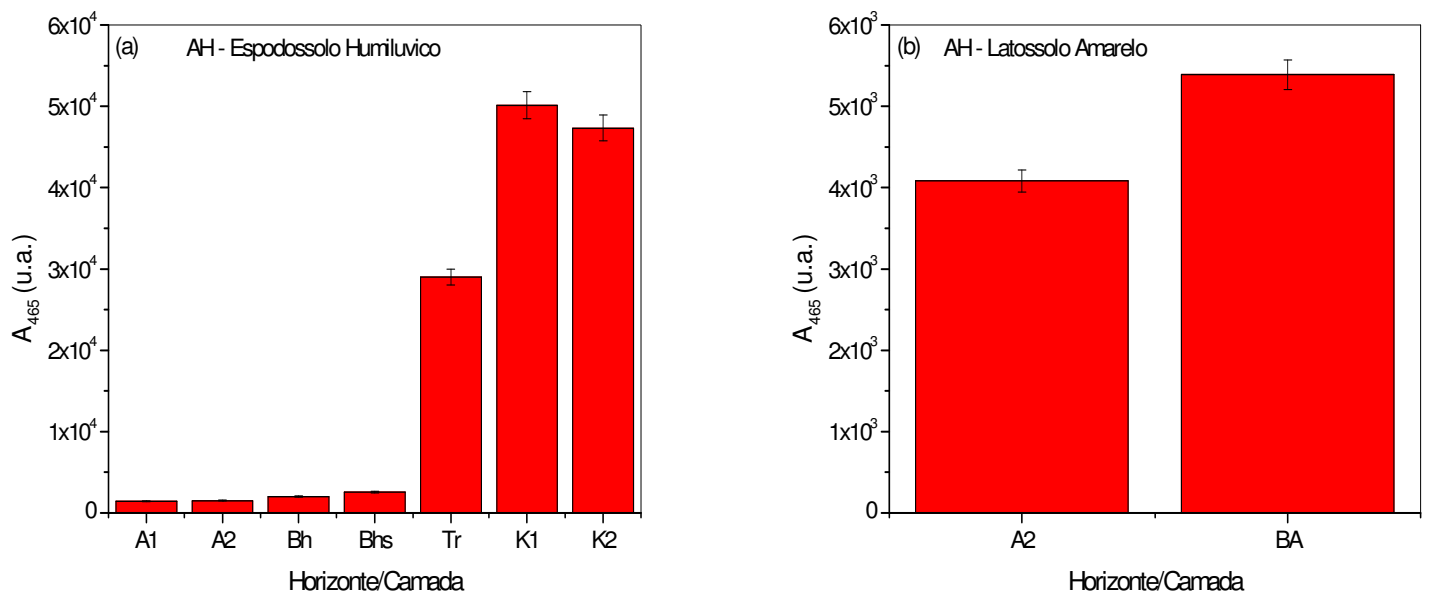

*Espodossolo Humiluvico: não foi possível a extração de AH dos horizontes álbicos (E1 e E2). *Latossolo Amarelo: não foi possível a extração de AH das camadas mais profundas.

Foi observado a partir dos resultados do índice de humificação $A_{465}$ (Figura 5.14 (a)), de acordo com a metodologia de Milori et al. (2002), que os menores graus de humificação e menor intensidade de fluorescência (Figura 5.13 (a)) foram obtidos para os AH extraídos dos horizontes superficiais orgânicos (A1 e A2) e espódicos (Bh e Bhs) para o Espodossolo Humilúvico. Entre os horizontes espódicos e os superficiais orgânicos não observa-se diferenças significativas no grau de humificação, apenas um ligeiro aumento a partir dos horizontes Bh e Bhs, mas ao se comparar com o horizonte de transição ( $\mathrm{Tr}$ ) e os de caulim (K1 e K2), ocorre um aumento significativo no grau de humificação, estando relacionado à presença de compostos com estruturas complexas, como núcleos aromáticos conjugados e/ou substituídos.

O maior grau de humificação dos $\mathrm{AH}$ extraídos do Espodossolo Humilúvico dos horizontes $\mathrm{Tr}, \mathrm{K} 1$ e K2, pode também estar relacionado as diferenças texturais apresentadas neste perfil, visto que estes horizontes apresentam maior conteúdo de argila ( $\mathrm{Tr}=50,95 \% ; \mathrm{K} 1=26,95 \%$ e K2 $=29,32 \%$ ) comparado aos demais horizontes (superficiais e espódicos) (Ishida, 2010), podendo favorecer a estabilidade da MO humificada por meio da formação de complexos organominerais ou organometálicos com íons $\mathrm{Al}$ e $\mathrm{Fe}$, onde a $\mathrm{MO}$ humificada dos horizontes superficiais é eluviada ao longo do perfil formando os horizontes espódicos e o de transição em subsuperfície, 
indicando a ocorrência do processo pedogenético de podzolização. Estes resultados corroboram com os obtidos através da metodologia de Zsolnay et al. (1999).

Os resultados obtidos para o índice de humificação $A_{465}$ para o Latossolo Amarelo (Figura 5.14 (b)), apresentaram comportamento semelhante aos resultados mostrados anteriormente pela metodologia de Zsolnay et al. (1999), observando-se um aumento no grau de humificação e uma intensidade de fluorescência maior para o AH do horizonte superficial BA em relação ao horizonte A2, pois conforme descrito anteriormente, estes horizontes são constantemente influenciados pela $\mathrm{MO}$, mas não se pode inferir uma tendência sobre o comportamento do grau de humificação em profundidade, em virtude da ausência de amostras de AH para estes horizontes.

\subsubsection{ESPECTROS DE VARREDURA SINCRONIZADA $(\Delta \lambda=55 \mathrm{~nm})$}

O espectro de varredura sincronizada, medido com diferença constante entre excitação e emissão $(\Delta \lambda=55 \mathrm{~nm})$, permitiu avaliar o grau de humificação dos $\mathrm{AH}$ extraídos dos solos através da metodologia proposta por Kalbitz et al. (1999). De acordo com este método, os espectros de fluorescência de varredura sincronizada dos $\mathrm{AH}$ apresentam dois picos em torno de 360 e $400 \mathrm{~nm}$, e um ombro em torno de $470 \mathrm{~nm}$. Esses perfis mudam dependendo do grau de humificação, e isto pode ser medido através da razão entre os picos de fluorescência.

Os espectros de varredura sincronizada de fluorescência das amostras de $\mathrm{AH}$ medidos com diferença de comprimento de onda de emissão e excitação ( $\Delta \lambda=55$ nm) estão mostrados na Figura 5.15. 
Figura 5.15 - Espectros de varredura sincronizada de fluorescência obtidos para as amostras de $\mathrm{AH}$ (concentração $10 \mathrm{mg} \mathrm{L}^{-1}, \mathrm{pH} 8,0$ ) do Espodossolo Humilúvico (a) e Latossolo Amarelo (b), com comprimento de onda de emissão e excitação $\left(\Delta \lambda=\lambda_{\text {em }}\right.$ $-\lambda_{\mathrm{ex}}=55 \mathrm{~nm}$ ), nos perfis de amostragem.
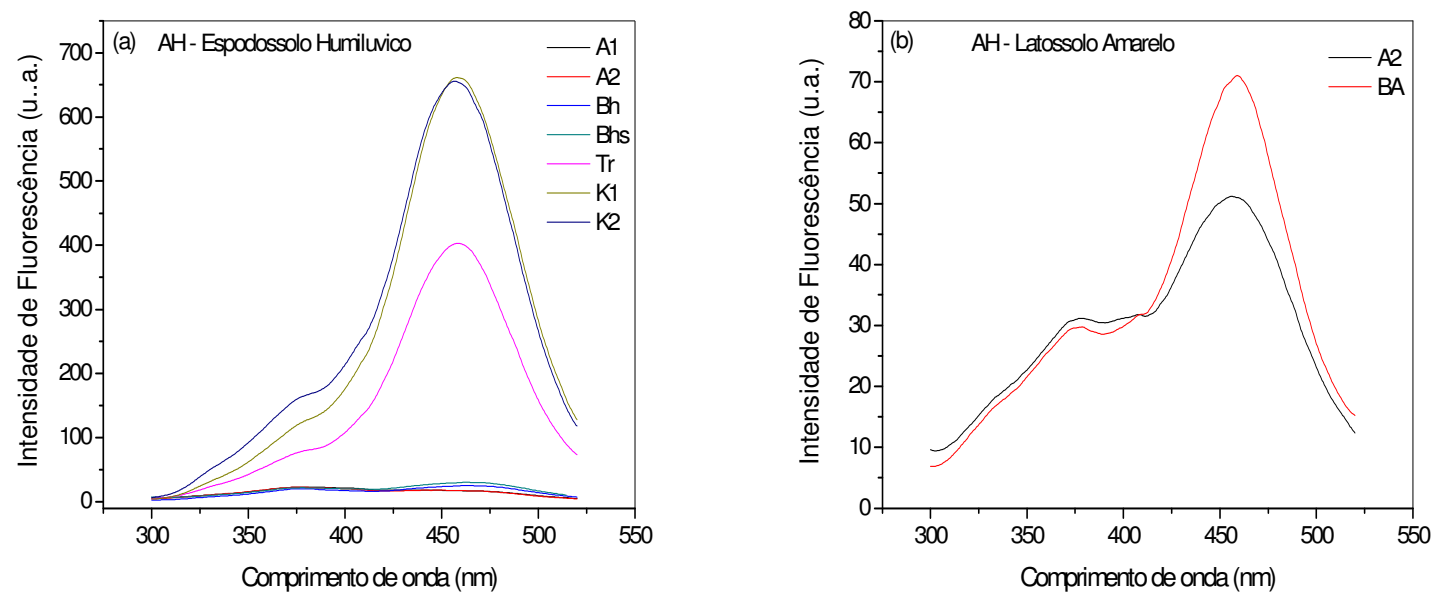

*Espodossolo Humiluvico: não foi possível a extração de AH dos horizontes álbicos (E1 e E2).

*Latossolo Amarelo: não foi possível a extração de AH das camadas mais profundas.

Os espectros de varredura sincronizada dos $\mathrm{AH}$ (Figura 5.15) diferem na forma dos seus correspondentes EAF2 (Figura 5.6). Neste caso, os resultados dos AH mostrados na Figura 5.15 apresentam dois picos, um intenso em $460 \mathrm{~nm}$ e outro em $378 \mathrm{~nm}$, enquanto que os espectros dos EAF2 (Figura 5.6) mostraram dois picos dominantes, um em $450 \mathrm{~nm}$ e o outro em $370 \mathrm{~nm}$. Isto significa que os grupos fluoróforos que compõem os $\mathrm{AH}$ são dominados por policíclicos aromáticos de maior tamanho molecular do que os que compõem os EAF2. O pico em $378 \mathrm{~nm}$ é um indicativo de substâncias simples e pouco humificadas, enquanto o pico em $460 \mathrm{~nm}$ está associado com substâncias com estruturas mais complexas, mais humificadas, como compostos aromáticos.

Foi observado através dos espectros no modo sincronizado dos $\mathrm{AH}$, a mesma tendência dos espectros de emissão com excitação em $240 \mathrm{~nm}$ (Zsolnay et al., 1999) e 465 nm (Milori et al., 2002), uma intensidade de fluorescência maior para os AH extraídos do Espodossolo Humilúvico dos horizontes $\mathrm{Tr}, \mathrm{K} 1$ e $\mathrm{K} 2$, em destaque as amostras de $\mathrm{AH}$ dos horizontes de caulim ( $\mathrm{K} 1$ e $\mathrm{K} 2$ ) sendo as que mais fluorescem (Figura 5.15 (a)). Para o Latossolo Amarelo (Figura 5.15 (b)), notou-se o mesmo comportamento espectral das outras duas metodologias citadas anteriormente, sendo o horizonte superficial BA o que apresentou maior intensidade de fluorescência em relação ao horizonte A2. 
A região do espectro com comprimentos de onda mais para o vermelho está associada a núcleos aromáticos substituídos e/ou conjugados, ou sistemas insaturados conjugados com elétron bastante delocalizado. A região mais para o azul é associada a compostos mais simples. Então, a razão entre a intensidade de fluorescência em 400 e $360 \mathrm{~nm}$, ou 470 e $360 \mathrm{~nm}$ pode ser usada para medir o grau de humificação das SH. No caso do presente estudo foi possível à identificação de dois picos médios, um em $460 \mathrm{~nm}$ e outro em $378 \mathrm{~nm}$, e com isso usar a razão $\mathrm{I}_{460} / \mathrm{I}_{378}$ como índice de humificação para os $\mathrm{AH}$.

A Figura 5.16 mostra os índices de humificação $I_{460} / l_{378}$ (Kalbitz et al., 1999) das amostras de $\mathrm{AH}$ dos solos estudados.

Figura 5.16 - Valores do índice de humificação $\left(\mathrm{l}_{460} / \mathrm{l}_{378}\right)$ obtidos para os $\mathrm{AH}$ extraídos do Espodossolo Humilúvico (a) e Latossolo Amarelo (b) pela metodologia de Kalbitz et al. (1999), nos perfis de amostragem.
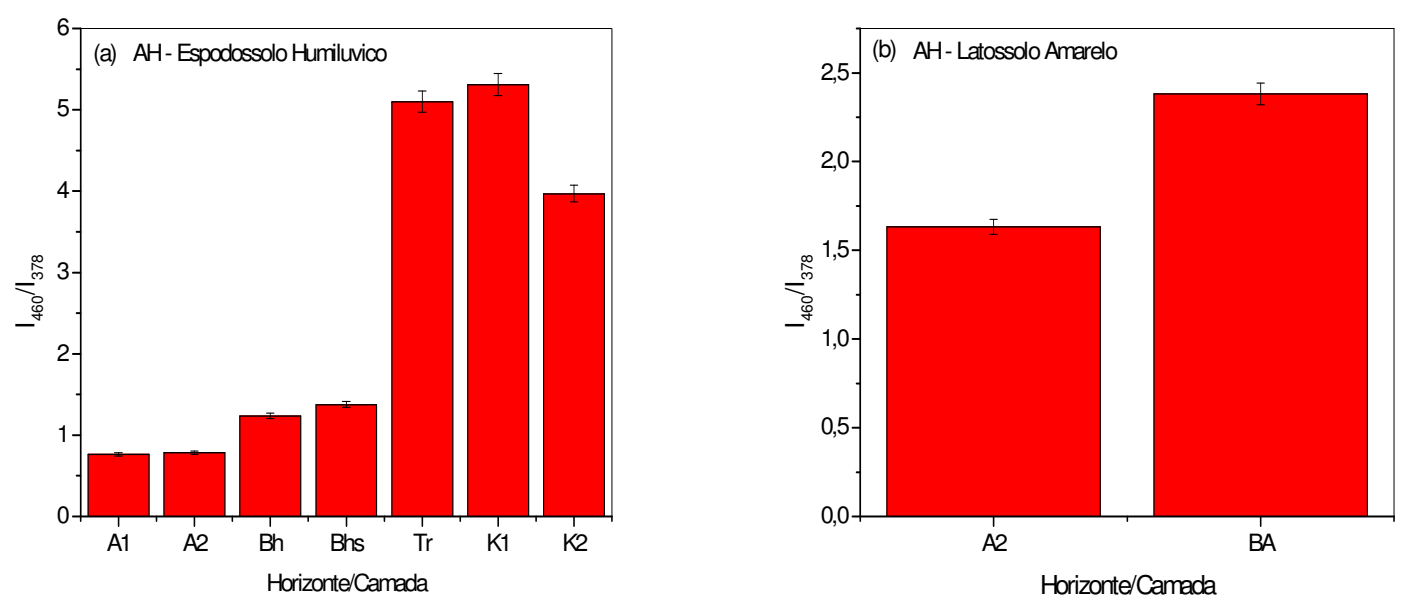

*Espodossolo Humiluvico: não foi possível a extração de AH dos horizontes álbicos (E1 e E2). *Latossolo Amarelo: não foi possível a extração de AH das camadas mais profundas.

A partir dos resultados obtidos para o índice de humificação $I_{460} / I_{378}$ proposto por Kalbitz et al. (1999) e pela Figura 5.16, observou-se a mesma tendência das metodologias anteriores para os solos estudados. Para o Espodossolo Humilúvico (Figura 5.16 (a)), é possível observar que os maiores graus de humificação e intensidade de fluorescência foram obtidos para os $\mathrm{AH}$ do Espodossolo Humilúvico dos horizontes Tr, K1 e K2, destacando-se o maior grau de humificação e intensidade de fluorescência para os horizontes $\operatorname{Tr}$ e K1, neste caso. Já os menores graus de humificação e intensidade de fluorescência foram determinados nos $\mathrm{AH}$ provenientes dos horizontes superficiais orgânicos (A1 e A2) e espódicos (Bh e Bhs). 
Para o Latossolo Amarelo (Figura 5.16 (b)), o horizonte superficial BA apresentou maior grau de humificação e intensidade de fluorescência em comparação ao horizonte $A 2$, mas não se pode inferir uma tendência sobre o grau de humificação em profundidade, pois não foi possível a obtenção de amostras de $\mathrm{AH}$ para estes horizontes. Estes resultados corroboram com os obtidos pelas metodologias de Zsolnay et al. (1999) e Milori et al. (2002).

A análise espectroscópica dos $\mathrm{AH}$ extraídos do Espodossolo Humilúvico permitiu a obtenção dos índices de humificação através das diferentes metodologias utilizadas para fluorescência, e estão apresentadas nas Figuras 5.17, 5.18 e 5.19.

Figura 5.17 - Correlação entre os resultados obtidos pelas metodologias de Milori et al. (2002) $\left(A_{465}\right)$ e Zsolnay et al. (1999) $\left(A_{4} / A_{1}\right)$ para os AH extraídos do Espodossolo Humilúvico.

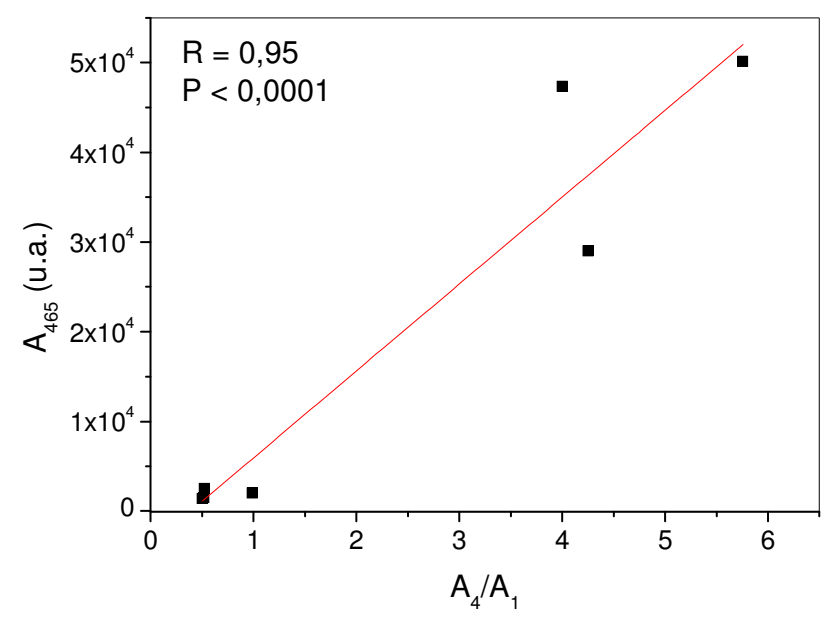

Figura 5.18 - Correlação entre os resultados obtidos pelas metodologias de Milori et al. (2002) $\left(A_{465}\right)$ e Kalbitz et al. (1999) $\left(\mathrm{I}_{460} / /_{378}\right)$ para os AH extraídos do Espodossolo Humilúvico.

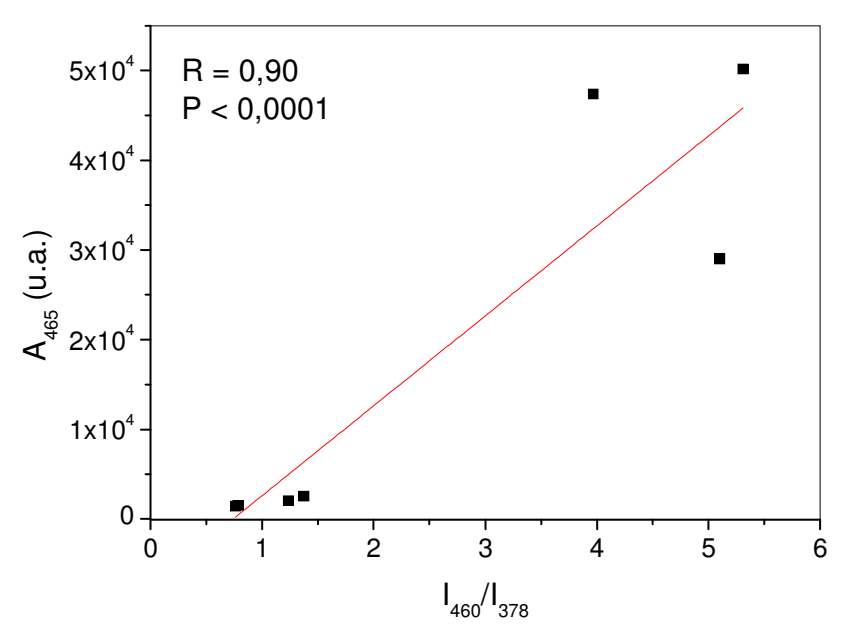


Figura 5.19 - Correlação entre os resultados obtidos pelas metodologias de Zsolnay et al. (1999) $\left(\mathrm{A}_{4} / \mathrm{A}_{1}\right)$ e Kalbitz et al. (1999) $\left(\mathrm{I}_{460} / \mathrm{l}_{378}\right)$ para os $\mathrm{AH}$ extraídos do Espodossolo Humilúvico.

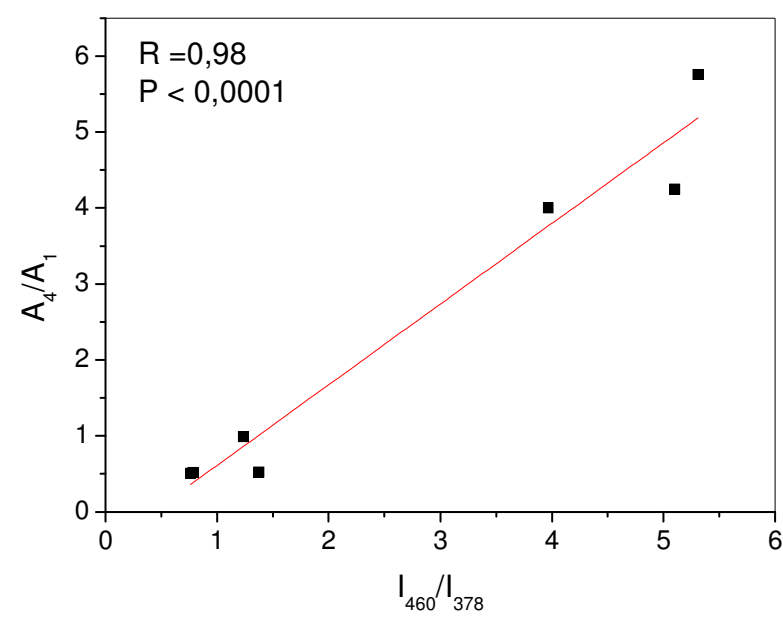

As correlações entre os índices de humificação obtidos pelas diferentes metodologias de fluorescência apresentaram coeficientes de correlação de Pearson's muito forte $(R \geq 0,90$ com $P<0,0001)$. Uma hipótese para explicar estes resultados seria que o horizonte de transição (Tr) do Espodossolo Humilúvico, ocorre o acúmulo de $\mathrm{AH}$ em subsuperfície e a infiltração deste nos horizontes de caulim (K1 e K2). O horizonte K1 estaria funcionando como uma "peneira molecular" permitindo a passagem para o horizonte $\mathrm{K} 2$ de compostos com estruturas mais complexas, mais humificadas, mais recalcitrantes, mas de pequeno tamanho molecular, como compostos com 2 anéis aromáticos (naftaleno), policíclios aromáticos com 3 ou 4 anéis e estruturas do tipo quinona.

\subsubsection{ESPECTROS TRIDIMENSIONAIS DE FLUORESCÊNCIA - MATRIZ EXCITAÇÃO-EMISSÃO (MEE)}

Os espectros de fluorescência tridimensionais no modo MEE (ou curvas de nível) dos $\mathrm{AH}$ estão representados nas Figuras 5.20 e 5.21. Após o preparo das soluções de $\mathrm{AH}$ e das diluições das amostras de $\mathrm{AH}$ (Tabelas 4.1 e 4.2), descritas no item 4.6.1.1 (materiais e métodos), os espectros de fluorescência adquiridos no modo MEE para os AH foram tratados pelo método do PARAFAC, após difusão química e mitigação do efeito de filtro interno (para evitar o efeito de reabsorção), com o auxílio do Espectrômetro de Absorção UV-Visível, até que a absorção em 254 nm ficasse menor que 0,1 para as amostras de AH (Luciani et al., 2008, 2009). 
Figura 5.20 - Espectros de fluorescência total no modo MEE (ou curvas de nível) obtidos para as amostras de $\mathrm{AH}$ (concentração $10 \mathrm{mg} \mathrm{L}^{-1}, \mathrm{pH} 8,0$ ) dos horizontes (a) A1, (b) A2, (c) Bh, (d) Bhs, (e) Tr, (f) K1 e (g) K2 do Espodossolo Humilúvico.

\section{Intensidade (u.a.)}

(a) A1

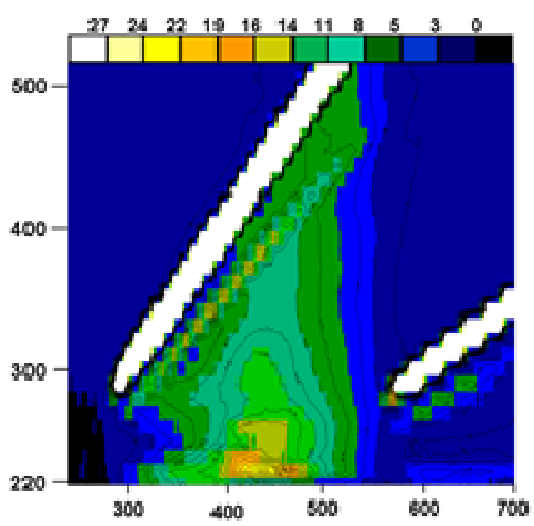

(d) Bhs
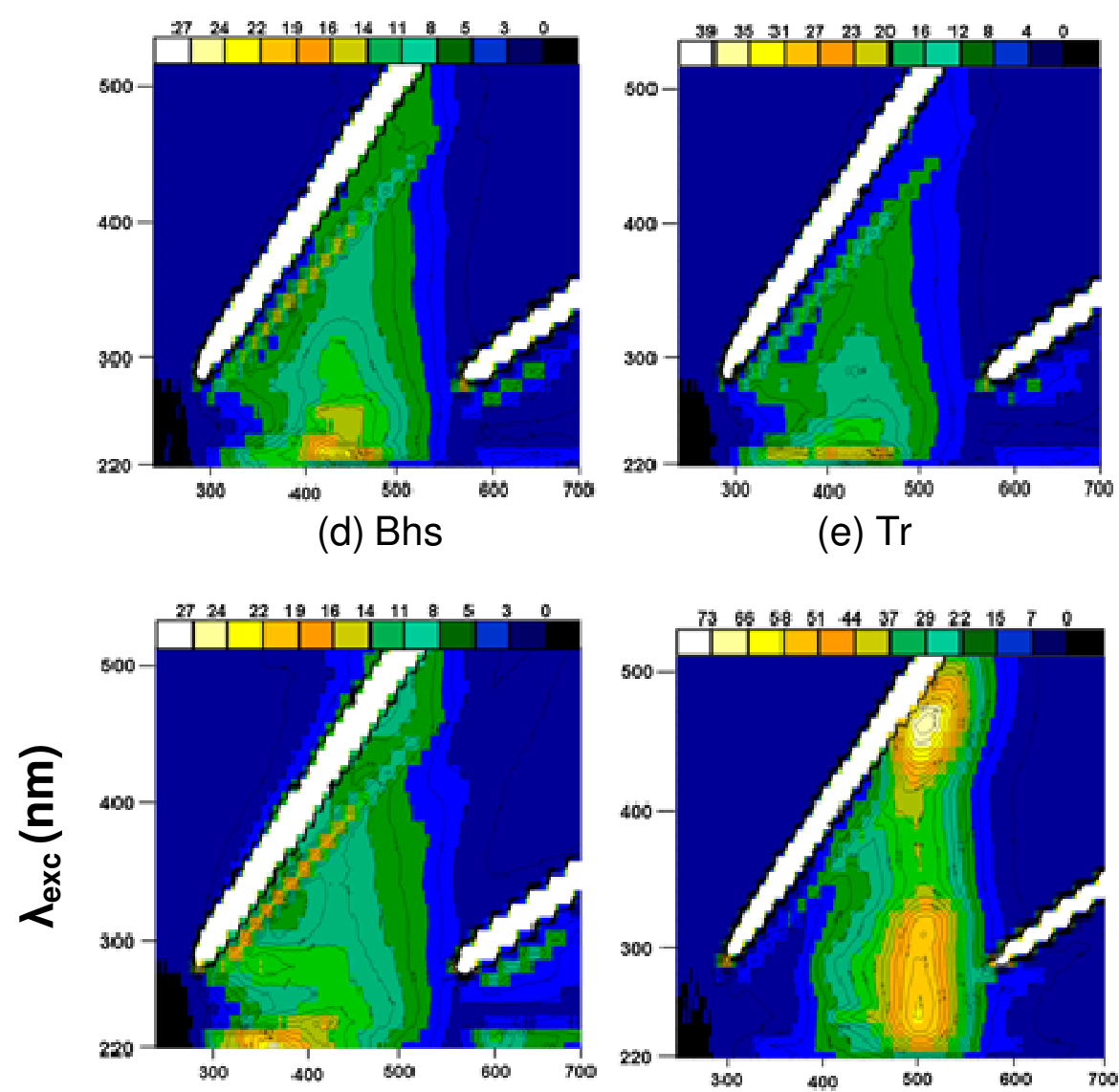

(e) $\operatorname{Tr}$
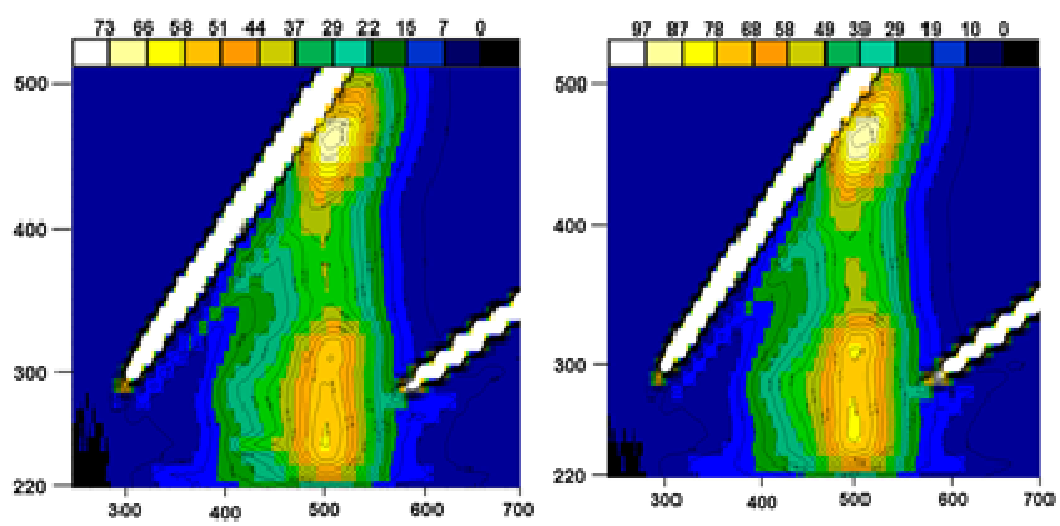

(g) K2

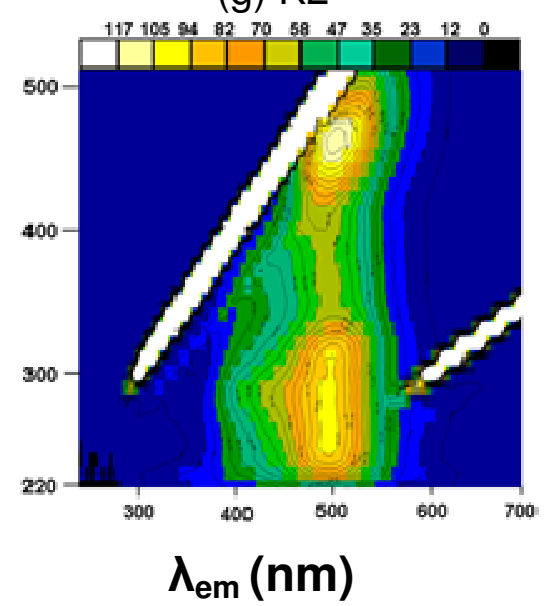

*Espodossolo Humiluvico: não foi possível a extração de AH dos horizontes álbicos (E1 e E2). 
Figura 5.21 - Espectros de fluorescência total no modo MEE (ou curvas de nível) obtidos para as amostras de $\mathrm{AH}$ (concentração $10 \mathrm{mg} \mathrm{L}^{-1}, \mathrm{pH} 8,0$ ) dos horizontes (a) A2 e (b) BA do Latossolo Amarelo.

\section{Intensidade (u.a.)}

(a) A2

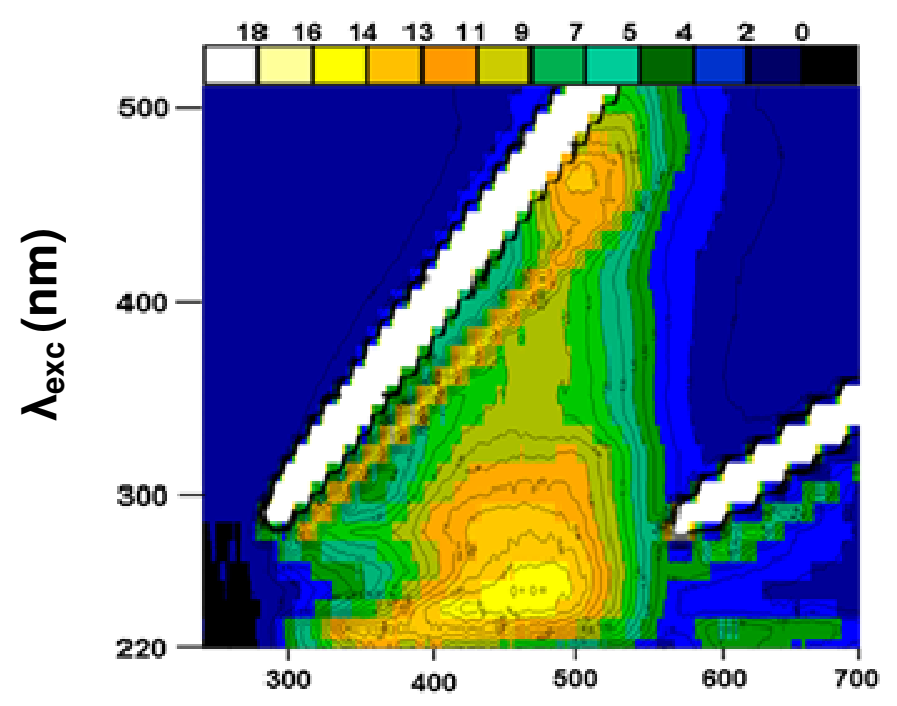

(b) BA

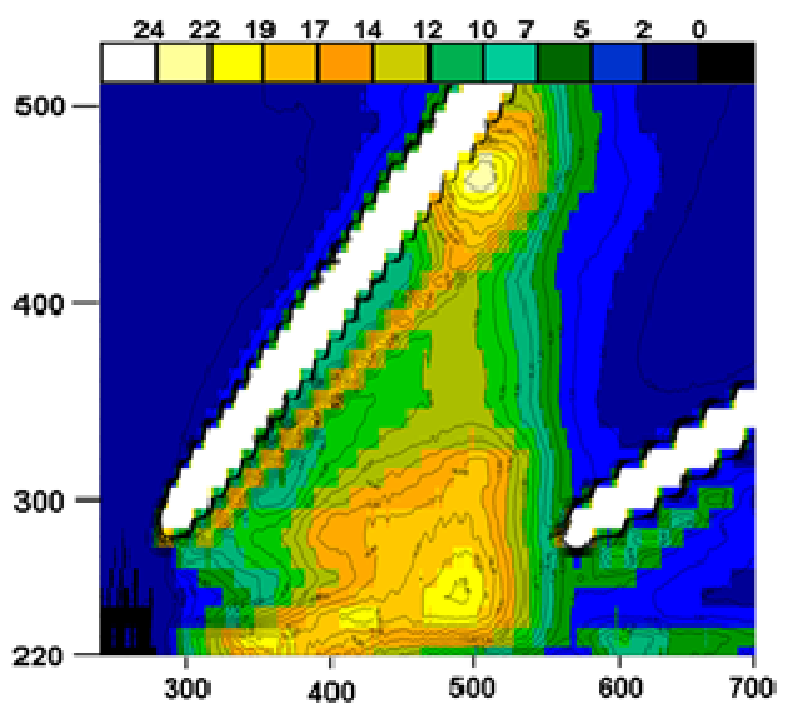

\section{$\lambda_{\mathrm{em}}(\mathrm{nm})$}

*Latossolo Amarelo: não foi possível a extração de $\mathrm{AH}$ dos horizontes mais profundos.

Os valores de intensidade de emissão de fluorescência seguem as escalas de cores colocadas acima das figuras e aparecem sob a forma de curvas de nível.

$\mathrm{AH}$ de solos são caracterizados por apresentarem típicos comprimentos de onda longos de máxima emissão, espectros no modo sincronizado relativamente mais intensos, picos de fluorescência total em longos comprimentos de onda e pequenos valores de intensidade de fluorescência, como podem ser observados nos espectros de fluorescência total no modo MEE (Figura 5.20 para o Espodossolo Humilúvico e Figura 5.21 para o Latossolo Amarelo). Estes dados mostram a presença nos $\mathrm{AH}$ de componentes, no caso deste estudo, com cadeias compostas por anéis aromáticos linearmente condensados e outros sistemas com ligações insaturadas, que possuem um grande grau de conjugação e, ainda, contém substituintes retiradores de elétrons, tais como grupos carbonílicos e carboxílicos (Senesi et al., 1991; Valeur, 2001; Bertoncini et al., 2005). 
A fluorescência dos AH para o Espodossolo Humilúvico aumenta com a profundidade do solo (Figura 5.20) e para o Latossolo Amarelo aumentou do horizonte A2 para o BA (Figura 5.21).

Ao analisar as Figuras 5.20 (Espodossolo Humilúvico) e 5.21 (Latossolo Amarelo), representando os espectros de curvas de nível dos $\mathrm{AH}$ utilizando a localização de picos, foi possível observar máximos nos comprimentos de onda de excitação/emissão $\left(\lambda_{e x d} / \lambda_{e m}\right): 250 / 500 ; 455 / 510 ; 310 / 500$ e 250/460 nm. Os $\mathrm{AH}$ apresentam o principal pico em ( $\lambda_{\mathrm{exc}} / \lambda_{\mathrm{em}} 455 / 510$ que, de acordo com Matthews et al. (1996), são típicos de $A H$ terrestres derivados da lignina (denominados de picos $L$ ). Os AHs apresentam também o pico C $\left(\lambda_{\text {exd }} / \lambda_{\text {em }} 320 / 500\right)$ e o pico $\mathrm{A}\left(\lambda_{\text {exc }} / \lambda_{\text {em }} 250 / 450\right)$ (Coble, 1996), normalmente com menor intensidade de fluorescência.

Rivero et al. (1998) consideram que o deslocamento da intensidade máxima de fluorescência, para $\lambda$ mais longos, é atribuído aos substituintes nos anéis aromáticos. Em geral, materiais com menor peso molecular apresentam maior intensidade de fluorescência que os de maior peso molecular.

Pelos espectros de fluorescência tridimensionais (MEE) observa-se grande diferença entre os cromóforos que emitem fluorescência nos AH e EAF2 (Figuras 5.8, 5.9, 5.20 e 5.21). O deslocamento da intensidade máxima de emissão, para o vermelho, deve-se à complexidade maior do $\mathrm{AH}$ de solo em relação aos ácidos fúlvicos terrestres e aquáticos, indicando que os $\mathrm{AH}$ apresentam moléculas mais ricas em aromáticos condensados.

Os espectros de fluorescência no modo matriz excitação-emissão (MEE) obtidos para os $\mathrm{AH}$ do Espodossolo Humilúvico e Latossolo Amarelo, também foram tratados pelo método matemático PARAFAC. Com o emprego deste método, foi possível identificar a contribuição das intensidades de dois fluoróforos (Figura 5.22), com diagnóstico de consistência do tensor núcleo (CORCONDIA) de 84,2\%. 
Figura 5.22 - Fluoróforos 1 e 2 obtidos pelo método PARAFAC e descritivos da fluorescência tridimensional (MEE) dos $\mathrm{AH}$ extraídos do Espodossolo Humilúvico e Latossolo Amarelo.
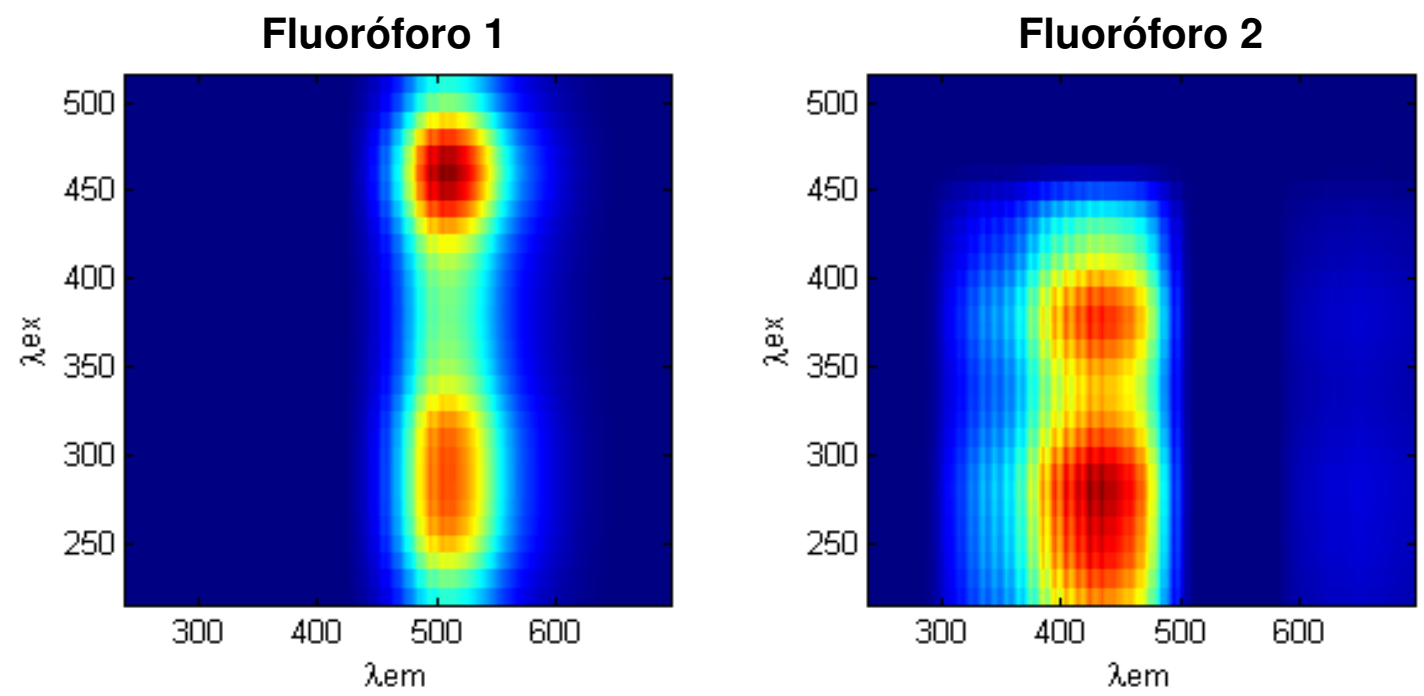

O fluoróforo 1 é composto por dois picos não-separados de excitação diferente, mas no mesmo comprimento de onda de emissão. O principal pico em (455/510) que, de acordo com Matthews et al. (1996), são típicos de $\mathrm{AH}$ terrestres derivados da lignina (denominados de picos L) e o outro (310/500) é típico das componentes tipo C (Coble, 1996) e associadas aos ácidos húmicos (grupos de fluoróforos mais complexos). O fluoróforo 2 (350/440 nm, 260/440 nm) é composto por um par de fluoróforos típicos das componentes do tipo C e A (Coble, 1996) e é usualmente associado as substâncias húmicas terrestres, no caso deste estudo, aos ácidos húmicos (grupos de fluoróforos mais simples) (Figura 5.22).

Os resultados mostraram um incremento na contribuição dos dois fluoróforos em profundidade para o Espodossolo Humilúvico (Figura 5.23 (a)). Para as camadas superiores até o horizonte espódico (Bhs) nota-se uma contribuição maior do fluoróforo 2, mas a partir do horizonte de transição (Tr) este comportamento se inverte, observando-se uma contribuição mais significativa do fluoróforo 1 neste horizonte e nos horizontes inferiores de caulim (K1 e K2).

Para o Latossolo Amarelo (Figura 5.23 (b)), observou-se uma contribuição mais significativa dos dois fluoróforos para o horizonte superficial (BA) em comparação ao horizonte superficial A2, destacando-se à contribuição do fluoróforo 2, associada aos $\mathrm{AH}$ (grupos de fluoróforos mais simples), e isto pode ser devido ao aporte de MO (serapilheira), devido a degradação da MOS, mas não se pode inferir 
uma tendência de aumento ou diminuição na contribuição dos fluoróforos em profundidade, pois não foi possível a extração de $\mathrm{AH}$ para as camadas intermediárias e profundas.

O fluoróforo 1 associado aos AH (grupos de fluoróforos mais complexos), está relacionado com substâncias com estruturas mais complexas, mais humificadas, como anéis aromáticos condensados e/ou conjugação de anéis aromáticos simples e derivados da lignina que é um dos constituintes de plantas de mais difícil degradação, cujas moléculas são formadas a partir de 3 precursores básicos, que são os álcoois sinapílico, coniferílico e p-cumarílico. O fluoróforo 2 também usualmente associado aos $\mathrm{AH}$ (grupos de fluoróforos mais simples), indica a presença de compostos com estruturas muito mais simples, mais lábeis, pouco humificadas, menor grau de humificação e presença de anéis aromáticos simples na molécula.

Figura 5.23 - Contribuições à fluorescência dos fluoróforos 1 e 2 dos AH extraídos do Espodossolo Humilúvico (a) e Latossolo Amarelo (b), nos perfis de amostragem.
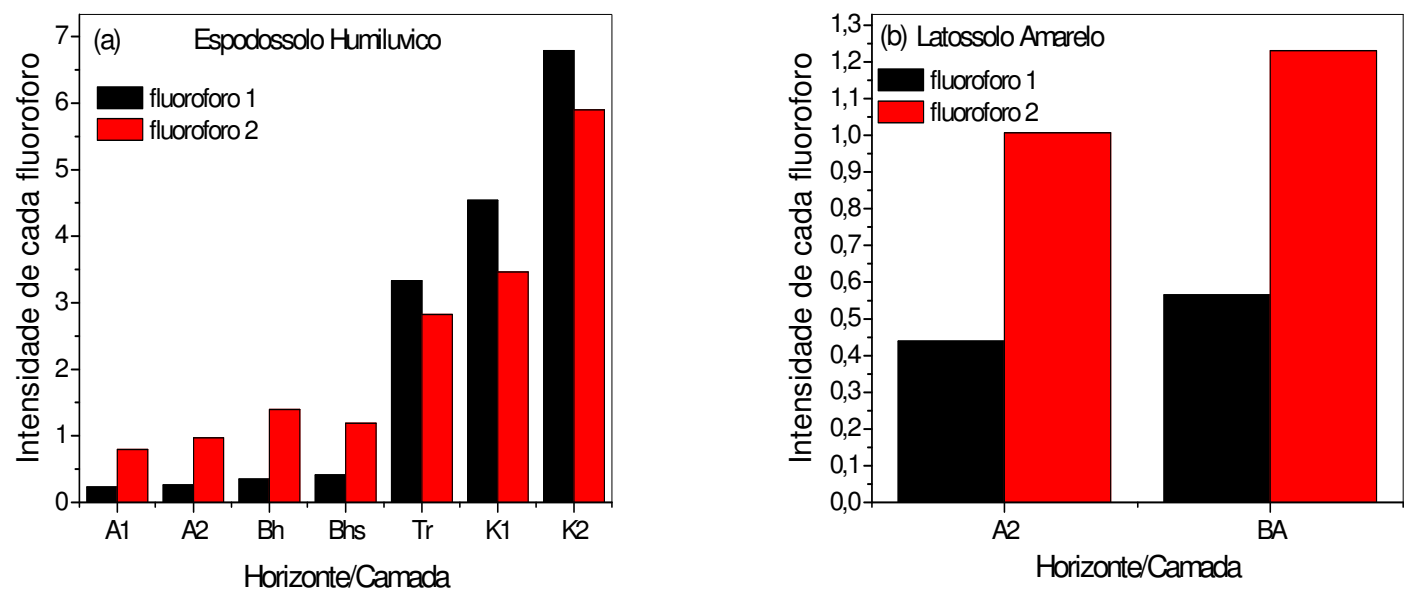

*Espodossolo Humiluvico: não foi possível a extração de AH dos horizontes álbicos (E1 e E2). *Latossolo Amarelo: não foi possível a extração de AH das camadas mais profundas.

Para o Espodossolo Humilúvico (Figura 5.23 (a)), foi possível observar que os horizontes $\mathrm{Tr}$ e de caulim (K1 e K2) apresentaram os maiores valores de intensidade de fluorescência (Figura 5.20 (e), (f) e (g)), e, a partir do horizonte Tr destaca-se uma maior contribuição do fluoróforo 1 em relação ao 2, com esta contribuição aumentando nos horizontes $\mathrm{K} 1$ e K2, sendo estes os que apresentam além da maior contribuição a fluorescência dos $\mathrm{AH}$, os mais humificados. É importante enfatizar que o horizonte K2 apresenta a maior contribuição dos fluoróforos e baixo teor de 
carbono, estando este pouco carbono presente em um tipo de estrutura com eficiência quântica de fluorescência muito alta.

Estes resultados obtidos para o Espodossolo Humilúvico corroboram com o modelo de estrutura supramolecular (Conte; Piccolo, 1999; Piccolo, 2001; 2002; Simpson et al., 2002; Sutton; Sposito, 2005), pois a proporção entre a contribuição dos fluoróforos 1 e 2 não se mantêm no perfil e, a partir do horizonte de transição (Tr) ocorre uma inversão, observando uma contribuição mais significativa do fluoróforo 1 neste horizonte e nos horizontes de caulim (K1 e K2). Como se houvesse dois tipos de ácidos húmicos, um mais recalcitrante (complexo) e o outro mais lábil (simples). Os resultados não corroboram com o modelo de estrutura macromolecular, pois para isso acontecer a proporção entre a contribuição dos fluorofóros 1 e 2 se manteria ao longo do perfil e, não ocorreria a inversão a partir do horizonte de transição (Tr).

No modelo de estrutura supramolecular para $\mathrm{AH}$, proposto por Simpson et al. (2002) (Figura 3.7), os autores demonstraram que as SH extraídas de solos são formadas por uma mistura de substâncias agregadas de baixa massa molecular. Este modelo ilustra algumas estruturas identificadas nas substâncias húmicas (cadeias alifáticas, fragmentos aromáticos provenientes da lignina), corroborando com os resultados obtidos para o Espodossolo Humilúvico (Figura 5.23 (a)), onde também foram identificados nos fluoróforos 1 e 2, substâncias com estruturas mais complexas, mais humificadas, com anéis aromáticos condensados e/ou conjugação de anéis aromáticos simples e derivados da lignina e a presença de compostos com estruturas simples, mais lábeis, pouco humificadas, menor grau de humificação e presença de anéis aromáticos simples na molécula.

Os resultados obtidos utilizando a combinação da espectroscopia de fluorescência no modo MEE e PARAFAC relativos às contribuições a fluorescência do fluoróforo 1 associados aos ácidos húmicos (grupos de fluoróforos mais complexos) e fluoróforo 2 associados aos ácidos húmicos (grupos de fluoróforos mais simples), corroboram com os resultados obtidos para os índices de humificação $A_{4} / A_{1}$ proposto por Zsolnay et al. (1999) (Figura 5.12) e $A_{465}$ proposto por Milori et al. (2002) (Figura 5.14) para o Espodossolo Humilúvico e Latossolo Amarelo. Esta combinação de MEE com PARAFAC nós da uma informação mais detalhada, permitindo identificar a contribuição e a participação de cada fluoróforo na fluorescência, enquanto que nas metodologias que utilizam a fluorescência 
bidimensional, vemos a fluorescência como um todo, não sendo possível a separação da contribuição dos fluoróforos à fluorescência.

$\mathrm{Na}$ Figura 5.24 são apresentadas as correlações entre o índice de humificação $A_{465}$ obtido através da espectroscopia de fluorescência dos $\mathrm{AH}$ extraídos do Espodossolo Humilúvico, com a contribuição das intensidades dos fluoróforos determinados pela combinação da espectroscopia de fluorescência no modo MEE e PARAFAC.

Figura 5.24 - Correlação entre os resultados obtidos pelas metodologias de Milori et al. (2002) $\left(A_{465}\right)$ e a contribuição a fluorescência do fluoróforo 1 (a) e fluoróforo 2 (b) para os AH extraídos do Espodossolo Humilúvico.
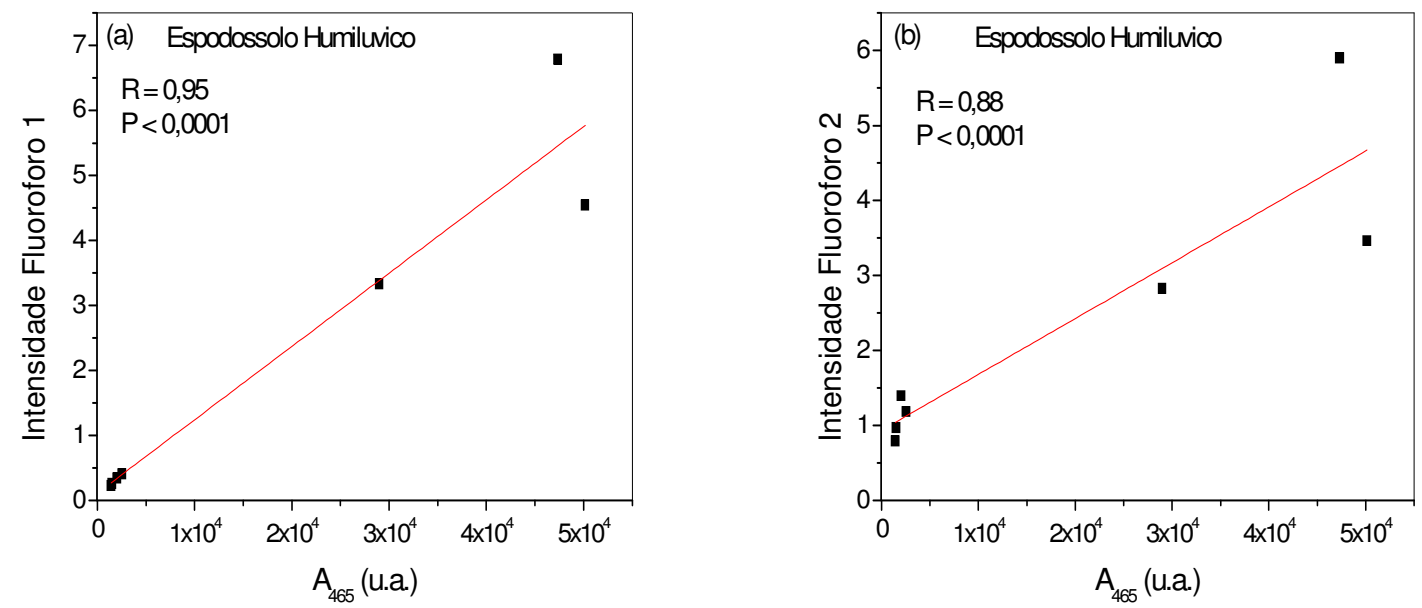

As correlações entre o índice de humificação obtido pela metodologia de Milori et al. (2002) com a contribuição das intensidades dos fluoróforos determinados pela combinação de MEE e PARAFAC mostradas na Figura 5.24 apresentou coeficiente de correlação para os fluoróforo $1(R=0,95)$, com baixa dispersão $P<$ 0,0001 .

Não foi possível a obtenção das correlações entre o índice de humificação $A_{465}$ obtido pela metodologia de Milori et al. (2002) com a contribuição dos fluoróforos determinados pela combinação de MEE e PARAFAC para o Latossolo Amarelo, pois foi possível a extração de $\mathrm{AH}$ apenas para as camadas superficiais $\mathrm{A} 2$ e BA.

A espectroscopia de fluorescência MEE foi uma técnica mais seletiva e sensível do que a fluorescência bidimensional para os $A H$, mostrando informações interessantes, variações estruturais e grande diferença entre os cromóforos que emitem fluorescência nos EAF2 e AH. A combinação de MEE e PARAFAC permitiu 
caracterizar quantitativamente os $\mathrm{AH}$, identificando a contribuição das intensidades de dois fluoróforos, associados aos $\mathrm{AH}$, grupos de fluoróforos mais complexos e simples, conforme descrito anteriormente.

Os resultados obtidos utilizando esta combinação para o Espodossolo Humilúvico corroboram com o modelo de estrutura supramolecular para $\mathrm{AH}$. Estes resultados também corroboram com os resultados do índice de humificação $A_{465}$ obtido pela fluorescência bidimensional, e as correlações entre estes índices e os fluorórofos obtidos pela combinação de MEE com PARAFAC foram altas e muito forte para a metodologia de Milori et al. (2002).

\subsection{SOLO INTEIRO}

\subsubsection{ESPECTROMETRIA DE EMISSÃO ÓTICA COM PLASMA ACOPLADO INDUTIVAMENTE (ICP OES)}

Os valores obtidos para os teores totais de alumínio e ferro por ICP OES nas amostras de solo do Espodossolo Humilúvico e Latossolo Amarelo foram adquiridos segundo o procedimento de digestão da amostra do item 4.6.3.2. Na Tabela 5.4 são apresentados os resultados dessas determinações com os respectivos limites de quantificação (LOQ), realizadas de acordo com as condições descritas anteriormente no item 4.6.3.3 (materiais e métodos). 
Tabela 5.4 - Teores totais de alumínio e ferro das amostras de solo inteiro dos Perfis P1 (Espodossolo Humilúvico) e P2 (Latossolo Amarelo) obtidos por ICP OES.

\begin{tabular}{ccccc}
\hline Amostras $^{(1)}$ & $\begin{array}{c}\text { Horizonte/ } \\
\text { Camada }\end{array}$ & $\begin{array}{c}\text { Profundidade } \\
(\mathbf{c m})\end{array}$ & $\begin{array}{c}\% \mathbf{A l} \\
\left(\mathbf{x 1 0 ^ { - 4 }}\right)\end{array}$ & $\begin{array}{c}\% \mathbf{F e} \\
\left.\mathbf{( x 1 0 ^ { - 4 }}\right)\end{array}$ \\
\hline EH & $\mathrm{A} 1$ & $0-5$ & $25,0 \pm 0,3$ & $3,6 \pm 0,4$ \\
EH & $\mathrm{A} 2$ & $5-30$ & $10,8 \pm 0,3$ & $1,8 \pm 0,4$ \\
EH & E1 & $30-180$ & $1,0 \pm 0,3$ & $0,4 \pm 0,4$ \\
EH & E2 & $180-202,5$ & $2,4 \pm 0,3$ & $0,9 \pm 0,4$ \\
EH & Bh & $202,5-204$ & $36,0 \pm 0,3$ & $5,1 \pm 0,4$ \\
EH & Bhs & $204-214$ & $59,9 \pm 0,3$ & $8,9 \pm 0,4$ \\
EH & Transição & $214-245$ & $610,1 \pm 0,3$ & $1,3 \pm 0,4$ \\
EH & K1 & $245-290$ & $326,4 \pm 0,3$ & $34,8 \pm 0,4$ \\
EH & K2 & $290+$ & $273,3 \pm 0,3$ & $3,1 \pm 0,4$ \\
\hline & & & & \\
LA & A2 & $10-20$ & $147,9 \pm 0,3$ & $50,3 \pm 0,4$ \\
LA & BA & $20-30$ & $158,8 \pm 0,3$ & $51,6 \pm 0,4$ \\
LA & Bw1 & $30-60$ & $169,9 \pm 0,3$ & $68,8 \pm 0,4$ \\
LA & Bw2 & $60-90$ & $196,9 \pm 0,3$ & $59,7 \pm 0,4$ \\
LA & Bw3 & $90-120$ & $194,2 \pm 0,3$ & $29,5 \pm 0,4$ \\
LA & Transição & $120-210$ & $111,6 \pm 0,3$ & $8,2 \pm 0,4$ \\
LA & Kn1 & $210-250$ & $57,6 \pm 0,3$ & $21,5 \pm 0,4$ \\
LA & Kn3 & $320-380$ & $38,3 \pm 0,3$ & $7,0 \pm 0,4$ \\
LA & Kn4 & $380+$ & $22,1 \pm 0,3$ & $3,4 \pm 0,4$ \\
\hline
\end{tabular}

(1)EH: Espodossolo Humilúvico; LA: Latossolo Amarelo.

Os teores de alumínio foram mais elevados que os de ferro tanto no Espodossolo Humilúvico como no Latossolo Amarelo (Tabela 5.4).

Houve uma clara tendência de aumento em subsuperfície nos teores de alumínio até o horizonte de transição e para o ferro até os horizontes espódicos (Bh e Bhs) para o Espodossolo Humilúvico (Figura 5.25 (a) e (b)).

Como pode ser observado na Tabela 5.4 e Figura 5.25 (a), os resultados mostraram uma diminuição nos teores de alumínio para o Espodossolo Humilúvico dos horizontes superficiais orgânicos (A1 e A2) até os horizontes álbicos (E1 e E2), ocorrendo um ligeiro aumento nos horizontes espódicos (Bh e Bhs). O horizonte de transição (Tr) foi o que apresentou o maior teor de alumínio, o que significa acumulação absoluta, indicando a formação de complexos entre este elemento e a MOS.

Para os teores de Fe no Espodossolo Humilúvico (Tabela 5.4 e Figura 5.25 (b)), notou-se uma diminuição nos teores dos horizontes superficiais orgânicos (A1 e A2) até os horizontes álbicos (E1 e E2). Nos horizontes espódicos (Bh e Bhs) foi observado um aumento no teor de ferro, em comparação aos horizontes superiores, 
voltando a diminuir no horizonte de transição.

Neste perfil, observa-se que a translocação da MO ligada ao ferro e ao alumínio com posterior acúmulo no horizonte de transição é facilitada em solos de textura mais arenosa, como é o caso deste Espodossolo Humilúvico e na maioria dos Espodossolos do mundo (Andriesse, 1969; Anderson et al., 1982; Oliveira et al., 1992; Gomes, 1995; Resende et al., 1997; Moura Filho, 1998; Côrrea et al., 1999; Oliveira, 2007). O ferro estaria se movendo não ligado a MO e sim por oxirredução, estando mais relacionado a ela do que com a complexação.

Os teores de alumínio conforme citado anteriormente foram mais elevados que os de ferro para o Espodossolo Humilúvico, sugerindo maior participação de formas de alumínio ligadas a ácidos orgânicos no processo de podzolização que o ferro. Além de uma possível maior riqueza de Al neste sistema LatossoloEspodossolo, em ambientes com lençol freático elevado, o enriquecimento de ferro não ocorre, provavelmente devido a este elemento estar saindo do sistema por redução.

No Espodossolo Humilúvico, segundo as observações feitas por Ishida (2010) para este perfil de solo, nota-se que as soluções ácidas carregadas de complexos organometálicos (ferro e alumínio) circulam rapidamente através dos poros de circulação dos horizontes álbicos (E1 e E2) pobres em superfícies de trocas, não permitindo a retenção desses complexos produzidos nos horizontes superficiais orgânicos (A1 e A2). Parte desses complexos se depositam em profundidade sobre o caulim (K1 e K2), constituindo os horizontes espódicos (Bh e Bhs) e, acumulandose na transição, concordando com os resultados de ICP OES.

Estes resultados corroboram com o estudo desenvolvido por Oliveira (2007) utilizando um conjunto de Espodossolos situados no Sul do Estado da Bahia, onde observou acúmulo de ferro e alumínio nos horizonte B espódico destes solos, e, que os teores de alumínio foram mais elevados que os de ferro neste mesmo horizonte, resultado similar ao observado acima, sugerindo maior participação de formas de alumínio ligadas a ácidos orgânicos no processo de podzolização que o ferro. Também corrobora com os resultados do trabalho de Ishida (2010), trabalhando com os mesmos perfis de solo utilizados neste estudo, observou em sua análise mineralógica para o Espossolo Humilúvico que as perdas são totais do horizonte superficial $\mathrm{A} 1$ até o espódico Bhs e a partir deste, ocorre ganho de $\mathrm{Al}$, o que significa acumulação absoluta no horizonte de transição, resultado da translocação do 
alumínio e do ferro na forma de complexos orgânicos para os horizontes espódicos.

Figura 5.25 - Dados dos teores de alumínio (a) e ferro (b) obtidos para as amostras de solo do Espodossolo Humilúvico por ICP OES no perfil de amostragem.
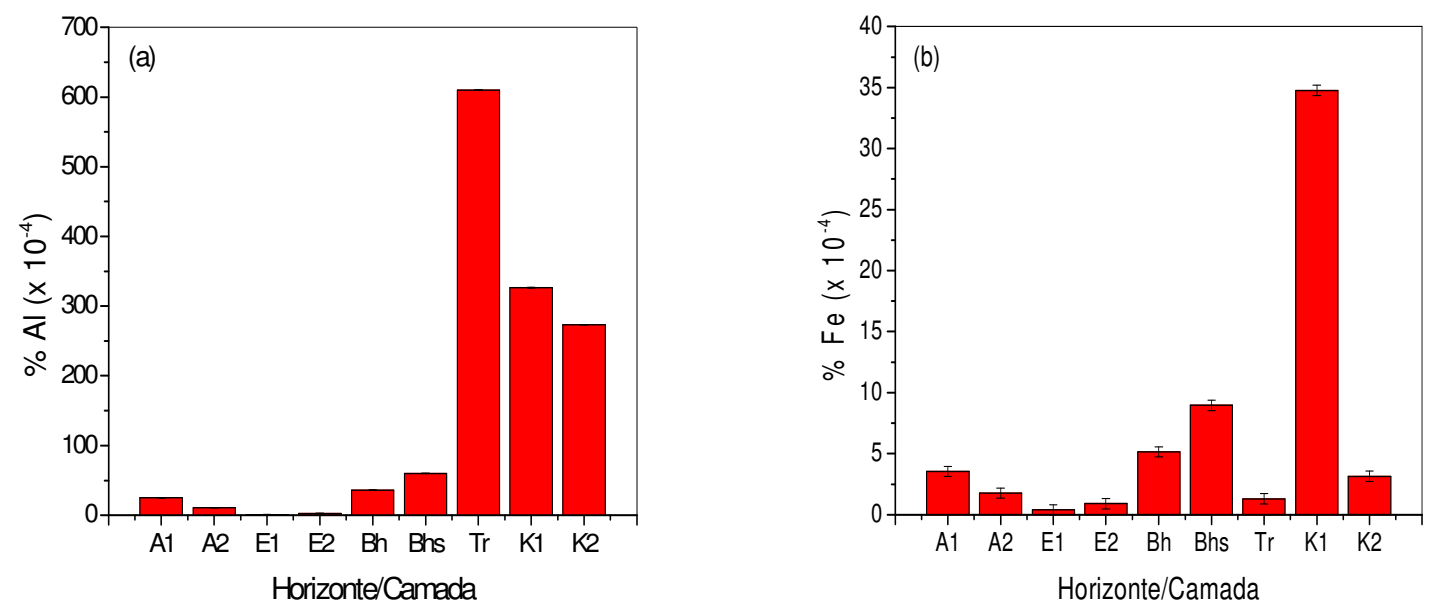

Figura 5.26 - Dados dos teores de alumínio (a) e ferro (b) obtidos para as amostras de solo do Latossolo Amarelo por ICP OES no perfil de amostragem.
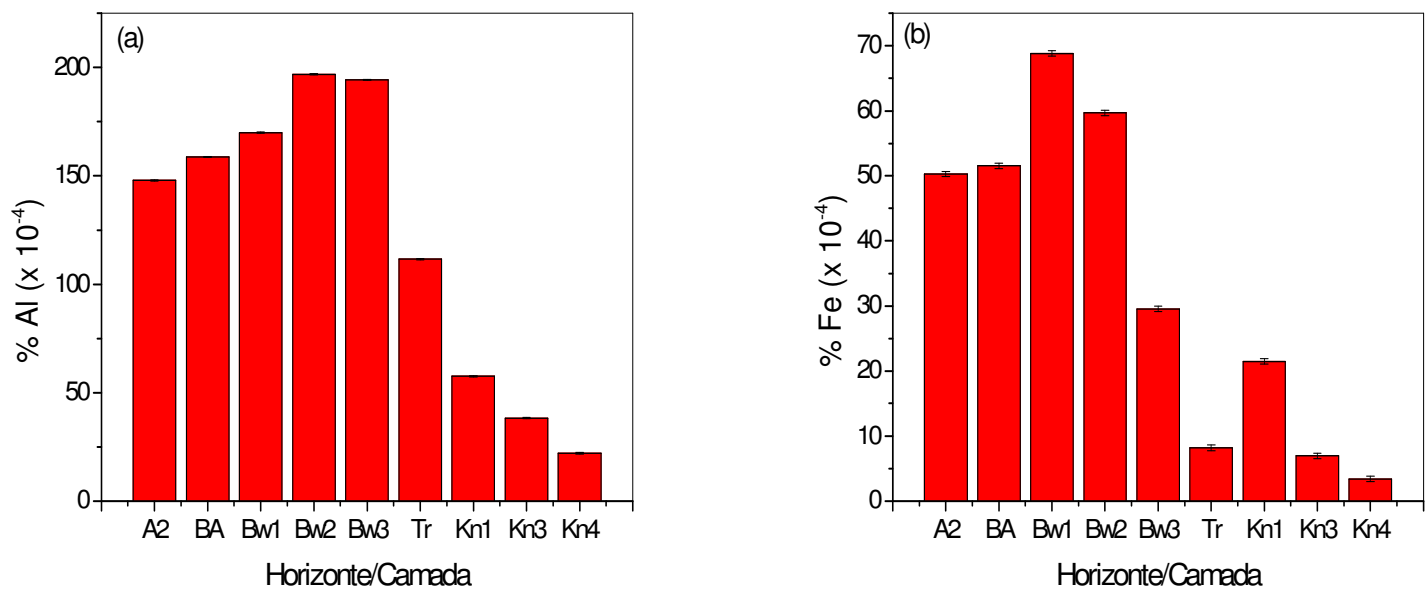

Para o Latossolo Amarelo, os teores de alumínio são marcados por um ligeiro incremento do horizonte superficial A2 ao latossólico Bw3 e passam a diminuir do horizonte de transição (Tr) até o horizonte de caulim Kn4 (Tabela 5.4 e Figura 5.26 (a)). Estes resultados teriam relação com a dissolução da caulinita, em razão de perdas de alumínio observadas na maior parte dos horizontes superficiais (A2 e BA) e latossólicos (Bw1, Bw2 e Bw3) corroborando com os resultados da análise mineralógica de Ishida (2010) para estes horizontes. Na transição e nos horizontes de caulim houve diminuição nos teores de alumínio, contrastando os resultados de 
Ishida (2010) para estes horizontes, onde observou pequenos ganhos de alumínio para estes horizontes.

Da mesma forma que no Espodossolo Humilúvico, os teores de ferro foram mais baixos que os teores de alumínio ao longo de todo o perfil. Entretanto, o Latossolo Amarelo apresenta um progressivo aumento do horizonte superficial A2 ao latossólico Bw1. Os teores de ferro sofrem diminuição do horizonte latossólico Bw2 até o horizonte de caulim $\mathrm{Kn} 4$, exceção ao horizonte $\mathrm{Kn} 1$ onde volta a ter um aumento (Tabela 5.4 e Figura 5.26 (b)). Montes (2009) também observou diminuição nos valores de alumínio e ferro quando comparados aos teores encontrados no Espodossolo Humilúvico.

Uma hipótese para explicar estes resultados seria que tanto a mobilização como a precipitação dos complexos organometálicos (ferro e alumínio) e dos óxidos e oxidróxidos de ferro (goethita e hematita) são controlados pela oscilação do nível dos aquíferos suspensos. Os períodos mais chuvosos propiciam a mobilização dos complexos organometálicos e do ferro reduzido, enquanto nos períodos menos chuvosos, o nível dos aquíferos baixa e as condições oxidantes permitem a precipitação do ferro na porosidade e a menor mobilização dos complexos organometálicos. Em ambientes com períodos mais chuvosos e lençol freático suspenso, como citado anteriormente, o enriquecimento de ferro não ocorre, provavelmente devido a este elemento estar na forma reduzida $\left(\mathrm{Fe}^{2+}\right)$.

\subsubsection{NOVAS FERRAMENTAS DE ANÁLISE PARA SOLOS}

\subsubsection{ESPECTROSCOPIA DE EMISSÃO ÓTICA COM PLASMA INDUZIDO POR LASER (LIBS)}

A análise LIBS das amostras de solo resultou em um espectro de linhas de emissão complexo. A Figura 5.27 ilustra um espectro de LIBS característico obtido para o horizonte superficial organo-mineral A1 do Espodossolo Humilúvico (0 - 5 $\mathrm{cm})$. 
Figura 5.27 - Espectro típico de LIBS obtido para o horizonte superficial organomineral $A 1$ do Espodossolo Humilúvico sem correção do offset.

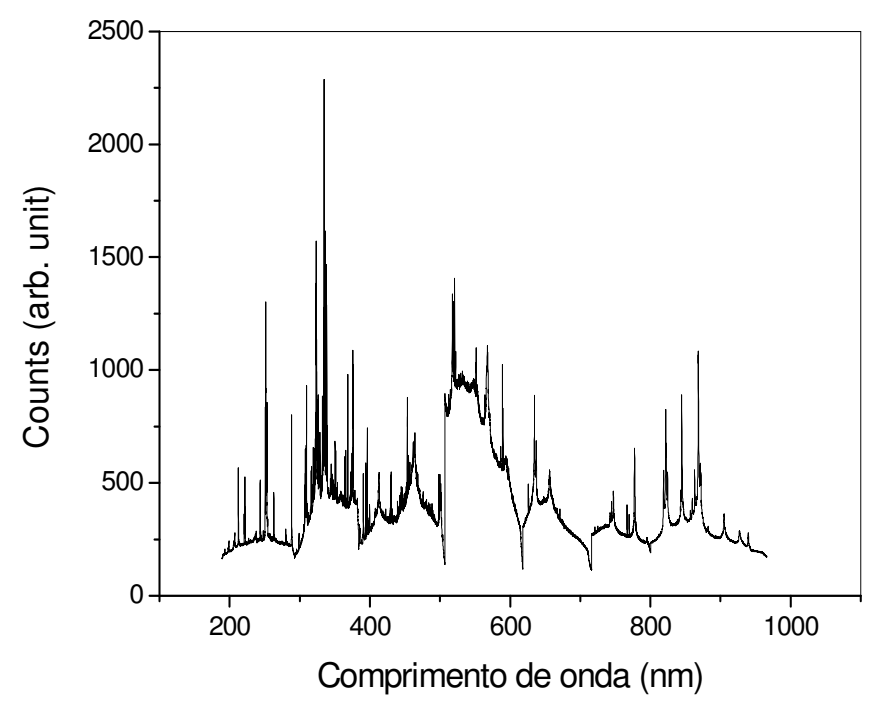

A Figura 5.28 mostra um espectro típico de LIBS do horizonte de transição ( $\mathrm{Tr}$ ) do Espodssolo Humilúvico. Na Figura 5.28 não é possível observar linhas de $\mathrm{Fe}$ no espectro LIBS das pastilhas do Espodossolo Humilúvico, provavelmente, porque a concentração de Fe presente está abaixo do limite de detecção ótica.

A linha de $C$ em 247,86 nm sofre interferência pela linha atômica de $\mathrm{Fe}$ em 247,94 nm, e a linha de C em 193,03 nm tem interferência por três linhas de Al em 193,04 nm (iônica), 193,16 nm (atômica) e 193,58 nm (atômica), não separáveis nos sistemas LIBS de baixa resolução $(\sim 0,1 \mathrm{~nm})$. É importante enfatizar que o Fe é geralmente encontrado em solos brasileiros (Barford et al., 2001; Montes et al., 2011), e a sua interferência na linha de carbono em $247,86 \mathrm{~nm}$ é relevante e, impede a sua utilização em modelos univariados para a quantificação de carbono no solo (Cremers et al., 2001; Ebinger et al., 2003; Krishna et al., 2012). 
Figura 5.28 - Espectro LIBS da amostra do Espodossolo Humilúvico no horizonte de transição (Tr).

(a)

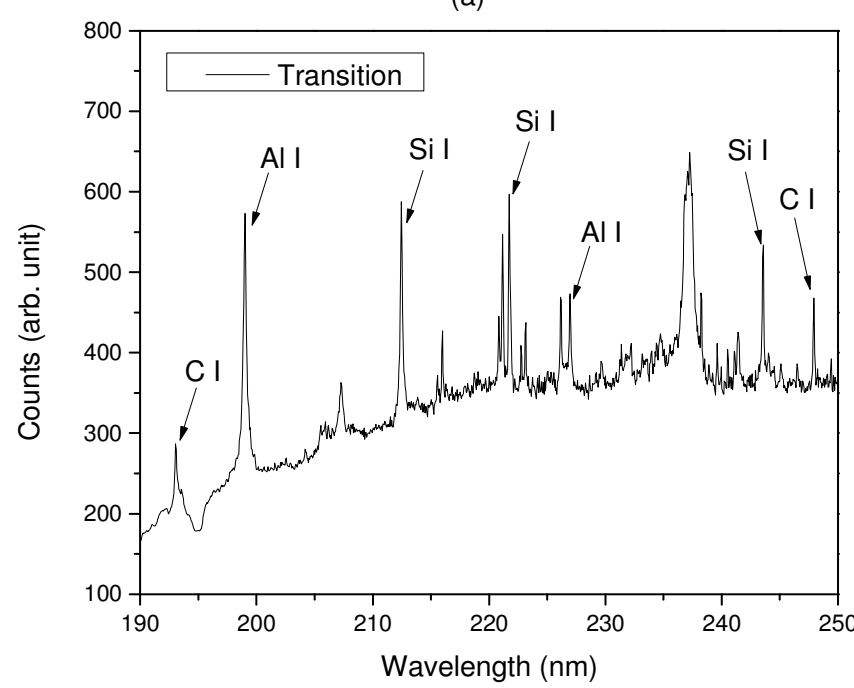

A Figura 5.29 mostra as linhas de $\mathrm{C}$ e Al em duas amostras do Espodossolo Humilúvico analisadas: (a) linha de C em 193,03 nm interferida por Al no horizonte espódico (Bhs) e (b) linha de C em 247,9 nm no horizonte de transição (Tr).

Figura 5.29 - Linhas de emissão de $\mathrm{C}$ em diferentes amostras do Espodossolo Humilúvico: (a) da linha de C em 193,03 nm interferida por Al no horizonte espódico Bhs e (b) da linha de C em 247,9 nm no horizonte de transição Tr.
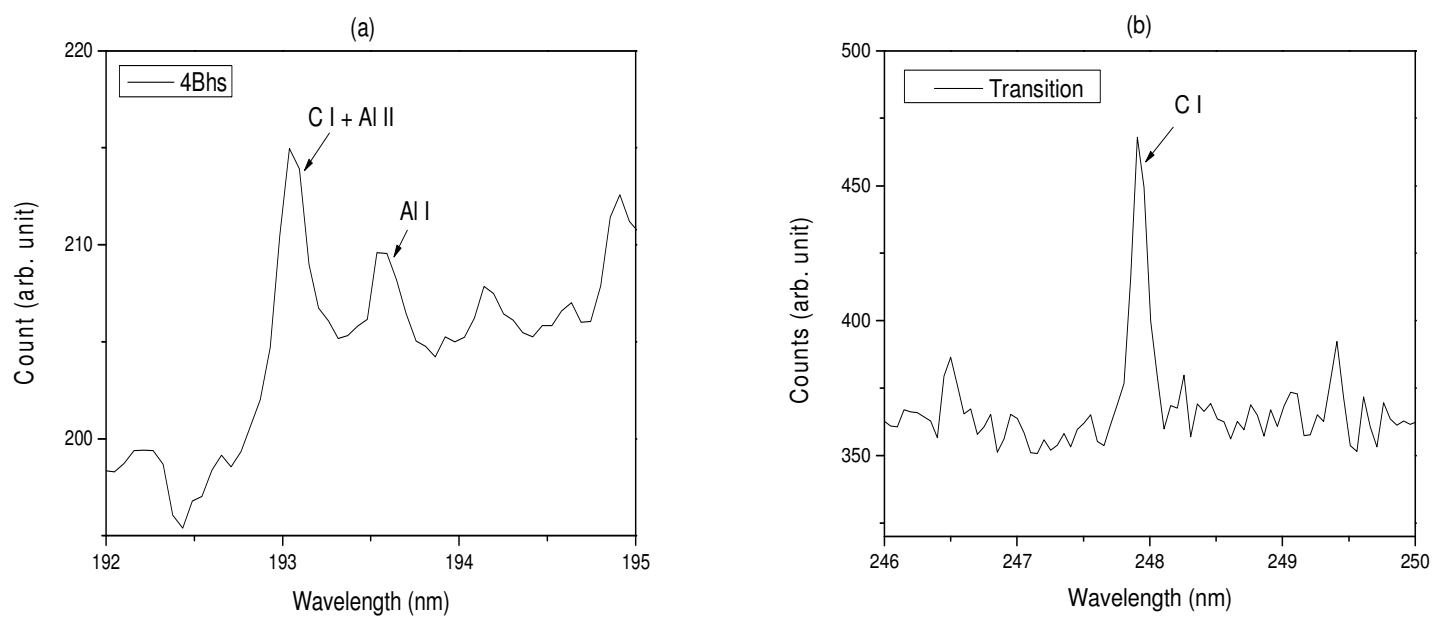

A fim de resolver o problema da interferência entre as linhas de $\mathrm{C}$ e Al, um novo modelo foi aplicado e testado para as amostras de solos. Na faixa espectral perto da linha de C detectada (193 nm), foi encontrado um pico em 193,03 nm composto por uma linha de emissão atômica de $\mathrm{C}$ e uma emissão iônica de $\mathrm{Al}$ e um segundo pico em 193,58 nm, correspondendo a uma emissão atômica de Al. Os 
picos observados foram alargados e, devido à baixa resolução do espectrômetro não é possível separar totalmente esses picos. A faixa espectral analisada 193,03193,58 nm, de acordo com o banco de dados do NIST, mostra apenas as transições devido ao dubleto de elementos iônicos (X III), que não são detectados pelo espectrômetro utilizado, ou elementos atômicos (XI) com uma probabilidade muito baixa de nível de transição. Confirmando, desta forma, que somente Al I, Al II e transições de C I podem estar presentes nesta região espectral. As linhas de emissão investigadas foram: (a) C I (193,03 nm) e Al II (193,04 nm); e (b) Al I $(193,58 \mathrm{~nm})$ e foram utilizados no modelo.

O pico de Al I da transição (193,58 nm) foi usado para corrigir a interferência do Al II da transição $(193,04 \mathrm{~nm})$ no pico da linha de C I (193,03 nm). A função de ajuste duplo foi necessário devido à falta de resolução do espectrômetro para resolver (separar) espacialmente esses picos. A função gaussiana foi escolhida por causa do erro pequeno no processo de ajuste. $A$ Área $1\left(A_{C}+A_{1}\right)$, correspondendo às transições em 193,03 nm (C I + Al II + Al I) e Área $2\left(A_{A I}\right)$ na transição em 193,58 nm (AI I) foram extrapolados após a realização do ajuste gaussiano duplo na faixa espectral. Um modelo de correção simples foi proposto para resolver a interferência das linhas de Al na área de C, obtida a partir da equação:

$$
A_{C+A l}-\alpha_{1} A_{A l}=A_{C 247}
$$

onde o $A_{\mathrm{C} 247}$ corresponde a um pico de carbono puro em 247,86 nm. O parâmetro " $\alpha_{1}$ " foi otimizado através da realização de um ajuste linear para o melhor coeficiente de Pearson. Assumindo a proporcionalidade entre as linhas de alumínio (193,04 nm e 193,58 nm), este parâmetro otimizado elimina a interferência de alumínio na região de carbono.

A Figura 5.30 mostra um espectro da amostra do Espodossolo Humilúvico no horizonte Bhs (linha cheia) em comparação com uma amostra de referência de $\mathrm{Al}$ (linha pontilhada) e para uma amostra de grafite (linha tracejada). 
Figura 5.30 - Espectro de uma amostra do horizonte espódico Bhs do Espodossolo Humilúvico (linha cheia) em comparação com a amostra de referência de Al (linha pontilhada) e de grafite (linha tracejada).

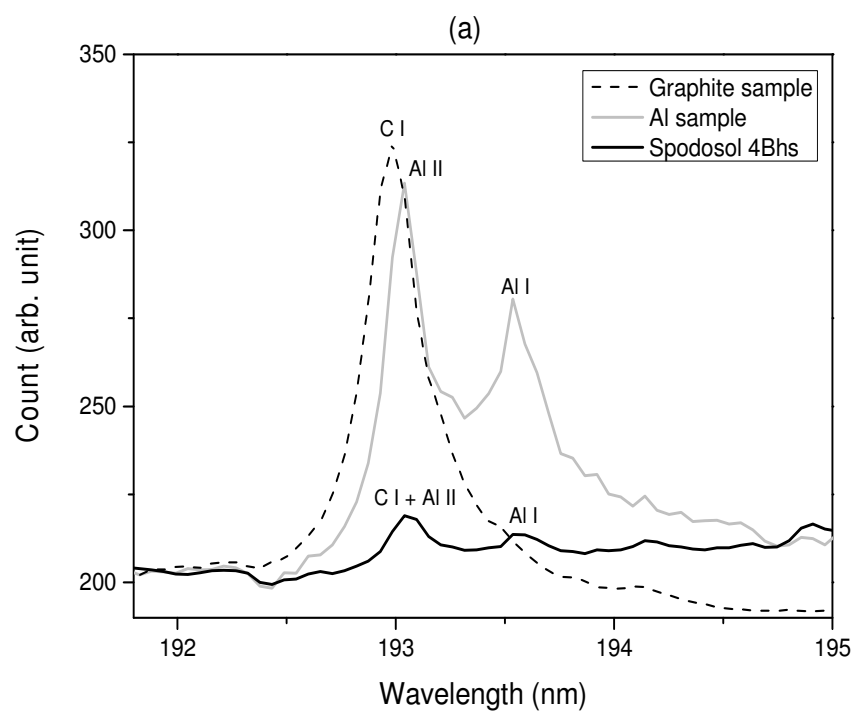

A fim de aplicar a equação (1), dois pressupostos são necessários: (a) a temperatura de excitação precisa ser a mesma para todas as amostras e (b) a relação entre as intensidades da linha de Al atômica e iônica necessita ser constante para todos os espectros.

Em relação à quantificação de carbono, a linha de emissão de $C$ (I) em 193,03 nm foi usada. As amostras de solo do Espodossolo Humilúvico foram consideradas na comparação entre as intensidades das linhas de $C$ do LIBS e o teor de $\mathrm{C}$ determinado pela técnica de referência utilizada o CHNS. As amostras extraídas do horizonte de caulim (K1 e K2), não foram contabilizadas, porque esses horizontes de caulim formados a partir de rochas sedimentares são considerados minério e não solo.

Como pode ser observado na Tabela 5.1, para a maioria das amostras de solo do Latossolo Amarelo o teor de carbono é inferior a 0,3\%, o limite de detecção do CHNS. No entanto, para efeito de comparações entre as linhas de emissões de LIBS e o teor de C, foram consideradas apenas as amostras de solos do Espodossolo Humilúvico.

A Figura 5.31 apresenta as áreas LIBS da linha de C em 193,03 nm, corrigido pelas linhas de $\mathrm{Al}$ como uma função do teor de $\mathrm{C}$ determinado por CHNS para as amostras do Espodossolo Humilúvico. Uma forte correlação entre estas medidas foi encontrada e o coeficiente de correlação de Pearson obtido para o ajuste logarítmico 
foi de $R=0,98$ com baixa dispersão $P<0,0001$.

Figura 5.31 - Correlação entre o teor de carbono determinado por CHNS (método padrão) e as intensidades LIBS da linha de C em 193,03 nm.

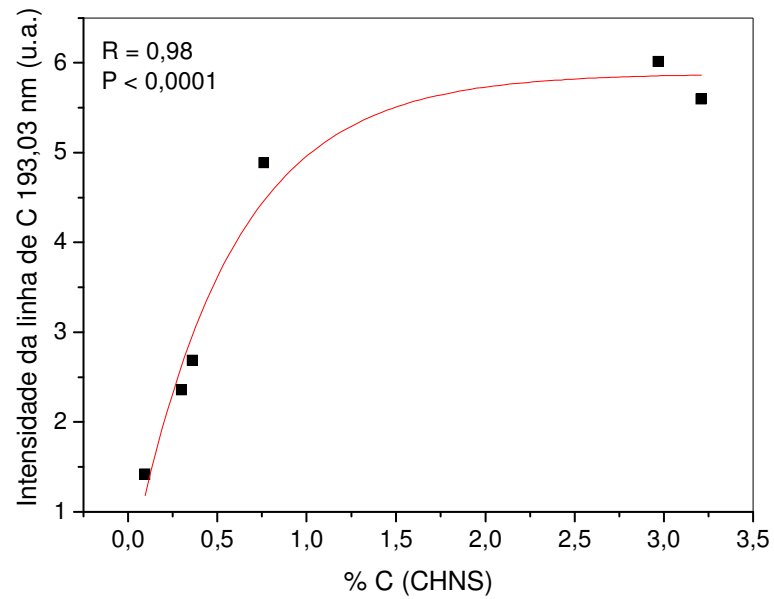

Este resultado indica que LIBS pode ser utilizado semi-quantitavivamente para avaliar o teor de carbono em cada horizonte do Espodossolo. Assim, LIBS pode ser usado como uma ferramenta de triagem no campo para selecionar amostras relevantes para futuras investigações laboratoriais.

$\mathrm{Na}$ Figura 5.32 é apresentado o gráfico de barras correspondente às áreas LIBS da linha de $C$ em 193,03 nm para as amostras do Espodossolo Humilúvico.

Figura 5.32 - Área LIBS da linha de C em 193,03 nm das amostras do Espodossolo Humilúvico no perfil de amostragem.

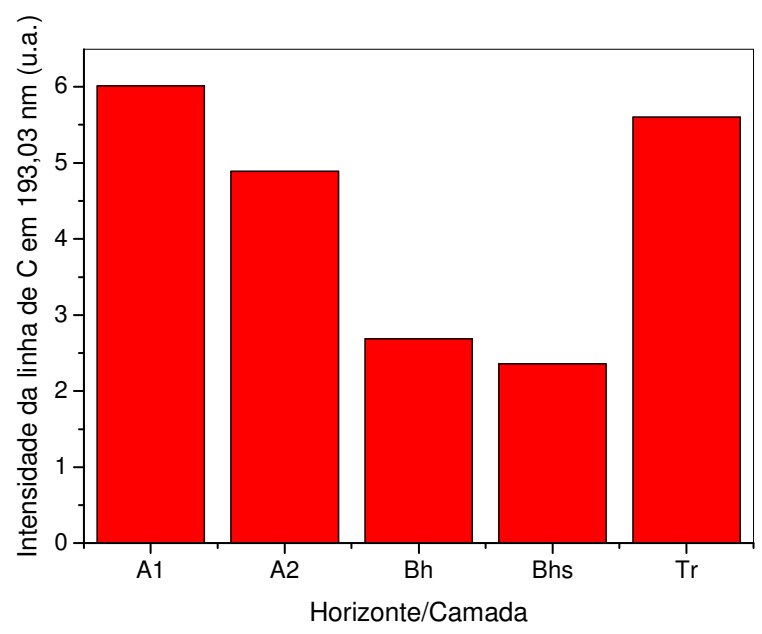

A variação do carbono em diferentes horizontes do solo indica que a MOS produzida na superfície foi translocada dos horizontes superiores arenosos, 
acumulando carbono no horizonte de transição ( $\mathrm{Tr}$ ) entre os horizontes arenosos e caulim, a uma profundidade de 1 a $3 \mathrm{~m}$. Estas características indicam um processo pedogenético de podzolização ocorrendo no Espodossolo Humilúvico (Figura 5.32).

Para o Latossolo Amarelo, não foi possível a obtenção das áreas LIBS da linha de C em 193, 03 nm, devido à concentração de carbono não atingir o limite de detecção do LIBS e sofrer interferência por três linhas de Al em 193,04nm (iônica), 193,16 nm (atômica) e 193,58 nm (atômica).

Comparações entre a concentração de elementos como ferro e alumínio no perfil do solo também podem explicar propriedades importantes, tais como os processos pedogenéticos. Assim, os teores de Fe e Al nas amostras de solos estudados foram determinados por ICP OES, após digestão ácida utilizando água régia $\left(1 \mathrm{HNO}_{3}: 3 \mathrm{HCl} \mathrm{v} \mathrm{v}{ }^{-1}\right)$ em um sistema aberto. As concentrações obtidas através deste procedimento foram correlacionadas com as áreas LIBS da linha de emissão de Al (II) em 199,01 nm extraídos a partir dos espectros LIBS anteriormente utilizados para a avaliação de C.

A Figura 5.33 apresenta a correlação entre as áreas LIBS da linha de Al em $199,01 \mathrm{~nm}$ e os teores de Al determinado por ICP OES para as amostras do Espodossolo Humilúvico e Latossolo Amarelo.

Figura 5.33 - Correlação entre o teor de alumínio determinado por ICP OES (método padrão) e as intensidades LIBS da linha de Al em 199,01 nm do Espodossolo Humilúvico (a) e Latossolo Amarelo (b), nos perfis de amostragem.
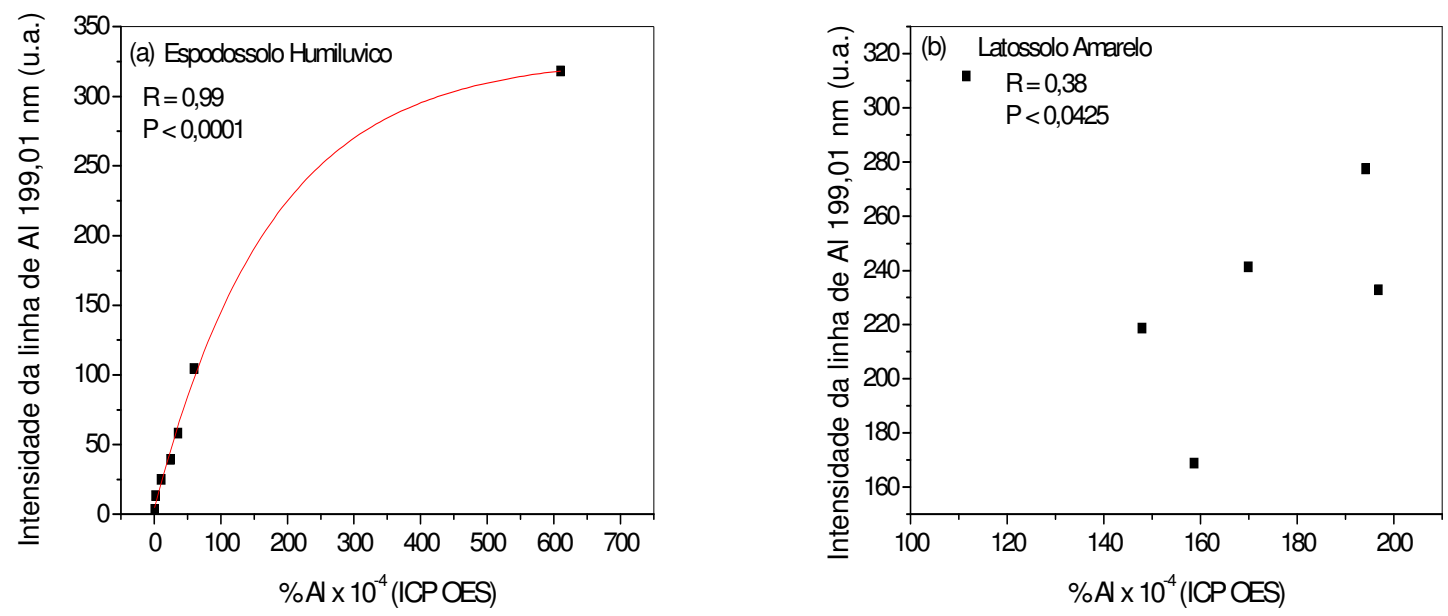

Uma forte correlação entre essas medidas foi encontrada para o Espodosolo Humilúvico e o coeficiente de correlação de Pearson obtido para o ajuste logarítmico 
foi de $R=0,99$ com baixa dispersão $P<0,0001$ (Figura 5.33 (a)). Por outro lado, para o Latossolo Amarelo o coeficiente de correlação de Pearson foi baixo, $R=0,38$ (não foi possível obter um valor alto porque nessa linha do Al, nesse solo, sofre uma interferência pela linha de Ti II (198,99 nm)) com $P<0,0425$ para as medidas de ICP OES e LIBS (Figura 5.33 (b)). Para o Espodossolo Humilúvico pode-se notar os bons resultados de LIBS para baixos valores de Al total.

Em relação ao ferro, não foi possível fazer uma correlação entre os valores das análises de Fe total por ICP OES e os valores das análises determinadas por LIBS. Isto pode ser devido aos baixos teores de Fe das amostras de solos estudadas, não atingindo o limite de detecção do LIBS.

\subsubsection{ESPECTROSCOPIA DE FLUORESCÊNCIA INDUZIDA POR LASER (FIL)}

A avaliação quanto ao grau de humificação, parâmetro importante para a determinação da estabilidade da MOS (Santos, 2009), em amostras de solos inteiros, pela FIL, é uma metodologia nova, porém com resultados importantes e eficientes, por não ser destrutiva, ágil, limpa, e bem próximas às condições naturais (Milori et al., 2003, 2006).

As análises de FIL foram feitas a fim de se obter informação a respeito do índice de humificação $\left(\mathrm{H}_{\mathrm{FIL}}\right)$ da matéria orgânica do solo, usando amostras de solo inteiro (solos não submetidos a tratamentos químicos ou físicos).

$\mathrm{O}$ índice de humificação $\mathrm{H}_{\mathrm{FIL}}$ foi obtido através do cálculo da razão entre o valor da área sob o espectro de emissão de fluorescência (ACF) com excitação na região do azul e ultravioleta próximo e o valor de carbono orgânico total (COT) presente na amostra de solo inteiro (Milori et al., 2006), ou seja:

$$
H_{F L L}=\frac{A C F}{C O T}
$$

A razão entre $A C F$ e COT foi feita para normalizar amostras com diferentes teores de carbono. A adoção da área sobre a curva de fluorescência (ACF) como parâmetro para estimativa da humificação se baseia na metodologia para análise de fluorescência de AH em solução proposta por Milori et al. (2002), ou seja, o índice de humificação $A_{465}$.

Os espectros de fluorescência induzida por laser obtidos para as amostras de 
solo inteiro do Espodossolo Humilúvico e Latossolo Amarelo nos perfis da amostragem são apresentados na Figura 5.34.

Figura 5.34 - Espectros de FIL obtidos para todas as amostras de solo inteiro do Espodossolo Humilúvico (a) e Latossolo Amarelo (b), nos perfis de amostragem.
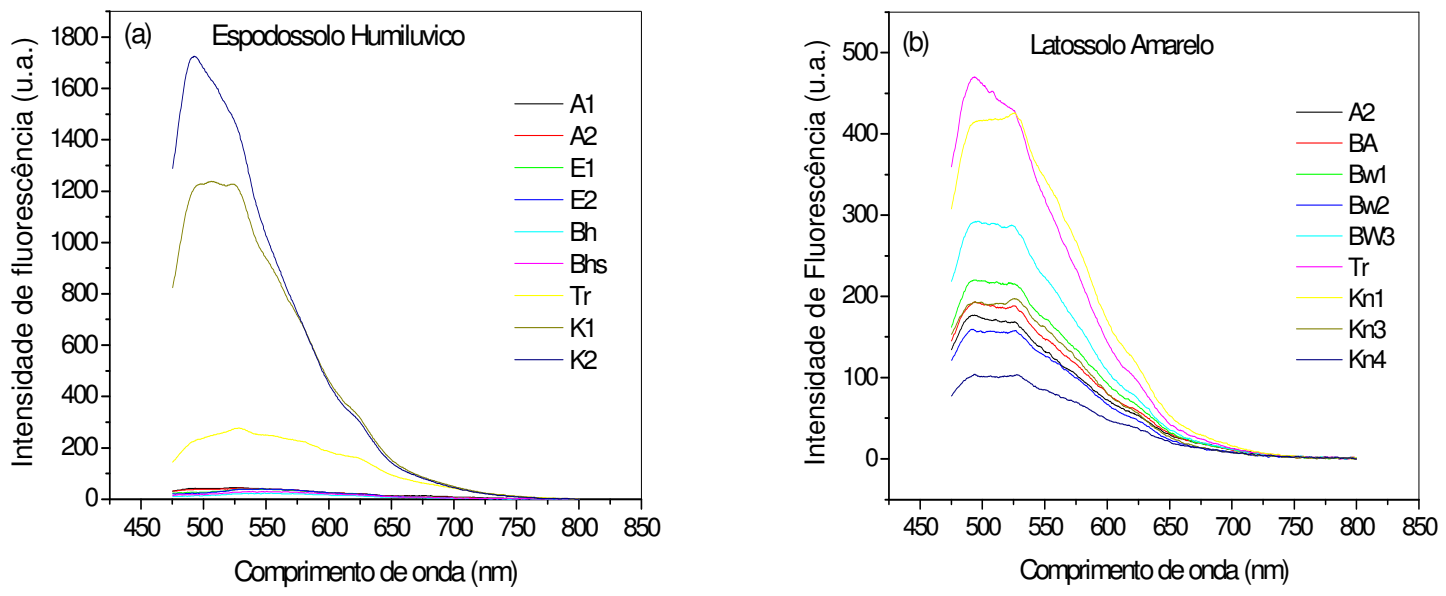

Os espectros de emissão de FIL das amostras de solo inteiro (Espodossolo Humilúvico e Latossolo Amarelo) mostrados na Figura 5.34, apresentam uma banda larga centrada em $510 \mathrm{~nm}$. Observou-se uma maior intensidade de sinal de fluorescência para as amostras de solo inteiro do Espodossolo Humilúvico do horizonte de transição (Tr), e, destacando-se os horizontes de caulim (K1 e K2) (Figura 5.34 (a)). Para o Latossolo Amarelo (Figura 5.34 (b)), nota-se que a maior intensidade de sinal de fluorescência foi observada para os horizontes Tr e Kn1.

$\mathrm{Na}$ Figura 5.35, tem-se o comportamento do grau de humificação em função das profundidades para os solos amazônicos analisados, Espodossolo Humilúvico e Latossolo Amarelo. 
Figura 5.35 - Valores de $\mathrm{H}_{\mathrm{FIL}}$ obtidos para todas as amostras de solo inteiro do Espodossolo Humilúvico (a) e Latossolo Amarelo (b), nos perfis de amostragem.
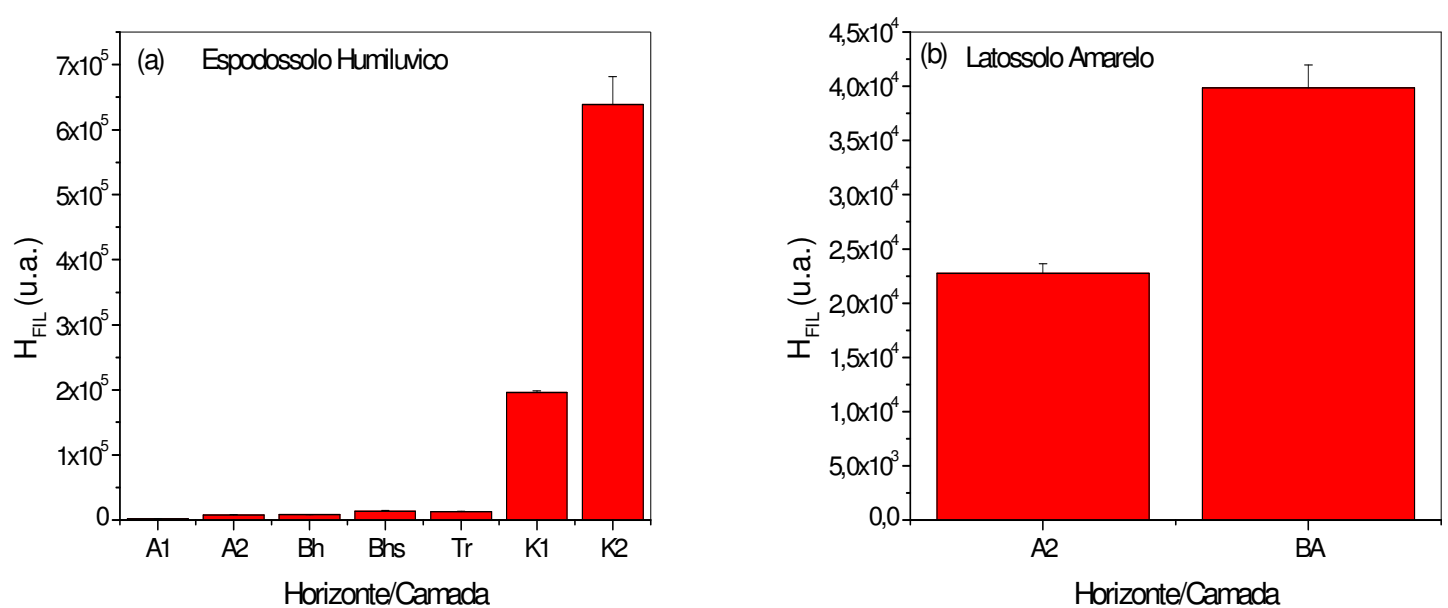

*Espodossolo Humiluvico: horizontes E1 e E2 (teor de carbono < LOD).

*Latossolo Amarelo: horizontes Bw1, Bw2, Bw3, Tr, Kn1, Kn3 e Kn4 (teor de carbono < LOD).

Os resultados do grau de humificação obtidos pela espectroscopia de FIL do Espodossolo Humilúvico nos horizontes superficiais orgânicos (A1 e A2) não apresentou variações significativas no grau de humificação da $\mathrm{MO}$, pelo fato de serem mais ricos em matéria orgânica, decomposta ou não, conforme observado por (Ishida, 2010). Abaixo dos horizontes superficiais orgânicos desenvolvem-se horizontes álbicos acinzentados e quartsozos (E1 e E2), mas como nestes horizontes o teor de carbono é inferior ao limite de detecção do CHNS, não foi possível a obtenção do índice de humificação $\mathrm{H}_{\mathrm{FIL}}$.

Nos horizontes álbicos (E1 e E2), a ocorrência de uma frente de intemperismo que provoca a decomposição da $\mathrm{MO}$, também ocasiona a dissolução dos minerais mais alteráveis, o acúmulo residual de quartzo e a mobilização do ferro e alumínio, extraídos dos oxidróxidos e óxidos, provavelmente como complexos organometálicos quando reagem com os ácidos orgânicos (Anderson et al., 1982), que são características indicando que neste perfil ocorre o processo pedogenético de podzolização de forma intensa transformando o Latossolo em Espodossolo (Lucas et al., 1984; Ishida, 2010).

Na parte intermediária do Espodossolo Humilúvico ocorre a formação dos horizontes espódicos Bh e Bhs. O processo de formação desses horizontes é um exemplo clássico da importância das substâncias húmicas na gênese dos solos. 0 material orgânico humificado dos horizontes superficiais do solo forma complexos 
organometálicos com íons Al e Fe, principalmente, sendo eluviado ao longo do perfil para formar os horizontes Bh ou Bhs em subsuperfície (Buol et al., 1980). Entre os horizontes espódicos e o de transição ( $T r$ ) não observa-se diferenças significativas no grau de humificação.

O horizonte Bh é pouco espesso e contínuo, bruno-acinzentado devido ao depósito de matéria orgânica (tipo monomórfica), caracterizada por uma massa contínua e uniforme na cor e densidade, entre os grãos de quartzo (Figura 5.36 (a)) e à presença de raízes em diferentes estágios de decomposição, observados ao microscópio petrográfico. O horizonte Bhs é bruno acinzentado em razão da iluviação da matéria orgânica polimórfica no topo (Figura 5.36 (b)) e é avermelhado, argiloso e endurecido devido à precipitação dos óxidos e oxidróxidos de ferro na base (Figura 5.36 (c)), conforme descrito no trabalho de Ishida (2010).

Foram observados no topo do horizonte de transição (Tr) canais constituídos por restos de raízes em avançado estágio de decomposição (Figura 5.36 (e)) cortados por raízes finas aparentemente ainda frescas. Observações feitas por Ishida (2010) através de um microscópio petrográfico evidenciam a ocorrência de intensa atividade biológica (Figura 5.36 (d)). Conforme relatado no trabalho citado, a presença desses horizontes indica a ocorrência de uma frente de podzolização que consiste na migração, mobilização e acúmulo tanto de ferro e alumínio como de compostos orgânicos e matéria orgânica, que é uma peculiaridade dos Espodossolos de apresentar um horizonte com acúmulo expressivo de $\mathrm{MO}$ em subsuperfície, o horizonte espódico (Bh ou Bhs) (Figura 5.35 (a)). 
Figura 5.36 - (a) Foto do perfil do Espodossolo Humilúvico mostrando a localização aproximada das fotomicrografias (b, c, d, e) de lâminas delgadas obtidas ao microscópio petrográfico. As setas brancas em (a) indicam os canais constituídos por restos de raízes decompostas; (b) horizonte Bh (espódico) com iluviação de matéria orgânica amorfa (monomórfica) depositada na porosidade entre os cristais de quartzo; (c) o topo do horizonte Bhs apresenta matéria orgânica polimórfica depositada na porosidade, porém em menor quantidade do que em Bh; (d) na base do horizonte Bhs foi observado plasma ferruginoso; (e) imagem obtida na transição entre os horizontes Bhs e de transição mostra no lado esquerdo plasma ferruginoso e do lado direito um pedotúbulo preenchido por raiz em avançado estágio de decomposição cortado por uma raiz fresca e fina.
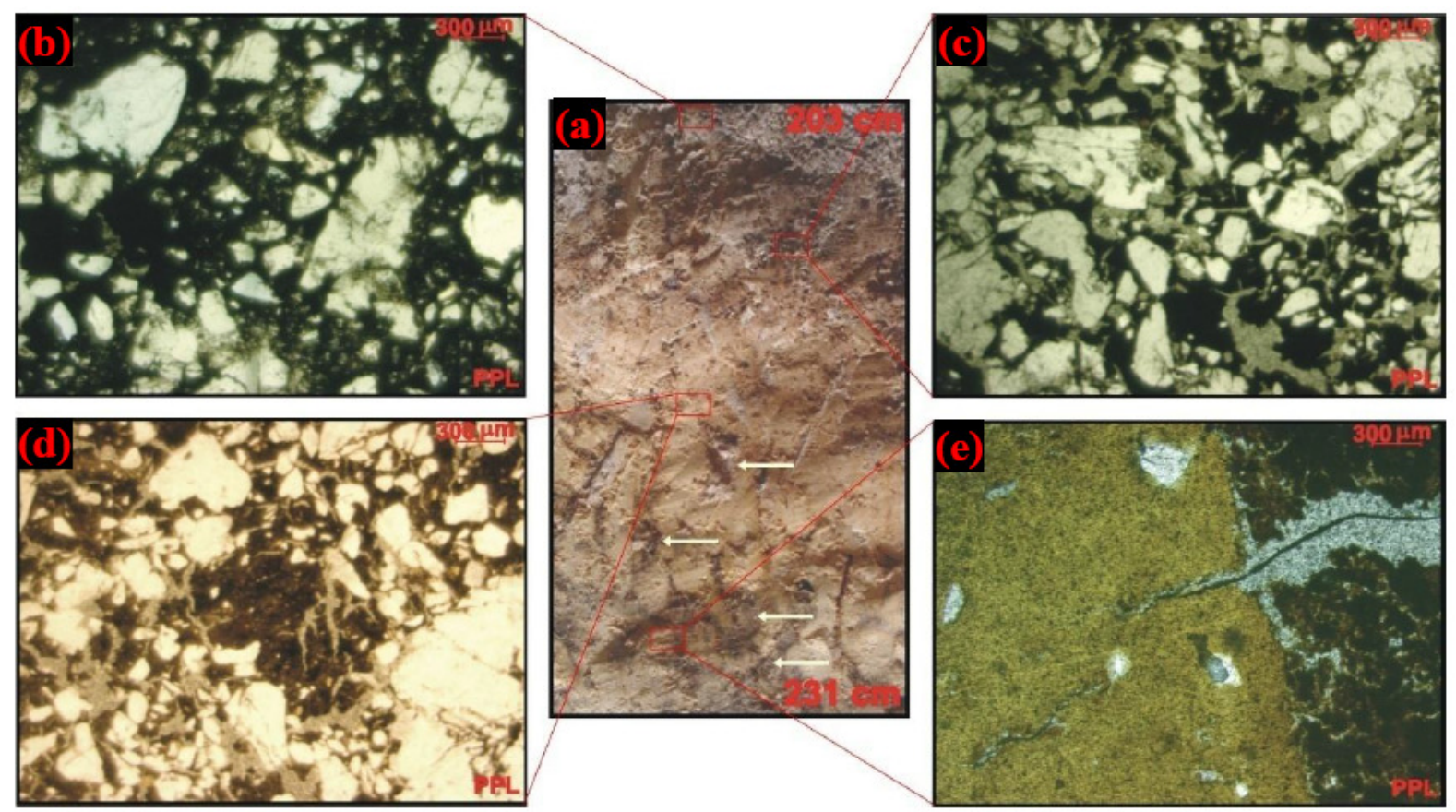

Fonte: Adaptado de Ishida (2010).

A parte inferior do perfil, horizontes K1 e K2 (Figura 5.35 (a)) apresentou o maior grau de humificação em comparação com os demais horizontes, e isso se deve ao fato que nestes horizontes foram observados canais com raízes em elevado estágio de decomposição (Figura 5.37). Assim, as ocorrências dos horizontes espódicos e dos mosqueados (manchas avermelhadas e amareladas), especialmente nos caulins (K1 e K2), indicam que tanto a precipitação como a mobilização dos complexos organometálicos (ferro e alumínio) são controladas pela oscilação do nível dos aquíferos suspensos. Nos horizontes de caulins, este aumento no grau de humificação pode sugerir que parte da matéria orgânica humificada teria ficado retida nos poros desses horizontes argilosos. 
Figura 5.37 - Foto do perfil do Espodossolo Humilúvico mostrando canais de precipitação de $\mathrm{Fe}$ e de decomposição da $\mathrm{MO}$ indicados pelas setas branca e verde, respectivamente.

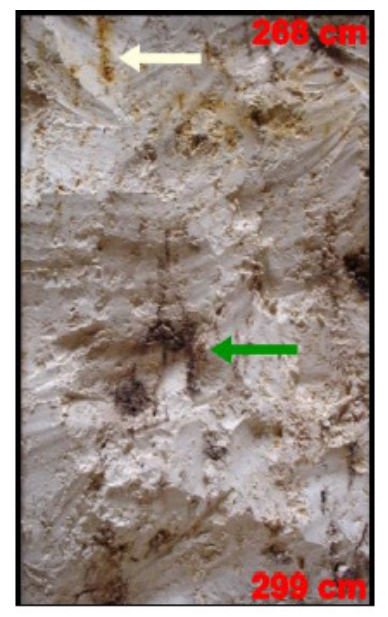

Fonte: Ishida (2010).

Uma hipótese para explicar este comportamento citado anteriormente, seria que no horizonte de transição $(\mathrm{Tr})$ do Espodossolo Humilúvico, estaria ocorrendo o acúmulo de matéria orgânica iluvial em subsuperfície. O horizonte K1 estaria funcionando como uma "peneira molecular" permitindo a passagem para o horizonte de caulim K2 de compostos com estruturas mais humificadas, mais complexas, de difícil degradação (mais recalcitrantes), mas de menor tamanho molecular, como anéis aromáticos condensados e/ou conjugação de anéis aromáticos simples, compostos por 2 anéis aromáticos (naftaleno) e policíclios aromáticos com 3 ou 4 anéis. Entretanto, estes resultados corroboram com os resultados obtidos para as amostras de $\mathrm{AH}$ em relação à contribuição das intensidades dos fluoróforos determinados pela combinação de MEE e PARAFAC.

Este comportamento também pode ser explicado pelo fato do horizonte de transição (Tr) do Espodossolo Humilúvico possuir o maior teor de argila no perfil $(50,95 \%)$ e, consequentemente maior número de poros, que aumentam com a perda dos minerais de argila, podendo favorecer a estabilidade da MO humificada por meio da formação de complexos organominerais, tornando a $\mathrm{MO}$ relativamente bem mais protegida da degradação microbiana, com isso, maior teor de carbono e menor grau de humificação foram observados para este horizonte. A textura arenosa e a grande porosidade dos horizontes superficiais orgânicos (A1 e A2), álbicos (E1 e E2) e espódicos (Bh e Bhs) (Tabela 3.1), permitem a migração da MO através dos horizontes e sua acumulação no horizonte profundo (Tr). Os compostos orgânicos 
associados à argila são mais lábeis, têm mais constituintes alifáticos e incluem mais resíduos bioquímicos da biomassa microbiana (Favoretto et al., 2008).

Para o Latossolo Amarelo, observou-se um aumento no grau de humificação $\mathrm{H}_{\mathrm{FIL}}$ do horizonte superficial BA em relação ao A2 (Figura 5.35 (b)), pois conforme observação de campo de Ishida (2010), estes horizontes são constantemente influenciados pela $\mathrm{MO}$, ocasionando este aumento, devido à presença na superfície do solo de uma serrapilheira constituída por manto de raízes e folhas, em decomposição, ocasionando a degradação da MOS em profundidade. Não se pode inferir uma tendência de incremento ou decréscimo do grau de humificação em profundidade para este solo, pois o teor de carbono para as amostras dos horizontes intermediários e profundos é inferior a $0,3 \%$, o limite de detecção do CHNS, não sendo possível a obtenção do índice de humificação $\mathrm{H}_{\mathrm{FIL}}$.

A espectroscopia de FIL utilizando amostras de solo inteiro (solo não submetido a tratamentos químicos ou físicos) deve considerar a MOS como um todo.

$\mathrm{Na}$ Figura 5.38 temos uma comparação entre o grau de humificação avaliado por FIL utilizando amostras de solo inteiro do Espodossolo Humilúvico, com a contribuição das intensidades dos fluoróforos determinados pela combinação da espectroscopia de fluorescência no modo MEE e PARAFAC para os AH extraídos deste mesmo solo.

Figura 5.38 - Correlação entre o grau de humificação determinado por FIL ( $\left.\mathrm{H}_{\mathrm{FIL}}\right)$ e a contribuição a fluorescência dos fluoróforos 1 (a) e 2 (b) para os AH extraídos do Espodossolo Humilúvico.
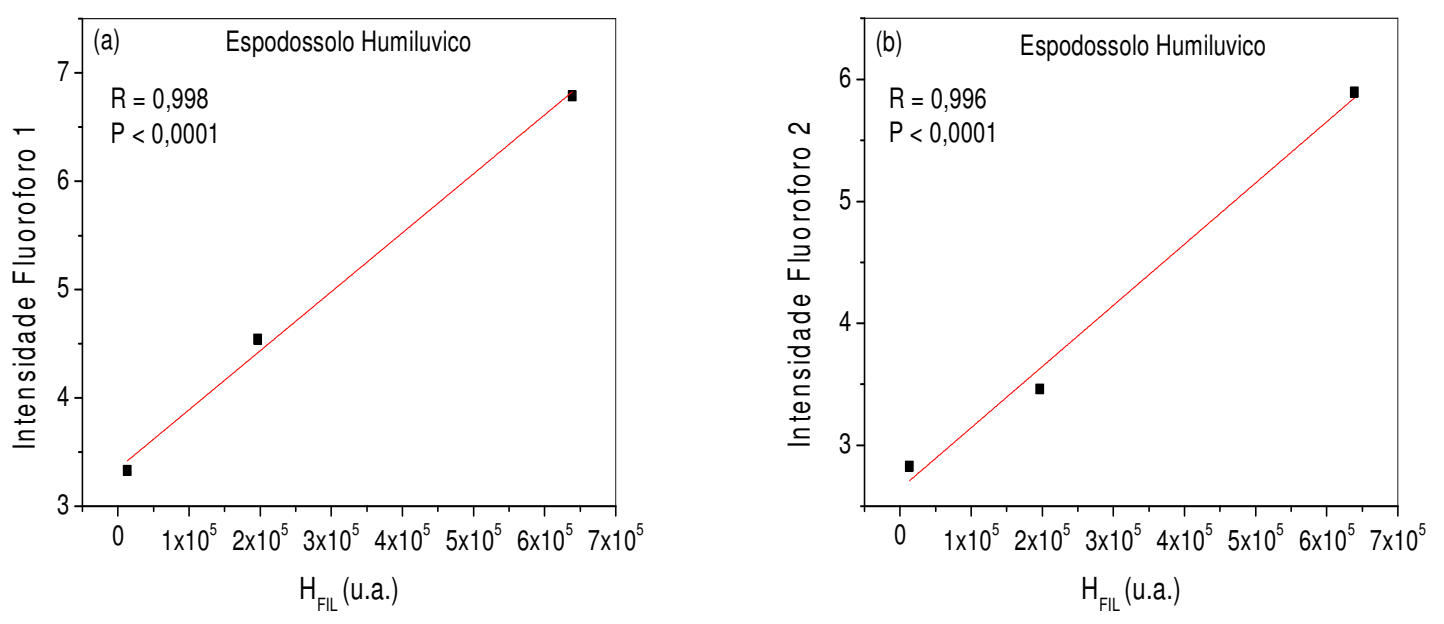
Os valores obtidos para as correlações entre o índice de humificação $\left(\mathrm{H}_{\mathrm{FL}}\right)$ determinado por FIL com a contribuição das intensidades dos fluoróforos determinados pela combinação de MEE e PARAFAC mostradas na Figura 5.38 apresentaram coeficiente de correlação de Pearson muito forte para os fluoróforos 1 e $2(R=0,998$ e $R=0,996)$ com baixa dispersão $P<0,0001$. É importante ressaltar que as medidas utilizando métodos de fluorescência convencionais analisam apenas o $\mathrm{AH}$ e os experimentos usando FIL analisa a MO total. Assim, a fração insolúvel das $\mathrm{SH}$ (humina) e o ácido fúlvico também são analisados por FIL. Além disso, a fração humina pode compor mais de $80 \%$ do material húmico da MOS. As correlações entre os dados são elevados e em ambos os casos, o grau de humificação reflete satisfatoriamente as características da MOS, mostrando que o método proposto tem um grande potencial para aplicação em análise de solos.

Não foi possível a obtenção das correlações entre os índices de humificação $\left(\mathrm{H}_{\mathrm{FLL}}\right)$ determinado por FIL com a contribuição das intensidades dos fluoróforos determinados pela combinação de MEE e PARAFAC para o Latossolo Amarelo, pois foi possível a extração de $\mathrm{AH}$ apenas para as camadas superficiais A2 e BA.

A técnica de FIL mostrou algumas vantagens sobre a espectroscopia de fluorescência convencional, porque foi demonstrado ser uma técnica não destrutiva, simples, sensível, rápida e de baixo custo em análises de amostras in situ. Além disso, a FIL não necessita de extração e fracionamento químico das $\mathrm{SH}$ do solo e, permite o estudo da MOS o mais próximo possível das suas condições naturais, ao contrário da fluorescência convencional de AH (Martins et al., 2011; Milori et al., $2003 ; 2006 ; 2011)$. No entanto, a principal vantagem deste novo método é a possibilidade de ser integrado em um sistema embarcado para aplicação em agricultura de precisão e futuramente serem levados para análises em campo. 


\section{CONCLUSÕES}

Através dos resultados obtidos pela análise elementar o Latossolo Amarelo, observou-se baixíssimo teor de carbono que não se acumula na profundidade, pois o teor de carbono para a maioria das amostras dos horizontes intermediários e profundos é inferior a 0,3\%, o limite de detecção do CHNS. Observou-se uma diminuição no teor de carbono do horizonte superficial A2 em relação ao BA, devido a degradação da MOS. Pela espectroscopia de FIL observou-se um aumento no grau de humificação do horizonte superficial $B A$ em relação ao $A 2$, em virtude da degradação da MOS.

Para o Espodossolo Humilúvico, ocorre acúmulo de muito carbono em profundidade no horizonte de transição (Tr), mas com baixo grau de humificação $\left(\mathrm{H}_{\mathrm{FIL}}\right)$. Atuações antrópicas podem colocar em risco esse estoque de carbono. No horizonte de transição ( $\mathrm{Tr}$ ) ocorre acúmulo de $\mathrm{AH}$ e carbono em subsuperfície e a infiltração destes nos horizontes de caulim (K1 e K2). O horizonte K1 estaria funcionando como uma "peneira molecular" permitindo a passagem para o horizonte K2 de compostos aromáticos condensados de pequeno tamanho molecular que passaram pelo horizonte K1 e estão se acumulando em K2 (acúmulo de carbono mais humificado).

A técnica de FIL mostrou algumas vantagens sobre a espectroscopia de fluorescência convencional, porque foi demonstrado ser uma técnica não destrutiva, eficiente, simples, sensível, rápida e de baixo custo em análises de amostras in situ. Além disso, a FIL não necessita de extração e fracionamento químico das $\mathrm{SH}$ do solo e, permite o estudo da MOS o mais próximo possível das suas condições naturais, ao contrário da fluorescência convencional de AH. No entanto, a principal vantagem deste novo método é a possibilidade de ser integrado em um sistema embarcado para aplicação em agricultura de precisão sendo bastante útil para entender a dinâmica da MOS e permitir futuramente análises de solos e MO em campo.

Ao analisar os espectros tridimensionais de fluorescência dos EAF2 foram observadas mudanças estruturais interessantes. A combinação dos espectros de MEE com PARAFAC permitiu caracterizar qualitativamente os EAF2, podendo identificar e associar com mais clareza os três fluoróforos obtidos, com seus respectivos componentes, ácidos fúlvicos (grupos de fluoróforos simples e 
complexos) e proteína do tipo triptofano, com CORCONDIA de $85,8 \%$.

De maneira geral, a espectroscopia de fluorescência bidimensional para os AH do Espodossolo Humilúvico forneceu resultados bastante coerentes, demonstrando para as três metodologias empregadas, Zsolnay, Milori e Kalbitz, o mesmo comportamento, um incremento no grau de humificação ao longo do perfil, destacando-se o maior grau de humificação para os horizontes de transição (Tr) e caulim (K1). Para o Latossolo Amarelo, o horizonte superficial BA apresentou maior grau de humificação em comparação ao horizonte $\mathrm{A} 2$, apresentando a mesma tendência para as três metodologias de fluorescência.

A espectroscopia de fluorescência MEE foi uma técnica mais seletiva e sensível em relação à fluorescência bidimensional para os $A H$, mostrando informações interessantes, variações estruturais e grande diferença entre os cromóforos que emitem fluorescência nos EAF2 e AH. A combinação de MEE e PARAFAC permitiu caracterizar quantitativamente os $\mathrm{AH}$, identificando a contribuição das intensidades de dois fluoróforos, associados aos $\mathrm{AH}$, grupos de fluoróforos mais complexos e simples, com CORCONDIA de $84,2 \%$.

Os resultados obtidos utilizando esta combinação relativos às contribuições a fluorescência dos fluoróforos 1 e 2 para o Latossolo Amarelo, mostrou uma contribuição mais significativa dos dois fluoróforos para o horizonte BA em comparação ao horizonte superficial A2. Em profundidade não se pode inferir uma tendência de aumento ou decréscimo. Para o Espodossolo Humilúvico aproporção entre a contribuição dos fluoróforos 1 e 2 não se mantêm, corroborando com o modelo de estrutura supramolecular para o $\mathrm{AH}$ e, com os resultados do índice de humificação $A_{465}$ obtido pela fluorescência bidimensional e o índice de humificação $\mathrm{H}_{\mathrm{FIL}}$ obtido por FIL. A combinação de MEE com PARAFAC nós da uma informação mais detalhada, permitindo identificar a contribuição e a participação de cada fluoróforo na fluorescência, enquanto que nas metodologias que utilizam a fluorescência bidimensional, vemos a fluorescência como um todo, não sendo possível a separação da contribuição dos fluoróforos à fluorescência.

A análise dos elementos ferro e alumínio por ICP OES nas amostras de solos estudados apresentaram teores de alumínio maiores que os de ferro, ocorrendo uma tendência de aumento em subsuperfície nos teores de alumínio até o horizonte de transição ( $\mathrm{Tr}$ ) e para o ferro até os horizontes espódicos (Bh e Bhs) para o Espodossolo Humilúvico, corroborando com os resultados encontrados na literatura. 
Para o Latossolo Amarelo, os teores de alumínio são marcados por um ligeiro incremento do horizonte superficial A2 ao latossólico Bw3 e passam a diminuir do horizonte de transição $(\mathrm{Tr})$ até o horizonte de caulim Kn4. Os teores de ferro apresentaram um progressivo aumento do horizonte superficial A2 ao latossólico Bw1, observando-se uma diminuição do horizonte latossólico Bw2 até o horizonte de caulim Kn4.

A fim de facilitar os estudos de dinâmica de carbono e outros elementos no solo, a possibilidade de aplicação de LIBS para a análise semi-quantitativa de carbono e alumínio foi investigada utilizando amostras de solo do sistema LatossoloEspodossolo. A partir dos resultados, uma forte correlação entre essas medidas foi encontrada e os coeficientes de correlação de Pearson's obtidos para o ajuste logarítmico foi de $R=0,98$ e $R=0,99$ para o carbono e o alumínio, respectivamente, entre os valores obtidos por LIBS e as técnicas de referências (CHNS e ICP OES) para o Espodossolo Humilúvico. Nenhuma relação foi observada para o ferro, provavelmente devido aos teores estarem abaixo do limite de detecção.

A técnica LIBS pode, portanto, ser utilizada para avaliação em campo, possibilitando os estudos de dinâmica de carbono e outros elementos no solo. Pode ser uma ferramenta alternativa para análise semi-quantitativa de carbono e alumínio em solos da região Amazônica.

A associação das técnicas de espectroscopia de fluorescência tridimensional (MEE) combinada com PARAFAC, FIL e LIBS, podem trazer informações a respeito dos processos de transformação das SHs no solo, podem se tornar métodos analíticos interessantes para o estudo de $\mathrm{SH}$ seguindo os preceitos da química verde e contribuir com uma nova era de instrumentação para análises de solos e MO em campo. 


\section{REFERÊNCIAS BIBLIOGRÁFICAS}

ABBRUZZINI, T.F. Qualidade e quantidade da matéria orgânica do solo em cultivo convencional e orgânico de cana-de-açúcar. 2011. 92 f. Dissertação (Mestrado em Ciências - Solos e Nutrição de Plantas) - Escola Superior de Agricultura Luiz de Queiroz, Universidade de São Paulo, Piracicaba, 2011.

ABREU JUNIOR, C.H.; MARTIN-NETO, L.; MILORI, D.M.B.P.; SIMÕES, M.L.; SILVA, W.T.L. Métodos analíticos utilizados em química do solo. In: ALLEONI, L. R.F.; MELO, V.F. Química e mineralogia do solo. Viçosa: SBCS, 2009. v. 2, p. 529-685.

ADANI, F.; GENEVINI, P.; TAMBONE, F.; MONTANERI, E. Compost effect on soil humic acid: a NMR study. Chemosphere, v. 65, p. 1414-1418, 2006.

AIKEN, G.R.; THURMAN, E.M. ; MALCOM, R.L. ; WALTON, H.F. Comparison of XAD macroporus resins for the concentration of fulvic acid from aqueous solution. Analytical Chemistry, v. 51, p. 1755-1803, 1979.

ALFAIA, S.S. Destino de fertilizantes nitrogenados $\left({ }^{15} \mathrm{~N}\right)$ em um latossolo amarelo cultivado com feijão caupi (Vigna unguiculata L.). Acta Amazônica, v. 27, n.2, p. 65-72, 1997.

ALMEIDA, M.R.A. Influência do uso do lodo de esgoto na distribuição das substâncias húmicas do solo. 2007. 161 f. Dissertação (Mestrado em Ciências Química Analítica) - Instituto de Química, Universidade Federal do Rio de Janeiro, Rio de Janeiro, 2007.

ALVAREZ-PUEBLA, R.A.; VALENZUELA-CALAHORRO, C.; GARRIDO, J.J. Theoretical study on fulvic acid structure, conformation and aggregation a molecular modeling approach. Science of the Total Environment, v. 358, p. 243-254, 2006.

ANDERSEN, C.M.; BRO, R. Practical aspects of PARAFAC modeling of fluorescence excitation-emission data. Journal of Chemometrics, v. 17, p. 200215, 2003.

ANDERSON, H.A.; ERROW, M.L.; FARMER, V.C.; HEPBURN, A.; RUSSEL, J.D.; WALKER, A.D. A reassessment of podzol formation processes. European Journal of Soil Science, v. 33, p. 125-136, 1982. 
ANDRADE, $H$. Evolução de uma seqüência de solos argilosos até arenosos no Complexo Guianense da Amazônia. 1990. 179f. Tese (Doutorado) - Escola Superior de Agricultura Luiz de Queiroz, Universidade de São Paulo, Piracicaba, 1990.

ANDRIESSE, J.P. A study of the environment and characteristics of tropical podzols in Sarawak (east-Malaysia). Geoderma, v. 2, p. 201-227, 1969.

ARAGÃO, L.E.O.C.; MALHI, Y.; BARBIER N.; LIMA A.; SHIMABUKURO Y.; ANDERSON L.; SAATCHI S. Interactions between rainfall, deforestation and fires during recent years in Brazilian Amazonia. Philosophical Transactions of the Royal Society - Biological Sciences, n. 363, p. 1779-1985, 2008.

ARAÚJO, A.S.F.; SANTOS, B.B.; MONTEIRO, R.T.R. Responses of soil microbial biomass and activity for practices of organic and conventional farming systems in Piauí state, Brazil. European Journal of Soil Biology, v. 44, n. 2, p. 225-230, 2008.

ARENARE, B.S. Estudo da estrutura, morfologia e mineralogia de um sistema de solos laterítico-podzolizado na bacia do Alto Rio Negro - AM. 2007. $155 \mathrm{f}$. Dissertação (Mestrado em Geografia) - Instituto de Geociências e Ciências Exatas, Universidade Estadual Paulista, Rio Claro, 2007.

ATKINS, P.W. Physical chemistry. $6^{\text {th }}$. ed. Oxford: Oxford University Press, 1998. $1014 \mathrm{p}$.

AZEVEDO, J.C.R. Estudo biogeoquímico da Lagoa dos Patos-MS, pertencente à planície do alto rio Paraná. 2005. 195 f. Tese (Doutorado em Ciências Ambientais) - Ecologia de Ambientes Aquáticos Continentais, Universidade Estadual de Maringá, Maringá, 2005.

BAES, A.V.; BLOOM, P.R. Fulvic acid ultraviolet-visible spectra: influence of solvent and pH. Soil Science Society of America Journal, v. 54, p. 1248, 1990.

BAKER, A. Fluorescence excitation-emission Matrix characterization of some sewage-impacted rivers. Environmental Science e Technology, v. 35, p.948-953, 2001.

BAKER, A.; SPENCER, R.G.M. Characterization of dissolved organic matter from source to sea using fluorescence and absorbance spectroscopy. Science of the Total Environment, v. 333, n. 1-3, p. 217-232, 2004. 
BALAN, E.; ALLARD, T.; FRITSCH, E.; SÉLO, M.; FALGUÈRES, C.; FALGUÈRES, C.; CHABAUX, F.; PIERRET, M. C.; CALAS, G. Formation and evolution of lateritic profiles in the middle Amazon basin: Insights from radiation-induced defects in kaolinite. Geochimica et Cosmochimica Acta, v. 69, n. 9, p. 2193-2204, 2005.

BARDY, M.; FRITSCH, E.; DERENNE, S.; ALLARD, T.; NASCIMENTO, N.R.; BUENO, G.T. Micromorphology and spectroscopic characteristics of organic matter in waterlogged podzols of the upper Amazon basin. Geoderma, v. 145, n. 3-4, p. 222-230, 2008.

BARFORD, C.C.; WOFSY, S.C.; GOULDEN, M.L.; MUNGER, J.W.; PYLE, E.H.; URBANSKI, S.P.; HUTYRA, L.; SALESKA, S.R.; FITZJARRALD, D.; MOORE, K. Factors controlling long and short-term sequestration of atmospheric $\mathrm{CO}_{2}$ in a midlatitude forest. Science, v. 294, p. 1688-1691, 2001.

BATJES, N.H.; DIJKSHOORNn, J.A. Carbon and nitrogen stocks in the soils of the Amazon Region. Geoderma, v. 89, p. 273-286, 1999.

BAYER, C.; MARTIN-NETO, L.; MIELNICZUK, J.; CERETTA, C.A. Fracionamento da matéria orgânica e sua avaliação qualitativa por EPR num solo submetido dez anos a diferentes sistemas de cultura em plantio direto. In: SIMPÓSIO NACIONAL DE INSTRUMENTAÇÃO AGROPECUÁRIA, 1., 1996, São Carlos. Anais... São Carlos: Embrapa Instrumentação Agropecuária, 1997. p. 115-121.

BAYER, C.; MARTIN-NETO, L.; MIELNICZUK, J.; SAAB, S. C.; MILORI, D. M. B. P.; BAGNATO, V. S. Tillage and cropping system effects on soil humic acid characteristics as determined by electron spin resonance and fluorescence spestroscopies. Geoderma, v. 105, p. 81-92, 2002.

BENITES, V.M.; MADARI, B.; MACHADO, P.L.O.A. Extração e fracionamento quantitativo de substâncias húmicas do solo: um procedimento simplificado de baixo custo. Rio de Janeiro: Embrapa Solos, 2003. 7p. (Embrapa Solos. Comunicado Técnico, 16).

BERNOUX, M.; CARVALHO, M.C.S.; VOLKOFF, B.; CERRI, C.C. Brazil's soil carbon stocks. Soil Science Society of America Journal, v. 66, p. 888-896, 2002.

BERTONCINI, E.I.; D'ORAZIO, V.; SENESI, N.; MATTIAZZO, M.E. Fluorescente analysis of humic and fulvic acids from two Brazilian oxisols as affected by biosolid amendment. Analytical Bioanalytical Chemistry, v. 381, p. 1281-1288, 2005. 
BETTINELLI, M.; BEONE, G.M.; SPEZIA, S.; BAFFI, C. Determination of heavy metals in soils and sediments by microwave-assisted digestion and inductively coupled plasma optical emission spectrometry analysis. Analytica Chimica Acta, v. 424, p. 289, 2000.

BIEROZA, M.; BAKER, A.; BRIDGEMAN, J. Exploratory analysis of excitationemission matrix fluorescence spectra with self-organizing maps as a basis for determination of organic matter removal efficiency at water treatment works. Journal Geophysical Research, v. 114, p. 1-8, 2009.

BIEROZA, M.; BAKER, A.; BRIDGEMAN, J. 2011. Classification and calibration of organic matter fluorescence data with multiway analysis methods and artificial neural networks: an operational tool for improved drinking water treatment. Environmetrics, v. 22, p. 256-270, 2011.

BISPO, C.J.C. Balanço de água em cultivo de soja no Leste da Amazônia. 2007. 148 f. Dissertação (Mestrado em Ciências Ambientais) - Universidade Federal do Pará/Embrapa/Museu Emílio Goeldi, Belém, 2007.

BLANCHE, K.R.; LUDWIG, J.A.; CUNNINGHAM, S.A. Proximit to rainforest enhances pollination and fruit set in orchards. Journal of Applied Ecology, v. 43, n.6, p. 1182-1187, 2006.

BOEHME,J.; COBLE, P.; CONMY,R.; STOVALL-LEONARD, A. Examining CDOM fluorescence variability using principal component analysis: seasonal and regional modeling of three-dimensional fluorescence in the Gulf of Mexico .Marine Chemistry, v. 89, p. 3-14, 2004.

BORISOVER, M.; LAOR, Y.; PARPAROV, A.; BUKHANOVSKY, N.; LADO, M. Spatial and seasonal patterns of fluorescent organic matter in Lake Kinneret (Sea of Galilee) and its catchment basin. Water Research, v. 43, p. 3104-3116, 2009.

BOSS, C.B.; FREDEEN, K.J. ICP-OES Instrumentation. In: BOSS, C.B.; FREDEEN, k.J. Concepts, instrumentation and techniques in inductively coupled plasma optical emission spectrometry. 2 ed. New York: Perkin Elmer Corporation, 1997. p. 4-22.

BOULET, R.; CHAUVEL, A.; HUMBEL, F. X.; LUCAS, Y. Analyse structurale et cartographie en pédologie: I - Prise en compte de l'organisation bidimensionelle de la couverture pédologique: les études de toposéquences et leurs principaux apports à la connaissance dês sols. Cahiers ORSTOM, Séries Pédologie, Bondy, v. 19, n. 4, p. 309-321, 1982. 
BRABANT, P. In: RIGHI, D.; CHAUVEL, A. (Ed.). Podzols et podzolisation. Paris: INRA, 1987. p. 13-24.

BRAUMMER, H. Podzols in Zambia. Geoderma, v. 10, p. 249-260, 1973.

BRAVARD, S.; RIGHI, D. Geochemical differences in an oxisol-spodosol toposequence of Amazonia, Brazil. Geoderma, v. 44, n. 1, p. 29-42, 1989.

BRAVARD, S.; RIGHI, D. Podzols in Amazônia. Catena, v. 17, n. 4-5, p. 461-475, 1990.

BUENO, G.T. Appauvrissement et podzolisation des latérites du bassin du Rio Negro et gênese des Podzols dans le haut bassin amazonien. 2009. $191 \mathrm{f}$. Tese (Doutorado em Geografia) - Universidade Estadual Paulista, Rio Claro, 2009.

BUOL, S.W.; HOLE, F.D.; MC CRACKEN, R.J. Soil genesis and classification. Ames: lowa State University Press, 1980. 404 p.

BUURMAN, P.; JONGMANS, A.G. Podzolisation and soil organic matter dynamics. Geoderma, v. 125, p. 11-183, 2005.

CAMARGO, O.A. de; MONIZ, A.; JORGE, J.A.; VALADARES, J.M.A.S. Métodos de análise química, mineralógica e física de solos do Instituto Agronômico de Campinas. Campinas: IAC, 1986. 94 p. (Boletim Técnico, 106).

CANELLAS, L.P.; SANTOS, G.A.; RUMJANEK, V.M.; MORAES, A.A.; GURIDI, F. Distribuição da matéria orgânica e características de ácidos húmicos em solos com adição de resíduos de origem urbana. Pesquisa Agropecuária Brasileira, v. 36, n. 12, p. 1529-1538, 2001.

CANNAVAN, F.S. Diversidade das comunidades bacterianas em solos de terra preta antropogênica da Amazônia Central e Oriental. 2007. 115 f. Dissertação (Mestrado em Ecologia Aplicada) - Escola Superior de Agricultura Luiz de Queiroz (Centro de Energia Nuclear na Agricultura), Universidade de São Paulo, Piracicaba, 2007.

CARVALHO, E.R.; MARTIN-NETO, L.; MILORI, D.M.B.P.; ROCHA, J.C.; ROSA, A.H. Interactions of chlorine with tropical aquatic fulvic acids and formation of intermediates observed by fluorescense spectroscopy. Journal of the Brazilian Chemical Society, v. 15, n. 53, p. 421, 2004. 
CARVALHO, J.L.N.; CERRI, C.E.P.; CERRI, C.C.; FEIGL, B.J.; PÍCOLLO, M.C.; GODINHO, V.P.; HERPIN, U. Changes of chemical properties in an oxisol after clearing of native Cerrado vegetation for agricultural use in Vilhena, Rondonia State,

Brazil. Soil Tillage Research, v. 96, p. 95-102, 2007.

CERRI, C. C.; CERRI, C. E. P. Agricultura e aquecimento global. Boletim da Sociedade Brasileira de Ciência do Solo, v. 32, n.1, p. 40-44, 2007.

CHATTERJEE, A.; LAL. R.; WIELOPOLSKI, L.; MARTIN, M.Z.; EBINGER, M.H. Evaluation of different soil carbon determination methods. Critical Reviews in Plant Science, v. 28, p. 164-178, 2009.

CHEN, Y.; SENESI, N.; SCHNITZER, M. Information provided on humic substances by E4/E6 ratios. Soil Science Society of America Journal, v. 41, p 352-358, 1977.

CHEN, J. GU, B.; LEBOEUF, E. J.; PAN, H.; DAI, S. Spectroscopic characterization of the structural and functional properties of natural organic matter fractions.

Chemosphere, v. 48, p. 59-68, 2002.

CHEN, W.; WESTERHOFF, P.; LEENHERR, J.; BOOKSH, K. Fluorescence excitation-emission matrix regional integration to quantify spectra for dissolved organic matter. Environmental Science and Technology, v. 37, p. 5701-5710, 2003.

COBLE, P.G. Characterization of marine and terrestrial DOM in seawater using excitation - emission matrix spectroscopy. Marine Chemistry, v. 51, p. 325-346, 1996.

COBLE, P.G.; DEL CASTILLO,C.E.; AVRIL, B. Distribution and optical properties DOM in the Arabian Sea during the 1995 Southwest Monsoon. Deep-Sea ResearchPart II, v. 45, p. 2195-2223, 1998.

COELHO, M.R.; MARTINS, V.M.; VIDAL-TORRADO, P.; SOUZA, C.R. O recurso natural solo. In: MANZATTO, C.V.; JUNIOR, E.F.; PERES, J.R.R. (Ed.), Uso agrícola dos solos brasileiros. Rio de Janeiro: Embrapa solos, 2002. p. 1-12.

CONTE, P.; PICCOLO, A. Conformation arrangement of dissolved humic substances: influence of solution composition on association of humic molecules. Environmental Science and Technology, v. 33, p. 1682-1690, 1999. 
CÔRREA, M.M.; MOREAL, A.M.; KER, J.C.; CARVALHO, A.F. Avaliação de critérios de classificação de Espodossolos do Pantanal Matogrossense e de Tabuleiros Costeiros relacionados ao Grupo Barreiras. CD-ROOM. Congresso Brasileiro de Ciência do Solo, Brasília, 1999.

CORY, R.M.; MCKNIGHT, D.M. Fluorescence spectroscopy reveals ubiquitous presence of oxidized and reduced quinones in dissolved organic matter.

Environmental Science Technology, v. 39, p. 8142-8149, 2005.

COSTA, A.S. Caracterização da matéria orgânica dissolvida nas águas das bacias hidrográficas do estado de Sergipe. 2011. 188 f. Dissertação (Mestrado em Química) - Núcleo de Pós-Graduação em Química, Universidade Federal de Sergipe, São Cristovão, 2011.

COUCEIRO, P.R.C.; SANTANA, G.P. Caulinita em solo da Amazônia: caracterização e permutabilidade. Acta Amazônica, v. 29, n. 2, p. 267-75; 1999.

CREMERS, D.A.; EBINGER, M.H.; BRESHEARS, D.D.; UNKEFER, P.J.; KAMMERDIENER, S.A.; FERRIS, M.J.; CATLETT, K.M.; BROWN, J.R. Measuring total soil carbon with laser-induced breakdown spectroscopy (LIBS). Journal of Environmental Quality, v. 30, p. 2202-2206, 2001.

CUNHA, T.J.F.; MADARI, B.E.; CANELLAS, L.P.; RIBEIRO, L.P.; BENITES, V.M.; SANTOS, G.A. Soil organic matter and fertility of anthropogenic dark earths (terra preta de índio) in the Brazilian amazon basin. Revista Brasileira de Ciência do Solo, v. 33, p. 85-93, 2009.

DA SILVA, R.; MILORI, D. M. B. P.; FERREIRA, E.; FERREIRA, E.; KRUG, F.; MARTIN-NETO, L. Total carbon measurement in whole tropical soil sample.

Spectrochimica Acta. Part B, Atomic Spectroscopy, v. 63, p. 1221-1224, 2008.

DeCONINCK, F. Major mechanisms in formation of spodic horizons. Geoderma, v. 24, p. 101-128, 1980.

DIALLO, M.S. ; SIMPSON, A.J. ;GASSMAN, P. ; FAULON, J.L. ; JOHNSON, J.H. ; GODDARD, W.A. ; HATCHER, P.G. 3-D Structural modeling of humic acids through experimental characterization, computer assisted structure elucidation and atomistic simulations. Environmental Science \& Technology, v. 37, p. 1783-1793, 2003. 
DINIZ, A.D. Origem e dinâmica do mercúrio em sistemas de transformação latossolo-podzol na bacia do rio Negro, Amazonas. 2010. $143 \mathrm{f}$. Tese (Doutorado em Geografia - Análise Ambiental e Sistemas de Informação) - Instituto de Geociências e Ciências Exatas, Universidade Estadual Paulista, Rio Claro, 2010.

DUBROEUCQ, D.; BLANCANEAUX, P. Les podzols du haut rio Negro, region de Marao, Venezuela. Environnement et relations lithologiques. In: RIGHI, D.; CHAUVEL, A. (Ed.). Podzols et podzolisation. Paris: INRA, 1987. p. 37-52.

DUBROEUCQ, D.; VOLKOFF, B. From Oxisols to spodosols and histosols: evolution of the soil mantles in the Rio Negro basin (Amazonia). Catena, v. 32, p. 245-280, 1998.

DUBROEUCQ, D.; VOLKOFF, P.; FAURE, B. Podzols du bassin du haut rio Negro. Étude et Gestion des Sols, v. 6, p. 131-153, 1999.

DUBUISSON, C.; POUSSEL, E.; MERMET, J.M. Comparison of axially and radially viewed inductively coupled plasma atomic emission spectrometry in terms of signalto-background ratio and matrix effects. Journal of Analytical Atomic

Spectrometry, v. 12, p. 281, 1997.

DUCHAUFOUR, P. Pedology: pedogenesis and classification. London: George Allen \& Unwin, 1982. 448 p.

EBINGER, M.H.; NORFLEET, M.L.; BRESHEARS, D.D.; CREMERS, D.A.; FERRIS, M. J.; UNKEFER, P.J.; LAMB, M.S.; GODDARD, K.L.; MEYER, C.W. Extending the applicability of laser-induced breakdown spectroscopy for total soil carbon measurement. Soil Science Society of America, v. 67, p. 1616-1619, 2003.

EMPRESA BRASILEIRA DE PESQUISA AGROPECUÁRIA. Centro Nacional de Pesquisa em Solos. Sistema brasileiro de classificação de solos. 2. ed. Brasília: Embrapa, Produção de Informação; Rio de Janeiro: Embrapa Solos, 2006. 306 p.

FOOD AND AGRICULTURE ORGANIZATION OF THE UNITED NATIONS. Soil Map of the World: 1:5.000.000. Paris: United Nations Educacional, Scientific, and Cultural Organization, 1971. v. 4 - South America.

FARMER, V.C.; FRASER. A.R. Chemical and coloidall stability of soils in the $\mathrm{Al}_{2} \mathrm{O}_{3}-$ $\mathrm{Fe}_{2} \mathrm{O}_{3}-\mathrm{SiO}_{2}-\mathrm{H}_{2} \mathrm{O}$ system: their role in podsolization. Journal of Soil Science, v. 33, n. 4, p. 737-742, 1982. 
FARMER, V.C.; RUSSEL, J.D.; BERROW, M.L. Imogolite and proto-imogolite allophane in spodic horizons: evidence for a mobile aluminium slicate complex in podzol forma-tion. Journal of Soil Science, v. 31, n. 4, p. 673-684, 1980.

FARMER, V.C.; RUSSEL, J.D.; SMITH, B.F.L. Extraction of inorganic forms of translocated $\mathrm{Al}, \mathrm{Fe}$ and $\mathrm{Si}$ from a Podzol Bs horizon. Journal of Soil Science, v. 34, p. $571-576,1983$.

FAVORETTO, C.M.; GONÇALVES, D.; MILORI, D.M.B.P.; ROSA, J.A.; LEITE, W.C.; BRINATTI, A.M.; SAAB, S.C. Determinação da humificação da matéria orgânica de um latossolo e de suas frações organo-minerais. Química Nova, v. 31, n. 8, p. 19941996, 2008.

FEARNSIDE, P.M. Amazonian deforestation and global warming: carbon stocks in vegetation replacing Brazil's Amazon forest. Forest Ecology and Management, $v$. 80, p. 21-34, 1996.

FELLER, C.; BEARE, M. H. Physical control of soil organic matter dynamics in the tropics. Geoderma, v. 79, p. 69-116, 1997.

FERIOLI, F.; BUCKLEY, S.G. Measurements of hydrocarbons using laser-induced breakdown spectroscopy. Combustion and Flame, v. 144, p. 435-447, 2006.

FERREIRA, E.C.; MILORI, D.M.B.P.; FERREIRA, E.J.; SANTOS, L.M.; MARTINNETO, L.; NOGUEIRA, A.R.A. Evaluation of laser induced breakdown spectroscopy for multielemental determination in soils under sewage sludge application. Talanta, v. 85, p. $435-440,2011$.

FIALHO, L. L. Caracterização da matéria orgânica em processo de compostagem por métodos convencionais e espectroscópicos. 2007. $170 \mathrm{f}$. Tese (Doutorado em Ciências - Química Analítica) - Instituto de Química de São Carlos, Universidade de São Paulo, São Carlos, 2007.

FICHET, P.; TABARANT, M.; SALLÉ, B.; GAUTIER, C. Comparisons between LIBS and ICP/OES. Analytical and Bioanalytica Chemistry, v. 385, p. 338-344, 2006.

FRITSCH, E.; ALLARD, T.; BENEDETTI, M.F.; NASCIMENTO, N.R.; Li, Y.; CALAS,G. Organic complexition and translocation of ferric iron in podzols of the Negro River watershed.Separetion of secondary Fe species from Al species. Geochimica et Cosmochimica Acta, v. 73, p. 1813-1825, 2009. 
FRITSCH, E.; BALAN, E.; NASCIMENTO, N.R.; ALLARD, T.; BARDY, M.; BUENO, G.T.; DERENNE, S.; MELFI, A.J.; CALAS, G. Deciphering the weathering processes using environmental mineralogy and geochemistry: Towards an integraded model of laterite and podzol genesis in the Upper Amazon Basin. Comptes Rendus Geoscience, v. 343, p. 188-198, 2011.

FRITSCH, E.; BOCQUIER, G.; BOULET, R.; DOSSO, M.; HUMBEL, F. X. Les systems transformants d'une couverture ferrallitique de Guyane française. Analyse structural d'une formation supergène et mode de représentation. Cahiers ORSTOM, Séries Pédologie, v. 22, p. 361-395, 1986.

FRITSCH, E.; HERBILLON, A. J.; JEANROY, E.; PILLON, P.; BARRES, O. Variations minéralogiques et structurales accompagnant le passage "sols rouges sols jaunes" dans un bassin versant caractéristique de la zone de contact forêtsavane de l'Afrique occidentale (Booro-Borotou, Côte d'Ivoire). Sciences Géologiques Bulletin, v. 42, n. 2, p. 65-89, 1989.

FRITSCH, E.; MONTES-LAUAR, C.; BOULET, R.; MELFI, A.J.; BALAN, E.; MAGAT, $P$. Lateritic and redoximorphic features in a faulted landscape near Manaus, Brazil. European Journal of Soil Science, v. 53, p. 203-217, 2002.

FRITSCH, E.; VALENTIN, C.; MOREL, P.; LEBLOND, P. La couverture pédologique : interactions avec les roches, le modelé et les formes de dégradation superficielles. In : Structure et fonctionnement hydro-pédologique d'un bassin versant de savane humide. Booro Borotou. In: Collection "Etudes et Thèses". Paris: ORSTOM, 1990. p. 31-57.

FUENTES, M.; GONZÁLEZ-GAITANO, G.; GARCÍA-MINA, J. M. The usefulness of UV-visible and fluorescence spectroscopies to study the chemical nature of humic substances from soils and composts. Organic Geochemistry, v. 37, p. 1949-1959, 2006.

FURTADO, L.G. Amazônia: Desenvolvimento, sociodiversidade e qualidade de vida. Belém: UFPA, NUMA, 1997. 165 p. (UFPA. Universidade e meio ambiente, n. 9).

GINÉ-ROSIAS, F.M. Espectrometria de emissão atômica com plasma acoplado indutivamente (ICP AES). Piracicaba: Cena, 1998. 148 p.

GOMES, F.H. Gênese e classificação de solos sob vegetação de restinga na Ilha do Cardoso - SP. 2005. 107 f. Tese (Doutorado em Agronomia - Solos e Nutrição de Plantas) - Escola Superior de Agricultura Luiz de Queiroz, Universidade de São Paulo, Piracicaba, 2005. 
GOMES, F.H.; VIDAL-TORRADO, P.; MACÍAS, F.; GHERARDI, B.; PEREX, X.L.O. Solos sob vegetação de restinga na llha do Cardoso (SP). Caracterização e classificação. Revista Brasileira de Ciência do Solo, v. 31, p. 1563-1580, 2007.

GOMES, J.B.V. Caracterização, gênese e uso de solos de três sítios de restinga sob diferentes coberturas vegetais no Estado do Rio de Janeiro. 1995. 170 . Dissertação (Mestrado em Solos e Nutrição de Plantas) - Universidade Federal de Viçosa, Viçosa, 1995.

GONZÁLEZ-PÉREZ, M.; MARTIN-NETO, L.; SAAB, S.C.; NOVOTNY, E.H.; MILORI, D.M.B.P.; BAGNATO, V.S.; COLNAGO, L.A.; MELO, W.J.; KNICKER, H.

Characterization of humic acids from a Brazilian Oxisol under different tillage systems by EPR, ${ }^{13} \mathrm{C}$ NMR, FTIR and fluorescence spectroscopy. Geoderma, v. 118, p. 181190, 2004.

GONZÁLEZ-PÉREZ, M.; MILORI, D.M.B.P.; COLNAGO, L.A.; MARTIN-NETO, L.; MELO, W.J. A laser-induced fluorescence spectroscopic study of organic matter in a Brazilian oxisol under different tillage systems. Geoderma, v. 138, p. 20-24, 2007.

GREENFIELD, S.; JONES, I.L.; BERRY, C.T. High-pressure plasmas as spectroscopy emission sources. Analyst, v. 89, p. 713, 1964.

GUERRA, J.G.M.; SANTOS, G.A. Métodos químicos e físicos. In: SANTOS, G.A.; CAMARGO, F.A.O. (Ed.). Fundamentos da matéria orgânica do solo ecossistemas tropicais e subtropicais. Porto Alegre: Ed. Gênesis, 1999. 49 p.

GUO, W.; STEDMON, C.A.; HAN, Y.C.; WU, F.; YU, X.; LIU, M. The conservative and non-conservative behavior of chromophoric dissolved organic matter in Chinese estuarine waters. Marine Chemistry, v. 107, p. 357-366, 2007.

GUO, X.J.; HE, X.S.; ZHANG, H.; DENG, Y.; CHEN, L.; JIANG, J.Y. Characterization of dissolved organic matter extracted from fermentation effluent of swine manure slurry using spectroscopic techniques and parallel factor analysis (PARAFAC).

Microchemical Journal, v. 102, p. 115-122, 2012.

HALL, G.; KENNY, J. E. Estuarine water classification using EEM spectroscopy and PARAFAC-SIMCA. Analytica Chimica Acta, v. 581, p.118-124, 2007.

HARRIS, D.C. Quantitative chemical analysis. 6 $6_{m}^{a}$ ed. New York: W.H. Freeman, 2003. 928 p. 
HAYES, M.H.B.; MACCARTHY, P.; MALCOLM, R.L.; SWIFT, R.S. Humics substances II: in search of struture. New York: John Willey, 1989. p. 747.

HE, X.S.; XI, B.D.; LI, X.; PAN, H.W.; AN, D.; BAI, S.C.; LI, D.; CUI, D.Y. Fluorescence excitation-emission matrix spectra coupled with parallel factor and regional integration analysis to characterize organic matter humification.

Chemosphere, p. 1-8, 2013.

HEES, P.A.W.; LUNDSTRÖM, U.S.; GIESLER, R. Low molecular weight organic acids and their Al-complexes in soil solution-composition, distribution and seasonal variation in three podzolized soils. Geoderma, v. 94, p. 173-200, 2000.

HOENING, M.; KERSABIEC, A.M. Sample preparation steps for analysis by atomic spectroscopy methods: present status. Spectrochimica Acta Part B, v. 51, p. 1297, 1996.

HOLBROOK, R.D.; YEN, J.H.; GRIZZAR, T.J. Characterizing natural organic material from the Occoquan Watershed (Northern Virginia, US) using fluorescence spectroscopy and PARAFAC . Science of the Total Environment, v. 361, n. 1-3, p. 249-266, 2006.

HORBE, A.M.C.; HORBE, M.A.; SUGUIO, K. Tropical Spodosols in northeastern Amazonas State, Brazil. Geoderma, v. 119, p. 55-68, 2004.

HOUGHTON, R.A.; SKOLE, D.L.; NOBRE, C.A.; HACKLER, J.L.; LAWRENCE, K.T.; CHOMENTOWSKI, W.R. Annual fluxes of carbon from deforestation and regrowth in the Brazilian Amazon. Nature, v. 403, p. 301-304, 2000.

HOLLAND, J.F.; TEETS, R.E.; KELLY, P.M.; TIMNICKI, A. Correction of right-angle fluorescence measurements for absorption of excitation radiation. Analytical Chemistry, v. 49, n. 6, p. 706-710, 1977.

HUA, B.; DOLAN F.; McGHEE, C.; CLEVENGER, T.E.; DENG, B.L. Water-source characterization and classification with fluorescence EEM spectroscopy: PARAFAC analysis. International Journal of Environmental Analtical Chemistry, v. 87, n.2, p. 135-147, 2007.

HUANG, S.W.; CHIANG, P.N.; LIU, J.C.; HUNG, J.T.; KUAN, W.H.; TZOU, Y.M.; WANG, S.L.; HUANG, J.H.; CHEN, C.C.; WANG, M.K.; LOEPPERT, R.H. Chromate reduction on humic acid derived from a peat soil - Exploration of the activated sites on HAs for chromate removal. Chemosphere, v. 87, p. 587-594, 2012. 
HUDSON, N.; BAKER, A.; REYNOLDS, D. Fluorescence analysis of dissolved organic matter in natural, waste and polluted waters, a review. River Research and Applications, v. 23, n. 6, p. 631-649, 2007.

IBANGA, I.J.; BUOL, S.W.; BOWEN, L.H. Iron oxides in petroferric materials. Soil Science Society of America Journal, v. 47, p. 1240-1246, 1983.

IBRAHIM, L. Caracterização física, química, mineralógica e morfológica em uma sequência de solos em Lins/SP. 2002. 86 f. Dissertação (Mestrado em Agronomia) - Escola Superior de Agricultura Luiz de Queiroz, Universidade de São Paulo, Piracicaba, 2002.

IDE, K.; NAKAMURA, Y. Determination of Ti, V, Zr, Nb, Mo and Ta in high-purity iron using cupferron co-precipitation separation by axially viewed ICP-AES with ultrasonic nebulization system and a long torch. Metallurgical and Materials Transactions, v. 43, n. 6, p. 1409, 2002.

IKEYA, K.; YAMAMOTO, S.; WATANABE, A. Semiquantitative GC/MS analysis of thermochemolysis products of soil humic acids with various degrees of humification. Organic Geochemistry, v. 35, p. 583- 594, 2004.

INGLE, J.D.; CROUCH, S.R. Spectrochemical analysis. New Jersey: Prentice Hall, 1988. $450 \mathrm{p}$.

INSTITUTO BRASILEIRO DE GEOGRAFIA E ESTATÍSTICA (IBGE). Levantamento pedológico. São Paulo: CREN - IBGE. 2009. folhas NA-19, NA-20, AS-19 e AS-20.

INSTITUTO NACIONAL DE PESQUISAS ESPACIAIS (INPE). ZEEs da Amazônia contam com dadosde desmatamento do INPE. 2006. Disponível em:

<www.inpe.br/noticias/noticia.php?Cod_Noticia=947>. Acesso em: 15 mar. 2010.

INTERGOVERNMENTAL PANEL ON CLIMATE CHANGE (IPCC). Climate Change 2007: the physical science basis. Contribution of working group I to the fourth assessment report of the intergovernmental panel on climate change. Paris: WMO/UNEP, 2007. p. 18.

ISHIDA, D. A. Caracterização e gênese de solos e de depósito de caulim associado, São Gabriel da Cachoeira - AM. 2010. 172 f. Tese (Doutorado em Geoquímica e Geotectônica) - Instituto de Geociências, Universidade de São Paulo, São Paulo, 2010. 
ISHII, S.K.L.; BOYER, T.H. Behavior of reoccurring PARAFAC components in fluorescent dissolved organic matter in natural and engineered systems: a critical review. Environmental Science \& Technology, v. 46, n. 4, p. 2006-2017, 2012.

JACOMINE, P.K.T.; CAMARGO, M.N. Classificação pedológica nacional em vigor. In: ALVAREZ, V.H.; FONTES, L.E.F.; FONTES, M.P.F. (Ed.), Solos nos grandes domínios morfoclimáticos do Brasil e o desenvolvimento sustentado. ViçosaMG: SBCS-UFV, 1996. p. 675-689.

JAMET, R.; GUILLET, B.; ROBERT, M.; RANGER, J.; VENEAU, G. Study of current dynamics of soils from a podzol-oxisol sequence in Tahiti (French polynesia) using the test-mineral technique. Geoderma, v. 73, p. 107-124, 1996.

JOURAIPHY, A.; AMIR, S.; GHAROUS, M. E.; REVEL, J. C.; HAFIDI, M. Chemical and spectroscopic analysis of organic matter transformation during composting of sewage sludge and green plant waste. International Biodeterioration \& Biodegradation, v. 56, p. 101-108, 2005.

KALBITZ, K.; GEYER, W.; GEYER, S. Spectroscopic properties of dissolved humic substances - a reflection of land use history in a fen area. Biogeochemistry, v. 47, p. 219-238, 1999.

KER, J. C. Latossolos do Brasil: uma revisão. Geonomos, v. 5, p. 17-40, 1997.

KLINGE, H. Podzol soils in the amazon basin. Journal of Soil Science, v. 16, n. 1, p. $95-103,1965$.

KORSHIN, G. V.; CHI-WANG, L.; BENJAMIN, M. M. Monitoring the properties of natural organic matter through UV spectroscopy: a consistent theory. Water Research, v. 31, n. 7, p. 1787-1795, 1997.

KOWALCZUK, P.; COOPER, W.J.; WHITEHEAD, R.F.; DURAKO, M.J.; SHELDON, $W$. Characterization of CDOM in an organic-rich river and surrounding coastal ocean in the South Atlantic Bight. Aquatic Sciences, v. 65, n. 4, p. 384-401, 2003.

KOWALCZUK, P.; DURAKO, M.J.; YOUNG, H.; KAHN, A.E.; COPPER, W.; GONSIOR M. Characterization of dissolved organic matter fluorescence in the South Atlantic Bight with use of PARAFAC model: Inter annual variability. Marine Chemsitry, v.113, p. 182-196, 2009. 
KRISHNA, k.A.; K.K.; YU-YUEH, F.; SINGH, J.P.; MCINTYRE, D.L.; JAIN, J. Application of laser-induced breakdown spectroscopy for total carbon quantification in soil samples. Applied optics, v. 51, p. B149-B154, 2012.

KUBISTA, M.; SJOBACK, R.; ERIKSSON, S.; ALBINSSON, B. Experimental correction for the inner-filter effect in fluorescence-spectra. Analyst, v. 119, n. 3, p. 417419, 1994.

KULOVAARA, M.; CORIN, N.; BACKLUND, P.; TERVO, J. Impact of UV 254 radiation on aquatic humic substances. Chemosphere, v. 33, p. 783-790, 1996.

KUMAR, A.; YUEH, F.; SINGH, J.P.; BURGESS, S. Characterization on malignant tissue cells by laser-induced breakdown spectroscopy. Applied Optics, v.43, p.5399, 2004.

LAKOWICZ, J.R. Principles of fluorescence spectroscopy. New York: Kluwer Academic/Plenum Publishers, 1999. 698 p.

LANDGRAF, M.D.; MESSIAS, R.A.; REZENDE. M.O.O. A importância ambiental da vermicompostagem: vantagens e aplicações. São Carlos: Rima, 2005. 106 p.

LAURANCE, W.F.; ALBERNAZ, A.K.M.; DA COSTA, C. Is deforestation accelerating in the Brazilian Amazon. Environmental Conservation, v. 28, n. 4, p. 305-311, 2001.

LAURANCE, W.F.; COCHRANE, M.A.; BERGEN, S.; FEARNSIDE, P.M.;

DELAMÔNICA, P.; BARBER, C.; DANGELO, S.; FERNANDES, T. The future of the Brazilian Amazon. Science, v. 291, p. 438-439, 2001.

LIMA, J.P.M. Interação de pesticidas da família dos carbamatos com ácidos fúlvicos. 2001. 141 f. Dissertaçaão (Mestrado em Química) - Faculdade de Ciências, Universidade do Porto, Porto, Portugal, 2001.

LIU, L.; SONG, C.; YAN, Z.; LI, F. Characterizing the release of different composition of dissolved organic matter in soil under acid rain leaching using three-dimensional excitation-emission matrix spectroscopy. Chemosphere, v. 77, p. 15-21, 2009.

LIYING, W.; FENGCHANG, W.; RUNYU, Z.; WEN, L.; HAIQING, L. Characterization of dissolved organic matter fractions from Lake Hongfeng, Southwestern China Plateau. Journal of Environmental Sciences, v. 21, p. 581-588, 2009. 
LOPES, J.M. Caracterização e evolução das substâncias húmicas de horizontes espódicos na planície costeira do Estado de São Paulo. 2010. 108 f. Dissertação (Mestrado na area de Solos e Nutrição de Plantas) - Escola Superior de Agricultura Luiz de Queiroz, Universidade de São Paulo, Piracicaba, 2010.

LU, X.Q.; JAFFE, R. Interaction between $\mathrm{Hg}$ (II) and natural dissolved organic matter: a fluorescence spectroscopy based study. Water Research, v. 35, p. 1793-1803, 2001.

LUCAS, Y. Systèmes pédologiques en Amazonie brésilienne. Equilibres, desequilibres et transformations. 1989. 157f. Thèse (Doctorat), Université de Poitiers, Poitiers, 1989.

LUCAS, Y.; BOULET, R.; ANDRIEUX, P. Un système pédologique aval en Guyane Française Organisation et fonctionnement hydrodynamique. Cachiers ORSTOM, Séries Pédologie, Bondy, v. 22, n. 1, p. 3-16, 1986.

LUCAS, Y.; BOULET, R.; CHAUVEL, A. Intervention simultanée des phénomènes d'enfoncement vertical et de transformation latérale dans la mise en place de systems de sols de la zone tropicale humide. Cas des systèmes sols ferrallitiques podzols de l'Amazonie Brésilienne. Comptes Rendus de l'Académie des Sciences, v. 306, p. 1395-1400, 1988.

LUCAS, Y.; BOULET, R.; CHAUVEL, A.; VEILLON, L. Systèmes sols FerrallitiquesPodzols en région amazonienne. In: RIGHI, D.; CHAUVEL, A. Podzols et podzolisation. Paris: AFES e INRA, 1987. p. 53-65.

LUCAS, Y.; CHAUVEL, A.; BOULET, R.; RANZANI, G.; SCATOLINI, F. Transição latossolos-podzois sobre a formação barreiras na região de Manaus, Amazônia. Revista Brasileira de Ciência do Solo, v. 8, p. 325-335, 1984.

LUCAS, Y.; MONTES, C.R.; MOUNIER, S.; CAZALET, M.L.; ISHIDA, D.; ACHARD, R.; GARNIER, C.; MELFI, A.J. Biogeochemistry of an Amazonian podzol-ferralsol soil system with white kaolin. Biogeosciences, v. 9, p. 3705-3720, 2012.

LUCAS, Y.; NAHON, D.; CORNU S.; EYROLLE, F. Genèse et fonctionnement des sols en milieu equatorial. Comptes Rendus Geoscience, v. 322, n. 1, p. 1-16, 1996. LUCHESE, E.B.; FAVERO, L.O.B.; LENZI, E. Fundamentos da química do solo: teoria e prática. Rio de Janeiro: Freitas Bastos Editora, 2002. 159 p. 
LUCIANI, X.; MOUNIER, S.; PARAQUETTI, H.H.M.; REDON, R.; LUCAS, Y.; BOIS, A .; Lacerda, L.D.; Raynaud, A., Ripert, A.. Tracing of dissolved organic matter from the SEPETIBA Bay (Brazil) by PARAFAC analysis of total luminescence matrices. Marine Environmental Research, v. 2, p. 148-157, 2008.

LUCIANI, X.; MOUNIER, S.; REDON, R.; BOIS, A. A simple correction method of inner filter effects affecting FEEM ans its application to the PARAFAC decomposition. Chemometrics and Intelligent Laboratory Systems, v. 96, p. 227-238, 2009.

LUNDSTRÖM, U.S. The role of organic acids in soil solution chemistry in a podzolized soil. Journal of Soil Science, v. 44, n. 1, p. 121-133, 1993.

LUNDSTRÖM, U.S.; VAN BREEMEN, N.; BAIN, D.C. The podzolization process. a review. Geoderma, v. 94, p. 91-107, 2000a.

LUNDSTRÖM, U.S.; van BREEMEN, N.; BAIN, D.C.; VAN HEES, P.A.W.; GIESLER, R.; GUSTAFSSON, J.P.; ILVESNIEMI, H.; KARLTTUN, E.; MELKERUD, P.A.; OLSSON, M.; RIISE, G.; WAHLBERG, O.; BERGELIN, A.; BISHOP, K.; JONGMANS, A.G.; MAGNUSSON, T.; MANNERKOSKI, H.; NORDGREN, A.; NYBERG, L.; STARR, M.; TAU STRAND, L. Advances in understanding the podzolization process resulting from a multidisciplinary study of three coniferous forest soils in the Nordic Countries. Geoderma, v. 94, p. 335-353, 2000 b.

MA, J.; DEL VECCHIO, R.; GOLANOSKI, K.S.; BOYLE, E.S.; BLOUGH, N.V. Optical properties of humic substances and CDOM: effects of borohydride reduction.

Environmental Science and Technology, v. 44, p. 5395-5402, 2010.

MACDONALD, B.C.; LVIN, S.J.; PATTERSON, H. Correction of fluorescence inner filter effects and the partitioning of pyrene to dissolved organic carbon. Analytica Chimica Acta, v. 338, n. 1-2, p. 155-162, 1997.

MAFRA, A. L. Organização e pedogênese de um sistema Latossolo-Podzol na região do Alto Río Negro, AM. 2000. Tese (Doutorado em Solos e Nutrição de Plantas)-Escola Superior de Agricultura Luiz de Queiroz, Universidade de São Paulo, Piracaba, 2000.

MAFRA, A.L.; MIKLÓS, A.A.W.; VOLKOFF, B.; MELFI, A.J. Pedogênese numa sequência Latossolo-Espodossolo na região do alto rio Negro, Amazonas. Revista Brasileira de Ciência do Solo, v. 26, p. 381-394, 2002. 
MALHI, Y.; WOOD, D.; BAKER, T.R.; WRIGHT, J.; PHILLIPS, O.L.; COCHRANE, T.; MEIR, P.; CHAVE, J.; ALMEIDA, S.; ARROYO, L.; HIGUCHI, N.; KILLEEN, T.; LAURANCE, S.G.; LAURANCE, W.F.; LEWIS, S.L.; MONTEAGUDO, A.; NEILL, D.A.; VARGAS, P.N.; PITMAN, N.C.A.; QUESADA, C.A.; SALOMÃO, R.; SILVA, J.N.M.; LEZAMA, A.T.; TERBORGH, J.; MARTÍNEZ, R.V.; VINCETI, B. The regional variation of aboveground live biomass in old-growth Amazonian forests. Global Change Biology, v. 12, p. 1107-1138, 2006.

MANAHAN, S. E. Introdution to chemistry: fundamentals of environmental chemistry. Boca Raton: CRC, 2001. 1024 p.

MANGRICH, A.S. Estruturas químicas de: estratégias de pesquisa. In: ENCONTRO BRASILEIRO DE SUBSTÂNCIAS HÚMICAS, 4., 2001, Viçosa. Anais... Viçosa: Sociedade Brasileira de Substâncias Húmicas/ Universidade Federal de Viçosa, 2001. p. 15-17.

MANZI, A.O. Aquecimento global, Mudanças climáticas e o futuro da Amazônia. GEAA: Grupo de Estudos estratégicos Amazônicos/ Mudanças Climáticas; Água no mundo moderno; Biodiversidade Amazônica. Manaus: Editora INPA, 2008.

MARHUENDA-EGEA, F.C.; MARTÍNEZ-SABATER, E.; JORDÁ, J.; MORAL, R.; BUSTAMANTE, M.A.; PAREDES, C.; PÉREZ-MURCIA, M.D. Dissolved organic matter fractions formed during composting of winery and distillery residues: evaluation of the process by fluorescence excitation-emission matrix.

Chemosphere, v. 68, p. 301-309, 2007.

MARKOLF, H.N. Laser-tissue interactions. Berlin: Springer, 1999. 303 p.

MARTELLI, L.F.A. Avaliação quantitativa e qualitativa da matéria orgânica de solo sob a aplicação de efluente de esgoto tratado em biodigestor anaeróbio. 2011. 119 f. Dissertação (Mestrado em Ciências - Química Analítica) - Instituto de Química de São Carlos, Universidade de São Paulo, São Carlos, 2011.

MARTIN-NETO, L.; MILORI, D.M.B.P.; DA SILVA, W.T.L. (Ed.). Humic substances and soil and water environment. São Carlos: Rima, 2004. 609 p.

MARTIN-NETO, L.; MILORI, D.M.B.P.; DA SILVA, W.T.L.; SIMOES, M.L. EPR, FTIR, Raman, UV-visible light absorption and fluorescence spectroscopies in studies of humic substances. In: SENESI, N.; XING, B.; HUANG, P.M. (Ed.). Biophysicochemical processes involving natural organic matter in environmental systems. Hoboken: Wiley, 2009. p. 651-728. 
MARTIN-NETO, L.; NASCIMENTO, O.R.; TALAMONI, J.; POPPI, N.R. EPR of micronutrients-humic substances complexes extracted from brazilian soil. Soil Science, v. 151, p. 369-376, 1991.

MARTIN-NETO, L.; ROSSEL, R.; SPOSITO, G. Correlation of spectroscopic indicators of humification with mean annual rainfull along a temperature grassland climosequence. Geoderma, v. 81, p. 305-311, 1998.

MARTIN-NETO, L.; TRAGHETTA, D.G.; VAZ, C.M.P.; CRESTANA, S.; SPOSITO, G. On the interaction mechanisms of atrazine and hydroxyatrazine with humic substances. Journal of Environmental Quality, v. 30, p. 520-525, 2001.

MARTINS, B.H. Estudos espectroscópicos de matéria orgânica e ácidos húmicos de solos sob adição de efluente de esgoto tratado. 2009. $121 \mathrm{f}$. Dissertação (Mestrado em Ciências - Química Analítica) - Instituto de Química de São Carlos, Universidade de São Paulo, São Carlos, 2009.

MARTINS, T.; SAAB, S.C.; MILORI, D.M.B.P.; BRINATTI, A.M.; ROSA, J.A.; CASSARO, F.A.M.; PIRES, L.F. Soil organic matter humification under different tillage managements evaluated by Laser Induced Fluorescence (LIF) and C/N ratio.

Soil \& Tillage Research, v. 111, p. 231-235, 2011.

MATIAS, T.M. Análise química de materiais cerâmicos: digestão por fusão e medidas por ICP OES com configuração axial. 2007. $110 \mathrm{f}$. Tese (Doutorado em Ciências - Química Analítica) - Departamento de Química, Universidade Federal de São Carlos, São Carlos, 2007.

MATTHEWS, B.J.H.; JONES, A.C.; THEODOROU, N.K.; TUDHOPE, A.W. Excitation-emission-matrix fluorescence spectroscopy applied to humic acid bands in coral reefs. Marine Chemistry, v. 55, p. 317-332, 1996.

MC KNIGHT, D.M.; BOYLE, E.W.; WESTWEHOFF, P.K.; DORAN, P.T.; KULBE, T.; ANDERSON, D.T. Spectroflurometric characterization of dissolved organic matter for the identification of precursor organic material and aromaticity. Limnology and Oceanography, v. 46, p. 38-48, 2001.

MC PHIE, P. Enzyme purification and related techniques: dialysis. In: JACOBY, W.B. (Ed.). Methods and enzymology. New York: Academic Press, 1971. v. 22, p. 25175. 
MCDONALD, S.; BISHOP, A.; PRENZLER, P.D.; ROBARDS, K. Analytical chemistry of freshwater humic substances. Analytica Chimica Acta, v. 527, p. 105-124, 2004.

MENDONÇA, A.; DUARTE, A.C.; SANTOS, E.B.H. Spectroscopic properties of sedimentary humic acids from a salt marsh (Ria de Aveiro, Portugal): comparison of sediments colonized by Halimione portulacoides (L.) Aellen and non-vegetated sediments. Biogeochemistry, v. 69, n. 2, p. 159-174, 2004.

METZEGER, M.J.; ROUNSEVELL. M.D.A.; ACOSTA-MICHLIK, L.; LEEMANS, R.; SCHROTERE, D. The vulnerabilly of ecosystem services to land use change. Agriculture, Ecosystems and Environment, v. 114, n. 1, p. 69-85, 2006.

MIANO, T.; SPOSITO, G.; MARTIN, J.P. Fluorescence spectroscopy of model humic acid-type polymers. Geoderma, v. 47, p. 349-359, 1990.

MIIKKI, V.; SENESI, N.; HÄNNINEN, K. Characterization of humic material formed by composting of domestic and industrial biowastes. Part 2 Spectroscopic evaluation of humic acid structures. Chemosphere, v. 34, n. 8, p. 1639-1651, 1997.

MILORI, D. M. B. P.; MARTIN-NETO, L.; BAYER, C.; MIELNICZUK, J.; BAGNATO, V.S. Humification degree of soil humic acids determined by fluorescence spectroscopy. Soil Science, v. 167, p. 739-749, 2002.

MILORI, D.M.B.P.; GALETI, H.V.A.; MARTIN-NETO, L.; DIECKOW, J.; GONZÁLEZPÉREZ, M.; BAYER, C.; SALTON, J. "Organic matter study of whole soil samples using laser-induced fluorescense spectroscopy". Soil Science Society of America Journal, v. 70, p. 57-63, 2006.

MILORI, D.M.B.P.; GALETI, H.V.A.; MARTIN-NETO, L.; GONZÁLEZ-PÉREZ, M.; BAYER, C.; MIELNICZUK, J.; SALTON, J. "Humification degree of organic matter in whole soil determined by laser-induced fluorescence". In: MARTIN-NETO, L.; MILORI, D.M.B.P.; DA SILVA, W.T.L. (Ed.). Humic substances and soil and water environment. São Carlos: Rima, 2004. p. 609.

MILORI, D.M.B.P.; MARTIN-NETO, L.; P.R.; FERREIRA, E. C.; SEGNINI, A.; FERREIRA, E.J. SANTOS, C.H. DOS; ROMANO, R.A.; SILVA, W.T.A. da; SIMÕES, M.L.; POSADAS, A. Avaliação de um equipamento portátil para determinação do grau de humificação da matéria orgânica de solos. In: INAMASU, R.Y.; NAIME, J. M.; RESENDE, A.V. de; BASSOI, L.H.; BERNARDI, A. C.. (Org.). Agricultura de precisão: um novo olhar. São Carlos: Editora Cubo, 2011. v. 1, p. 91-95. 
MILORI, D.M.B.P; MARTIN-NETO, L.; BAYER, C. Nova metodologia utilizando fluorescência induzida por laser para análise de solos inteiros. In: CONGRESSO BRASILEIRO DE CIÊNCIA DO SOLO, 29., 2003, Ribeirão Preto - SP. Anais... Jaboticabal: UNESP, 2003. 1 CD-ROM.

MONTASER, A.; GOLIGHTLY, D.W. Inductively coupled plasmas in analytical atomic spectroscopy. New Jork: VCH, 1992. 984 p.

MONTES, C. R. Mecanismos e processos pedogenéticos envolvidos na formação dos depósitos de caolim de São Gabriel da Cachoeira. Piracicaba: Universidade de São Paulo, Centro de Energia Nuclear na Agricultura, 2009. Relatório Fapesp no 07/02543-0.

MONTES, C.R.; LUCAS, Y.; MELFI, A J.; ISHIDA, D.A. Systèmes sols ferrallitiques podzols et genèse des kaolins. Comptes Rendus Geoscience, v. 339, p. 50-56, 2007.

MONTES, C.R.; LUCAS, Y.; PEREIRA, O.J.R.; ACHARD, R.; GRIMALDI, M.; MELFI, A J. Deep plant-derived carbon storage in Amazonian podzols. Biogeosciences, $v$. 8, p. 113-120, 2011.

MOUNIER, S.; ZHAO, H.; GARNIER, C.; REDON, R. Copper complexing properties of dissolved organic matter: PARAFAC treatment of fluorescence quenching.

Biogeochemistry, v. 106, p. 107-116, 2011.

MOURA FILHO, G. Caracterização e Uso de solos arenosos associados à Foz do Rio São Francisco, no Litoral Sul de Alagoas. 1998. 169f. Tese (Doutorado em Solos e Nutrição de Plantas) - Departamento de Solos, Universidade Federal de Viçosa, Viçosa, 1998.

NARIMOTO, K.M. Técnicas espectroscópicas aplicadas à análise da matéria orgânica do solo em pomares de citros sob adição de lodo de esgoto. 2006. 112 f. Dissertação (Mestrado em Ciências - Química Analítica) - Instituto de Química de São Carlos, Universidade de São Paulo, São Carlos, 2006.

NASCIMENTO, A.M.R. Fundamentos da ciência do solo: gráficos, desenhos, tabelas. Rio de Janeiro: Universidade Federal Rural do Rio de Janeiro; Instituto de Agronomia - Departamento de Solos, 1995. 
NASCIMENTO, N.R.; BUENO, G.T.; FRITSCH, E.; HERBILLON, A.J.; ALLARD, T.; MELFI, A.J.; ASTOLFO, R.; BOUCHER, H.; Li, Y. Podzolization as a deferralitization process: a study of an Acrisol-Podzol sequence derived from Palaeozoic sandstones in the northern upper Amazon Basin. European Journal of Soil Science, v. 55, p. 523-538, 2004.

NASCIMENTO, N.R.; FRITSCH, E.; BUENO, G. T.; BARDY, M.; GRIMALDI, C.; MELFI, A. J. Podzolization as a deferralization process: dynamics and chemistry of ground and surface waters in an Acrisol - Podzol sequence of the upper Amazon Basin. European Journal of Soil Science, v. 59, n. 5, p. 911-924, 2008.

NELSON, D.W.; SOMMERS, L.E. Total carbon, organic carbon, and organic matter. In: BLACK, C.A. (Ed.). Methods of soil analysis: Chemical methods. Madison: Soil Science of America and American Society of Agronomy, 1996. pte 3, p. 961-1010.

NOIRTIN, E.L.R. Caracterização da matéria orgânica de solo irrigado com efluente de estação de tratamento de esgoto. 2010. 113 f. Tese (Doutorado em Geoquímica e Geotectônica) - Instituto de Geociências, Universidade de São Paulo, São Paulo, 2010.

NOVOTNY, E.H. Estudos espectroscópicos e cromatográficos de substâncias húmicas de solos sob diferentes sistemas de preparo. 2002. $231 \mathrm{f}$. Tese (Doutorado em Físico-Química) - Instituto de Químca de São Carlos, Universidade de São Paulo, São Carlos, 2002.

NOVOTNY, E.H.; MARTIN-NETO, L. Effects from humidity and metal ions on the free radical analysis of peat humus. Geoderma, v. 106, p. 305-317, 2002.

OHNO, T.; BRO, R. Dissolved organic matter characterization using multiway spectral decomposition of fluorescence landscapes. Soil Science Society of America Journal, v. 70, p. 2028-2037, 2006.

OLENDZKI, R.N. Caracterização das interações de substâncias húmicas com a matéria inorgânica em solos de cultivo de arroz irrigado: contribuição à aquisição de dados essenciais para avaliação global do sequestro de carbono no solo. 2006. 134 f. Tese (Doutorado em Química) - Setor de Ciências Exatas, Universidade Federal do Paraná, Curitiba, 2006.

OLIVEIRA, A.P. Pedogênese de espodossolos em ambientes da formação Barreiras e de restinga do sul da Bahia. 2007. 102 f. Dissertação (Mestrado em Ciências - Solos e Nutrição de Plantas) - Departamento de Solos, Universidade Federal de Viçosa, Viçosa, 2007. 
OLIVEIRA, L.L. Interações da estrutura da vegetação com a topografia e solo na floresta nacional do Amapá. 2012. 103 f. Tese (Doutorado em Biodiversidade Tropical) - Instituto de Pesquisas Científicas e Tecnológicas do Amapá (IEPA), Universidade Federal do Amapá, Macapá, 2012.

OLK, D.C.; BRUNETTI, G.; SENESI, N. Decrease in humification or organic matter with intensifies lowland rice crooping: a wet chemical and spectroscopy investigation. Soil Science Society of America Journal, v. 64, p. 1337-1347, 2000.

OUATMANE, A.; D'ORAZIO, V.; HAFIDI, M.; SENESI, N. Chemical and physicochemical characterization of humic acid-like materials from composts.

Compost Science Land Utilization, v. 10, n. 1, p. 39-46, 2002.

PATEL-SORRENTINO, N.; LUCAS, Y.; EYROLLES, F.; Melfi, A.J. Fe, Al and Si species and organic matter leached off a ferrallitic and podzolic soil system from Central Amazonia. Geoderma, v. 137, p. 444-454, 2007.

PEREIRA, O.J.R. Distribuição dos depósitos de argilas cauliníticas brancas associados à sistemas pedológicos Latossolo/Espodossolo na região amazônica: análise de imagens orbitais e estudos de campo. 2011. $155 \mathrm{f}$. Dissertação (Mestrado em Ciências - Química na Agricultura e no Ambiente) Centro de Energia Nuclear na Agricultura, Universidade de São Paulo, Piracicaba, 2011.

PEURAVUORI, J.; KOIVIKKO, R.; PIHLAJA, K. Characterization, differentiation and classification of aquatic humic matter separated with different sorbents: synchronous scanning fluorescence spectroscopy. Water Research, v. 36, p. 4552-4562, 2002.

PEURAVUORI, J.; PIHLAJA, K. Molecular size distribution and spectroscopic properties of aquatic humic substances. Analytica Chimica Acta, v. 337, n. 2, p. 133-149, 1997.

PICCOLO, A. The supramolecular structure of humic substances. Soil Science, v. 166, n. 11, p. 810-832, 2001.

PICCOLO, A.; CONTE, P. Molecular size of humic substances: supramolecular associations versus macromolecular polymers. Advances in Environmental Research, v. 3, n. 4, p. 508-521, 2000. 
PIGATIN, L.B.F. Compostos orgânicos de origem agroindustrial e urbana aplicados à produção vegetal e fertilidade do solo. 2011. $103 \mathrm{f}$. Dissertação (Mestrado em Ciências - Química Analítica) - Instituto de Química de São Carlos, Universidade de São Paulo, São Carlos, 2011.

PLAZA, C.; BRUNETTI, G.; SENESI, N.; POLO, A. Molecular and quantitative analysis of metal ion binding to humic acids from sewage sludge and sludgeamended soils by fluorescence spectroscopy. Environment Science Technology, v. 40, p. 917-923, 2006.

PLAZA, C.; D'ORAZIO, V.; SENESI, N. Copper (II) complexation of humic acids from the first generation of EUROSOILS by total luminescence spectroscopy. Geoderma, v. 125, n. 1-2, p. 177-186, 2005.

PROVENZANO, M.R.; D'ORAZIO, V.; JERZYKIEWICZ, M.; SENESI, N. Fluorescence behavior of $\mathrm{Zn}$ and $\mathrm{Ni}$ complexes of humic acids from different sources. Chemosphere, v. 55, n. 6, p. 885-892, 2004.

RADAMBRASIL. Ministério de Minas e Energia, Departamento Nacional de Produção Mineral. Levantamento de recursos naturais. Rio de Janeiro, 1978. 1 v.

REATTO. A. Principais classes de solos com ocorrência de cerrado no Meio Norte (Maranhão, Piauí) e suas potencialidades agrícolas. In: SIMPÓSIO SOBRE OS CERRADOS DO MEIO-NORTE, 1., 1997. Teresina, PI. Anais... Teresina: Embrapa Meio Norte, 1997. p. 39-44.

REEVES, D.W. The role of soil organic matter in maintaining soil quality in continuous cropping systems. Soil and Tilage Research, v. 43, p. 131-67, 1997.

RESENDE, M.; CURI, N.; RESENDE, S.B.; CORREAA, G.F. Pedologia: base para distinção de ambientes. 2 ed. Viçosa: NEPUT, 1997. 367 p.

REYNOLDS, D. M. The differentiation of biodegradable and non-biodegradable dissolved organic matter in waste waters using fluorescence spectroscopy. Journal of Chemical Technology and Biotechnology, v. 77, p. 965-972, 2002.

RICE, J.A.; MACCARTHY, P. A model of humin. Environmental Science and Technology, v. 24, p. 1875-1877, 1990. 
RICHARD, C.; COELHO, C.; GUYOT, G.; SHALOIKO, L.; TRUBETSKOJ, O.; TRUBETSKAYA, O. Fluorescence properties of the b5 $\mathrm{kDa}$ molecular size fractions of a soil humic acid. Geoderma, v. 163, p. 24-29, 2011.

RIESZ, J.; GILMORE, J.; MEREDITH, P. Quantitative photoluminescence of broad band absorbing melanins: a procedure to correct for inner filter and re-absorption effects. Spectrochimica Acta Part A: Molecular and Biomolecular Spectroscopy, v. 61, n. 9, p. 2153-2160, 2005.

RIVERO, C.; SENESI, N.; PAOLINI, J.; DÓRAZIO, V. Characteristics of humic acids of some Venezuelan soils. Geoderma, v. 81, p. 227-239, 1998.

ROCHA, A.C.C. Efeito de fertilizações orgânicas na composição de substâncias húmicas do solo. 2007. 113 f. Dissertação (Mestrado em Química Analítica) Universidade de Aveiro, Aveiro, 2007.

ROSA, A.H.; SIMÕES, M.L.; OLIVEIRA, L.C.; ROCHA, J.C.; MARTIN-NETO, L.; MILORI, D.M.B.P. Multimethod study of the degree of humification of humic substances extracted from different tropical soil profiles in Brazil's Amazonian region. Geoderma, v. 127, p. 1-10, 2005.

ROSSIN, B.G. Evolução pedo-morfológica de uma bacia de águas escuras e dinâmica das suas matérias orgânicas no decorrer desta evolução. Bacia do Alto Rio Negro-AM. 2013. 110 f. Dissertação (Mestrado em Geografia Organização do Espaço) - Instituto de Geociências e Ciências Exatas, Universidade Estadual Paulista, Rio Claro, 2013.

SAAB, S.C. Caracterização da matéria orgânica em gleissolos por espectroscopias de EPR, RMN, IV e UV-Visível. 1999. 111 f. Tese (Doutorado em Química Analítica) - Instituto de Química de São Carlos, Universidade de São Paulo, São Carlos, 1999.

SACCHI, C.A. Laser-induced electric breakdown in water. Journal of the Optical Society of America B, v. 8, p. 337-345, 1991.

SAMUELS, A.C.; DELUCIA, F. C.; McNESBY, K.L.; MIZIOLEK, A.W. Laser-induced breakdown spectroscopy analysis of energetic materials. Applied Optics, v.42, p. 6205, 2003. 
SÁNCHEZ-MONEDERO, M.A.; ROIG, A.; CEGARRA, J.; BERNAL, M.P.;

PAREDES, C. Effects of HCl-HF purification treatment on the chemical composition and structure of humic acids. European Journal of Soil Science, v. 53, p. 375-381, 2002.

SANDRONI, V.; SMITH, C.M.M.; DONAVAN, A. Microwave digestion of sediment, soils and urban particulate matter for trace metal analysis. Talanta, v. 60, p. 715, 2003.

SANTOS, C.H. Análises espectroscópicas da matéria orgânica de solos sob aplicação de águas residuárias. 2008. 165 f. Dissertação (Mestrado em Ciências Química Analítica) - Instituto de Química de São Carlos, Universidade de São Paulo, São Carlos, 2008.

SANTOS, E. Carbono, nitrogênio e relação C/N em Gleissolo e Cambissolo sob diferentes tipologias vegetais em área de ocorrência da floresta ombrófila densa, Antonia- PR. 2007. 104 f. Dissertação (Mestrado - Ciência do solo) - Setor de Ciências Agrárias, Universidade Federal do Paraná, Curitiba, 2007.

SANTOS, E.J. Determinação de nutrientes e contaminantes inorgânicos em café solúvel por espectrometria de emissão atômica com plasma de argônio induzido (ICP-AES). 1999. Dissertação (Mestrado em Química Analítica) - Instituto de Química, Universidade de São Paulo, São Paulo, 1999.

SANTOS, L.M. Dinâmica da matéria orgânica e destino de metais pesados em dois solos submetidos à adição de lodo de esgoto. 2006. 129 f. Dissertação (Mestrado em Ciências - Química Analítica) - Instituto de Química de São Carlos, Universidade de São Paulo, São Carlos, 2006.

SANTOS, L.M. Fracionamento de $\mathrm{Ba}, \mathrm{Cr}, \mathrm{Cu}$, Ni e $\mathrm{Zn}$ em solos tratados com lodo de esgoto em experimentos de longa duração. 2010. 120 f. Tese (Doutorado em Ciências - Química Analítica) - Departamento de Química, Universidade Federal de São Carlos, São Carlos, 2010.

SANTOS, L.M.; SIMÕES, M.L.; SILVA, W.T.L.; MILORI, D.M.B.P.; MONTES, C.R.; MELFI, AJ.; MARTIN-NETO, L. Caracterização química e espectroscópica de solos irrigados com efluente de esgoto tratado. Eclética Química, v.34. n.1, p.39-43, 2009.

SANTOS, R.D.; LEMOS, R.C.; SANTOS, H.G.; KER, J. C.; ANJOS, L.H.C. Manual de descrição e coleta de solo no campo. 5. ed. Viçosa: Sociedade Brasileira de Ciência do Solo, 2005. 100 p. 
SANTOS-JUNIOR, D.; TARELHO, L.V.G.; KRUG, F.J.; MILORI, D.M.B.P.; MARTINNETO, L.; VIEIRA-JUNIOR, N.D. Espectrometria de emissão ótica com plasma induzido por laser (LIBS) - fundamentos, aplicações e perspectivas. Revista Analytica, v. 24, p. 72- 81, 2006.

SATO, J.H. Métodos para determinação do carbono orgânico em solos do cerrado. 2013. 90 f. Dissertação (Mestrado em Agronomia) - Faculdade de Agronomia e Medicina Veterinária, Universidade de Brasília, Brasília, 2013.

SCHNITZER, M. Organic matter characterization. In: METHODS of soil analysis: chemical and microbiological properties. Madison: ASA-SSSA, 1982. p. 582-594 (Agronomy monograph, 9).

SCHNITZER, M.; KHAN, S.U. Soil organic matter. Amsterdam: Elsevier, 1978. 319 p.

SCHNITZER, M.; LEVESQYE, M. Electron spin resonance as a guide to the degree of humification of peats. Soil Science, v. 127, p. 140-145, 1979.

SCHULTEN, H.R.; SCHNITZER, M. A state of the art structural concept for humic substances. Naturwissenschaften, v. 80, p. 29-30, 1993.

SCHULTEN, H.R.; SCHNITZER, M. Chemical model structures for soil organic matter and soils. Soil Science, v. 162, p. 115-130, 1997.

SCHWARTZ, D. Some podzols on Bateke sands and their origins, People's Republic of Congo. Geoderma, v. 43, p. 229-247, 1988.

SENESI, N. Application of electron spin resonance and fluorescense spectroscopies to the study of soil humic substances. In: HUMUS, its structure and role in agriculture and environmet. Amsterdam: Elsevier Science, 1992. p. 11-26.

SENESI, N. Molecular and quantitative aspects of chemistry of fulvic acids and its interactions with metals ions and organic chemicals. Part I. the electrons spin resonance approach. Analytica Chimica Acta, v. 232, p. 51-75, 1990.

SENESI, N.; MIANO, T.M.; PROVEZANO, M.R.; BRUNETTI, G. Characterization, differentiation, and classification of humic substances by fluorescence spectroscopy. Soil Science, v. 152, p. 259-271, 1991. 
SHENG, G.P.; YU, H.Q. Characterization of extracellular polymeric substances of aerobic and anaerobic sludge using three-dimensional excitation and emission matrix fluorescence spectroscopy. Water Research, v. 35, p. 1233-1239, 2006.

SIERRA, M.M.D.; GIOVANELA, M.; PARLANTI, E.; SORIANO-SIERRA, E.J. 3DFluorescence spectroscopic analysis of HPLC fractionated estuarine fulvic and humic acids. Journal of the Brazilian Chemical Society, v. 17, n.1, p. 113-124, 2006.

SIERRA, M.M.D.; GIOVANELA, M.; PARLANTI, E.; SORIANO-SIERRA, E.J. Fluorescence fingerprint of fulvic and humic acids from varied origins as viewed by single-scan and excitation/emission matrix techniques. Chemosphere, v. 58, p. 715733, 2005.

SILVA, E.A.; GOMES, J.B.V.; FILHO, J.C.A.; SILVA, C.A.; CARVALHO, S.A.; CURI, N. Podzolização em solos de áreas de depressão de topo dos Tabuleiros Costeiros no nordeste brasileiro. Revista Brasileira de Ciência do Solo, v. 37, p. 11-24, 2013.

SILVA, F.C.F.; JESUS, R.M.; RIBEIRO, A.G. Vegetação. In: PROJETO RADAM BRASIL. Folha SA.19 Içá. Rio de Janeiro: MME, 1977. p. 297-396. (Levantamento de Recursos Naturais, 14).

SILVA, I.R.; MENDONÇA, E.S. Matéria orgânica do solo. In: NOVAIS, R.F.; ALVAREZ, V.H.; BARROS, N.F.; FONTES, R.L.F.; CANTARUTTI, R.B.; NEVES, J.C.L. (Ed.). Fertilidade do solo. Viçosa: Sociedade Brasileira de Ciência do Solo, 2007, p. 374-470.

SILVA, R.M. Estudo de uma metodologia para estimar a quantidade de carbono em amostras de solo utilizando espectroscopia de emissão óptica com plasma induzido por laser (LIBS). 2008. 81 f. Dissertação (Mestrado em Ciências Química Analítica) - Instituto de Química de São Carlos, Universidade de São Paulo, São Carlos, 2008.

SIMPSON, A.J. Determining the molecular weight, aggregation, structures and interactions of natural organic matter using diffusion ordered spectroscopy. Magnetic Resonance in Chemistry, v. 40, p. S72-S80, 2002.

SKOOG, D.A.; HOLLER, F.J.; NIEMAN, T.A. Princípios de análise instrumental. Porto Alegre: Bookman, 2002. 836 p. 
SOARES-FILHO, B.; NEPSTAD, D.; CURRAN, L.; CERQUEIRA, G.; GARCIA, R.; RAMOS, C.; VOLL, E.; McDONALD, A.; LEFEBVRE, P.; SCHLESINGER, P.; McGRATH, D. Amazon conservation scenarios. Nature, v. 440, p. 1-35, 2006.

SOLOMON, S.; QIN, D.; MANNING, M.; CHEN, Z.; MARQUIS, M.; AVERYT, K.B.; TIGNOR M.; MILLER, H.L. (Ed.). Climate change, 2007: the physical science basis. Cambridge: University Press, 2007. 996 p.

SOMBROCK, W. G. Spatial and temporal patterns of Amapá rainfall. Consequences for the planning of agricultural occupation and the protection of primary forest.

Ambio, v. 30, n. 7, p. 388-396, 2001.

SOMBROEK, W.; RUIVO, M.L.; FEARNSIDE, P.M.; GLASER, B.; LEHMANN, J. Amazonian dark earths as carbon stores and sinks. In: LEHMANN, J.; KERN, D. C.; GLASER. B.; WOODS, W. I. (Ed.). Amazonian darks earths: origin, properties \& management. Dordrecht: Kluwer Academic, 2003. p. 125-139.

SOMBROEK, W.G. Amazon soil. Ph.D. Agricultural University Wageningen, Pudoc, Wageningen, 1996. $303 \mathrm{p}$.

SOMBROEK, W.G. Soil of the Amazon region. In: THE AMAZON: nology and landscape ecology of a mighty tropical river and its basin. Dordrecht: Springer, 1984. p. 522-535. (The Amazon Monographial Biological, 56).

STEDMON, C.A.; MARKAGER, S. Behaviour of the optical properties of coloured dissolved organic matter under conservative mixing. Estuarine Coastal and Shelf Science, v. 57, p. 1-7, 2003.

STEDMON, C.A.; MARKAGER, S. Resolving the variability in dissolved organic matter fluorescence in a temperature estuary and its catchment using PARAFAC analysis. Limnology and Oceanography, v. 50, n. 2, p. 686-697, 2005.

STEDMON, C.A.; MARKAGER, S.; BRO, R. Tracing dissolved organic matter in aquatic environments using a new approach to fluorescence spectroscopy. Marine Chemistry, v. 82, p. 239-254, 2003.

STEVENSON, F.J. Humus chemistry: genesis, composition, reaction. New York: Wiley Interscience, 1994. p. 443. 
SUTTON, R.; SPOSITO, G. Molecular structure in soil humic substances: the new view. Environmental Science \& Technology, v. 39, n. 23, p. 9009-9015, 2005.

SWIFT, R.S. Organic matter characterization. In: SPARKS, D. (Ed.). Methods of soil analysis. Madison: American Society of Agronomy, 1996. Pte3, p. 1011-1069. (Book Series Agronomy, 9).

TATZBER, M.; STEMMER, M.; SPIEGEL, H.; KATZLBERGER, C.; HANERNHAUER, G.; GERZABEK, M.H. Impact of different tillage practices on molecular characteristics of humic acids in a long-term field experiment - An application of three different spectroscopic methods. Science of the Total Environment, v. 406, p. 256-268, 2008.

THOMAS, M.; THORP, M.; McALISTER, J. Equatorial weathering, landform development and the formation of white sands in north western Kalimantan, Indonesia. Catena, v. 36, p. 205-232, 1999.

TREVISAN, M.G. Aplicação de métodos quimiométricos de ordem superior e fluorescência molecular na análise em matrizes biológicas. 2003. $86 \mathrm{f}$. Dissertação (Mestrado em Química) - Instituto de Química, Universidade Estadual de Campinas, Campinas, 2003.

TREVIZAN, L.C.; NOGUEIRA, A.R.A.; NÓBREGA, J.A. Single vessel procedure for acid vapor partial digestion of bovine liver in a focused microwave: simultaneous determination by ICP-OES. Talanta, v. 61, p. 81, 2003.

TUCKER, S.A.; AMSZI, V.L.; ACREE, W.E. Primary and secondary inner filtering effect of $\mathrm{K}_{2} \mathrm{Cr}_{2} \mathrm{O} 7$ on fluorescence emission intensities of quinine sulfate. Journal of Chemical Education, v. 69, n.1 69:1, A8-\&, 1992.

UNITED STATES DEPARTMENT OF AGRICULTURE. Natural Resources Conservation Service. Soil Survey Staff. Soil taxonomy: a basic system of soil classification for making and interpreting soil survey. 2 nd ed. Washington: USDA, 1999. p. 436.

UNITED STATES ENVIRONMENTAL PROTECTION AGENCY. Test methods for evaluating solid waste: physical/chemical methods. $3^{\underline{a}}$ ed. Washington Federal Region, 1995.

VALEUR, B. Molecular fluorescence: principles and applications. New York: Wiley, 2001. P. 54-58. 
VANDECASTEELE, C.; BLOCK, C.B. Modern methods for trace element determination. New York: John Willey, 1997. 344 p.

VEILLON, L. Sols ferrallitiques et podzols en Guyane septentrionale. 1990. 191f. Thèse (Doctorat), Université de Paris VI, Paris, 1990.

VEILLON, L.; SORIA-SOLANO, B. Transition sol ferralitique-podzol: cas d'une terrase sedimentaire de I'Ucayali (Pérou). Cahiers ORSTOM, Séries Pédologie, Bondy, v. 24, n. 2, p. 97-113, 1988.

VIEIRA, E.C.; KAMOGAWA, M.Y.; LEMOS, S.G.; NÓBREGA, J.A.; NOGUEIRA, A.R.A. Decomposição de amostras de solos assistida por radiação micro-ondas: estratégias para evitar a formação de fluoretos insolúveis. Revista Brasileira de Ciência do Solo, v. 29, p. 547, 2005.

VIEIRA, L.S.; SANTOS, P.C.T.C. Amazônia: seus solos e outros recursos naturais. São Paulo: Agronômica Ceres, 1987, p. 416.

WENDT, R.H.; FASSEL, V.A. Induction-coupled plasma spectrometry excitation source. Analytical Chemistry, v. 37, p. 920, 1965.

WORLD REFERENCE BASE FOR SOIL RESOURCES 2006. A frame for international classification, correlation and communication. Rome: Food and Agriculture Organization of the United Nations, 2006. 145 p. (World Soil Resources Reports, 103).

WU, F.C.; MIDORIKAWA, T.; TANOUE, E. Fluorescence properties of organic ligands for copper (II) in Lake Biwa and its rivers. Geochemical Journal, v. 35 p. 333-346, 2001.

YAMASHITA,Y.; JAFFÉ,R. Characterizing the interactions between trace metals and dissolved organic matter using excitation-emission matrix and parallel factor analysis. Environmental Science and Technology, v. 42, p.7374-7379, 2008.

YAPPERT, M.C.; INGLE, J.D. Correction of polychromatic luminescence signals for inner-filter-effects. Applied Spectroscopy, v. 43, n. 5, p. 759-767, 1989. 
YU, G.H.; LUO, Y.H.; WU, M.J.; TANG, Z.; LIU, D.Y.; YANG, X.M.; SHEN, Q.R. PARAFAC modeling of fluorescence excitation_emission spectra for rapid assessment of compost maturity. Bioresource Technology, v. 101, p. 8244-8251, 2010.

ZANETTI, E.A. Indicadores para a avaliação do manejo florestal sustentável - a Amazônia brasileira no cenário mundial. 2012. 337 f. Tese (Doutorado em Ciências Florestais) - Setor de Ciências Agrárias, Universidade Federal do Paraná, Curitiba, 2012.

ZECH, W.; SENESI, N.; GUGGNBERGER, G.; KAISER, K.; LEHMANN, J.; MIANO, T.M.; MILTNER, A.; SCHROTH, G. Factors controlling humification and mineralization of soil organic matter in the tropics. Geoderma, v. 79, p. 117-161, 1997.

ZSOLNAY, A.; BAIGAR, E.; JIMENEZ, M.; STEINWEG, B.; SACCOMANDI, F. Differentiating with fluorescence spectroscopy the sources of dissolved organic matter in soils subjected to drying. Chemosphere, v. 38, p. 45-50, 1999 